


\title{
Kristallstrukturuntersuchungen zum Katalyse- und Regulationsmechanismus der Tyrosin-regulierten 3-Deoxy-D-arabino-Heptulosonat-7-Phosphat-Synthase aus Saccharomyces cerevisiae
}

\author{
Dissertation \\ zur Erlangung des Doktorgrades \\ der Mathematisch-Naturwissenschaftlichen Fakultäten \\ der Georg-August-Universität zu Göttingen
}

vorgelegt von

Verena König

aus Münster

Göttingen 2002 
D 7

Referent: Prof. G.M. Sheldrick, Ph.D.

Korreferent: Prof. Dr. G. Braus

Tag der mündlichen Prüfung: 31.10.2002 


\section{Inhaltsverzeichnis}

Inhaltsverzeichnis .. $\mathbf{I}$

Abkürzungsverzeichnis IV

I EINLEITUNG 1

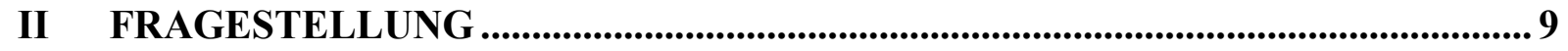

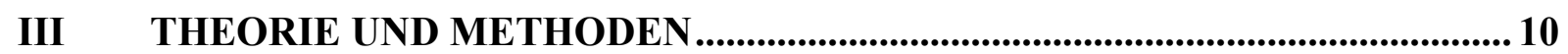

III.1 Aufreinigung von Enzymen ............................................................................................ 10

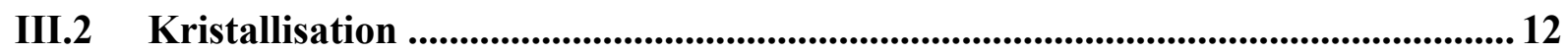

III.3 Datensammlung, -integration und -skalierung................................................. 15

III.4 Nicht-kristallographische Symmetrie (NCS) ................................................ 17

III.5 Molekularer Ersatz (Molecular Replacement) .................................................... 19

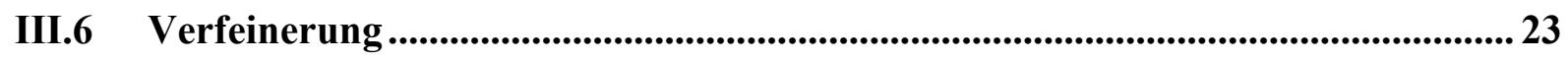

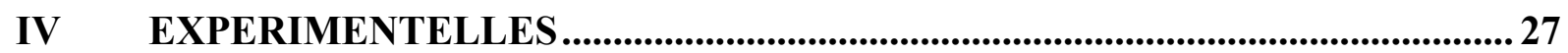

IV.1 Aufreinigung der DAHP Synthase aus $S$. cerevisiae ..........................................2 27

IV.2 Kristallisation der DAHP Synthase in verschiedenen Komplexen ......................... 30

IV.3 Datensammlung -integration und -skalierung ................................................38

IV.4 Strukturlösung und Verfeinerung ...................................................................

V ERGEBNISSE UND DISKUSSION ........................................................................5 50

V.1 Das aktive Zentrum.............................................................................................5

V.1.1 Vergleich der Komplexstrukturen ...................................................... 51

V.1.1.1 DAHP Synthase komplexiert mit Mangan(II) (3a und 4a)........................... 51

V.1.1.2 DAHP Synthase komplexiert mit Metall(II) und PEP (2b, 4b und 4c).......... 52 
V.1.1.3 DAHP Synthase komplexiert mit PEP (1HFB) ............................................. 53

V.1.1.4 DAHP Synthase komplexiert mit Cobalt(II) und P2G (4d).......................... 54

V.1.1.5 DAHP Synthase komplexiert mit Cobalt(II), PEP und G3P (4e) ................... 55

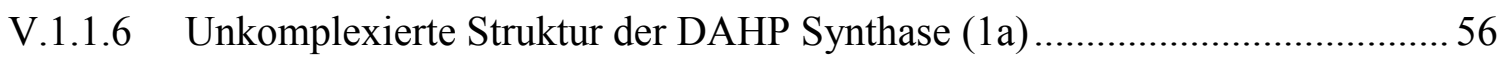

V.1.2 Vergleiche innerhalb der Komplex-Strukturen ............................................... 58

V.1.2.1 Vergleich innerhalb der Mangan(II)-Komplex-Strukturen (3a, 4a) ................58

V.1.2.2 Vergleich zwischen der unkomplexierten Struktur (1a) und den Mangan(II)-

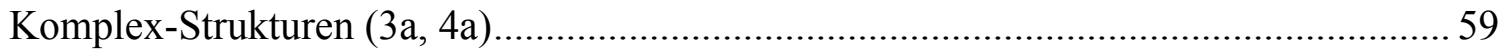

V.1.2.3 Vergleich der Mangan(II)-Komplex-Struktur (4a) und der PEP-Mangan(II)Komplex-Struktur (4b) im monoklinen Kristallsystem 60

V.1.2.4 Vergleich zwischen der Cobalt(II)-PEP-Komplex-Struktur (4c) und der PEPKomplex-Struktur 1HFB 60

V.1.2.5 Vergleich zwischen den Metall(II)-PEP-Komplex-Strukturen (4b und 4c).... 62

V.1.2.6 Vergleich zwischen der Cobalt(II)-PEP- und der Cobalt(II)-P2G-KomplexStruktur 63

V.1.2.7 Vergleich zwischen der Cobalt(II)-PEP- und der Cobalt(II)-PEP-G3PKomplex-Struktur. 63

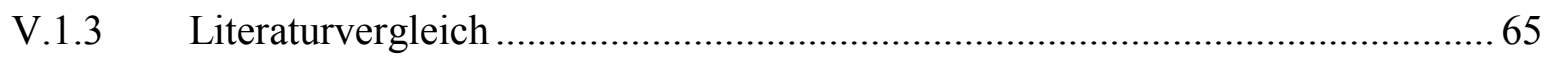

V.1.3.1 Strukturvergleiche mit Komplexen der phe-sensitiven DAHP Synthase aus E. coli 65

V.1.3.1.1 Vergleich zwischen der Struktur der phe-sensitiven DAHP Synhase aus E. coli komplexiert mit Blei(II) und PEP (1QR7) und der Cobalt(II)-PEP-KomplexStruktur 4c 65

V.1.3.1.2 Strukturvergleich zwischen der phe-sensitiven DAHP Synhase aus E. coli komplexiert mit Mangan(II) und dem PEP-Analogon P2G (1GG1) und der Cobalt(II)P2G-Komplex-Struktur 4d

V.1.3.2 Strukturvergleiche mit Komplexen der mechanistisch verwandten KDOP Synthasen 69

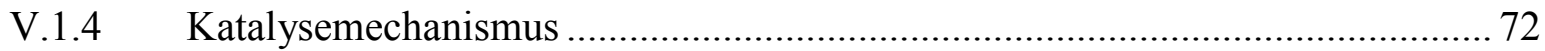

V.2 Mechanismus der allosterischen Regulierung ......................................................... 81

V.2.1 Die Struktur des DAHP Synthase-Tyrosin-Mangan(II)-Komplex...................... 81

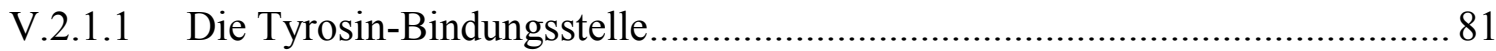

V.2.1.2 Vergleich des Tyrosin-Mangan(II)-Komplex (2c) mit dem PEP-Mangan(II)(4b) bzw. mit dem PEP-Cobalt(II)-G3P-Komplex (4e ). 
V.2.1.2.1 Änderungen im aktiven Zentrum........................................................ 86

V.2.1.2.2 Änderungen in der Effektor-Bindungstasche ........................................ 88

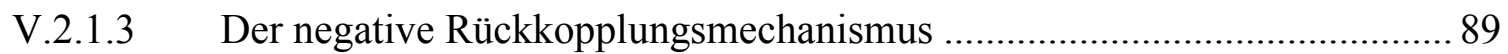

V.2.2 Strukturbeschreibung des Phenylalanin-Mangan(II)-Komplexes (4d) ..... 94

V.2.3 Strukturbeschreibung der Punktmutante Gly226Ser (2e) ................................ 96

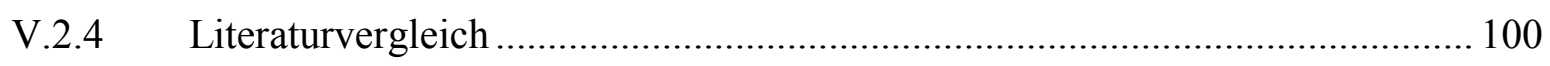

V.3 Raumgruppen, Kristallpackungen und Oligomerisierung................................ 101

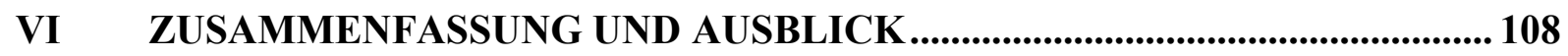

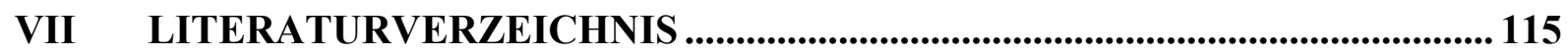




\section{Abkürzungsverzeichnis}
$(\mathrm{w} / \mathrm{w})$
weight-weight
A5P
Arabinose-5-phosphat
Abb.
Abbildung
AS
Aminosäure
BSA
Rinderserumalbumin
$\mathrm{CC}$
correlation coefficient (Korrelationskoeffizient)
c-terminal
carboxy-terminal
DAHP
3-Deoxy-D-arabino-Heptulosonat-7-Phosphat
DESY
Deutsches Elektronen Synchrotron
DTT
Dithiothreitol
E. coli
Escherichia coli
E4P
Erythrose-4-phosphat
EDTA
Ethylendiamintetraacetat
EMBL
European Molecular Biology Laboratory
esd
estimated standard deviation
et al.
et alii (und andere)
$\mathrm{F}_{\mathrm{c}}$
berechneter Strukturfaktor
FFT
Fast Fourier Transformation
$\mathrm{F}_{\mathrm{o}}$
beobachteter Strukturfaktor
fom
figure of merit
G3P
Glycerol-3-Phosphat
$\mathrm{h}$
Stunde
HOMO
highest occupied molecular orbital
Kap.
Kapitel
$\mathrm{K}_{\text {cat }}$
Wechselzahl
$\mathrm{kDa}$
Kilodalton
$\mathrm{K}_{\mathrm{i}}$
Inhibierungskonstante
$\mathrm{K}_{\mathrm{M}}$
Michaelis-Menten-Konstante
LUMO
lowest unoccupied molecular orbital
$\mathrm{M}$
molar, $\mathrm{mol} / \mathrm{l}$
MR
molecular replacement („Methode des molekularen Ersatzes“)
NCS non-crystallographic symmetry (nicht-kristallographische Symmetrie) 


$\begin{array}{ll}\text { n-terminal } & \text { amino-terminal } \\ \mathrm{P} 1_{\mathrm{gr}} & \text { große P1-Zelle } \\ \mathrm{P} 1_{\mathrm{kl}} & \text { kleine P1-Zelle } \\ \mathrm{P} 2 \mathrm{G} & \text { 2-Phosphoglycolat } \\ \mathrm{PDB} & \text { Protein Data Bank } \\ \mathrm{PEG} & \text { Polyethylenglykol } \\ \mathrm{PEP} & \text { Phosphoenolpyruvat } \\ \mathrm{Phe} / \text { phe } & \text { Phenylalanin } \\ \mathrm{PMSF} & \text { Phenylmethansulfonylfluorid } \\ \text { rms } & \text { root mean square (mittlere Quadratwurzel) } \\ \text { Tris } & \text { Tris-(hydroxymethyl)-aminoethan } \\ \mathrm{S} & \text { Sekunde } \\ \text { S. cerevisiae } & \text { Saccharomyces cerevisiae } \\ \text { SDS-PAGE } & \text { sodium dodecyl sulfate-polyacrylamide gel electrophoresis } \\ & \text { (Natriumdodecylsulfat-Gelelektrophorese) } \\ \text { Tab. } & \text { Tabelle } \\ \text { TLS } & \text { translation libration screw (Translation, Schwingung, Schraube) } \\ \text { Trp / trp } & \text { Tryptophan } \\ \text { Tyr / tyr } & \text { Tyrosin } \\ \text { Upm } & \text { Umdrehungen pro Minute }\end{array}$

\section{Es wurde zur Benennung der im Rahmen dieser Arbeit diskutierten Enzymstrukturen folgende Nomenklatur verwendet:}

Tyrosin-sensitive DAHP Synthase aus $S$. cerevisiae in der Raumgruppe

1A

$\mathbf{2 a}$

$\mathbf{2 b}$

2c

2d
$\mathrm{P} 1_{\mathrm{kl}}$

Tyrosin-sensitive DAHP Synthase aus S. cerevisiae + Mangan(II) in Raumgruppe $\mathrm{P} 1_{\mathrm{gr}}$

Tyrosin-sensitive DAHP Synthase aus $S$. cerevisiae + Mangan(II) + PEP in Raumgruppe $\mathrm{P} 1_{\mathrm{gr}}$

Tyrosin-sensitive DAHP Synthase aus $S$. cerevisiae + Mangan(II) + Tyrosin in Raumgruppe $\mathrm{P} 1_{\text {gr }}$

Tyrosin-sensitive DAHP Synthase aus S. cerevisiae + Mangan(II) + Phenylalanin in Raumgruppe $\mathrm{P} 1_{\mathrm{gr}}$ 
$2 \mathrm{e}$

3a

$4 a$

4b

$4 c$

4d

$4 e$

1HFB (pdb-Code) Tyrosin-sensitive DAHP Synthase aus S. cerevisiae + PEP

1QR7 (pdb-Code) Phenylalanin-sensitive DAHP Synthase aus E. coli + Blei(II) + PEP

1GG1 (pdb-Code) Phenylalanin-sensitive DAHP Synthase aus E. coli + Mangan(II) + P2G

1FWW (pdb-Code) KDOP Synthase aus Aquifex aeolicus + PEP + A5P

Die in dieser Arbeit vorliegenden graphischen Darstellungen der Enzymstrukturen wurden mit dem Programm DINO [DINO 2001] erstellt. 


\section{I $\quad$ Einleitung}

[Voet 1995; Stryer 1994; Braus 1991]

In allen Lebewesen basiert die strukturelle und funktionelle Vielfalt der Proteine auf der Variation von nur 20 natürlichen Aminosäuren. Sie werden in essentielle und nichtessentielle Aminosäuren eingeteilt. Die nichtessentiellen werden vom Organismus selbst aufgebaut, während für die essentiellen Aminosäuren kein organismuseigener Syntheseweg existiert, so dass diese mit der Nahrung aufgenommen werden müssen. Die sehr energieaufwendige Synthese der aromatischen Aminosäuren Phenylalanin, Tyrosin und Tryptophan existiert nur im Prokaryonten-, Hefen-, Algen- und Pflanzenstoffwechsel. Für den Menschen gehören Phenylalanin und Tryptophan demnach zu den essentiellen Aminosäuren, während Tyrosin eine Sonderstellung einnimmt, da es vom menschlichen Organimus durch eine PhenylalaninHydroxylase aus der essentiellen Aminosäure Phenylalanin synthetisiert werden kann.

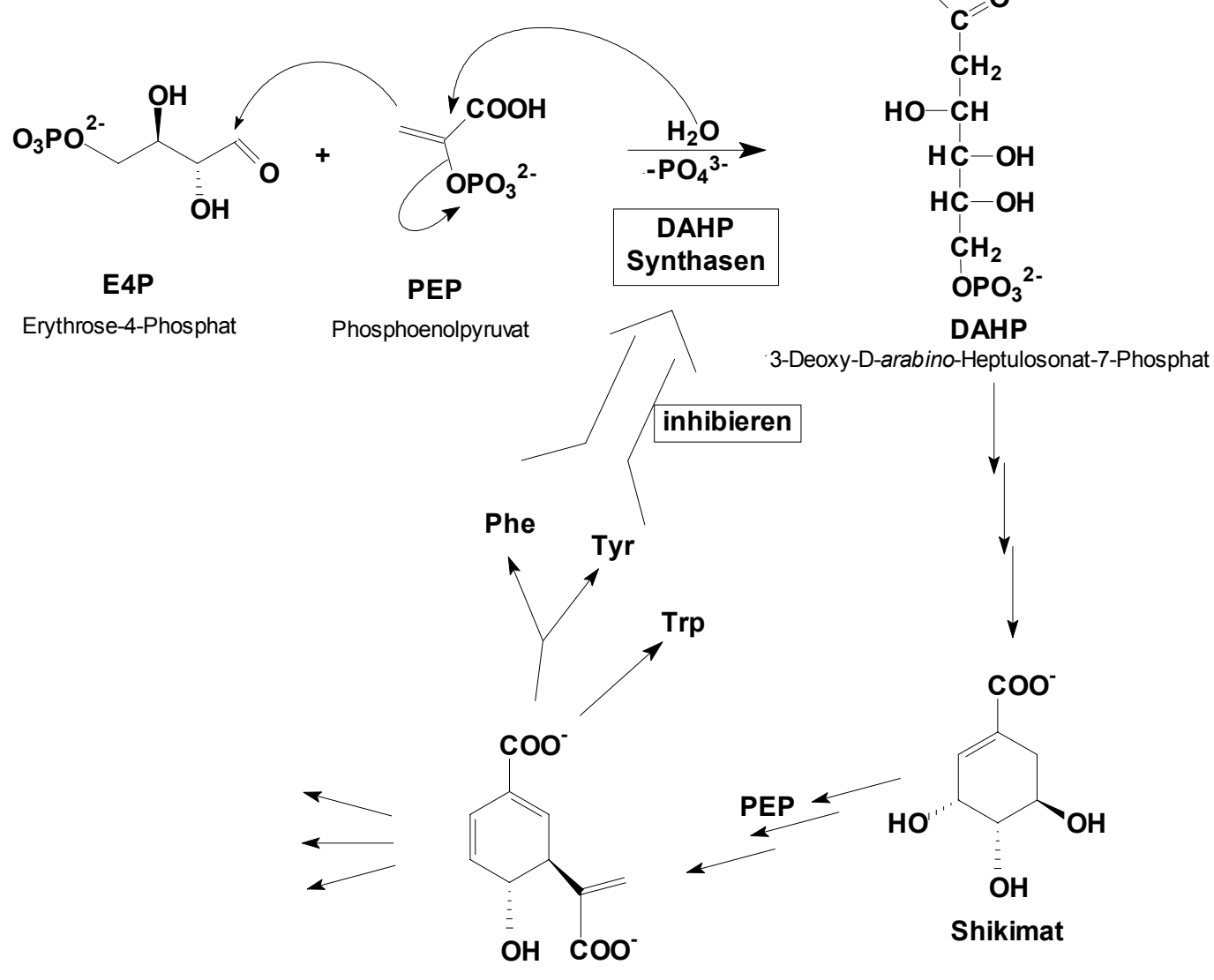

Chorismat

Abb. Ia Schematische Darstellung des Synthese- und Rückkopplungsweges der aromatischen Aminosäuren. Der erste Schritt des Shikimat-Weges wird in S. cerevisiae durch zwei negativ rückgekoppelte Isoenzyme katalysiert, das durch Phenylalanin regulierbare Aro3p und das durch Tyrosin regulierbare Aro4p. 
Die Synthese aller aromatischen Aminosäuren verläuft zunächst einheitlich über den Shikimat-Weg. Die erste Stufe des mehrstufigen Shikimat-Weges besteht aus der stereoselektiven Verknüpfung von Phosphoenolpyruvat (PEP) und Erythrose-4-Phosphat (E4P). Das erstgenannte Edukt stammt aus der Glycolyse, das zweitgenannte aus dem Pentosephosphatweg. Der durch die Kondensation entstandene C7-Zucker 3-Deoxy-Darabino-Heptulosonat-7-Phosphat (DAHP) wird unter Verlust der Phosphorylgruppe zu 5Dehydrochinat umgewandelt, das nach Wasserabspaltung unter Mitwirkung eines Äquivalentes NADPH zu Shikimat reduziert wird. Nach Phosphorylierung des Shikimates wird dieses mit einem weiteren PEP-Molekül verknüpft, das nach Entfernen der Phosphorylgruppe zu Chorismat umgewandelt wird. Diesen Syntheseanfang durchlaufen die drei aromatischen Aminosäuren gemeinsam. Nach der Bildung des Chorismates teilen sich die Aufbauwege: Tryptophan wird über einen fünfstufigen Synthesefortgang aufgebaut. Die Synthesewege von Phenylalanin und Tyrosin verlaufen zunächst weiterhin gemeinsam über das durch eine Mutase gebildete Prephenat. Dieses wird für die Phenylalaninsynthese durch Wasserabspaltung und Decarboxylierung zu Phenylpyruvat und für die Tyrosinsynthese durch oxidative Decarboxylierung zu p-Hydroxyphenylpyruvat umgeformt. Aus diesen $\alpha$ Ketoglutarsäuren werden durch Transaminierung Tyrosin und Phenylalanin gebildet.

Der allen drei aromatischen Aminosäuren gemeinsame erste Schritt des Shikimatweges, wird durch die Deoxy-arabino-Heptulosonat-7-Phosphat Synthase (DAHP Synthase) katalysiert. Dieses Enzym sorgt zum einen für die Herabsetzung der Aktivierungsenergie, zum anderen aber auch für den stereoselektiven Ablauf der Reaktion. Selektiv wird an der Verknüpfungsstelle der beiden Substrate nur ein R-C4 des neugebildeten DAHP aufgebaut. Diese Stereoselektivität wird, wie Markierungsexperimente zeigten [Floss 1972], dadurch gewährleistet, dass die Edukte während der Reaktion so gelagert sind, dass die si-Seite des PEP die re-Seite der Carbonylgruppe des E4P angreifen kann. Bemerkenswert ist die Abspaltungsart der Phosphatgruppe des PEP, die durch eine C-O-Bindungsspaltung [DeLeo 1973] und nicht, wie in vielen anderen Enzymen üblich, über eine P-O-Bindungsspaltung verläuft. Dieser Mechanismus macht das Vorhandensein eines Wassermoleküls nötig, aus dem das Sauerstoffatom der neu aufgebauten Carbonylgruppe des DAHP stammt. Die DAHP Synthasen benötigen im aktiven Zustand ein zweiwertiges Kation, bei dem es sich im nativen Fall um ein Fe(II)-Ion [Ray 1991; Paravicini 1989; McCandliss 1978], Cu(II)-Ion [Baasov 1989] oder Zn(II)-Ion [Stephens 1991] oder ein Gemisch aus diesen Ionen [Jordan 2001] handelt. Die mit EDTA aufgereinigte, metallfreie Form des Enzym ist inaktiv, lässt sich 
jedoch mit verschiedenen zweiwertigen Kationen unterschiedlich gut reaktivieren $(\mathrm{Co}(\mathrm{II})>>$ $\mathrm{Zn}(\mathrm{II}), \mathrm{Cu}(\mathrm{II}), \mathrm{Fe}(\mathrm{II})>\mathrm{Cd}(\mathrm{II})>\mathrm{Mn}(\mathrm{II}), \mathrm{Mg}(\mathrm{II}))$ [G. Schnappauf, 1998; Stephens 1991]. Die DAHP Synthase existiert in E. coli in Form dreier Isoenzyme, die spezifisch durch die jeweiligen Endprodukte Phenylalanin, Tyrosin und Tryptophan reguliert werden. In S. cerevisiae existieren nur zwei Isoenzyme, ein phe- und ein tyr-sensitives. Diese negative Rückkopplung durch das eigene Endprodukt führt zu einer effektiven Nutzung von Energie und Biomasse, da die Synthese nur stattfindet, wenn das Endprodukt nicht in ausreichender Menge zur Verfügung steht. Mit dem Vorhandensein verschiedener Isoenzyme wird verhindert, dass durch den Überschuss eines der drei Endprodukte die Quelle der Zwischenprodukte für die beiden anderen Aminosäuren vollständig blockiert wird. Ein Sequenzvergleich der drei Isoenzyme aus E. coli deutet auf $41 \%$ Identität und 15\% Ähnlichkeit zwischen den Aminosäuren der phe-, tyr- und trp-sensitiven Isoenzyme hin [Shumilin 1999]. Aufgrund dieser Homologien wird eine gemeinsame evolutionäre Vorfahrenschaft diskutiert [Ahmad 1986; Ray 1988; Liao 2000].

\begin{tabular}{|l|ll|}
\hline $\begin{array}{l}\text { kinetische } \\
\text { Daten }\end{array}$ & $\begin{array}{l}\text { DAHPS (tyr) } \\
\text { S. cerevisiae } \\
\text { [Schnappauf, 1998] }\end{array}$ & $\begin{array}{l}\text { DAHPS (phe) } \\
\text { S. cerevisiae } \\
\text { [Paravicini, 1989] }\end{array}$ \\
\hline $\mathrm{K}_{\mathrm{M}}(\mathrm{PEP})[\mu \mathrm{M}]$ & 125 & 18 \\
$\mathrm{~K}_{\mathrm{M}}(\mathrm{E} 4 \mathrm{P})[\mu \mathrm{M}]$ & 500 & 130 \\
$\mathrm{~K}_{\mathrm{cat}}\left[\mathrm{s}^{-1}\right]$ & 6 & 10 \\
$\mathrm{~K}_{\mathrm{i}}[\mu \mathrm{M}]$ & 0.9 & 10 \\
$\begin{array}{l}\text { Art der } \\
\text { Inhibierung }\end{array}$ & $\begin{array}{l}\text { PEP: komp. } \\
\text { E4P } \text { nicht komp. }\end{array}$ & PEP: nicht komp. \\
\end{tabular}

Tab. Ia Zusammenfassung der kinetischen Daten für die beiden Isoenzyme Aro3p und Aro4p.

Biochemische und kinetischen Daten der beiden Isoenzyme aus S. cerevisiae sind in Tab. Ia zusammengefasst. Bemerkenswert ist die unterschiedliche Art des allosterischen Mechanismus in den einzelnen Isoenzymen. Während es sich bei der tyr-sensitiven DAHP Synthase aus $S$. cerevisiae um eine kompetitive Hemmung in bezug auf das Substrat PEP und um eine nichtkompetitive Hemmung in bezug auf E4P handelt, wird bei der phe-sensitiven DAHP Synthase der umgekehrte Fall beobachtet. Hier handelt es sich um einen nichtkompetitiven Mechanismus in bezug auf PEP und um einen kompetitiven in bezug auf 
E4P. Auch das tyr-sensitive Enzym aus $S$. cerevisiae lässt sich durch Phenylalanin in hoher Konzentration inhibieren. Hierbei wird die gleiche Art der Hemmung beobachtet wie mit dem Effektor Tyrosin.

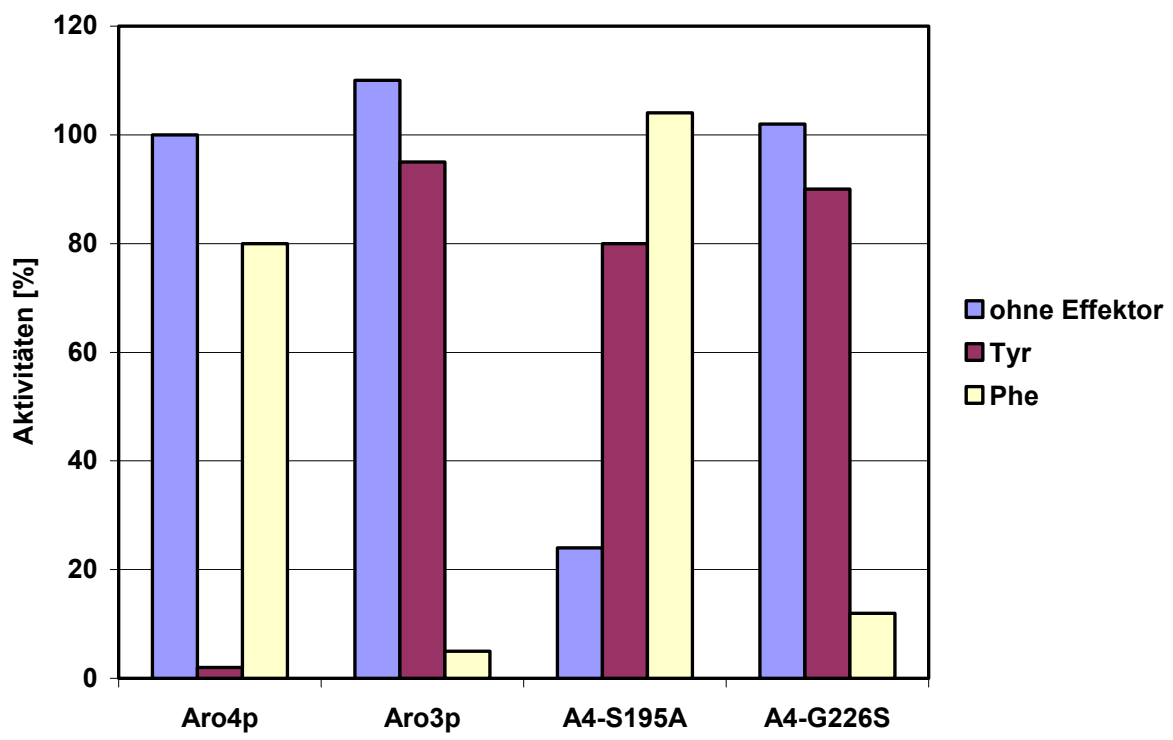

Tab. Ib Histogramm der Aktivitäten der Isoenzyme aus S. cerevisiae und zweier ausgewählter Punktmutanten in An- und Abwesenheit ihrer Effektoren Tyrosin und Phenylalanin. Erkennbar ist die Aufhebung der negativen Rückkopplung bei der Mutanten Ser195Ala und die Änderung der Regulierbarkeit von Tyrosin auf Phenylalanin bei der Punktmutanten Gly226Ser [Hartmann 2001].

Um die Ursachen der unterschiedlich selektiven Hemmungen der Isoenzyme zu ergründen, wurden verschiedene Punktmutationen der tyr-sensitiven DAHP Synthase aus S. cerevisiae auf ihre Regulierbarkeit getestet. Dabei kam der Mutante G226S besondere Aufmerksamkeit zu. Durch den Austausch des Gly226 durch Ser226, das der Aminosäure in der phe-sensitiven Sequenz an dieser Stelle entspricht (siehe Alignment), wurde die Tyr-Regulierbarkeit vollständig aufgehoben. Stattdessen wurde die Mutante jedoch durch Phenylalanin regulierbar (siehe Tab. Ib) [Hartmann 2001].

Aus Röntgenstrukturanalysen an phe- [I. Shumilin 1999; Wagner 2001] und tyr-sensitiven [Hartmann eingereicht] DAHP Synthasen aus E. coli bzw. S. cerevisiae konnte die dreidimensionale Struktur dieser beiden Isoenzyme bestimmt werden $(A b b . I c)$. Es handelt sich bei den DAHP Synthasen um ein $(\beta / \alpha)_{8}$-TIM-Barrel, das um bestimmte Strukturelemente erweitert wurde. Die folgende Strukturbeschreibung bezieht sich auf die mit PEP komplexierte tyr-sensitive DAHP Synthase aus S. cerevisiae [Hartmann eingereicht, pdbCode: 1HFB] 


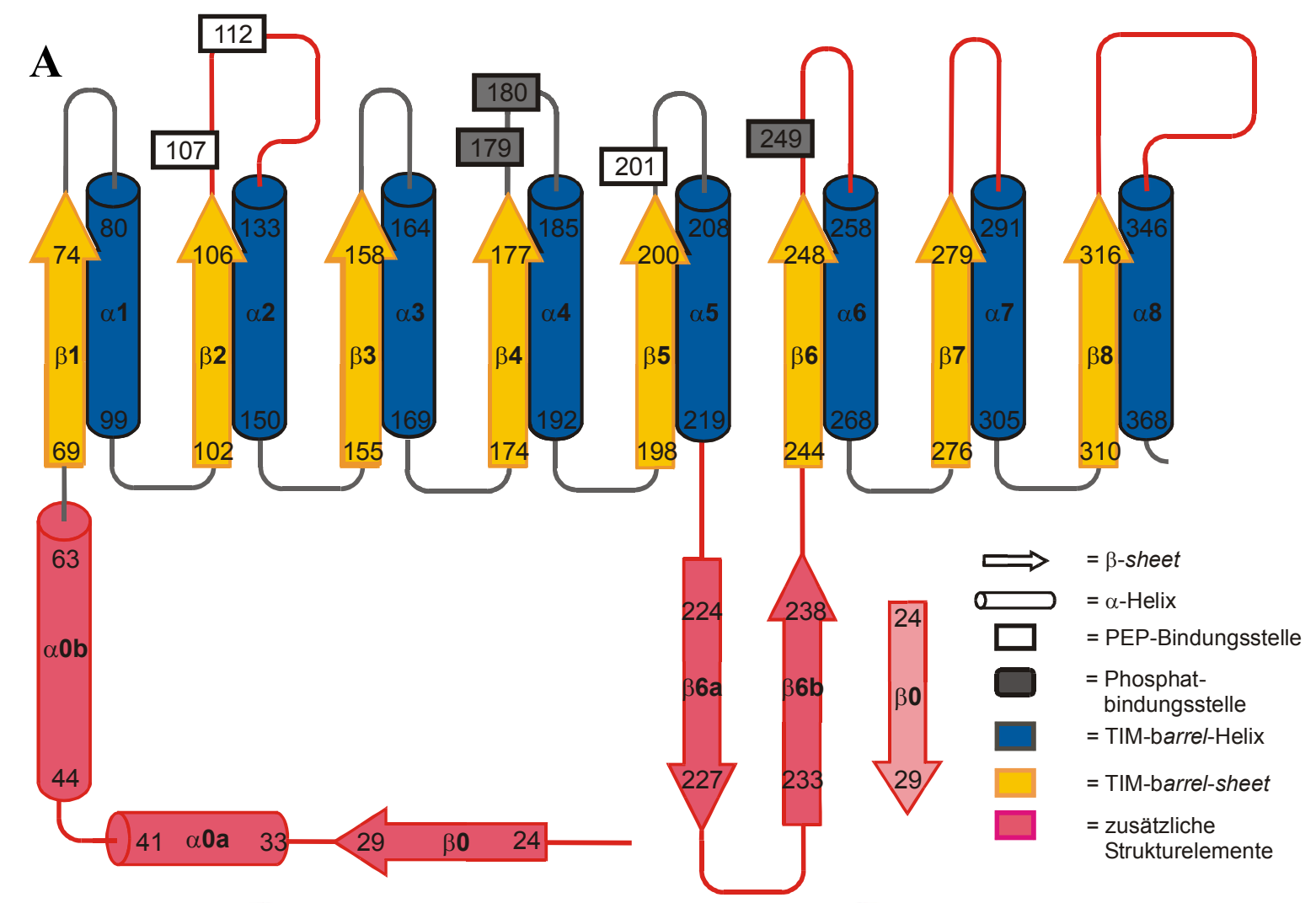

B
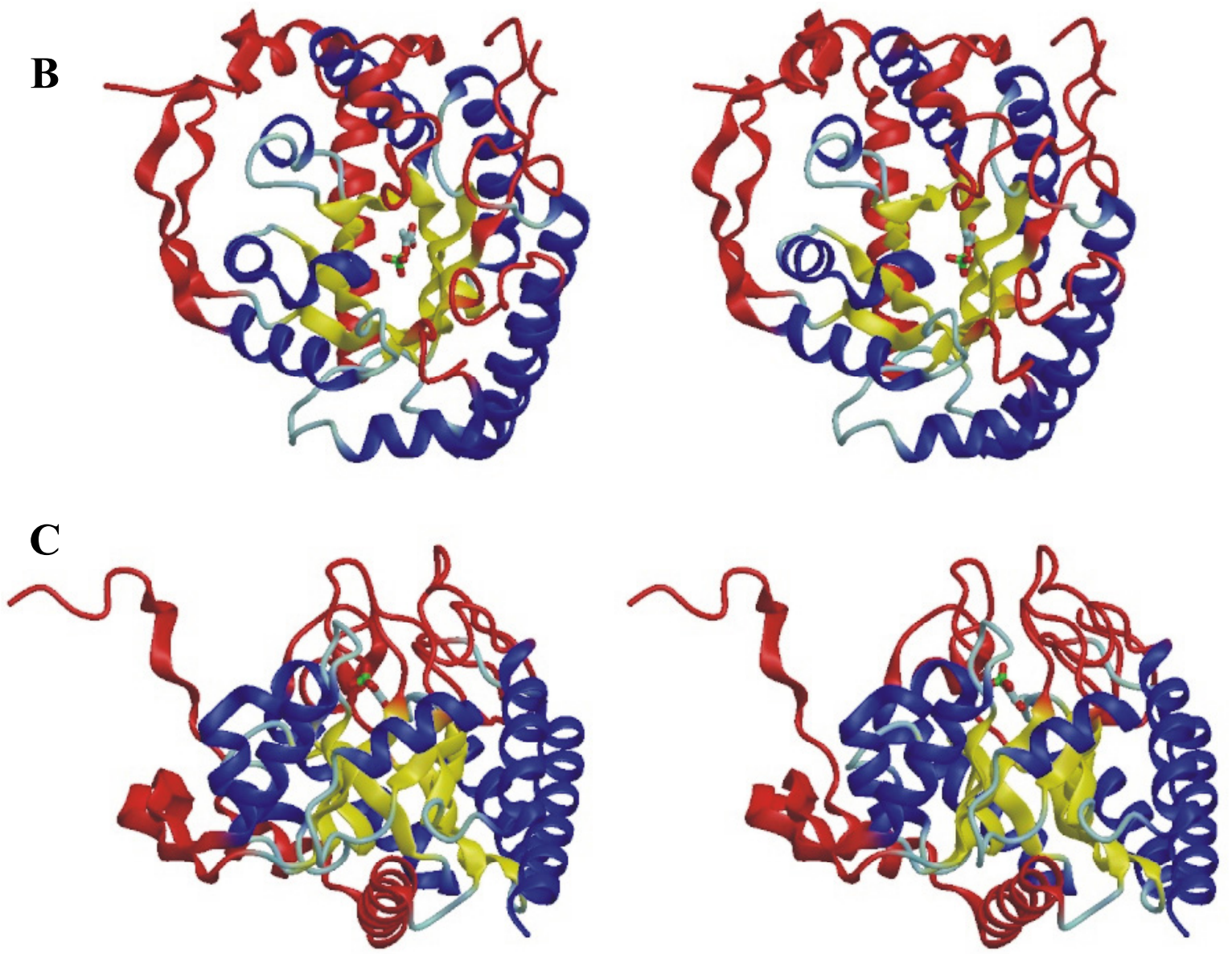

Abb. Ic A: Schematische Darstellung der Sekundärstruktur der tyr-sensitiven DAHP Synthase aus S. cerevisiae mit eingezeichneter PEP-Bindungsstelle; Farbgebung siehe Legende. B: Stereographische Darstellung der Tertiärstruktur der tyr-sensitiven DAHP Synthase aus S. cerevisiae mit Blick in das TIM-Barrel; Farbgebung entsprechend A. C: Um $90^{\circ}$ gedrehte stereographische Ansicht auf das Monomer der tyr-sensitiven DAHP Synthase aus S. cerevisiae, Farbgebung entsprechend A. 
Dem ersten $\beta / \alpha$-Fragment sind eine lange (AS44-63) und eine kurze (AS33-41) $\alpha$-Helix sowie ein kurzer $\beta$-Strang (AS29-24) vorgeordnet. Die ersten 23 AS sind in dieser Struktur nicht modelliert. Auf der C-Seite des barrels sind jeweils zwischen $\beta$-Strang und $\alpha$-Helix 2 , 7 und 8 loops mit einer Länge von 26, 12 und 30 AS eingefügt. Zwischen den Fragmenten 5 und 6 sind auf der n-terminalen Seite des barrels zwei zusätzliche $\beta$-Stränge eingeschoben. Die PEP-Bindungsstelle befindet sich wie oft in Enzymen der TIM-Barrel-Form auf der cterminalen Seite des barrels.

Das Enzym liegt als eng verbundenes Dimer vor, wobei sich der N-Terminus des ersten Monomers um das zweite Monomer innerhalb des Dimers legt und umgekehrt. Dadurch bildet sich zwischen dem zusätzlich eingefügten $\beta$-Faltblatt aus $\beta 6 \mathrm{a}$ und $\beta 6 \mathrm{~b}$ und dem n-terminalen $\beta$-Strang $\beta 0$ ein dreisträngiges antiparalleles $\beta$-Faltblatt aus. Über den Oligomerisierungsstatus findet man für die verschiedenen Isoenzyme aus verschiedenen Organismen unterschiedliche Angaben [Schoner 1976; McCandliss 1977; Ray 1991; Paravicini 1989; Akowski1997; Park 1998; Jordan 2001;].

Ein in bezug auf den Katalysemechanismus zur Gruppe der DAHP Synthasen verwandtes Enzym ist die 3-Deoxy-D-manno-Octulosonat-8-Phosphate-Synthase (KDOP Synthase). Diese verknüpft PEP stereoselektiv mit dem C5-Zucker D-arabino-5-Phosphat (A5P). Auch hier findet sich die ungewöhnliche C-O-Bindungsspaltung und somit die Notwendigkeit der Einbindung eines Wassermoleküls in die Reaktion. Die KDOP Synthasen sind in die Biosynthese der Lipopolysaccharide gram-negativer Bakterien involviert [Muday 1990, R. L. Doong 1991]. Im Gegensatz zu den DAHP Synthasen werden sie nicht über eine negative Rückkopplung reguliert. Sie lassen sich in zwei Gruppen einteilen, die Gruppe der Metalloenzyme und die, die zur Katalyse der Reaktion kein Metallion benötigt [Brick 2001; Duewel 2000]. Trotz geringer Homologie in der Primärsequenz wird aufgrund struktureller und mechanistischer Ähnlichkeiten der KDOP zu den DAHP Synthasen eine gemeinsame Abstammung diskutiert [Duewel 2000].

In der medizinischen Forschung wird stets nach neuen Targets für antibakterielle und fungizide Arzneimittel gesucht. Hierfür bieten sich Enzymsysteme an, die für diese Organismen spezifisch sind, in Wirbeltieren jedoch nicht existieren [Roberts 1998; Keelin 1999]. Da das Vorkommen der Familie der DAHP Synthasen, bzw. der gesamte ShikimatWeg, und auch das Vorkommen der Familie der KDOP Synthasen auf Prokaryonten, Pilze und Pflanzen beschränkt ist, könnte die Entwicklung effektiver Inhibitoren dieser Enzymfamilien medizinisch von Bedeutung sein. Die Kenntnis über den dreidimensionale Aufbau des aktiven Zentrums sowie über den Mechanismus der Katalyse und der Regulation 
spielt in der heutigen Forschung für das Entwickeln neuer Effektoren für Target-Enzyme eine immer größere Rolle (structural-based drug-design).

Die Zahl der in der Proteindatenbank PDB [Berman 2002] deponierten Enzymstrukturen mit TIM-Barrel-Motiv wächst ständig. In kürzlich veröffentlichten Forschungsergebnissen [Nozomi, 2002; Wilmanns 2000] wurde die Übereinstimmung der Motiv-Struktur auf der einen und die unterschiedlichen Funktionen auf der anderen Seite im Hinblick auf Strukturelemente und Evolution untersucht. Das Verständnis des allgemeinen Mechanismus der TIM-Barrel-Struktur sowie enzymspezifischer struktureller Zusätze, eröffnet theoretisch die Möglichkeit, durch gezielte Modifikationen an einem einzigen Grundgerüst eine Vielzahl funktionell unterschiedlicher Enzyme zu entwickeln. 

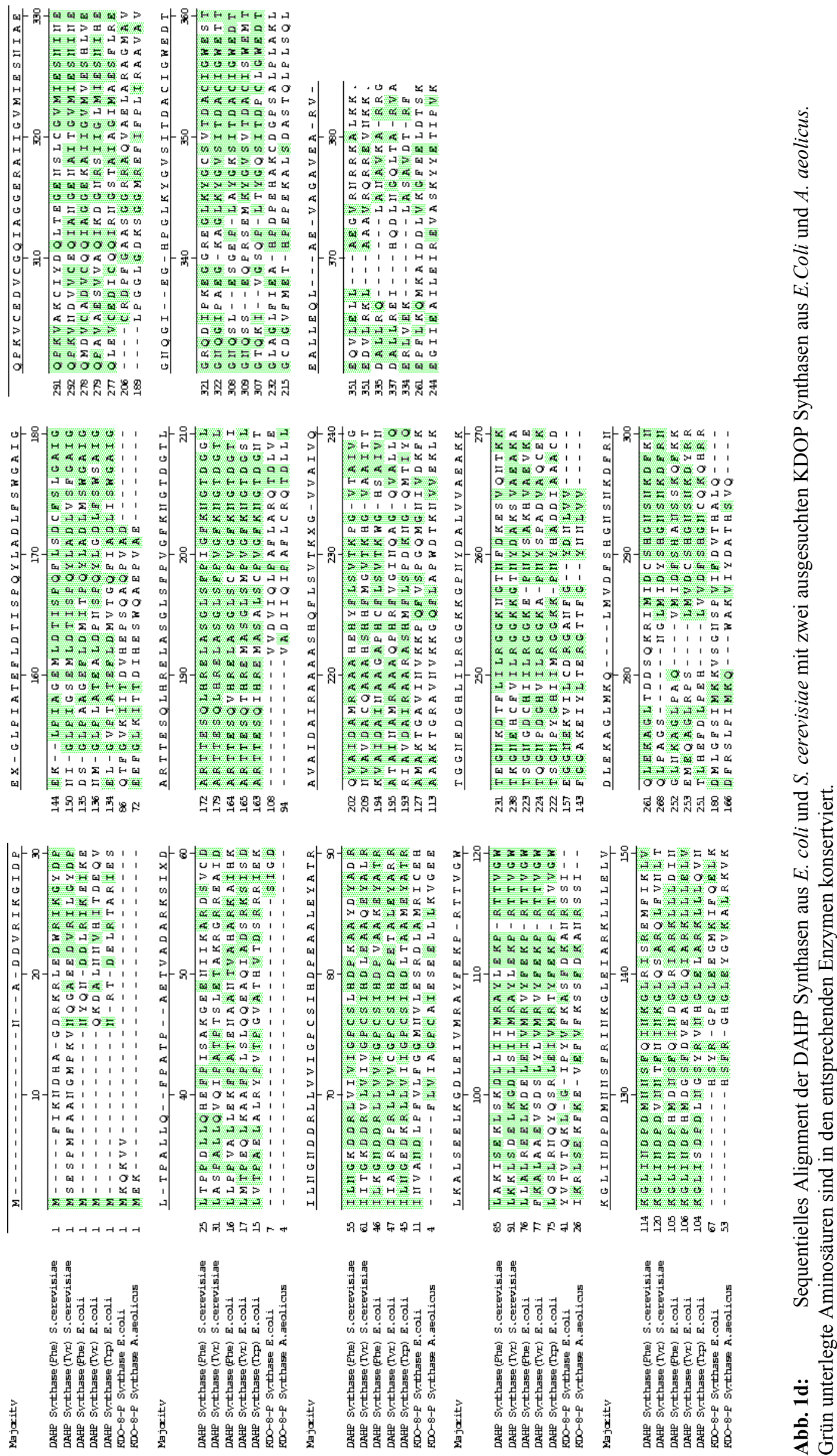


\section{Fragestellung}

Im Rahmen dieser Arbeit sollen die zuvor aufgereinigte tyr-sensitive DAHP Synthase aus S. cerevisiae und verschiedene Komplexe dieses Enzyms röntgenstrukturanalytisch betrachtet werden.

Die Fragestellung lässt sich in zwei Bereiche einteilen.

Im ersten Teil soll der Katalysemechanismus und damit die aktive Tasche des Enzyms näher untersucht werden. Hierzu gehören die Bindungsstelle für das zweite Substrat E4P, die essentielle Rolle des zweiwertigen Kations, die unterschiedliche Aktivierbarkeit des Enzyms durch unterschiedliche Kationen, die mögliche Lokalisation des für die Reaktion benötigten Wassermoleküls, der Oligomerisierungszustand des aktiven Enzyms und mögliche Varianten des Reaktionsmechanismus. Metall-Enzym-Komplexe, Metall-Substrat-Komplexe und Doppelkomplexe mit jeweils einem Substrat und einem Substratanalogon sollen über diese Fragestellungen Aufschluss geben.

Im zweiten Teil soll der negative Rückkopplungsmechanismus (negative feedback regulation) des Enzyms näher untersucht werden. Hierzu gehören das Auffinden der Effektorbindungsstelle sowie das Ausarbeiten einer möglichen Informationsübertragung von der Effektorbindungsstelle zur aktiven Tasche. Eventuelle Rückschlüsse auf die unterschiedliche Regulierbarkeit der verschiedenen Isoenzyme könnten gezogen werden. Enzym-EffektorKomplexe sowohl mit Tyrosin als auch mit Phenylalanin, sowie ein Komplex der G226SMutante mit Phenylalanin und ein sich anschließender Vergleich der Strukturen mit der des nicht inhibierten Enzyms sollen zu diesen Fragestellungen Aufschluss geben. 


\section{Theorie und Methoden}

\section{III.1 Aufreinigung von Enzymen}

[Harris 1990; Lottspeich1998]

Um die Eigenschaften, Funktionsweisen und Aufgaben eines Enzyms zu verstehen, kann es zum einen im Gesamtkomplex des Organismus (z. B. E. coli, S. cerevisiae) untersucht werden (in vivo). Die Komplexität des Systems lässt jedoch nur schwer den tatsächlichen Anteil des zu untersuchenden Enzyms am Gesamtbild der Organismusfunktionen zu. Zusätzlich beschränken sich die Experimente auf physiologische Bedingungen. Physikalische, biochemische und kinetische Untersuchungen werden daher nicht in vivo, sondern an aus dem Organismus isoliertem und aufgereinigtem Enzym vorgenommen (in vitro). Auf die Einflüsse des Gesamtsystems in bezug auf die Eigenschaften und Funktionsweisen des Enzyms wird unter diesen Bedingungen verzichtet. Für in vitro-Untersuchungen muss das Enzym also selektiv aus dem Gesamtkomplex der Zelle isoliert werden. Durch Überexpression im Organismus wird die Menge des zu isolierenden Enzyms pro Zelle erhöht. Nach Aufschluss der Zellen wird das Enzym aus der Menge aller Zellproteine mit verschiedenen Trennmethoden aufgrund seiner physikalischen und chemischen Eigenschaften isoliert.

\section{Proteinfällung}

Einen ersten groben Aufreinigungsschritt stellt häufig die Proteinfällung dar. Hierbei werden die unterschiedlichen Eigenschaften der einzelnen Proteine zu aggregieren ausgenutzt. Beim Aussalzen (salting out) werden hydrophobe Bereiche der Proteine durch die verstärkte Hydratation der Salzionen von solvatisierenden Wassermolekülen befreit, so dass Wechselwirkungen zwischen diesen Proteinflächen die Aggregation erhöhen. Je nach Beschaffenheit der Proteinoberfläche ist die zur Aggregation benötigte Salzkonzentration unterschiedlich. Um ein bestimmtes Protein zu isolieren, wird die Salzkonzentration zunächst so weit erhöht, dass das zu isolierende Enzym gerade noch gelöst bleibt. Nach Zentrifugation und Entfernen der gefällten Proteine kann im nächsten Schritt die Salzkonzentration gerade so weit erhöht werden, dass das entsprechende Enzym ausfällt, der größte Anteil der übrigen Proteine jedoch in Lösung bleibt. Der Vorteil dieser Methode ist, dass Proteine bei hohen Salzkonzentrationen zwar aggregieren, aber nicht denaturieren und sich bei Erniedrigung der Salzkonzentration wieder in Lösung bringen lassen. Als Fällungsmittel wird üblicherweise Ammoniumsulfat verwendet. 


\section{Chromatographische Aufreinigung}

Die Chromatographie beruht auf dem Prinzip der Gleichgewichtseinstellung zwischen einer mobilen und einer stationären Phase. In der Säulenchromatographie besteht die stationäre Phase meist aus runden Partikeln des entsprechenden Säulenmaterials, die von der mobilen Phase und dem aufzutrennenden Proteingemisch durchlaufen werden. Die Trennung erfolgt durch unterschiedliche Laufgeschwindigkeiten der Enzyme durch die Säule aufgrund unterschiedlicher Wechselwirkungen der einzelnen Proteine sowohl mit der mobilen als auch mit der stationären Phase. Je nach Eigenschaft des zu isolierenden Proteins können eine Vielzahl unterschiedlicher Trennmethoden verwendet werden.

\section{Prinzip der Ionen-Austausch-Säulen}

Die Oberfläche eines Proteins ist aufgrund von negativ (z. B. Asp, Asn) und positiv (z. B Arg, Lys) geladenen Aminosäureseitenketten abhängig vom pH-Wert der Umgebung elektrisch aufgeladen. Dieses Phänomen wird in der Ionen-Austausch-Chromatographie ausgenutzt, indem die stationäre Phase ebenfalls mit geladenen Gruppen derivatisiert wird, so dass die Adsorption entsprechend entgegengesetzt geladener Enzyme gefördert wird (Anionen- oder Kationen-Austauscher). Im äquilibrierten Zustand der Säule sollten die Gegenionen so gewählt sein, dass sie geringe Wechselwirkungen mit dem Säulenmaterial besitzen, damit sie leicht durch das stärker bindende Enzym verdrängt werden können. Das zur Elution verwendete Gegenion des Säulenmaterials sollte stärker als das Protein binden, so dass es das Enzym aus der stationären Phase verdrängt. Um eine möglichst gute Trennung zu erhalten, sollte die Ionenkonzentration im Adsorptionsschritt so hoch wie für eine Bindung des zu isolierenden Enzyms möglich gewählt werden, um die Bindung anderer Proteine an die Säule $\mathrm{zu}$ verhindern. Im Elutionsschritt hingegen sollte die Ionenkonzentration so gering wie für die Loslösung des Proteins gerade notwendig gewählt werden, um das Loslösen anderer, an der Säule gebundener Proteine zu verhindern.

\section{Prinzip der hydrophoben Säulen}

Das Prinzip der hydrophoben Säule ist dem der Proteinfällung ähnlich. Die zu reinigende Proteinlösung wird mit einem Puffer hoher Salz-Konzentration auf die Säule gegeben, so dass hydrophobe Bereiche der Proteine, da sie aufgrund der verstärkten Hydratation der Salzionen von ihrer Solvatationshülle befreit sind, an das hydrophobe Säulenmaterial adsorbieren können. Zur Elution wird die Salzkonzentration langsam graduell erniedrigt, der pH-Wert erhöht, oder dem Eluenten eine hydrophobe Lösungsmittelkomponente hinzugefügt, um das Protein vom Säulenmaterial zu trennen. 


\section{III.2 Kristallisation}

\section{[McPherson 1999; McPherson 1985]}

Voraussetzung für ein Röntgenbeugungsexperiment ist ein Kristall, der den Kriterien eines Einkristalls entspricht. Kristalle entstehen aus übersättigten Lösungen durch langsames Einstellen des Gleichgewichtes aus einem thermodynamisch instabilen Zustand. Die Bildung eines Kristalls lässt sich in zwei Teilschritte gliedern, die sich in unterschiedlichen Bereichen des Phasendiagramms wiederfinden (siehe Abb. III.2a).

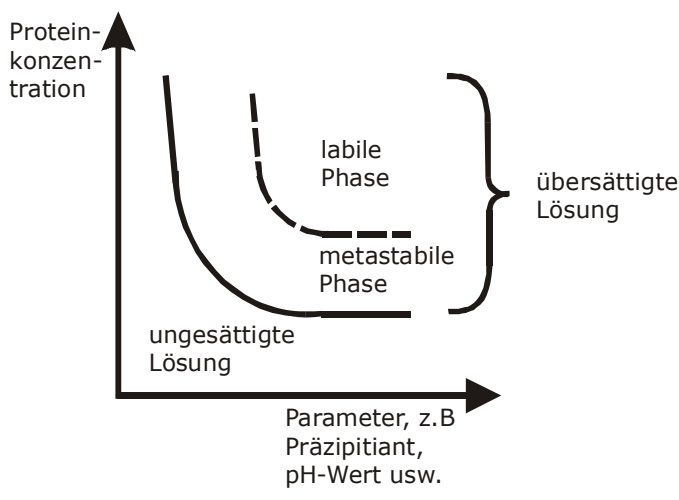

Abb. III.2a Schematisiertes Phasendiagramm einer Proteinlösung in Abhängigkeit der Proteinkonzentration und eines weiteren Parameters,

Die Löslichkeitskurve teilt das Phasendiagramm in die Bereiche der ungesättigten und der übersättigten Lösung ein. Der Bereich der übersättigten Lösung lässt sich wiederum in den Bereich der stärker übersättigten, labilen und den der geringer übersättigten, metastabilen Phase gliedern. Während in der labilen Phase sowohl spontane Keimbildung als auch Kristallwachstum möglich ist, findet in der metastabilen Phase nur Kristallwachstum, nicht aber die Keimbildung statt. Für den ersten Schritt, die Kristallkeimbildung, muss das System zunächst in die stark übersättigte, labile Phase gebracht werden. Sind Kristallkeime vorhanden, sollte der Wachstumsprozess in der metastabilen Phase stattfinden, um die weitere Keimbildung $\mathrm{zu}$ verhindern, ein Kristallwachstum jedoch $\mathrm{zu}$ ermöglichen. Neben der Konzentration der zu kristallisierenden Substanz ist das Löslichkeitsdiagramm insbesondere bei Makromolekülen von vielen weiteren Faktoren wie der Temperatur, dem pH-Wert und der Konzentration von Additiven abhängig. Aufgrund ihrer schwachen intermolekularen Wechselwirkungen ist besonders die Keimung von Proteinkristallen gegenüber kleinen Systemänderungen, wie z. B. Temperaturschwankungen oder Verunreinigungen, sehr empfindlich. Wichtig ist bei der Kristallisation ein langsames Kristallwachstum, das Fehlordnungen und Gitterfehler vermindert. Wegen der hohen Empfindlichkeit gegenüber äußeren Einflüssen, erhält man durch Variation aller möglicher Parameter eine unüberschaubar große Anzahl möglicher Kristallisationsbedingungen. Oft stehen jedoch nur wenige 
Milligramm eines aufgereinigten Proteins zur Verfügung, so dass nur eine limitierte Anzahl an Kristallisationsvarianten angesetzt werden kann. Hat man keine Vorinformationen zur Kristallisation eines Proteins, so empfiehlt sich ein erstes screening. Hierfür sind im Handel unterschiedliche Zusammenstellungen verschiedenster Kristallisationsbedingungen erhältlich, die sich in früheren Kristallisationsansätzen bewährt haben. Ist unter diesen Ansätzen ein vielversprechendes Ergebnis, kann diese Bedingung systematisch verfeinert werden.

\section{Methoden}

Hanging-drop

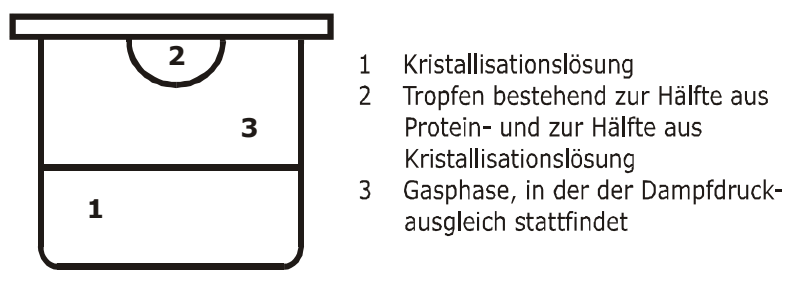

Abb. III.2b Schematische Darstellung der Hanging-drop Methode

Das Prinzip entspricht einer verfeinerten Gasdiffusionsmethode: In einem mit Siliconfett abgedichteten Reservoir befindet sich die Kristallisationslösung. Den „Deckel“ bildet ein siliconisiertes Deckgläschen, an dem der Tropfen hängt (hanging drop) (Abb. III.2b). Dieser besteht im allgemeinen zu gleichen Teilen aus der Kristallisationslösung des Reservoirs und aus der Proteinlösung. Dadurch ist die Konzentration der Kristallisationslösung im Tropfen zu Beginn des Experimentes im Vergleich zu Reservoirlösung verringert. Aufgrund des Dampfdruckausgleichs in der Gasphase findet bei niedrigsiedenden Fällungsmitteln durch langsame Anreicherung dieser Komponente im Tropfen eine Verschiebung des Gleichgewichtes in Richtung der Keimbildung statt. Ist Wasser die niedrigsiedende Komponente, bewirkt sein Entweichen aus dem Tropfen eine Proteinkonzentrationserhöhung und somit eine Möglichkeit zur Keimbildung. Sowohl die Tropfengröße als auch seine Form haben Einfluss auf die Kinetik der Kristallkeimbildung, so dass hier zusätzliche Variationen (z. B. sitting-drop oder größere bzw. kleinere Tropfen) denkbar sind.

\section{Seeding}

Eine Methode, die Keimbildung vom Kristallwachstum $\mathrm{zu}$ trennen, ist das sogenannte seeding. Hierbei werden Kristallisationskeime in einen äquilibrierten Tropfen, der sich in der metastabilen Phase befindet, gebracht, so dass nur die ,ausgesäten“ Keime wachsen, sich jedoch keine neuen Keime bilden. 


\section{Micro-seeding}

Bei dieser seeding-Variante ,zermörsert“ man schon vorhandene, jedoch zu kleine oder zu verwachsene Kristalle in einem Tropfen und streift z. B. mit einem Katzenschnurhaar durch die mit Mikrokeimen angereicherte Lösung. Einige Keime bleiben am Haar haften. Geht man mit diesem Schnurhaar durch einen zuvor äquilibrierten Tropfen, hinterlässt es dort eine Keimspur. Entlang dieser Keimspur sollten sich Kristalle ausbilden. Die Anzahl der transferierten Keime kann bei diesem sogenannten streak-seeding verringert werden, indem man das Katzenhaar nach dem Durchstreifen der Keimlösung noch durch andere, keine Keime enthaltenden Tropfen zieht. Dadurch vermindert sich die Zahl der anhaftenden Keime.

\section{Macro-seeding}

Bei dieser Variante werden schon gut ausgebildete Kristalle, die jedoch zu klein für ein Beugungsexperiment sind, in frische Kristallisationslösungen transferiert: mit Hilfe eines loops oder, bei empfindlicheren Kristallen, mit Hilfe einer Kapillare muss der Kristall zunächst in eine Waschlösung gebracht werden, in der er sich gerade aufzulösen beginnt. Dadurch wird die Kristalloberfläche von an ihr haftenden Keimen und Verunreinigungen befreit. Dieser Vorgang sollte mehrere Male wiederholt werden, bevor man den Kristall in die äquilibrierte Kristallisationslösung bringt, in der er weiterwachsen sollte. Der gesamte Vorgang des macro-seedings kann so oft wiederholt werden, bis der Kristall die gewünschte Größe besitzt oder bis er auch bei noch gesättigter Lösung kein Wachstum mehr zeigt.

Cryobedingungen [Graman 1997]

Heutzutage werden in der Röntgenstrukturanalyse in den allermeisten Fällen Proteindatensätze bei tiefen Temperaturen gemessen. Dies hat positiven Einfluss auf die Auslenkungsparameter der Moleküle, so dass sich die Streukraft erhöht, und vermindert die Strahlenschäden an den Kristallen, so dass ihre Haltbarkeit verlängert wird. Auch ist durch das Einfrieren der Kristalle ihre Aufbewahrung in Dewars über einen langen Zeitraum möglich, so dass ein Kristall mehrmals an verschiedenen Geräten z. B. mit unterschiedlichen Wellenlängen vermessen werden kann. Durch das Einfrieren entsteht jedoch das Problem, dass wegen des hohen Wasseranteil im Kristall dieser beim Gefrieren durch die entstehenden Eiskristallcluster reißt. Außerdem verursachen die im Lösungsmittelfilm kristallisierten Wassermoleküle sogenannte Eisringe auf dem Beugungsbild. Beide Phänomene können verhindert werden, indem man die Kristallisationslösung von vornherein mit sogenannten Cryoprotektanden (wie z.B. Glycerol oder PEG, Zucker, Ammoniumsulfat) versetzt, die die Kinetik der Eiskeimbildung verlangsamen und so die Eisbildung verhindern. Enthält die Kristallisationslösung keine Protektanden, so müssen sie der Lösung nachträglich zugesetzt 
werden. Hierfür setzt man Erntelösungen mit steigendem Anteil (5-30\%) an Cryoprotektanden an. Durch kurzzeitiges (10-60 s) Tränken (soaken) der Kristalle in diesen stufenweise stärker mit Cryoprotektand angereicherten Lösungen diffundieren die Moleküle des Cryoprotektanden in die Kristallkanäle und verhindern dort die Eiskeimbildung.

\section{III.3 Datensammlung, -integration und -skalierung}

[Dauter 1999]

Bei den im Rahmen dieser Arbeit verwendeten Röntgenquellen handelt es sich zum einen um eine Kupfer-Drehanode und zum anderen um Synchrotronstrahlung. Diese hat im Vergleich zu konventionellen Röntgenquellen neben höherer Intensität besonders bei MADExperimenten den Vorteil, dass die Wellenlänge frei wählbar ist. In Synchrotrons der zweiten und dritten Generation, die speziell zur Erzeugung des elektromagnetischen Strahlenspektrums erbaut wurden, sorgen Wiggler und Undulatoren durch Erzwingen eines „Slalomkurses“ der Elektronenpakete und Überlagerung der tangential austretenden Lichtwellen für zusätzliche Intensität. Als Detektoren werden zur Zeit hauptsächlich Image Plateoder CCD (charge coupled device)-Zähler eingesetzt. Erstere haben den Vorteil einer großen, variierbaren aktiven Fläche, deren Auslesezeit jedoch recht lang ist im Vergleich zu den aufgrund steigender Intensität immer kürzer werdenden Belichtungszeiten. $C C D$-Zähler besitzen zwar einen kleineren Ausleseradius, können jedoch auf einem 20-Arm zu höheren Auflösungsbereichen bewegt werden. Ihre geringe Auslesezeit von wenigen Sekunden lässt sie verstärkt an Synchrotrons der zweiten und dritten Generation zum Einsatz kommen.

Im Rahmen dieser Arbeit wurden alle Datensätze auf einem Ein-Kreis-Diffraktometer gesammelt. Dies erleichtert zwar die Handhabung des Gerätes, birgt jedoch den Nachteil, dass besonders bei niedrigsymmetrischen Raumgruppen, hoher Auflösung und langer Wellenlänge ein Teil des reziproken Raums der Messung nicht zugänglich ist (blind region). Dieser kann jedoch durch geeignete Kristallorientierung und Hinzunahme der Friedelpaargegenteile oder in der Raumgruppe P1 durch Messen mit einer zweiten Kristallorientierung aufgefüllt werden. Der Startwinkel einer Messung sollte je nach Kristallsystem und Kristallorientierung im loop so gewählt werden, dass in kürzester Zeit ein vollständiger Datensatz gesammelt werden kann. Die Wahl des Oszillationswinkels hängt von den Zelldimensionen des Kristalls ab. Je länger eine Zellkante und je höher die Mosaizität des Kristalls, desto feiner muss der Oszillationsradius gewählt werden, um ein Überlappen der sogenannten lunes (Reflexe einer Ebene des reziproken Raums) zu verhindern. 
Die Datensammlung, -integration und -skalierung wurde mit den Programmen Denzo [Otwinowski 1993] und Scalepack [Otwinowski 1993] bzw. mit dem Programmpaket HKL2000 [Otwinowski 1997] vorgenommen. Das Programm Denzo ermöglicht eine graphische Darstellung des Beugungsbildes und mittels Autoindizierung eines einzelnen Diffraktionsbildes die Bestimmung der Zellkonstanten, des Bravais-Gitters und der Orientierungsmatrix des Kristalls auf dem Goniometer. Durch Verfeinerung der Kristallparameter- (Zellkonstanten und Orientierungsmatrix) sowie zuvor angegebener Gerätkonstanten (Kristall-Detektor-Abstand, Strahlposition, Detektorposition und -orientierung) wird versucht, eine größtmögliche Übereinstimmung zwischen tatsächlichen und vorherbestimmten Reflexpositionen $\mathrm{zu}$ erhalten. Hierzu wird folgende fehlergewichtete leastsquares-Zielfunktion minimiert:

$$
\begin{aligned}
& \text { pred }=\text { aufgrund eines Modells erwartete Werte } \\
& \begin{array}{ll}
\frac{(\text { pred }-o b s)^{2}}{\sigma^{2}}=\chi^{2} & \text { obs }=\text { beobachtete Werte } \\
& \sigma=\text { aus der Messungenauigkeit und der }
\end{array} \\
& \text { Güte der Vorhersage abgeschätzter Fehler }
\end{aligned}
$$

$\mathrm{Zu}$ achten ist bei ihrer Anwendung auf starke Korrelationen zwischen den einzelnen Parametern. Um z. B. zu verhindern, dass Zellparameterfehler durch Variation der KristallDetektor-Distanz ausgeglichen werden, hält man häufig zunächst den zuletzt genannten Parameter konstant und verfeinert ihn erst, wenn alle anderen Parameter bereits angeglichen sind. Die so angepassten Parameter werden im Laufe der Integration von Bild zu Bild neu verfeinert. Wichtig für eine präzise Vorherbestimmung der Reflexpositionen ist die richtige Einstellung der Boxgröße und des Reflex- bzw. Hintergrundradius, innerhalb derer ein Reflex integriert werden soll, sowie das Vorhandensein eines gut angepassten Reflexprofils. Dieses wird nur aus starken Reflexen erstellt, die sich in einem individuell gewählten Radius um den entsprechenden Reflex befinden. Die aus der Integration erhaltenen Reflexintensitäten und ihre abgeschätzten Fehler werden nachfolgend mit dem Programm Scalepack skaliert und gemittelt. Ein im Anschluss durchgeführtes, sogenanntes postrefinement ermöglicht die Verfeinerung der Zellparameter und der Mosaizität. Zunächst werden die Reflexe und ihre abgeschätzten Fehler mit einem anhand eines Vergleichs der Symmetrieäquivalente für jeweils ein Bild ermittelten Skalierungsfaktor versehen, um Intensitätsunterschiede zwischen einzelnen Bildern auszugleichen.

Während der Skalierung wird die Summe der gewichteten Unterschiede zwischen den gemittelten und den einzeln gemessenen Intensitäten aller Reflexe minimiert. Das Fehlermodell kann durch individuelle Anpassung der zuvor als Standardwerte angegebenen 
Skalierungsfaktoren optimiert werden. Ein gut angepasstes Fehlermodell zeichnet sich durch $\chi^{2}$-Werte um 1 aus.

$R_{\text {sym }}=\frac{\sum\left|F_{o}^{2}-<F_{o}^{2}>\right|}{\sum F_{o}^{2}} \quad$ mit $\quad \mathrm{F}_{\mathrm{o}}{ }^{2}=$ gemessene Intensitäten

Aus einer abschließend ausgegebenen Statistik kann anhand des Verhältnisses I / $\sigma(\mathrm{I})$ und des $\mathrm{R}_{\text {sym }}$ entschieden werden, bis zu welcher Auflösung der Datensatz für die Verfeinerung verwendet wird. Die erstellte Reflexdatei enthält skalierte und über identische oder symmetrieäquivalente Reflexe gemittelte Intensitäten $\left(\mathrm{F}^{2}\right)$ mit ihren geschätzten Fehlern $(\sigma)$.

\section{III.4 Nicht-kristallographische Symmetrie (NCS)}

[Rossmann 1962, 2001; Tong 1997; Drenth 1994]

Häufig befinden sich in einer asymmetrischen Einheit einer Elementarzelle mehrere „Kopien“ eines Moleküls oder Molekülteils. In biologischen Systemen handelt es sich dabei oft um Untereinheiten (z. B. Virushülle) oder aber z. B. bei Enzymen um die Verdopplung abgeschlossener Monomere, die in ihrer oligomeren Form vorliegen. Diese ähnlichen Bereiche einer asymmetrischen Einheit sind durch Symmetrieoperatoren ineinander überführbar, die jedoch nicht der kristallgraphischen Symmetrie des Kristallgitters entsprechen. Man spricht daher von lokaler, bzw. nicht-kristallographischer Symmetrie (NCS). Diese wird wiederum eingeteilt in geschlossene (proper) und offene (improper) Symmetrie. Erstere entspricht einer geschlossenen Punktgruppe (z. B. 2, 3, 5-zählige Achse), während letztere das Originalmolekül nicht durch eine der Kopien darstellen kann (z. B. Achsendrehung um $67^{\circ}$ ). Geringfügige Unterschiede (z. B. Seitenkettenlagen an der Moleküloberfläche) zwischen den über nicht-kristallographische Symmetrie verwandten Molekülen werden durch unterschiedliche Umgebungen verursacht und sind in erster Näherung zu vernachlässigen. Sind die Unterschiede zwischen den einzelnen Molekülen jedoch z. B. aufgrund von Domänenbewegungen zu groß, wird die NCS aufgehoben.

$\mathrm{Ob}$ und in welcher Form ein Kristallgitter NCS beinhaltet, lässt sich zumeist schon vor der Strukturlösung anhand der Patterson-Dichtekarte erkennen. Dieser Pattersonraum berechnet sich aus einer Fouriersynthese der Amplitudenbeträge ohne Phaseninformation und spiegelt die Abstandsvektoren innerhalb der Zelle wider. Der Ursprung entspricht der Summe der Nullvektoren, also der Atomabstände zu sich selbst. Alle anderen Vektoren lassen sich in zwei Gruppen einteilen, die der Abstände innerhalb eines Moleküls (self-vectors) und die der Abstände zwischen den verschiedenen Molekülen (cross-vectors). Während sich die self- 
vectors aufgrund der kurzen Abstände innerhalb der Moleküle eher im Bereich um den Ursprung befinden, liegt der größte Teil der cross-Vektoren weiter entfernt vom Ursprung. Um die Orientierung der durch NCS miteinander verknüpften Moleküle zueinander zu bestimmen, benötigt man zunächst nur die self-Vektoren. Es wird die Pattersonfunktion für den Bereich $(\Omega)$ berechnet, für den das Verhältnis der intra- zu den intermolekularen Vektoren möglichst groß ist. Ein typischer Wert sind 50-75\% des sphärischen Radius der Untereinheit. Eine Selbstrotationsfunktion zeigt nun Zusammenhänge zwischen der Originalund einer um den Ursprung gedrehten Funktion. Beobachtet man während der Drehung Maxima in der Selbstrotationsfunktion, so überlagern sich die intramolekularen Vektoren zweier NCS verwandter Moleküle. Anhand einer Selbstrotationsfunktion lassen sich also Rückschlüsse auf die relative Orientierung der NCS verwandten Moleküle ziehen, nicht aber auf ihre relative Lage zueinander.

$$
R F([C])=\int_{\Omega} P_{A}(u) P_{B}([C] u) d u
$$

wobei :

$[C]=\left[\alpha_{B}\right][\rho]\left[\beta_{A}\right]$ mit

$[\alpha]$ und $[\beta]=$ deorthogonalisierendeund orthogonalisierende Matrizen

$[\rho]=$ Rotationsmatrix

Häufig wird die Rotation $[\rho]$ in Form von Polarwinkeln beschrieben, so dass $\psi$ und $\phi$ die Orientierung der NCS-Achse und $\kappa$ den Winkel der Rotation angeben. Gleichung (1) wird im Bereich $\Omega$ für alle Rasterpunkte eines Rastergitters berechnet, dessen Rastergröße festgelegt werden muss. Meist wird $\kappa$ festgesetzt $\left(180^{\circ}, 120^{\circ}, 90^{\circ}\right)$ und die Rotationssuche auf $\psi$ und $\phi$ beschränkt. Die Resultate können in einer stereographischen Projektion dargestellt werden (siehe Kap. V.3).

Zur Berechnung der Selbstrotationsfunktion haben sich zwei unterschiedliche Arten durchgesetzt. Die sogenannte Slow-Rotation-Function [Tong 1990] berechnet sich über die Fouriertransformierten der Pattersonfunktionen und der G-Funktion, die einer Fouriertransformierten über einen Bereich eines bestimmten Radius entspricht.

$$
R F([C])=\sum_{h} \sum_{p} F_{h}^{2} F_{p}^{2} G_{h p}
$$

Da diese Funktion proportional zu den Reflexintensitäten ist, kann sich die Berechnung auf starke Reflexe beschränken. Trotzdem bleibt sie sehr rechenintensiv. 
Auch translatorische Elemente innerhalb einer asymmetrischen Einheit können schon in der Pattersonfunktion erkannt werden. Diese verursachen im Vektorraum der Pattersonfunktion neben dem Ursprungsmaximum weitere Maxima, die durch die Überlagerung der in Betrag und Richtung gleichen intermolekularen Abstandsvektoren verursacht werden.

NCS kann auf verschiedenen Stufen der kristallographischen Untersuchung zur Anwendung kommen. Vor der Strukturlösung kann die Bestimmung der NCS erste Hinweise auf die Kristallpackung und auf einen möglichen Oligomerisierungszustand der biologisch aktiven Form geben. Für die Strukturlösung mit Schweratomderivaten ist das Wissen über die NCS oftmals essentiell, sowohl für das Auffinden der Schweratompositionen als auch für die nachfolgende Dichtemodifikation mit NCS-averaging und solvent-flattening. Auf die Funktion bei der Strukturlösung mit Hilfe des molekularen Ersatzes wird in Kap. III.5 eingegangen. Während der Strukturverfeinerung kann nicht-kristallographische Symmetrie besonders bei niedrig aufgelösten Daten sinnvoll eingesetzt werden. Zum einen kann sie während der Verfeinerung der Atomkoordinaten das Daten-zu-Parameter-Verhältnis verbessern, zum anderen kann sie bei der Berechnung der Elektronendichte ausgenutzt werden, indem über NCS-verwandte Bereiche gemittelt wird (NCS-averaging).

In dieser Arbeit wurde nichtkristallographische Symmetrien mit den Programmen LSQKAB [Kabsch 1976] und GLRF [Tong 1997] bestimmt. Selbstrotationsfunktionen wurden ebenfalls mit dem Programm GLRF berechnet. Während der Verfeinerung wurde NCS teilweise in den Programmen CNS [Brünger 1998] und Refmac [Murhudov 1997] eingesetzt. Zur Berechnung gemittelter Elektronendichten (NCS-avereging) wurden Masken in CCP4 [CCP4 1994] erstellt und in CNS verwendet.

\section{III.5 Molekularer Ersatz (Molecular Replacement)}

Neben der Strukturlösung mit Hilfe eines Schweratomderivates (SIR) oder der Ausnutzung anomaler Streuung (SAS, MAD) bzw. ihrer Kombination (SIRAS) gewinnt die Methode des Molekularen Ersatzes (molecular replacement) für die Strukturbestimmung biologischer Moleküle immer mehr an Bedeutung. Ein großer Vorteil dieser Methode ist, dass nur ein nativer Datensatz benötigt wird. Hinzu kommt die immer größer werdende Anzahl an Proteinstrukturen, die strukturelle Homologien $\mathrm{zu}$ neuen Molekülstrukturen immer wahrscheinlicher werden und eine zukünftige, standardmäßig systematische Durchsuchung der PDB [Bergman 2002] nach Suchfragmenten sinnvoll erscheinen lässt. Heutzutage wird 
der Molekulare Ersatz meist für Enzyme eingesetzt, deren Struktur schon in einer anderen Raumgruppe existiert, für Komplexstrukturen eines bekannten Enzyms oder für Enzyme, von deren Homologe z. B. aus anderen Organismen bereits Strukturen existieren. Als Modelle können sowohl Kristall- als auch NMR-Strukturen verwendet werden. Eine Gefahr dieser Strukturlösungsmethode liegt darin, dass nur die Amplituden aus den Messdaten stammen, die für die resultierende Elektronendichte bedeutsameren Phasen jedoch zunächst vom Suchmodell übernommen werden, so dass die Dichtekarte zu Beginn der Verfeinerung entscheidend vom Suchmodell geprägt ist (model bias). Diesem Problem kann z. B. mit simulated annealing (Kap. III.6) begegnet werden.

Das Prinzip des Molekularen Ersatzes entspricht einer sechsdimensionalen Suche des Modells in den Daten der zu lösenden Struktur, so dass die Summe über alle $\left|F_{o}-F_{c}\right|$ minimiert wird. Durch diese sechs Variablen, drei Rotations- und drei Translationsmöglichkeiten, kann die bekannte Struktur auf die Position der unbekannten Struktur in der neuen Zelle transformiert werden.

$$
\begin{aligned}
X^{\prime}=[C] X+t \quad \text { mit } \quad \mathrm{X} & =\text { alte Koordinaten } \\
\mathrm{X}^{\prime} & =\text { neue Koordinaten } \\
{[\mathrm{C}] } & =\text { Rotationsmatrix } \\
\mathrm{t} & =\text { Translationsvektor }
\end{aligned}
$$

Da eine sechsdimensionale Suche einen enormen Rechenaufwand benötigt, wird sie in den meisten MR-Programmen in zwei Schritte unterteilt. Wie bei der Ermittlung der nichtkristallographischen Symmetrie kann man auch in diesem Fall die Patterson-Funktion auswerten. Auch hier teilt man den Vektorraum in den Bereich der nahe am Ursprung liegenden intramolekularen self vectors und der mehrheitlich weiter entfernt liegenden intermolekularen Vektoren (cross vectors) ein. Für die Rotationssuche werden zunächst ebenfalls nur die self-Vektoren benötigt. Im Fall des Molekularen Ersatzes werden nicht zwei identische Pattersonfunktionen übereinander rotiert, sondern die des bekannten Fragmentes über der des zu lösenden Moleküls. Auch hier wird durch Auffinden von Maxima in der Rotationsfunktion, die sich über einen Bereich mit einem großen Verhältnis von intra- zu intermolekularen Vektoren erstreckt, die Orientierung des bekannten Moleküls zum unbekannten festgelegt. Die Suche kann ebenfalls im Realen oder Reziproken Raum durchgeführt werden und auch hier ist die Benutzung der von Crowther [Crowther 1972] entwickelten fast-rotation-function möglich. Das Auffinden von Maxima in der Rotationspattersonfunktion der self-vectors aus den Daten des Suchfragmentes und denen der zu bestimmenden Struktur ermöglicht die korrekte Orientierung des Moleküls in der neuen Zelle. 
Die Positionierung des richtig orientierten Moleküls in der Zelle kann auf unterschiedliche Arten erfolgen. In P1 ist eine Translationssuche, sofern sich nur ein Molekül in der asymmetrischen Einheit befindet, nicht nötig, da der Ursprung frei gewählt werden kann und keine Restriktionen durch Symmetrieoperatoren bestehen. In allen anderen Raumgruppen ändern sich bei der Translation der richtig orientierten Moleküle sowohl die Lage als auch die Abstandsvektoren zwischen den symmetrieverwandten Molekülen. Eine Variante, die korrekte relative Lage der Moleküle zueinander und zum Ursprung zu ermitteln, ist die willkürliche Verschiebung des richtig orientierten Moleküls in der asymmetrischen Einheit. Eine Minimierung der Differenz zwischen $\left|\mathrm{F}_{\mathrm{o}}\right|$ der Daten und $\left|\mathrm{F}_{\mathrm{c}}\right|$ des rotierten und translatierten Suchmodells sollte zu der richtigen Lage des Moleküls in der neuen Zelle führen. Gütekriterien können hier sowohl der R-Wert als auch der Korrelationskoeffizient zwischen den Strukturfaktoren des Suchmodells und denen der neu zu besimmenden Struktur sein. Um Rechenzeit zu sparen wird häufig nur einmal das $F_{c}$ des Suchmodells berechnet und alle weiteren durch Einbeziehung der durch die Translation verursachten Phasenverschiebungen. Eine zweite Möglichkeit der Translationssuche nutzt die cross-Vektoren im Pattersonraum aus. In diesem Fall wird die Pattersonfunktion des translatierten Suchmodells und seiner Symmetrieäquvalente mit der aus den $F_{o}$ berechneten überlagert. Das Augenmerk liegt hierbei auf den intermolekularen cross-Vectoren. Diese Translationsfunktion wird für alle Punkte der asymmetrischen Einheit berechnet. Ein Maximum deutet die Übereinstimmung der Position des Suchmodells mit der tatsächlich in der Zelle vorliegenden an.

Die unterschiedlichen Prinzipien der im Rahmen dieser Arbeit benutzten MR-Programme sollen im folgenden kurz skizziert werden:

\section{MOLREP [Vagin 1997]}

Dieses MR-Programm teilt die sechsdimensionale Suche wie oben beschrieben in eine Rotationssuche und eine nachgeschaltete Translationssuche ein. Benötigt werden die Daten der unbekannten Struktur und die Koordinaten des Suchmodells. Für die Rotationssuche wird die von Crowther entwickelte fast-Rotation-Funktion [Crowther 1972] verwendet. Der Radius des $\mathrm{zu}$ berechnenden Bereichs wird anhand des Durchmesser des Suchfragmentes abgeschätzt. Eine Verbesserung gegenüber anderen MR-Programmen ist z. B. die an den Ursprungsmaxima durchgeführte Skalierung der beiden Pattersonfunktionen aneinander. Diese Skalierungsart wirkt sich besonders bei niedrig aufgelösten Daten positiv aus, da in diesen Fällen die Abschätzung des B-Faktors anhand der Wilson-Auftragung nicht sehr präzise ist. Auch die Einführung eines sogenannten soft low-resolution cut-off, bei dem die niedrig aufgelösten Reflexe nicht von vornherein eliminiert, sondern mit Hilfe einer Gauss- 
Funktion heruntergewichtet werden, führt zu besseren Ergebnissen, da weniger Probleme mit Reihenabbruch-Fehlern auftreten. Für die Translationssuche wird in diesem Programm die von Crowther \& Blow entwickelte und von Harada et al. weitergeführte Translationfunktion verwendet, die gleichzeitig alle Symmetrieäquivalente miteinbezieht und so das Signal-zuRausch-Verhältnis verbessert und die Position in der Zelle und nicht nur relativ zu den Symmetrieelementen angibt. Außerdem wird nicht die Summe sondern das Produkt über die Translations-Funktionen der einzelnen Symmetrieoperationen berechnet, was wiederum den Kontrast der Berechnung verstärkt. Zusätzlich wird eine sogenannte packing-Funktion miteinbezogen, die Maxima eliminiert, durch deren Lage Moleküle aufgrund von Packungsrestriktionen übereinander liegen würden. Diese Funktion macht eine Einbeziehung von Molekülen, deren Lage schon bekannt ist, möglich.

EPMR (evolutionary programming for molecular replacement) [Kissinger 1998]

Dieses Programm arbeitet im Gegensatz zu den meisten anderen MR-Programmen tatsächlich mit einer sechsdimensionalen Suche. Um den Rechenaufwand zu reduzieren, wird hierbei ein Algorithmus zur evolutionären Optimierung benutzt. Eine Anzahl anfänglich willkürlich generierter Suchmodellpositionen (Population) wird iterativ optimiert, indem die in bezug auf ihren Korrelationskoeffizienten besten Lösungen in Rotation und Translation leicht abgeänderte „Nachkommen produzieren“, während Lösungen mit schlechten Korrelationskoeffizienten ausscheiden. Die Wiederholung dieses Prozesses der Aussortierung und Aufstockung der Population durch leicht abgeänderte Koordinaten der bis dahin besten Lagen führt iterativ zur Fokussierung auf die Region der besten Positionen. Nach anschließender rigid-body-Verfeinerung der besten Lösung werden die Koordinaten dieses Modells ausgegeben. Auch hier wird, um die Rechenzeit $\mathrm{zu}$ verkürzen, nur einmal eine Fouriertransformation für das Suchmodell berechnet und alle weiteren Strukturfaktoren der leicht veränderten Positionen mit Hilfe der Phasenverschiebung bestimmt. Diese sechsdimensionale Suche hat gegenüber der getrennten Rotations- und Translationssuche den Vorteil, dass die in der Rotationssuche aufgetretenen Fehler, die die Translationssuche zum Teil erheblich beeinträchtigen können, hier nicht beibehalten, sondern sowohl Translationsals auch Rotationsfehler kontinuierlich minimiert werden. Ein weiterer Vorteil dieses Programms ist ein sehr gutes Signal-zu-Rausch-Verhältnis. Dieses resultiert daraus, dass jeweils alle Daten zur Fouriertransformation benutzt werden. In anderen Programmen werden die Vektoren in der Rotationssuche nur bis zu einem bestimmten Radius verwendet, so dass einige self-vectors zur Berechnung fehlen, einige cross-vectors jedoch verfälschend hinzugenommen werden. Ein möglicher Nachteil der sechsdimensionalen Suche im 
Programm EPMR ist, dass der Raum nicht systematisch abgesucht wird, so dass die Autoren ein mehrmaliges Benutzen des Programms empfehlen.

\section{III.6 Verfeinerung}

[Brünger 1997; Drenth 1994]

Um das aus der Strukturlösung erhaltene, grobe Strukturmodell zu verfeinern, wird in iterativen Schritten versucht, die Übereinstimmung des erstellten Strukturmodells mit den gemessenen Daten zu optimieren. Dies kann mit unterschiedlichen Zielfunktionen erreicht werden. Bei der für die Verfeinerung von Kleinmolekülen üblichen Methode der kleinsten Fehlerquadrate (least-squares) wird die Funktion der Summe über die gewichteten und quadrierten Differenzen zwischen den beobachteten und aus dem Strukturmodell berechneten Amplituden minimiert. Für dieses Minimierungsverfahren wird angenommen, dass die momentanen Phasen weitgehend korrekt sind und dass die Verteilungskurve der beobachteten Amplituden einer Gaußfunktion mit bekannten Fehlern entspricht. Beide Annahmen sind besonders für unvollständige oder fehlerbehaftete Modelle schlecht erfüllt. Eine weitere Zielfunktion zur Optimierung der Übereinstimmung zwischen dem erstellten Modell und den gesammelten Daten ist das Prinzip der „größten Wahrscheinlichkeit“" (maximum likelihood), dessen Spezialfall unter den oben angenommenen Bedingungen das least-squares-Verfahren ist. Bei dieser Methode, die ebenfalls davon ausgeht, dass das beste Modell am besten mit den Daten übereinstimmt, wird jedoch die Wahrscheinlichkeit, dass die gesammelten Daten dem erstellten Modell entsprechen, maximiert. Unter der Annahme, dass sowohl die Daten als auch das Modell mit unabhängigen Fehlern behaftet sind, werden die Einzelwahrscheinlichkeiten multipliziert.

$$
L=\prod_{i} P_{a}\left(F_{i} ; F_{i, c}\right)
$$

Da die Daten als solche invariant sind, werden die Parameter des Strukturmodells variiert, um die Funktion zu minimieren. Diese Methode ist im Vergleich zur least-squares-Verfeinerung sehr viel unempfindlicher gegenüber vom Modell induzierten Fehlern (model-bias) und daher für die Verfeinerung eines unvollständigen oder mit Fehlern behafteten Modell besonders bei niedrig aufgelösten Daten besser geeignet. Ein Kriterium für die Güte der Übereinstimmung ist für beide Zielfunktionen der sogenannte R-Wert. 


$$
R=\frac{\sum\left\|F_{o}|-k| F_{c}\right\|}{\sum\left|F_{o}\right|}
$$

Aufgrund der oftmals geringen Auflösung der Proteindatensätze ist das Verhältnis von Daten zu Parametern häufig so schlecht, dass das zu lösende Gleichungssystem nur knapp über, oder sogar unterbestimmt ist. Dies führt zwangsläufig zu einer Überinterpretation der Daten. Um $\mathrm{zu}$ verhindern, dass gegen das „Rauschen“ in den Daten verfeinert wird, benutzt man den

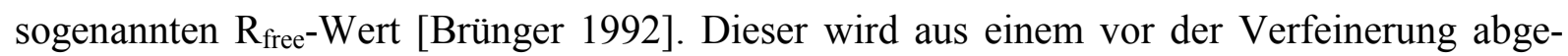
trennten Testdatensatz berechnet, gegen den nicht verfeinert wird. Entspricht das Modell den Daten und sind die Fehler statistisch verteilt, sollte der $\mathrm{R}_{\text {free }}-$ Wert den R-Wert nur um wenige Prozente übersteigen. Die Auswahl der Reflexe für diesen Testdatensatz sollte zufällig erfolgen. Beinhaltet der Datensatz jedoch nichtkristallographische Rotationssymmetrie, so sind Reflexe innerhalb eines bestimmten Auflösungsbereiches miteinander korreliert. Dies führt bei willkürlichem Herausnehmen von Reflexen dazu, dass sich miteinander korrelierte Reflexe sowohl im Arbeits- als auch im Testdatensatz befinden. Dadurch wird der $\mathrm{R}_{\text {free-Wert }}$ indirekt beeinflusst und die Differenz zwischen $\mathrm{R}$ - und $\mathrm{R}_{\text {free- }}$-Wert scheint gering. Ein $\mathrm{zu}$ niedriger $\mathrm{R}_{\text {free}}$-Wert lässt bei der Abschätzung der Fehler über Kreuz-Validierung auch diese zu klein, das Modell also als zu gut erscheinen. Dies führt zu einem falschen Gewichtungsschema. Um bei vorhandener NCS die Beeinflussung des $\mathrm{R}_{\text {free }}-$ Wertes durch das Modell zu verhindern, kann der Testdatensatz in dünnen Auflösungsschalen (thin shells) definiert werden. Dabei werden Reflexe einer gesamten Schale in den Testdatensatz aufgenommen, um sicherzustellen, dass alle NCS-verwandten Reflexe dieser Schale im Testdatensatz zu finden sind.

Um das Daten-zu-Parameter-Verhältnis bei niedrig aufgelösten Proteindatensätzen zu verbessern, müssen zusätzliche, meist chemische Informationen entweder als constraints (z. B. starre Gruppen von Phenylringen), die die Anzahl der Parameter verringern, oder als restraints (z. B. Bindungslängen-Vorgaben, restrained NCS), die wie zusätzliche Daten fungieren, eingeführt werden. Die B-Wert-Verfeinerung benötigt im anisotropen Fall für jedes Atom zusätzlich sechs Parameter, im isotropen Fall nur einen. Proteindatensätze werden daher meist isotrop verfeinert. Auch hier können durch Gruppierung von B-Werten (Haupt- und Seitenkette einer Aminosäure) Parameter eingespart, oder z. B. durch Angabe eines Gradienten (Zunahme der B-Werte von $\mathrm{C}_{\alpha}$ zum Seitenkettenende) als restraints Daten hinzugefügt werden. Eine detailliertere Beschreibungsmöglichkeit der Auslenkungsparameter lässt sich durch Verfeinerung eines auf eine Gruppe der asymmetrischen Einheit (z. B. 
Monomer eines Enzyms) bezogenen TLS-Modells erhalten. Hierbei werden die Translation, die Libration und die Schraubenbewegung (TLS) der Gruppe im Kristall durch drei Matrizen ausgedrückt, deren 20 Elemente ebenfalls gegen die Daten verfeinert werden [Winn 2000]. Um die oben beschriebenen Zielfunktionen (least-squares und maximum likelihood) zu minimieren bzw. zu maximieren, können unterschiedliche Algorithmen angewendet werden. Mit Hilfe der Methode des konjugierten Gradienten (conjugate gradient) erfolgt die nichtlineare Optimierung iterativ anhand der partiellen Ableitung nach den einzelnen Parametern. Die Verfeinerung ist konvergiert, wenn die Änderungen in den Parametern unter einen bestimmten Wert fallen. Diese Methode birgt die Gefahr, dass die zu minimierende Funktion in einem lokalen Minimum konvergiert und so das globale Minimum, also das beste Model der Struktur, nicht aufgefunden wird. Ein anderer Ansatz zur Optimierung der Zielfunktion ist das sogenannte „Simulierte Tempern“ (simulated annealing). Der Vorteil dieses Algorithmus ist, dass die Verfeinerung im Gegensatz zur conjugate gradient-Methode auch gegen den Gradienten verlaufen kann. Dadurch vergrößert sich der Konvergenzradius und die Parameter können sich über lokale Maxima hinweg dem globalen Minimum annähern. Dies wird durch das Anwenden eines molekulardynamischen Prozesses (molecular dynamic) erreicht. Die zu minimierende Funktion wird als potentielle Energie formuliert.

$E=E_{\text {chem }}+w_{\text {data }} \cdot E_{\text {data }}$

$E_{\text {chem }}$ enthält empirische Informationen über alle chemischen Wechselwirkungen, während $\mathrm{E}_{\text {data }}$ die Differenz zwischen beobachteten und berechneten Daten ausdrückt. $\mathrm{w}_{\text {data }}$ ist ein Gewichtungsfaktor. Beim simulated annealing wird nun die Energie durch Erhöhung der Temperatur als Kontrollparameter, der als solcher keine physikalische Bedeutung hat, vergrößert. Dies führt durch Koordinatenänderungen nach dem Prinzip der simulierten Molekularbewegung (molecular dynamics) zur Überschreitung von Energiebarrieren der Zielfunktion. Diese Simulation kann entweder mit kartesischen restraints oder aber mit constraints, die nur Torsionswinkelvariationen zulassen, durchgeführt werden. Letzterer Algorithmus ist wesentlich stabiler und für niedrig aufgelöste Daten besser geeignet. Um zu verhindern, dass sich das System aufgrund sinkender potentieller und damit steigender kinetischer Energie aus dem einmal erreichten globalen Minimum wieder herausbewegt, wird eine Temperaturkontrolle eingeführt, die bei zu großer Abweichung der momentanen Temperatur zur Anfangstemperatur die kinetische Energie bremst. Die „Temperatur“ kann schließlich entweder durch linear slow-cooling (langsames Absenken) oder quenching (abruptes Abkühlen) reduziert werden. Der Algorithmus des simulated annealing ist also 
besonders geeignet für schwach bestimmte oder mit Fehlern behaftete Modelle, wie sie z. B. $\mathrm{zu}$ Verfeinerungsbeginn bei durch MR gelösten Strukturen vorliegen. Durch den größeren Konvergenzradius und die Möglichkeit, lokale Minima zu durchschreiten, wird die Wahrscheinlichkeit, das weiter entfernte globale Minimum zu finden, vergrößert.

Unabhängig vom verwendeten Algorithmus werden die Elektronendichten zwischen den einzelnen Verfeinerungszyklen mit einem Graphikprogramm dargestellt und das Modell manuell entsprechend erweitert und angepasst. Für schlecht bestimmte Modellregionen kann es hilfreich sein, die Elektronendichte über nicht kristallographische Symmetrie zu mitteln. Im Idealfall werden so lokal begrenzte Fehler herausgemittelt und die Elektronendichte dadurch präzisiert. Fehlerhaft modulierte Strukturregionen können erkannt werden, indem systematisch kleine Bereiche (ca. 10\%) des Modells aus der Verfeinerung ausgespart werden. Die aus den einzelnen Dichten der jeweils ausgelassenen Modellbereiche kombinierte Elektronendichte sollte nur den korrekten Verlauf der Peptidkette wiedergeben. Elektronendichte von zuvor falsch positionierten Aminosäuren sollte in dieser (composite) omit map nicht mehr erscheinen.

Im Rahmen dieser Arbeit wurden die Verfeinerungsprogramme CNS und REFMAC benutzt. Mit dem Programm CNS (Crystallography and NMR System) [Brünger 1998] wurden Verfeinerungen ausschließlich mit der maximum likelihood Funktion durchgeführt. Es kann zwischen den Optimierungsalgorithmen conjugate gradient oder simulated annealing gewählt werden. Chemische Informationen werden in Form von Kraftfeldberechnungen in die Verfeinerung miteinbezogen, NCS-Matrizen können als restraints oder constraints integriert werden. B-Werte können flexibel entweder individuell oder als Gruppen verfeinert werden. Es besteht die Option composite-omit-maps sowie gemittelte Elektronendichtekarten automatisch zu erstellen.

Mit dem Programm REFMAC [Murshov 1997] können Verfeinerungen sowohl mit der leastsquares als auch mit der maximum likelihood Zielfunktion verfeinert werden. In der im Rahmen dieser Arbeit benutzten Version beschränkte sich die Optimierungsmethode auf den conjugate gradient Algorithmus. Standardabweichungen von optionalen restraints können bei Bedarf den jeweiligen Bedingungen angepasst werden. Auch REFMAC erlaubt die Einbeziehung von NCS in Form von restraints. Im Gegensatz zu CNS zeichnet sich dieses Programm durch die Möglichkeit einer anisotropen Verfeinerung individueller B-Faktoren bei hoher Auflösung aus, die mit Hilfe entsprechender restraints stabilisiert werden kann. Bei mittlerer Auflösung ist auch die Anpassung eines TLS-Modells für eine oder mehrere Gruppen der asymmetrischen Einheit möglich. 


\section{Experimentelles}

\section{IV.1 Aufreinigung der DAHP Synthase aus $S$. cerevisiae}

Die Anzucht der an DAHP Synthase überexpremierten Hefezellen [Schnappauf 1998] und die Aufreinigung des Enzyms erfolgte am Institut für Mikrobiologie der Universität Göttingen in der Abteilung von Herrn Prof. Dr. Braus. Im Rahmen dieser Arbeit wurden einige Aufreinigungen unter Anleitung von Dipl. Biol. Andrea Pfeil durchgeführt.

Die Aufreinigung erfolgte nach Schnappauf et al. [Schnappauf, 1998] in drei Reinigungsschritten, einer Ammoniumsulfat-Fällung, einer Säulenchromatographie basierend auf hydrophoben Wechselwirkungen mit Ethylaminosepharose und einer sich anschließenden Mono-QAnionenaustausch-Chromatographie.

Ammoniumsulfat-Fällung

Es wurden ca. $80 \mathrm{~g}$ an DAHP Synthase überexpemierter, gewaschener Hefezellen aufgetaut. Nach erfolgtem Zellaufschluss wurden die Zelltrümmer abzentrifugiert (13.000 Upm, 45 min., $4^{\circ} \mathrm{C}$ ). Während der weiteren Aufreinigung wurde bei einer Temperatur von $4^{\circ} \mathrm{C}$ gearbeitet. Alle verwendeten Lösungen enthielten 0.1 mM PMSF als Proteaseinhibitor und $1 \mathrm{mM}$ DTT als Antioxidansmittel. Um das Metallion aus dem Enzym zu entfernen und die Proteinlösung während der gesamten Aufreinigung metallfrei zu halten, wurden alle Lösungen mit $0.5 \mathrm{mM}$ EDTA versetzt.

Der Proteinlösung wurden pro $100 \mathrm{ml}$ Rohextrakt $7.84 \mathrm{~g} \mathrm{~K}_{2} \mathrm{HPO}_{4}(0.5 \mathrm{M})$ und $17.6 \mathrm{~g}$ feingemörsertes $\left(\mathrm{NH}_{4}\right)_{2} \mathrm{SO}_{4}$ unter Rühren zugegeben. Die Proteinsuspension wurde $20 \mathrm{~min}$ auf Eis gerührt und der Überstand nach Zentrifugation (23.00 Upm, 40 min., $\left.4^{\circ} \mathrm{C}\right)$ dekantiert und über Gauze filtriert, um Fettpartikel zu entfernen.

\section{Säulenchromatographie basierend auf hydrophoben Wechselwirkungen}

Der erste säulenchromatographische Reinigungsschritt erfolgte über eine Ethylaminosepharose-Säule(EAS). Die erstellten Pufferlösungen wurden vor Gebrauch entgast und filtriert. Die Säule wurde zunächst mit ca. $300 \mathrm{ml}$ Salzpuffer A (500 mM Kaliumphosphatpuffer pH 7.6, 30\% $\left.\left(\mathrm{NH}_{4}\right)_{2} \mathrm{SO}_{4}\right)$ äquilibriert. Nach Laden des Proteins auf die Säule und Waschen mit 1-2fachem Säulenvolumen an Puffer A wurden die an das Säulenmaterial gebundenen Proteine mit linear steigendem Puffer $\mathrm{B}\left(\mathrm{H}_{2} \mathrm{O}\right)$, also sinkendem Salzgehalt, eluiert. Bei einer Flussrate von $1.5 \mathrm{ml} / \mathrm{min}$ wurden die Proteine in $6.7 \mathrm{ml}$-Fraktionen gesammelt. Die die DAHP Synthase enthaltenden Fraktionen (über SDS-Gelelektrophorese 
getestet) wurden vereinigt und auf $40 \mathrm{ml}$ eingeengt. Über Nacht wurde die Proteinlösung gegen 10110 mM Tris-HCl-Puffer (pH 7.6) dialysiert.

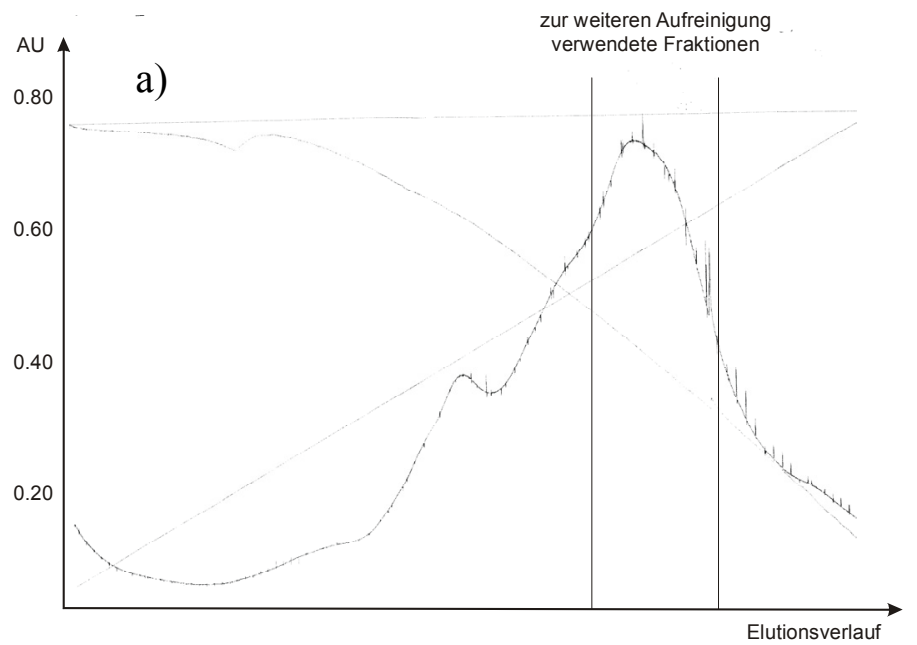

b)

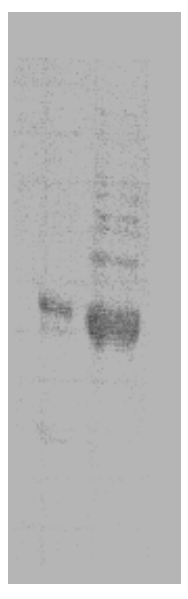

Abb. IV.1a a) Elutionsverhalten der DAHP Synthase: FPLC-Spektrum der Chromatographie über Ethylaminsepharose-Säulenmaterial. b) SDS-Polyacrylamidgel; links: aufgereinigte Proteinprobe, rechts: EASSäulen-Pool

\section{Anionenaustausch-Chromatographie}

Die Anionenaustauschsäule (MonoQ HR 16/10) wurde zunächst mit Puffer A (mind. $50 \mathrm{ml}$ 10 mM Tris-HCl (pH 7.6)) äquilibriert. Nach Laden der Säule mit dem EAS-Pool wurde mit steigendem Gradienten des Puffers B (10 mM Tris ( $\mathrm{pH} 7.6), 0.5 \mathrm{M} \mathrm{NaCl}$ ) eluiert. Bei einer Flussrate von $1.5 \mathrm{ml} / \mathrm{min}$ betrug die Endkonzentration $0.25 \mathrm{M} \mathrm{NaCl}$. Die Fraktionen wurden in Volumina von $4 \mathrm{ml}$ gesammelt. Die die DAHP Synthase enthaltenden Fraktionen wurden vereinigt und mit Hilfe von Ultrafiltration auf eine Endkonzentration von $13-18 \mathrm{mg} / \mathrm{ml}$ eingeengt, in Aliquots von $40 \mu \mathrm{l} \mathrm{zu}$ Kristallisationszwecken in flüssigem Stickstoff schockgefroren und bei $-80^{\circ} \mathrm{C}$ gelagert.

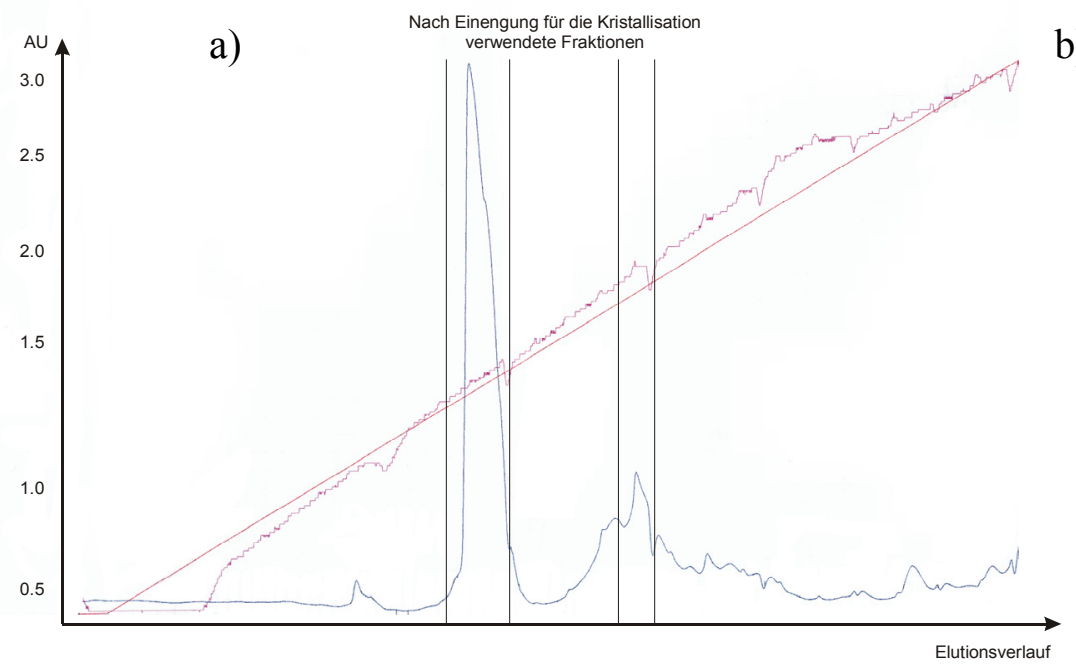

b)

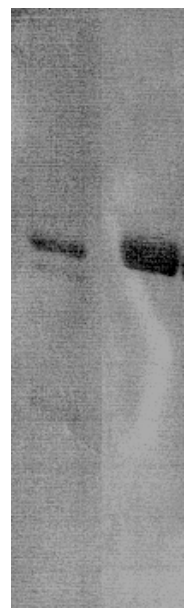

Abb. IV.1

a) Elutionsverhalten der DAHP Synthase: FPLC-Spektrum der Chromatographie über MonoQ-Säulenmaterial. b) SDS-Polyacrylamidgel; links: aufgereinigte Proteinprobe, rechts: Mono-Q-Säulen-Pool 


\section{Bestimmung des Proteingehaltes}

Die Bestimmung des Proteingehalts erfolgte nach der Methode von Bradford [Bradford 1976]. Als Standard diente eine BSA-Eichreihe in einem Konzentrationsbereich von $1-6 \mu \mathrm{g} / \mathrm{ml}$.

\section{SDS-Polyacrylamid-Gelelektrophorese}

Zum Nachweis der DAHP Synthase und zur Bestimmung des Reinheitsgrades der Probe wurde eine denaturierende SDS-Polyacrylamidgel-Elektrophorese nach Lämmli [Lämmli 1970] durchgeführt. Die Färbung der Banden erfolgte mit Coomassie blue R250.

\section{Aktivitätstest}

Die Aktivität des Enzyms wurde getestet, indem das Produkt DAHP nach einer Vorschrift von Jensen et al. [Jensen 1969, Takahashi 1971] durch Überführen in einen Farbkomplex photometrisch bei einer Wellenlänge von $550 \mathrm{~nm}$ nachgewiesen wurde. 


\section{IV.2 Kristallisation der DAHP Synthase in verschiedenen Komplexen}

Für die Kristallisation von Proteinen ist die Reinheit aller verwendeter Lösungen ein entscheidender Faktor. Alle im Rahmen dieser Arbeit für die Kristallisation verwendeten Lösungen wurden mit bi-destilliertem Wasser angesetzt und vor Gebrauch steril in keimfreie Aufbewahrungsgefäße filtriert. Für die Reproduzierbarkeit der Kristallisationsergebnisse ist ein einheitliches Vorgehensschema von Bedeutung. Alle Salz-, Puffer- und Additiv-Lösungen wurden als mol/l angesetzt, die organischen Fällungsmittel in Massenprozenten (w/w). Den PEG-Lösungen wurde, um Bakterien- und Schimmelbildung zu verhindern, jeweils $0.02 \%$ $\mathrm{NaN}_{3}$ zugesetzt. Die im Rahmen dieser Arbeit durchgeführten Kristallisationsversuche erfolgten ausschließlich nach der hanging drop Gasdiffusionsmethode. Als Reservoirmatrix wurden Gewebekulturplatten mit 24 Vertiefungen mit einem Volumen von $2.5 \mathrm{ml}$ der Firma Sarstedt verwendet. Die für die hanging drop Methode verwendeten Glasplättchen (Deckgläschen 18 x $18 \mathrm{~mm}$ ) wurden zuvor durch mehrminütiges Schwenken in einer Lösung bestehend aus 8\% Dichlordimethylsilan und 92\% Dichlormethan siliconisiert (Angaben in Volumenprozent). Verwendete Pipettenspitzen (Firma Gilson) und Reaktionsgefäße (Firma Eppendorf) wurden vor Gebrauch autoklaviert. Zum Verschließen der Reservoire wurde handelsübliches Siliconfett verwendet. Die Reservoirlösungen wurden direkt in die Vertiefungen zusammenpipettiert und durch mehrminütiges Schwenken gemischt. Die zur Aufbewahrung in Aliquots bei $-80^{\circ} \mathrm{C}$ in flüssigem Stickstoff schockgefrorenen Proteinlösungen wurden je nach Kristallisationsbedingung langsam auf Raumtemperatur oder $4{ }^{\circ} \mathrm{C}$ gebracht und vor Verwendung zur Kristallisation für $10 \mathrm{~min}$ mit $7000 \mathrm{~min}^{-1}$ zentrifugiert, um eventuelle Aufreinigungsrückstände aus der Lösung zu entfernen. Sofern nicht anders angegeben wurden die Kristallisationstropfen auf dem Glasplättchen im Verhältnis $1: 1$ aus der Reservoir- und der Proteinlösung gemischt. Die Tropfengrößen variierten zwischen 3 $8 \mu 1$.

Im Rahmen dieser Arbeit wurde die kristallographisch $\mathrm{zu}$ untersuchende tyr-sensitive DAHP Synthase aus S. cerevisiae in drei unterschiedlichen Raumgruppen, bzw. vier unterschiedlichen Zellen kristallisiert ( $\mathrm{P} 1_{\mathrm{kl}}, \mathrm{P} 1_{\mathrm{gr}}, \mathrm{C} 2$ und P3(1)21 (siehe Tab.III.3a)). Im folgenden soll auf die diesen Raumgruppenwechsel hervorrufenden Unterschiede in der Kristallisation eingegangen werden. 


\section{Kristallisation der unkomplexierten DAHP Synthase im triklinen Kristallsystem}

Die Kristallisationsbedingungen für die mit PEP komplexierte Struktur der tyr-sensitiven DAHP Synthase aus S. cerevisiae waren aus früheren Untersuchungen an diesem Enzym bekannt [Schneider 1999].

Um ein Gefühl für die Kristallisation des metallion- und substratfreien Enzyms zu erhalten, wurde zunächst ein von Stura entwickeltes footprint-Screening [Stura 1992] durchgeführt, das im Gegensatz zur sparse matrix Methode ein grobes, systematisches Raster über verschiedene Ionen- und PEG-Lösungen bei unterschiedlichen $\mathrm{pH}-\mathrm{Werten}$ testet. Aus den Versuchsergebnissen ließ sich ableiten, dass das Enzym in stark ionischen Lösungen unabhängig vom $\mathrm{pH}$ Wert präzipitiert. Unter den PEG-haltigen Bedingungen ließen sich innerhalb von 10 Tagen bei höheren $\mathrm{pH}-$ Werten ( $\mathrm{pH}$ 8-9) abhängig von der PEG-Konzentration unter bestimmten Bedingungen erste Kristallaggregate beobachten, während sich unter sauren Bedingungen sehr schnell Präzipitate bildeten.

Unter folgenden Bedingungen wurden mit der hanging drop Methode erste Kristallrosen bei Raumtemperatur innerhalb von 2-3 Tagen erhalten:

Die Proteinlösung besaß eine Konzentration von $13 \mathrm{mg} / \mathrm{ml}$ und wurde im Verhältnis 1:1 mit der Reservoirlösung, die aus 13-15\% PEG3400, 5\% Glycerol, 10 mM Tris pH 8-9 bestand, im Tropfen vermischt. Diese Kristallrosen waren für eine röntgenkristallographische Untersuchung nicht brauchbar. Durch streak-seeding in einen preäquilibrierten Tropfen geringfügig geringerer PEG-Konzentration erhielt man Einkristalle, die jedoch noch zu klein für ein Beugungsexperiment waren. Erst durch macro-seeding wurden Kristalle erhalten, die für eine röntgenographische Messung verwendet werden konnten. Auffällig ist die kurze Haltbarkeit der Kristalle. Innerhalb von 1-2 Tagen nach Wachstumsende werden die Kristalle von einer bräunlichen Schicht überzogen und beginnen sich aufzulösen. Dies beruht wahrscheinlich darauf, dass das leere Enzym sehr viel instabiler und dadurch anfälliger gegenüber seinem Abbau ist als das native Enzym, das mit einem Metallion und wahrscheinlich sogar mit PEP, dem ersten Substrat der Verknüpfungsreaktion, beladen ist [Schnappauf, 1998].

\section{Kristallisation der DAHP Synthase im triklinen System mit Mangan(II) komplexiert}

Um das mit EDTA metallionenfrei aufgereinigte Enzym für die Kristallisation wieder mit Ionen zu versetzen, wurden diese Metallionen der Reservoirlösung in einer Konzentration von 
$5 \mathrm{mM}$ zugefügt. Bei der Auswahl des Metallions aus den Elementen, mit denen die Aktivität des Enzyms wiederhergestellt werden kann, blieb bei Beibehaltung des basischen pH-Wertes von 8-9,5 keine große Auswahl. Da eine Hydroxidfällung verhindert werden sollte, um zusätzliche Kristallisationskeime auszuschließen, wurde zunächst Mangan(II) $\left(\mathrm{K}_{\mathrm{L}}\left(\mathrm{Mn}(\mathrm{OH})_{2}\right)=2 \times 10^{-13}\right)$ als Cosubstrat ausgewählt, das die Aktivität des Enzyms nur zu 20\% wiederherstellen kann. Auch von diesem DAHP Synthase-Komplex erhielt man unter ähnlichen Bedingungen zunächst verwachsene Kristallrosen, aus denen durch streak- und macro-seeding röntgenographisch messbare Kristalle gezüchtet werden konnten.

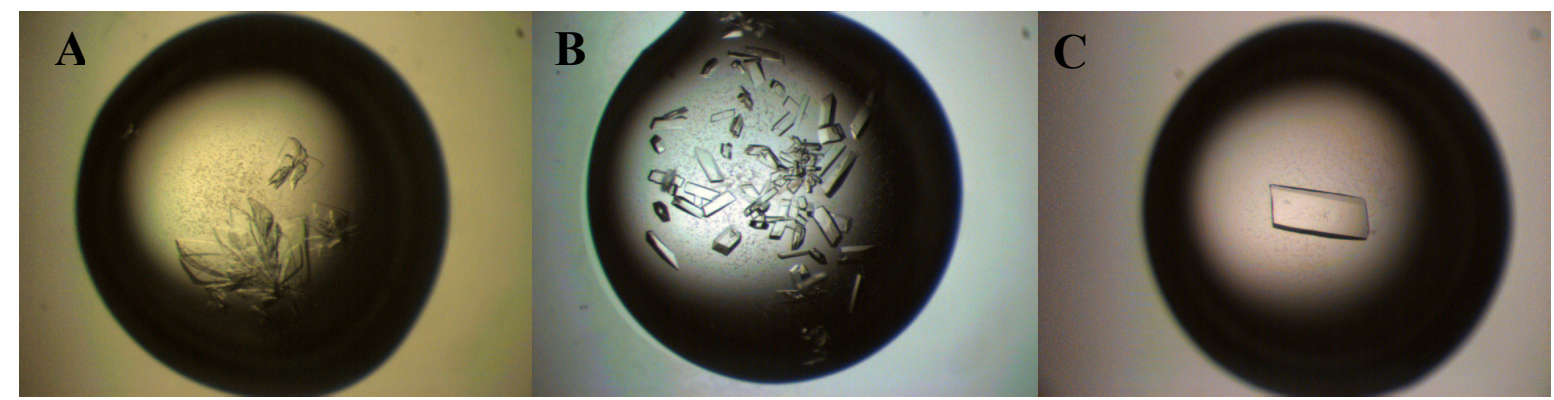

Abb. IV.2a Mehrstufiger Kristallisationsvorgang der mit Mangan(II) komplexierten DAHP Synthase. A: erste, verwachsene Kristallrosen. B: unverwachsene Kristalle nach streak-seeding. C: vereinzelter, zur Datensammlung geeigneter Kristall.

\section{Kristallisation der DAHP Synthase im monoklinen Kristallsystem mit Mangan(II) komplexiert}

In dieser Kristallisationsvariante wurde das Metallion nicht der Reservoirlösung in einer Konzentration von $5 \mathrm{mM}$ zugegeben. Statt dessen wurde die Proteinlösung $1 / 2 \mathrm{~h}$ vor dem Ansatz der Kristallisationsbedingungen bei $4^{\circ} \mathrm{C}$ mit einem Überschuss von 2.2 Äquivalenten Mangan(II)chlorid versetzt. Unter diesen Bedingungen findet eine nicht so starke Verwachsung der Kristalle statt, so dass man teilweise auf das seeding verzichten konnte. Auch die Kristalldimensionen waren im Gegensatz zu den im vorherigen Abschnitt beschriebenen plättchenförmigen Kristallen isometrischer (siehe Abb.IV.2b:A). Der Beginn der Keimbildung setzt bei niedrigeren PEG-Konzentrationen (8-9\%) ein. Bei der Zellbestimmung wurde die Raumgruppe $\mathrm{C} 2$ bestimmt.

\section{Kristallisation der DAHP Synthase im trigonalen Kristallsystem mit Mangan(II) komplexiert}

Um Qualität und Haltbarkeit der Kristalle zu verbessern, wurde versucht, die Kristallisationstemperatur herabzusetzen. Bei sonst nahezu identischen Kristallisationsbedingungen (5\% Glycerol, 13-18\% PEG3400, 20 mM Tris pH 9-9.5, 2 mM Mn(II)) erhielt man im Kühlraum bei 
$4^{\circ} \mathrm{C}$ unverwachsene, sechseckige Kristalle, die gut für Einkristalluntersuchungen geeignet waren (Abb. IV.2b:B). Auch hier ließen sich durch streak und macro seeding größere Kristalle züchten. Die leichte Verschiebung des pH-Wertes ins basische Milieu ist durch die Temperaturabhängigkeit des Tris-Puffers zu erklären. Mit Cobalt(II) erhielt man unter diesen Bedingungen Kristalle der gleichen sechseckigen Form, die jedoch durch die verwendeten Cryobedingungen eine starke Erhöhung der Mosaizität erfuhren, so dass sich die lange Zelkante von $270 \AA$ nicht im Diffraktionsbild auflösen ließ. Bemerkenswert ist die Tatsache, dass sich unter diesen Bedingungen sowohl bei Zusatz des Substrates PEP als auch bei Zusatz der Effektoren Tyrosin und Phenylalanin nicht diese trigonale Kristallform züchten ließ, sondern sich immer Kristalle in der großen P1 Zelle bildeten. Mögliche Ursachen werden in Kap. V.1.2.1 diskutiert.
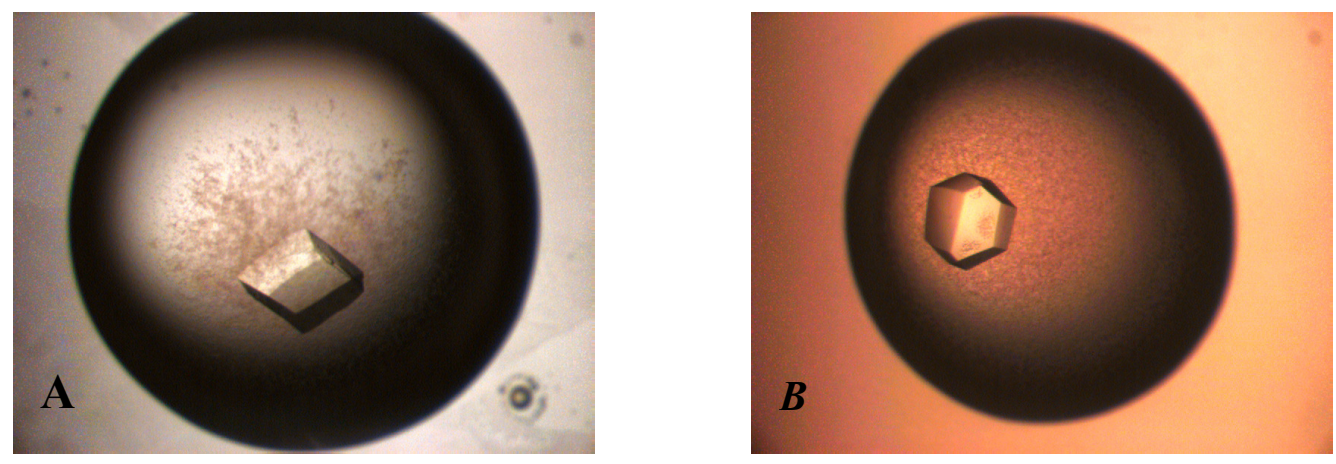

Abb. IV.2b Unverwachsene, ohne seeding erhaltene Kristalle der mit Mangan(II) komplexierten DAHP Synthase A: bei Raumtemperatur in der Raumgruppe C2, B: bei $4^{\circ} \mathrm{C}$ gewachsen in der Raumgruppe P3(1)21

\section{Kristallisation der DAHP Synthase im triklinen Kristallsystem mit Mangan(II) und PEP komplexiert}

Bei der Komplex-Struktur mit Metallion und PEP handelt es sich wahrscheinlich um die native Form des Enzyms [Schnappauf 1998, Candliss 1978]. Im Gegensatz zum Metallion, das in dieser Kristallisationsvariante der Reservoirlösung in einer Konzentration von $2 \mathrm{mM}$ zugesetzt wird, wurde das Substrat PEP $1 / 2 \mathrm{~h}$ vor dem Ansatz der Kristallisationsbedingungen mit einem Überschuss von 6.7 Äquivalenten der Proteinlösung bei $4^{\circ} \mathrm{C}$ zugegeben. Nach 3-4 Tagen bei Raumtemperatur bzw. 5-6 Tagen bei $4^{\circ} \mathrm{C}$ erhielt man unter den Bedingungen zwischen 14-16\% bzw. 17-20\% PEG-Konzentration verwachsene zackenförmige Kristalle, deren Qualität sich durch streek und macro seeding in preäquilibrierte Tropfen geringerer PEG-Konzentration verbessern ließ. Bei $4{ }^{\circ} \mathrm{C}$ konnten die Verwachsungen vermindert und die Haltbarkeit erhöht werden, das Wachstum verlangsamte sich allerdings, die Kristalle blieben insgesamt kleiner und die Erfolgsquote des seedings war wesentlich geringer. 
Kristallisation von DAHP Synthase im monoklinen Kristallsystem mit Mangan(II) bzw. Cobalt(II) und PEP bzw. seinem Analogon P2G komplexiert

Ähnlich wie in der Kristallisationsbedingung für die mit Mangan(II) komplexierte Struktur im monoklinen Kristallsystem wurden auch hier das Metallion (1.5 Äquivalente) und das Substrat bzw. das Analogon (6.7 Äquivalente) $1 / 2 \mathrm{~h}$ vor Beginn der Kristallisation der Proteinlösung zugesetzt und die PEG-Konzentration im Vergleich zu den Bedingungen der Enzymkomplexe im triklinen Kristallsystem leicht erhöht. Auch hier änderte sich die Raumgruppe von P1 zu C2, wodurch sich die Kristallqualität, die Kristalldimensionen und ihre Haltbarkeit verbesserten. Wurde Mangan(II) durch Cobalt(II) ersetzt, so wurde gleichzeitig der pH-Wert geringfügig auf 7.5-8 erniedrigt, um eine Hydroxidfällung zu vermeiden. Dies wirkte sich geringfügig nachteilig auf die Kristallstabilität aus, jedoch erniedrigte es die Keimbildung und somit die Verwachsungen der Kristalle.

\section{Kristallisation von DAHP Synthase im monoklinen Kristallsystem mit Cobalt(II) und PEP und dem E4P-Analogon G3P komplexiert}

Für die Kristallisation des mit Metallion, PEP und dem E4P Analogon G3P komplexierten Enzyms konnte nicht Mangan(II) als Kation verwendet werden, da bei Zusatz der Mangan(II)ionen $\mathrm{zu}$ einer G3P-haltigen Lösung ein flockiger Niederschlag ausfiel. Demzufolge wurde dieser Komplex bei leicht erniedrigtem pH-Wert nur mit Cobalt(II) durchgeführt. Wieder wurden die Metallionen (2 Äquivalente), das PEP (6.7 Äquivalente) und das E4P-Analogon G3P (15 Äquivalente) kurz vor Ansatz der Kristallisation der Proteinlösung zugesetzt, während die Reservoirlösung substratfrei gehalten wurde. Aufgrund der um $1 / 4$ schwächeren Bindung des E4P $(\mathrm{k}=500 \mu \mathrm{M})$ im Gegensatz zum zuerst bindenden Substrat PEP $(\mathrm{k}=125 \mu \mathrm{M})$ [Schnappauf 1998] wurde der Überschuss an Äquivalenten verdoppelt. Interessanterweise lässt sich dieser Enzymkomplex weder bei Raumtemperatur noch bei $4{ }^{\circ} \mathrm{C}$ im triklinen Kristallsystem kristallisieren. Die PEG-Konzentration musste auf 18-22\% erhöht werden. Die Haltbarkeit der Kristalle war im Vergleich zu den übrigen im monoklinen Kristallsystem kristallisierenden Komplexen mit 2-3 Tagen deutlich herabgesetzt.

\section{Versuch der Kristallisation der DAHP Synthase mit Cobalt(II), dem PEP-Analogon P2G und dem zweiten Substrat E4P}

Es wurde zunächst versucht, wie im vorhergehenden Abschnitt beschrieben, diese Doppelkomplexvariante zu kristallisieren. Es wurden kleine, stark verwachsene Kristalle erhalten, die beim Tränken in den benutzten Cryobedingungen (siehe dort) jedoch zerstört wurden. 
Kristallographische Untersuchungen an sehr kleinen Bruchstücken dieser Kristalle ergaben bei niedriger Auflösung ( $3 \AA$ ) lediglich Elektronendichtemaxima für das Metallion und die Phosphatgruppe des PEP. Nachträgliches Tränken mit einer E4P-haltigen Lösung (10 mM) von im monoklinen Kristallsystem mit Cobalt(II) und P2G kristallisierten Kristallen, führte zu einem Datensatz von $2.7 \AA$, in dem eindeutig die Elektronendichte für das Metall(II)ion und das P2G sichtbar waren, jedoch für das E4P lediglich ein Elektronenmaxima für eine nicht vollbesetzte Phosphatgruppe $\mathrm{zu}$ erkennen war. $\mathrm{Ob}$ es sich dabei tatsächlich um ein nicht vollbesetztes, möglicherweise fehlgeordnetes E4P handelt, oder sich das Substrat zersetzt hat und die Bindungsstelle des zweiten Substrates lediglich von einem Phosphation besetzt ist, müssen weitere Untersuchungen zeigen.

\section{Kristallisation der DAHP Synthase im triklinen Kristallsystem mit Mangan(II) und dem Effektor Tyrosin}

Schwierigkeiten bereitete lange die Kristallisation des Effektor-Enzym-Komplexes. Zunächst wurde mit einer Proteincharge kristallisiert, zu der der Effektor Tyrosin in einem Überschuss von 5 Äquivalenten direkt nach der Aufreinigung vor dem Tieffrieren der Aliquots zugegeben und bei $4{ }^{\circ} \mathrm{C}$ gerührt wurde. Mit dieser Proteincharge wurden unter unterschiedlichen Bedingungen nur Aggregate und Präzipitate erhalten. Bei späterer Zugabe des Tyrosin zu der Reservoirlösung wurde das gleiche Phänomen beobachtet.

Kristalle bildeten sich erst bei einer Temperatur von $4{ }^{\circ} \mathrm{C}$ und einem minimalen Überschuss des Effektors von 1.5 Äquivalenten, der kurz vor Kristallisationsansatz direkt der Proteinlösung zugegeben wurde. Dieses Verhalten deutet darauf hin, dass der Effektor bei genügend großem Überschuss nicht nur die für den Inhibierungs-Mechanismus vorgesehenen Bindungsstelle besetzt, sondern sich auch an andere Enzymbereiche anlagert, wodurch die Aggregatbildung des Enzyms hervorgerufen und eine Kristallisation des Komplexes verhindert wird.
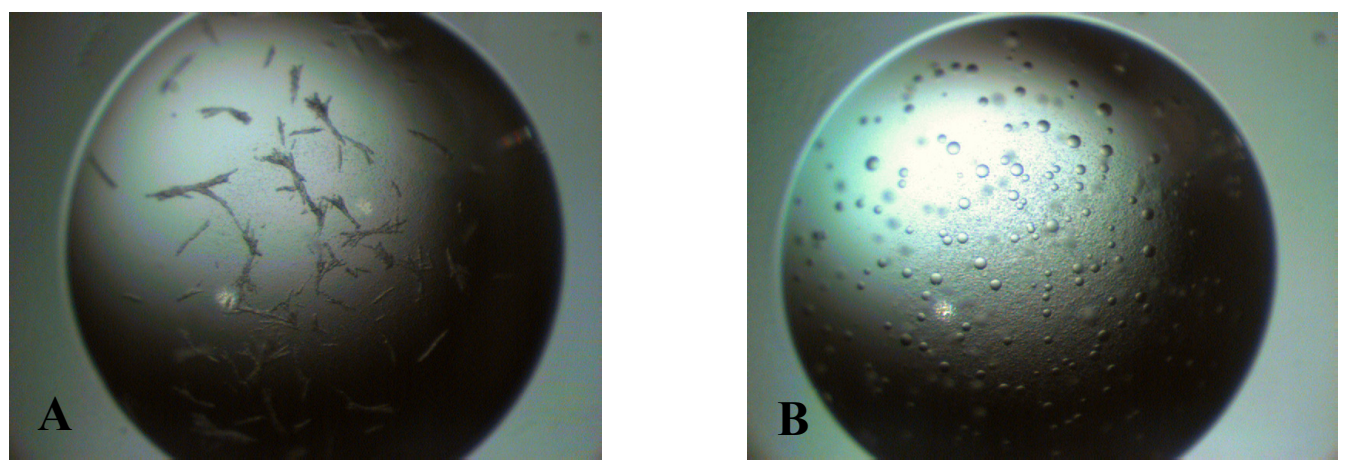

Abb.IV.2c Beispielhaft ausgesuchte Tropfen unterschiedlicher Kristallisationsbedingungen zur Kristallisation der DAHP Synthase mit Mangan(II) und dem Effektor Tyrosin. A: Aggregatbildung, B: Spherolitenbildung. 


\section{Kristallisation der DAHP Synthase bzw. ihrer G226S-Mutante im triklinen Kristallsystem mit Mangan(II) und den Effektoren Phenylalanin und Alanin}

Nachdem der Ort der Effektor-Bindungsstelle durch die Komplexstruktur 2c bekannt war, wurde versucht, das Enzym mit den nicht bzw. nur sehr schwach [Hartmann, 2001] auf das Enzym inhibierend wirkenden Aminosäuren Alanin bzw. Phenylalanin zu komplexieren. Unter ähnlichen Bedingungen wie im vorherigen Abschnitt beschrieben erhielt man in beiden Fällen ein Gemisch zweier Kristallformen in einem Tropfen. Bei der einen handelt es sich um die trigonale Kristallform, die, wie zu vermuten war, substratfrei nur das Metallion Mangan(II) enthält (ein Datensatz bis $2.6 \AA$ ließ keine Elektronendichte des Effektors erkennen). Die zweite Kristallform entspricht der im triklinen Kristallsystem kristallisierten Struktur mit Mangan(II) und Effektor, was im Fall der mit Phenylalanin versetzten Probe durch die Strukturen 2d und 2e verifiziert werden konnte.

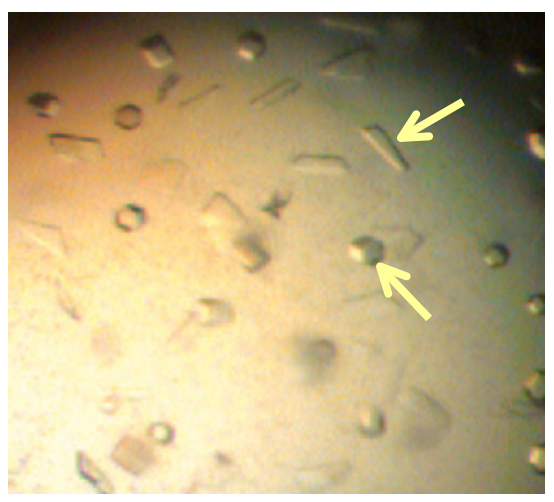

Abb. IV.2d In einem Kristallisationstropfen befinden sich sowohl trigonale, nur mit Mangan(II) komplexierte, als auch trikline mit Mangan(II) und Phenylalanin komlexierte Kristalle. Auf die beiden Kristallformen wird mit den eingezeichneten Pfeilen verwiesen.

Auch bei den Kristallen aus der mit Alanin versetzten Probe handelt es sich um die große trikline Form. Die Kristalle waren jedoch so instabil, dass nur Kristallteile untersucht werden konnten, deren Streukraft lediglich zur Zellbestimmung ausreichte. In Analogie zu den beiden anderen Aminosäure-Substrat-Komplexen, kann jedoch auch hier angenommen werden, dass das Alanin die Effektorbindungstasche besetzt und so die Kristallsystemänderung von trigonal nach triklin hervorruft. Eine mögliche Erklärung für das Auftreten der unterschiedlichen Kristallformen bestehend aus unterschiedlichen Enzymkomplexen könnten die unterschiedlichen Bindungskonstanten der Aminosäuren Tyrosin, Phenylalanin und Alanin an die Effektor-Bindungsstelle sein. Das Gleichgewicht der Komplexbildungsreaktion liegt für das Tyrosin aufgrund der Tyrosin-Spezifität der Bindungsstelle am weitesten auf der Seite des Komplexes, so dass nur die Komplex-Kristalle gebildet werden. In den Fällen der für die Bindungsstelle nicht spezifischen Aminosäuren Phenylalanin und Alanin sollte die Komplexbildungskonstante kleiner sein und das Gleichgewicht somit weiter auf der Seite des 
effektorfreien Enzyms liegen. Damit wären die Konzentrationen sowohl des effektorfreien als auch des mit dem Effektor besetzten Enzyms im Kristallisationstropfen ausreichend hoch, um Kristalle beider Komplexe zu bilden. Die geringe Stabilität der Alanin-Enzym-Komplexe lässt sich eventuell dadurch erklären, dass dieser Aminosäure durch Fehlen des aromatischen Rings wichtige Bindungsmöglichkeiten in der Tyrosinbindungsstelle fehlen, und sie demzufolge besonders schwach an das Enzym bindet.

\section{Cryobedingungen und Montage}

Alle Kristalle wurden für die Tieftemperaturmessungen mit Cryo-Puffern ähnlicher Zusammensetzung getränkt. Die Empfindlichkeit gegenüber Glycerol war bei Kristallen aller Komplexe und Raumgruppen vorhanden, wobei sie bei der trigonalen Kristallform am wenigsten ausgeprägt war. Auch durch langsame und schrittweise Erhöhung der Glycerolkonzentration konnte ein Auseinanderbrechen und Auflösen der Kristalle nicht verhindert werden. Durch gleichzeitiges Erhöhen des Fällungsmittels PEG3400, das geringfügig auch als Cryo-Puffer wirkt, wurde dem Auflösungsprozess der Kristalle entgegengewirkt. Die Endkonzentrationen an PEG3400 und Glycerol lagen jeweils bei etwa 25\%. Während man für die Cryo-Puffer der Metallion-Enzym- und Metallion-PEP-EnzymKomplexe aufgrund ihrer hohen Komplexsstabilitätskonstante keine Metallion- bzw. SubstratZusätze in der Cryo-Puffer-Lösung benötigte, wurde den Lösungen für die MetallionDoppelsubstrat-Komplexe und für die Metallion-Effektor-Komplexe jeweils E4P, G3P oder die entsprechende Aminosäure zugegeben, um ihr eventuelles Herausdiffundieren aus dem Komplex zu verhindern. Die Kristalle wurden wenige Minuten in der Endkonzentration des Cryopuffers belassen. Bei längerem Verbleib der Kristalle in der Cryoprotektandenlösung konnte teilweise ein Raumgruppenwechsel zwischen der kleinen und der großen P1-Zelle beobachtet werden (1b und 2d). Mittels eines loops bestehend aus einem schlaufenförmigen Nylonfaden, der in einer Metallhalterung befestigt ist, wurden die Kristalle mit einem Film von Cryoprotektand aus dem Tropfen gefischt und in flüssigem Stickstoff schockgefroren. In diesem Zustand wurden sie entweder mit Hilfe eines arcs direkt auf dem Goniometerkopf für eine Messung zentriert, oder in sogenannten cryo vials zur Aufbewahrung oder zum Transport in Dewars deponiert. 


\section{IV.3 Datensammlung -integration und -skalierung}

\section{Gerätekonstanten}

Die im Rahmen dieser Arbeit durchgeführten Datensammlungen erfolgten entweder an einer laboreigenen Cu-Drehanode oder an den Messplätzen X11, X13 und BW7B der Außenstation des EMBL Heidelberg am Doris Speicherring des DESY in Hamburg. Die Cu-Drehanode gehört zu einem Einkreisdiffraktometer, bei dem die Monochromatisierung und Fokussierung des Röntgenstrahls über ein Osmic-Spiegel-System erfolgt. Die Detektion des Beugungsbildes wurde mit einem image plate-Flächenzähler des Fabrikates MAR345 in verschiedenen Modi durchgeführt. Die zugehörige Tieftemperaturanlage ist eine Eigenanfertigung der Werkstatt der chemischen Fakultät Göttingen. Alle drei Messplätze des EMBL besitzen ein Einkreisdiffraktometer. Bei den Detektoren an den Messplätzen X11 und X13 handelt es sich zur Zeit um MarCCD-Flächenzähler, während sich am Messplatz BW7B ein MAR345-IP-Detektor befindet. In beiden Fällen findet die Fokussierung über Siliciummonochromatoren statt.

\section{Messstrategien}

Testdatensätze aller DAHP Synthase-Komplexe wurden mit kurzer Belichtungszeit und minimaler Redundanz an der Drehanode bis zu einer Auflösung zwischen 2.8-3.2 ̊̊ gesammelt. In Elektronendichtekarten dieser Auflösung konnte eindeutig das Vorhandensein von Metallionen, Substraten, Analoga oder Effektoren erkannt werden. Die Phosphatgruppe der Substrate und ihrer Analoga sowie die fest an das Enzym gebundene Carboxylatgruppe der Effektoren waren in jedem Fall unter den höchsten 20 Differenzelektronendichtemaxima zu finden. Konnte die Besetzung des aktiven Zentrums bzw. der Effektortasche verifiziert werden, wurden Datensätze mit längerer Belichtungszeit bis zu höchstmöglicher Auflösung entweder an der Drehanode oder an Messplätzen der Außenstelle des EMBL-Heidelberg gesammelt. Die Parameter der einzelnen Messungen sind in Tab. III.3a zusammengefasst.

Die Kristalle der Raumgruppe C2 zeigten gutes Streuverhalten, so dass jeweils ein Datensatz an der Drehanode mit gutem I/ $\sigma$-Verhältnis bis zu einer Auflösung von mindestens 1.9 A gesammelt werden konnte. Da selbst bei langer Belichtungszeit keine overloads (übersättigte Detektorregionen) beobachtet wurden, konnte die Messung mit nur einem Kristall-DetektorAbstand durchgeführt werden. Alle Synchrotron-Datensätze wurden in zwei Abschnitten gesammelt. Da beim Sammeln der hochaufgelösten Daten die Anzahl an overloads im niedrig aufgelösten Bereich sehr groß war, wurde dieser Bereich für einen zweiten, kürzer belichteten Datensatz nochmals gemessen. 


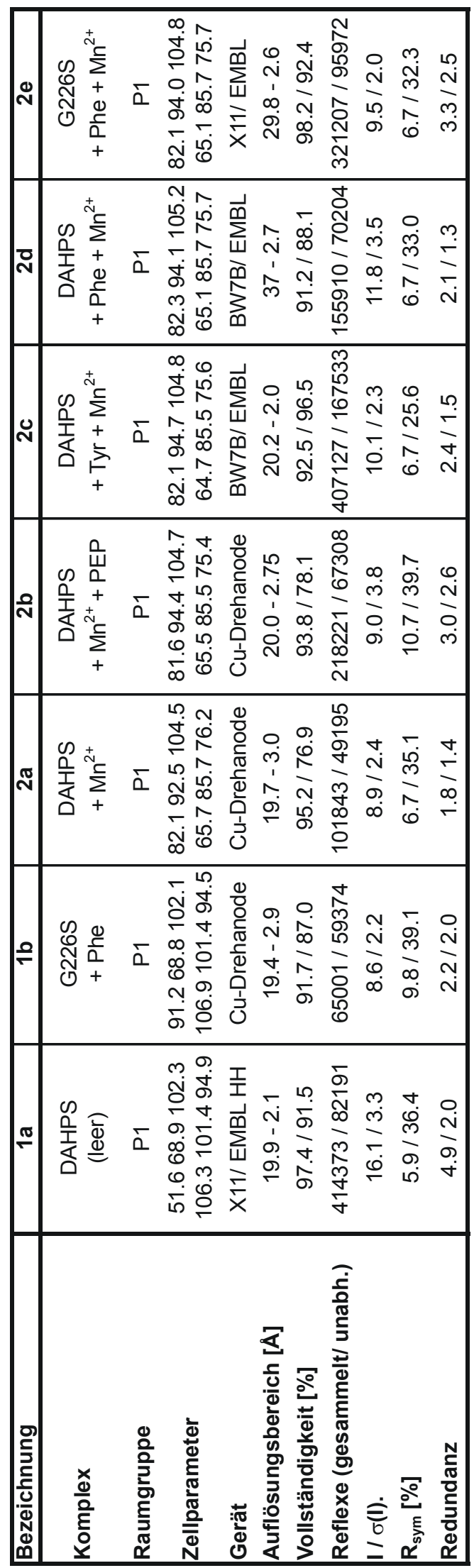

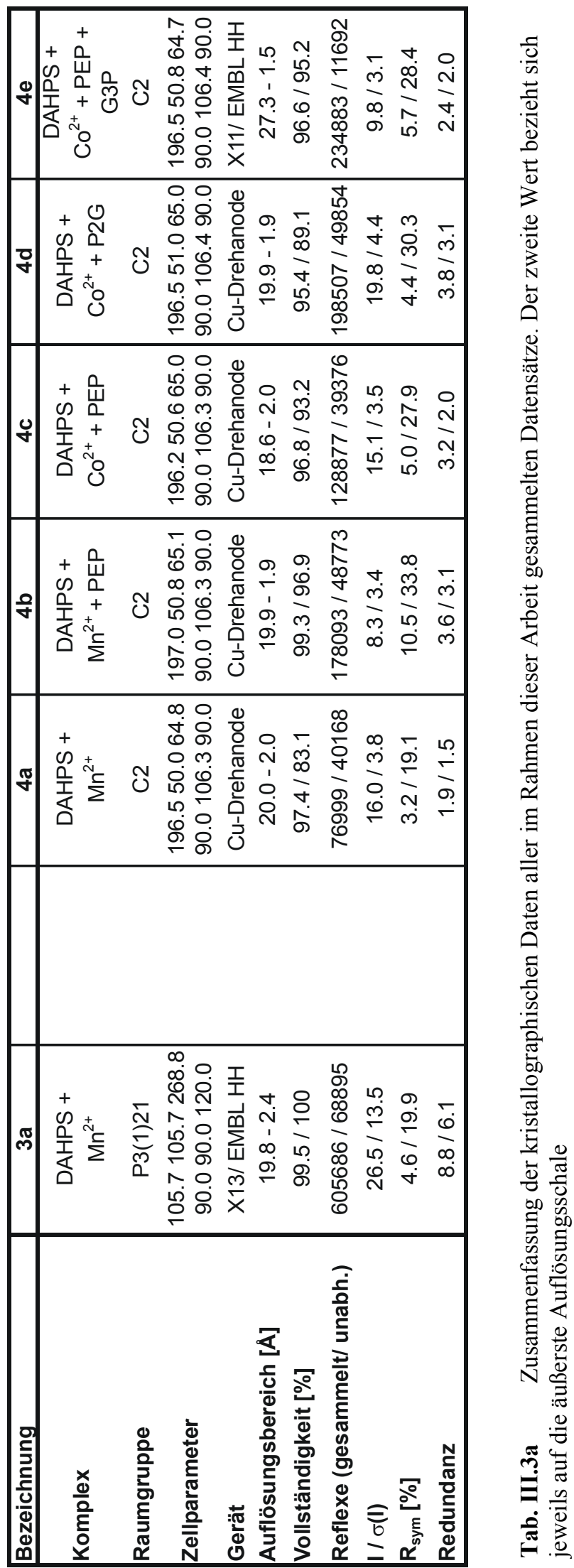


Der hochaufgelöste Datensatz wurde mit langer Belichtungszeit, kurzem Kristall-DetektorAbstand und kleinem Drehwinkel gesammelt, während der niedrigaufgelöste mit kürzerer Belichtungszeit, längerem Kristall-Detektor-Abstand und größerem Drehwinkel aufgenommen wurde. Um auch die sehr niedrig aufgelösten Reflexe zu messen, die großen Einfluss auf die Elektronendichtequalität haben, wurde der Primärstrahlfänger bei der niedrigaufgelösten Messung möglichst weit vom Kristall entfernt, ohne dass jedoch der Primärstrahl auf den Detektor trifft. Während die Auflösung aller übrigen Datensätze durch die Streukraft des Kristalls limitiert wurde, stellte den begrenzenden Faktor beim Sammeln des trigonalen Datensatzes die lange Zellkantenlänge $\mathrm{c}=269 \AA$ dar. Der Detektor konnte nur so nah an den Kristall herangefahren werden, dass sich die Reflexprofile der langen Zellkante gerade noch voneinander auflösen ließen.

Die Daten wurden zum Teil mit DENZO [Otwinowski 1997] und SCALEPACK [Otwinowski 1997], zum Teil mit dem Programmpaket HKL2000 [Otwinowski 1997] integriert und skaliert. In beiden Fällen wurden die symmetrieäquivalenten Reflexe nicht gemittelt. Während der Skalierung wurden beide Datensätze zusammen im Programm Scalepack mit zwei unterschiedlichen Fehler- und Skalierungsfaktormodellen aber der gleichen Zielfunktion skaliert.

Die Raumgruppenbestimmung, das Mitteln der Daten in der jeweiligen Raumgruppe sowie das Teilen der Daten in einen Arbeits- und einen Testdatensatz erfolgte im Programm XPREP [Sheldrick]. Der Testdatensatz enthielt jeweils fünf Prozent der gesamten Daten. Er wurde für die Datensätze der Raumgruppe C2 zufällig, für die Datensätze beider P1-Zellen und für den trigonalen Datensatz wegen mehrfacher rotationssymmetrischer NCS (siehe Kap. III.4) jedoch

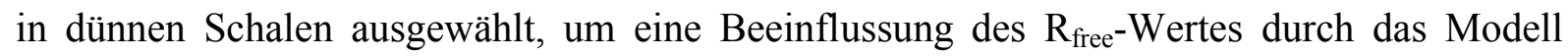
auszuschließen.

Da der Kristall 2d ein - wahrscheinlich aufgrund schlechter Messplatz-Einstellung hervorgerufenes - sehr anisotropes Streuverhalten zeigte (2.6 bis $3.0 \AA$ ), wurden Teilbereiche $\mathrm{zu}$ unterschiedlichen Auflösungsgrenzen integriert und anschließend zusammenskaliert, um ein Mitteln zwischen Reflexen und Hintergrundrauschen zu vermeiden. Eine dadurch hervorgerufene Unvollständigkeit des Datensatzes in der letzten Auflösungsschale (78\% vollständig) musste in Kauf genommen werden.

Obwohl die Integration des Datensatzes 3a problemlos verlief, konnte dieser Datensatz zunächst nicht skaliert werden. Aufgrund der langen Zellkante führten kleine Fehler in der Strahlposition zu einer Fehlindizierung, die im Verlauf der Integration nicht erkannt wurde, beim Skalieren der Daten jedoch zutage trat. Durch die Möglichkeit einer HKL- 
Indizierungsverschiebung in Scalepack konnte eine Fehlindizierung von $\left(\begin{array}{lll}0 & 0 & -1\end{array}\right)$ ermittelt werden. Anhand dieser Verschiebung der Indizierung wurde die Strahlposition im Programm DENZO manuell angepasst.

Alle Reflexe mit abgeschätzten Fehlern und Markierung für den Testdatensatz wurden mit dem Programm XPREP [Sheldrick 1997] nur bis zu einem I/ $\sigma$ von über zwei in der höchsten Auflösungsschale in Reflexdateien geschrieben. Der $\mathrm{R}_{\text {int }}$ dieser Schale sollte dabei nicht über $40 \%$ steigen. Es wurden Dateien der Formate cns, hklf3 und hklf4, die im Programmpaket ccp4i in ein mtz-Format umgewandelt wurde, erstellt. Dabei wurde darauf geachtet, dass die Markierung der Testdatensatzreflexe in allen Formaten identisch war.

\section{IV.4 Strukturlösung und Verfeinerung}

Alle im Rahmen dieser Arbeit verfeinerten Strukturen wurden nach dem Prinzip des Molekularen Ersatzes gelöst. Hierfür wurde als Suchmodell ein Monomer oder Dimer aus der Struktur 1HFB der nur mit PEP komplexierten tyr-sensitiven DAHP Synthase aus S. cerevisiae verwendet. Aus dem Modell wurden alle Wassermoleküle und das Substrat entfernt. Die Strukturen in den Raumgruppen $\mathrm{P} 1_{\mathrm{gr}}$ und $\mathrm{P} 1_{\mathrm{kl}}$ sowie $\mathrm{C} 2$ konnten problemlos mit dem MR-Programm EPMR (siehe Kap. III.5) gelöst werden. Hierzu wurde ein Auflösungsbereich zwischen 15 und $4 \AA$, eine Populationsgröße von 300 und eine Anzahl von 50 Generationen angegeben. Abhängig von der Anzahl der zu suchenden Modellkopien waren die Schwellenwerte des Korrelationskoeffizienten für eine wahrscheinlich richtige Lösung unterschiedlich gewählt. Das häufig bei der Suche nach mehreren Kopien auftretende Problem der Überlagerung konnte zum Teil mit der Angabe eines sogenannten bump-Radius verbessert werden, der eine Überlagerung im angegebenen Bereich um die schon vorhandenen Kopieschwerpunkte verhindert. Typischerweise lagen die Endwerte nach einer rigid-body-Verfeinerung der bis dahin besten Lösung bei Korrelationskoeffizienten von $\mathrm{CC}=0.64-0.70$ und $\mathrm{R}-$ Werten von $\mathrm{R}=0.32-0.41$. Die Raumgruppe des trigonalen Kristalls wurde mit dem Programm XPREP als P3(1)21 oder P3(2)21 vorgeschlagen, da eine Unterscheidung dieser beiden enantiomorphen Raumgruppen anhand der Reflexintensitäten und Auslöschungen nicht möglich ist. Lösungsversuche in beiden Raumgruppen mit dem Programm EPMR führten nicht zur Strukturlösung. Gelöst wurde diese Struktur letztlich in der Raumgruppe P3(1)21 mit dem im Programmpaket CCP4i integrierten MR-Programm MOLREP unter Verwendung der Standardwerte. Da das selbe Enzym lediglich in einer neuen 
Raumgruppe kristallisierte, wurden zwei Dimere mit einer erwarteten Vollständigkeit von 95\% und 90\% Ähnlichkeit der Struktur gesucht.

Die aus den MR-Programmen erhaltenen groben Strukturmodelle wurden im Programm CNS zunächst einer rigid-body-Verfeinerung (starres Modell) bis zu einer Auflösung von $2.7 \AA$ unterzogen. Bei einer ersten Evaluation der Elektronendichte mit dem Graphikprogramm XtalView [McRee 1992] waren besonders bei der inhibierten Struktur im Modell falsch positionierte Molekülbereiche deutlich zu erkennen. Diese eindeutig falschen Strukturteile wurden für den nächsten Verfeinerungsschritt aus dem Modell herausgenommen. Zusätzlich mögliche, nicht in der Differenzelektronendichte sichtbares model-bias sollte durch einen sich anschließenden simulated-annealing-Schritt im Programm CNS eliminiert werden. Hierzu wurde der gesamte Auflösungsbereich verwendet. Während der Verfeinerung fand eine anisotrope B-Faktor- und Wasserregion(bulk solvent)-Korrektur statt. Als Zielfunktion der Verfeinerung wurde die maximum likelihood-Funktion unter Gebrauch der Amplituden verwendet. Die Starttemperatur des simulated annealing-Prozesses wurde auf $4500 \mathrm{~K}$ und der Temperaturverlauf auf langsames Herunterkühlen festgelegt. Die Durchführung der angewendeten Molekulardynamik (moelcular dynamic) fand im Torsionswinkelverfeinerungsmodus (torsions-angle-dynamics) statt.

Die so erhaltenen Modelle und die dazugehörigen Elektronendichten wurden im Graphikprogramm XtalView [McRee 1999] evaluiert. Die Elektronendichte wurde in Form von einer bei $1 \sigma$ konturierten sigmaA gewichteten $\left(2 \mathrm{~F}_{\mathrm{o}}-\mathrm{F}_{\mathrm{c}}\right)$-Elektronendichtekarte und in Form einer bei $3 \sigma$ konturierten $\left(\mathrm{F}_{\mathrm{o}}-\mathrm{F}_{\mathrm{c}}\right)$-Differenzelektronendichtekarte dargestellt. In den wie in Kap. III.6 beschrieben erzeugten annealed omit-maps (Elektronendichten, aus deren Verfeinerung fehlerhafte Teilbereiche herausgenommen wurden) war in den meisten Fällen sowohl in der $\left(\mathrm{F}_{\mathrm{o}}-\mathrm{F}_{\mathrm{c}}\right)-$ als auch in der $\left(2 \mathrm{~F}_{\mathrm{o}}-\mathrm{F}_{\mathrm{c}}\right)$-Elektronendichtekarte deutlich der Verlauf der zuvor entfernten Modellbereiche sichtbar. Diese wurden manuell mit Hilfe des Programms XtalView entsprechend der Elektronendichte in das Modell eingefügt. Im nachfolgenden erneuten simulated annealing-Schritt sollten durch das manuelle Einfügen hervorgerufene Modellfehler in den neumodellierten Bereichen minimiert werden. B-Werte wurden auf einen einheitlichen Wert gesetzt und zunächst als Gruppen von Haupt und Seitenketten isotrop verfeinert. In nachfolgenden Verfeinerungsschritten wurden für jedes Atom eigene isotrope B-Faktoren ermittelt. Wassermoleküle wurden per Hand oder mit dem in CNS implementierten Programm wat_pick gesetzt. Nach der Verfeinerung sollten Wassermoleküle sinnvolle Wasserstoffbrückenbindungen entweder zum Enzym oder zu anderen Wassermolekülen ausbilden und je nach Auflösung des Datensatzes einen B-Wert von nicht größer 
als 50-80 $\AA^{2}$ besitzen. Gegen Ende der Verfeinerung wurde nicht mehr mit der Methode des simulated annealing verfeinert, da oft zuvor in der Elektronendichte liegende Seitenketten (Leu, Val, Asp, Glu) aufgrund des annealing-Prozesses als falsches Rotamer im Modell positioniert wurden. Die gleiche maximum-likelihood-Zielfunktion wurde in den abschließenden Verfeinerungszyklen mit der conjugate gradient Methode minimiert, um nur noch kleine Änderungen, die keine „Aktivierungsenergie“ benötigen, im Modell zuzulassen.

Die niedrigaufgelösten Datensätze (2a, 2b, 2d, 2e) wurden ausschließlich mit dem Programm CNS verfeinert. Um ihre zum Teil schlechte Elektronendichtequalität zu verbessern, wurden verschiedene Funktionen des Programms CNS genutzt. Z. B. ließ ein Vergleich der acht Monomere der beiden Datensätze 2d und 2e mit dem Programm ESCET [Schneider 2202] erkennen, dass sich die Moleküle untereinander nur minimal (konformationell invariable Enzymbereiche $>98 \%$ ) unterscheiden. Um die Verfeinerung stabiler zu gestalten, wurde für beide Verfeinerungen achtfache NCS auf bestimmte Molekülbereiche angewandt (restrained NCS). In beiden Fällen führte dies zu einem leichten Anstieg des R-Wertes, aber zu einem signifikanten Abfall des $\mathrm{R}_{\text {free }}$-Wertes. Das Sinken des $\mathrm{R}_{\text {free }}-$ Wertes deutet darauf hin, dass durch die Mittelung über die NCS-verwandten Moleküle tatsächlich die durch Überinterpretation der Daten verursachten Modellfehler eliminiert werden konnten. Um die zum Teil sehr schwache Elektronendichte besonders in der Region der Effektortasche zu verbessern, wurde ein Mitteln über die Elektronendichte der acht Moleküle vorgenommen. Hierfür wurde eine Maske um das Molekül A mit Hilfe des Programmpakets CCP4i [CCP4 1994] erstellt und die mit dem Programm lsqkab [Kabsch 1976] ermittelten Matrizen für die Symmetrieoperationen des Moleküls A auf die jeweils anderen Moleküle angefertigt. Diese Informationen wurden in das Programm CNS eingelesen und eine über die acht Moleküle gemittelte Elektronendichte errechnet. Die resultierende Dichte zeigte keine oder nur minimale Verbesserungen in ihrer Qualität. Besonders die Elekronendichte des Effektors Phenylalanin in der Struktur 2d wurde nicht eindeutiger bestimmt. Insgesamt wirkte die Elektronendichte weniger scharf konturiert. Dies deutet darauf hin, dass die Lage des Phenylalanins nicht voll besetzt ist, so dass die Mittelung über acht schlecht definierte Elektronendichten zu keiner verbesserten Qualität der gemittelten Dichte führt. Die Strukturen 2d und 2e zeichnen sich durch sehr hohe B-Faktoren (siehe Tab. IV.4b) und zum Teil schlecht bestimmte Seitenkettenpositionen sowie nicht vollbesetzte Lagen des Effektors Phenylalanin aus. In beiden Strukturen weisen zwar Differenzelektronendichten in allen Effektorbindungstaschen auf die Einlagerung des Phenylalanins hin, doch wurden nur die Effektoren verfeinert, die als solche in ihrer Differenzelektronendichte zu erkennen waren 
(siehe Tab. $I V .4 b$ ). Aussagen über Konformationsänderungen im Vergleich $\mathrm{zu}$ anderen Strukturen sind also mit Vorsicht zu betrachten.

Die Verfeinerung der höher aufgelösten Datensätze (1a, 2c, 3a, 4a-e) wurde, zeigte sich eine Konvergenz der CNS-Verfeinerung, mit dem Verfeinerungsprogramm Refmac weitergeführt. Mit diesem Programm wurde ebenfalls mit der conjugate gradient-Methode die maximum likelihood-Zielfunktion minimiert. Es wurde ein anisotropes Skalierungsmodell und eine bulk solvent-Korrektur angewandt. Die B-Werte wurden isotrop für jedes Atom einzeln verfeinert. Wasserstoffatome wurden in berechneten Positionen in die Minimierung miteinbezogen. In der Verfeinerung des mit 1.5 $\AA$ am höchsten aufgelösten Datensatzes (4e) wurde gegen Ende ein anisotropes B-Faktor-Modell verfeinert. Restraints wurden als stereochemische Informationen den Daten hinzugefügt. Auffällig war die Beobachtung, dass im Vergleich zur

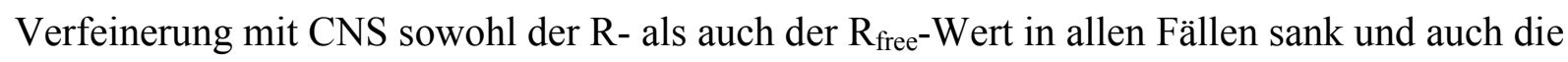
Elektronendichten schärfer konturiert wirkten, dass sich jedoch die Differenz zwischen Rund $\mathrm{R}_{\text {free}}$-Wert vergrößerte.

Die Verfeinerung der Struktur 1a zeichnete sich zunächst durch hohe B-Werte und eine schlecht bestimmte Elektronendichte, sowie eine große Differenz zwischen R- und $\mathrm{R}_{\text {free }}$-Wert aus. Um die Verfeinerung zu stabilisieren, wurde sie mit restraints für eine vierfache NCS der vier unabhängigen Moleküle durchgeführt, nachdem mit dem Programm ESCET ihre Ähnlichkeit untereinander bestätigt worden war. Daraus resultierte eine um einen Prozentpunkt kleinere R-Wert-Differenz, die im wesentlichen auf das Sinken des $\mathrm{R}_{\text {free }}$-Wertes zurückzuführen ist. Auch die B-Werte verkleinerten sich geringfügig. Ein weiterer Versuch, eine bessere Modellbeschreibung $\mathrm{zu}$ erstellen und so die Elektronendichte $\mathrm{zu}$ verbessern wurde durch Anwendung eines TLS-Modells unternommen. Hierdurch sanken beide R-Werte signifikant um mehr als einen Prozentpunkt und die individuellen B-Werte verkleinerten sich im Mittel um etwa 25\%. Durch Kombination beider Verfeinerungsvarianten wurde eine Senkung des R-Wertes um einen und des $\mathrm{R}_{\text {free }}$-Wertes um drei Prozentpunkte sowie eine Erniedrigung der individuellen B-Werte um etwa 30\% erreicht.

\begin{tabular}{|l|llll|}
\hline & $\mathrm{R}-$ Wert [\%] & $\mathrm{R}_{\text {free }}$-Wert [\%] & $\Delta \mathrm{R}$ & gemittelter B-Wert \\
\hline ohne weitere restraints & 21.6 & 27.6 & 6.0 & 57.6 \\
NCS & 21.8 & 26.7 & 4.9 & 56.8 \\
TLS & 20.4 & 25.7 & 5.3 & 40.5 \\
TLS + NCS & 20.4 & 24.2 & 4.2 & 38.8 \\
\hline
\end{tabular}

Tab. IV.4a Auflistung der R-Wertverläufe in Abhängigkeit der Verfeinerungsmethode für die Struktur 1a 
Die Verfeinerung der Struktur 3a des trigonalen Kristalls zeigte ebenfalls eine schlechte bzw. eine für eine Auflösung von 2.4 A nicht scharf genug konturierte Elektronendichte. Zunächst wurde eine in dieser Raumgruppe häufig beobachtete Verzwilligung über die zweizählige Achse vermutet. Die $\left|E^{2}-1\right|$-Statistik und auch der sehr kleine $\mathrm{R}_{\mathrm{sym}}$-Wert der höhersymmetrischen Raumgruppe P3(1)21 sprachen eigentlich gegen diese Annahme. Trotzdem wurde eine Verfeinerung in der niedrigsymmetrischeren Raumgruppe P3(1) unter Berücksichtigung einer Verzwilligung über die zweizählige Achse der höhersymmetrischen Raumgruppe $\left(\begin{array}{lll}0 & 1 & 0\end{array}\right.$ $\begin{array}{lllll}0 & 0 & 0 & 0 & -1)\end{array}$ mit dem Programm CNS versucht. Dazu wurden die Daten in der Raumgruppe P3(1) integriert, skaliert und mit CNS ein Testdatensatz generiert, der die Verwandtschaft der Reflexe durch die Zwillingsmatrix mitberücksichtigt.

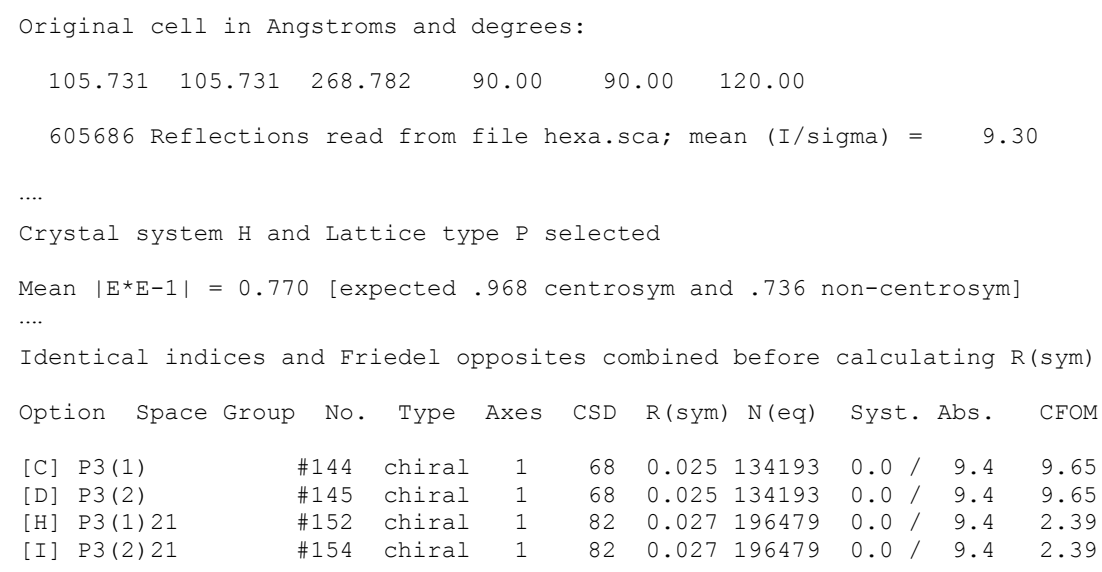

Abb. IV.4a Ausschnitte aus der xprep-Statistik des Datensatzes der Struktur 3a

Aus dieser Verfeinerung (simulated annealing, B-Wertverfeinerung, conjugate gradient-Verfeinerung) in der eine Verzwilligung zu etwa 50\% angenommen wurde, resultierte keine bessere Elektronendichtequalität. Der R-Wert sank zwar signifikant (19.8\%), jedoch vergrößerte sich die Differenz zwischen R- und $\mathrm{R}_{\text {free }}$-Wert auf 8.2 Prozentpunkte, so dass diese Verfeinerungsvariante nicht weiter fortgesetzt wurde.

Auch Verfeinerungen mit dem Programm Refmac unter der Berücksichtigung von NCS und TLS ergaben kein zufriedenstellendes Verfeinerungsmodell. Das zur Strukturdiskussion verwendete Modell wurde schließlich unter Berücksichtigung von zweifacher NCS mit dem Programm CNS verfeinert. Hierbei wurde der Beobachtung Rechnung getragen, dass sich die Monomere innerhalb eines Dimers in ihrer Konformation zu unterscheiden scheinen (ESCETTabelle siehe Kap.V.1.2.1). Die Evaluierung der Strukturen wurde mit den Programmen WHAT_IF [Rodriguez 1998] und Procheck [Laskowski 1993] durchgeführt. Es zeigten sich 
bei keiner der Strukturen größere Auffälligkeiten. In den Ramachandran-Auftragungen aller im Rahmen dieser Arbeit verfeinerten Strukturen lagen über 91\% der Aminosäuren in bevorzugten, und die restlichen Aminosäuren in erlaubten Regionen, lediglich das Histidin His282 liegt in allen Strukturen in einer nur generell erlaubten Region. Diese ungewöhnliche Konformation des His282 ist mit ihrer Involvierung in die Metallionkoordinationssphäre zu erklären (siehe Kap. V.1.1). In keiner der Strukturen befinden sich Aminosäuren in nicht erlaubten Regionen.

Alle verfeinerten Metallionen, Substrate, Analoga und Inhibitoren waren in einer Differenzelektronendichtekarte eindeutig zu erkennen. Exemplarisch sind in $A b b . I V .4 a$ und $A b b . I V .4 b$ Differenzelektronendichten des Substrates PEP und des E4P-Analogons G3P bei $1.5 \AA$ sowie die des Effektors Tyrosin bei einer Auflösung von $2.1 \AA ̊$ dargestellt.
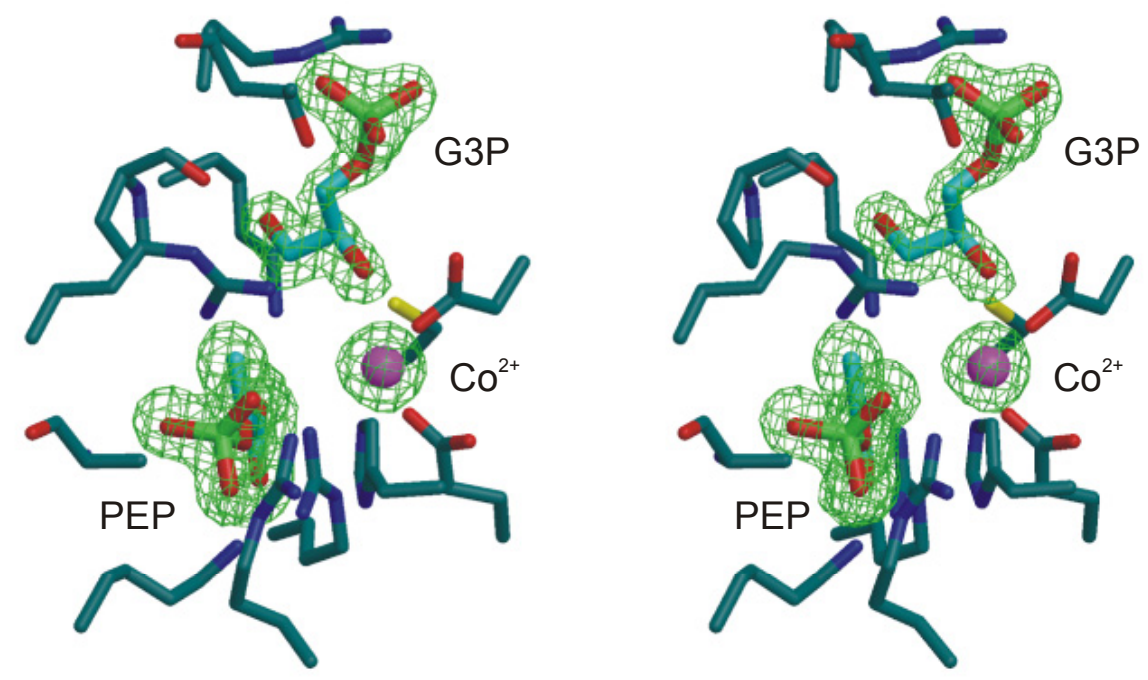

Abb. IV.4a Stereographische Darstellung des aktiven Zentrums der Struktur 4e bei einer Auflösung von $1.5 \AA$. Für die bei $3 \sigma$ dargestellte $\mathrm{F}_{\mathrm{o}}-\mathrm{F}_{\mathrm{c}}$-Elektronendichte wurden nach Ende der Verfeinerung das Substrat PEP, das Substartanalogon G3P und das Metallion aus dem Modell entfernt und mehrere Verfeinerungszyklen simulated-annealing durchgeführt, um model-bias durch das Modell zu minimieren.
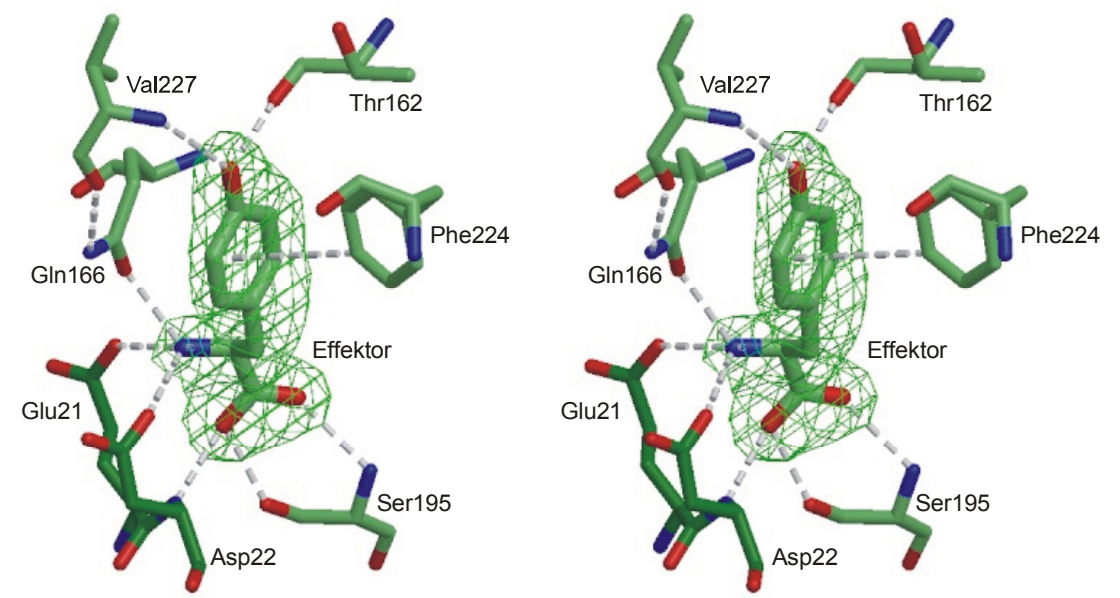

Abb. IV.4b Stereographische Darstellung der Effektorbindungstasche der Struktur 2c bei einer Auflösung von $2.1 \AA$ A. Für die bei $3 \sigma$ dargestellte $F_{\mathrm{o}}-\mathrm{F}_{\mathrm{c}}$-Elektronendichte wurde nach Ende der Verfeinerung der Effektor aus dem Modell entfernt und mehrere Verfeinerungszyklen simulated-annealing durchgeführt, um model-bias durch das Modell zu minimieren. 


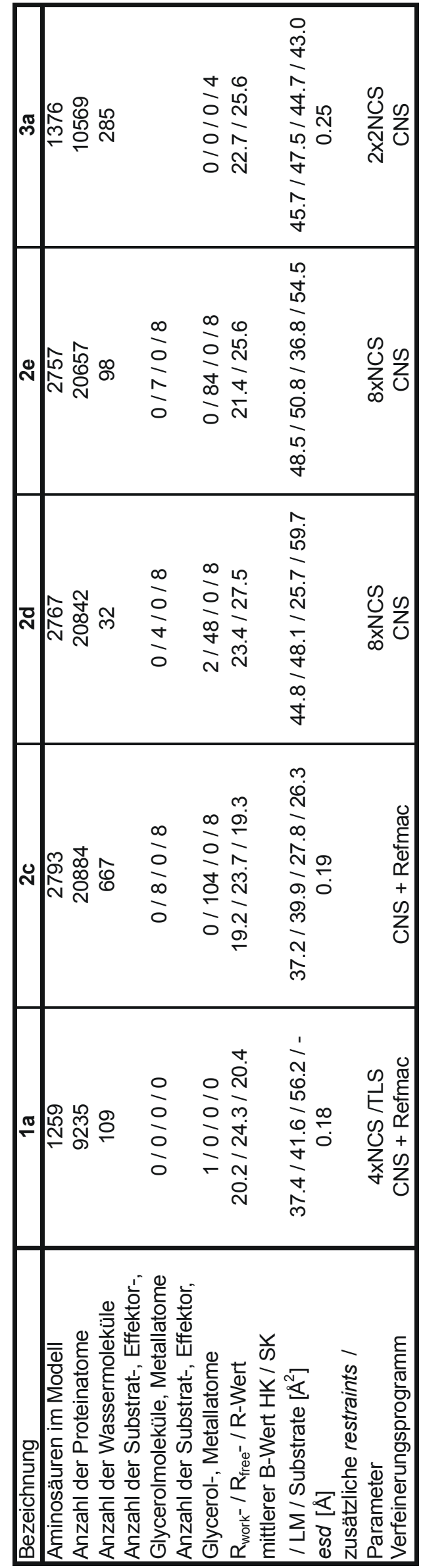

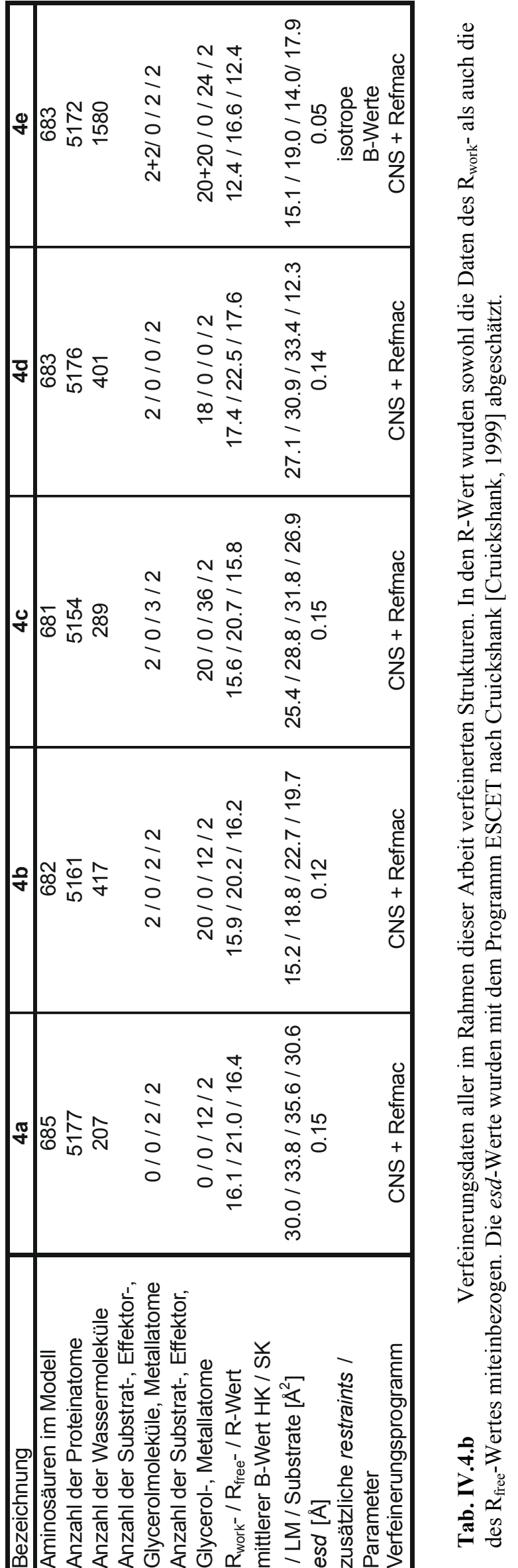




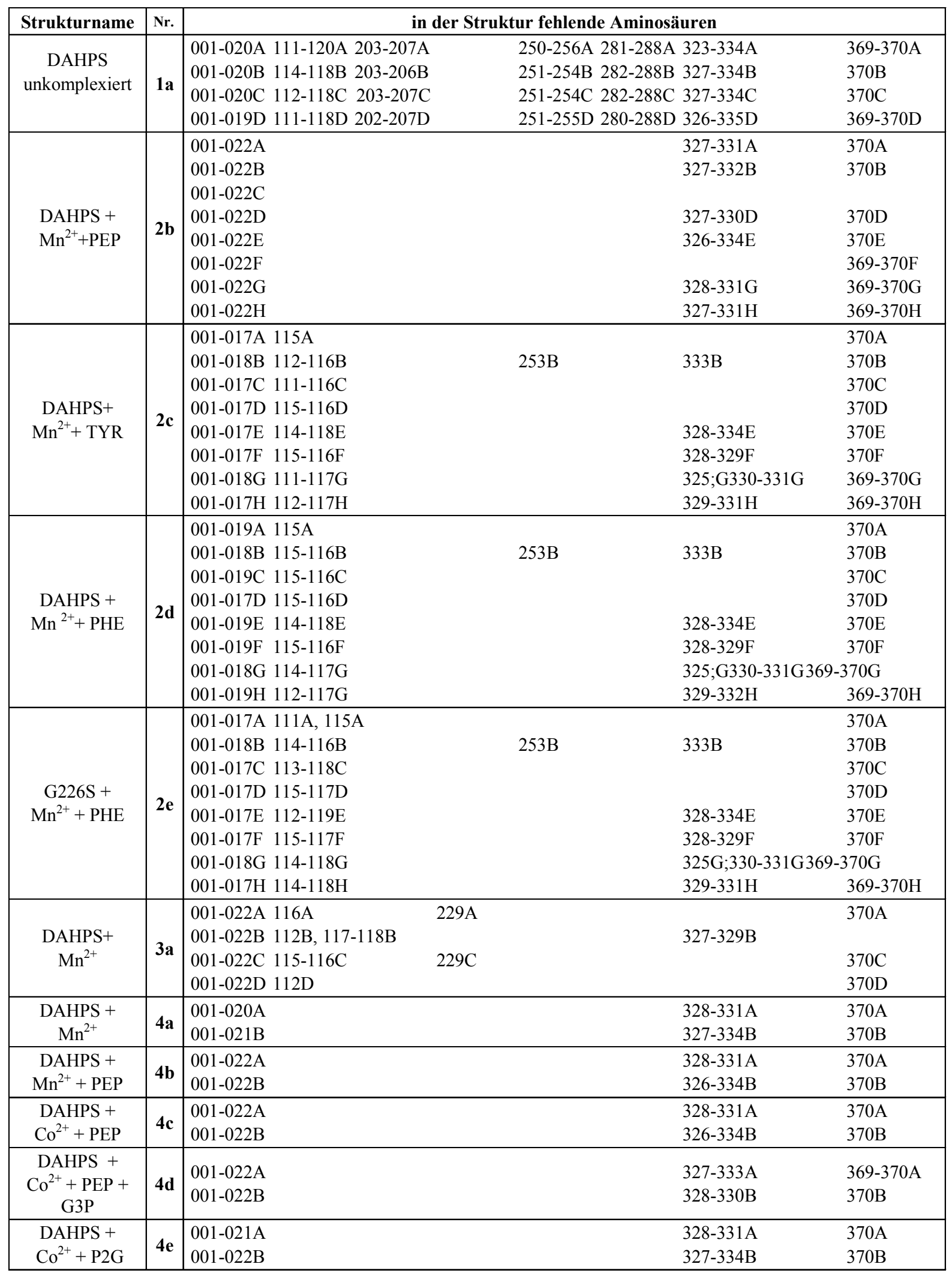

Tab. IV.4c Auflistung der in den einzelnen Strukturen nicht verfeinerten Enzymbereiche 


\begin{tabular}{|c|c|}
\hline Struktur & als Alanin verfeinerte Aminosäuren \\
\hline 1a & $\begin{array}{l}\text { Glu21 A, Asp 22A, 49A, 56A, 86A, 101A, 127A, 128A, 129A, 130A, 131A, Arg180A, 260A, 264A, 289A, } \\
\text { 290A, 291, 294, 301, 321A, 335A, 344A, 348A, 352A, 356A } \\
\text { Glu21B, Asp22B, 49B, 82B, 101B, Glu111B, Lys112B, Glu158B, 183B, 229B, 260B, 294B, 301B, 321B, } \\
\text { 335B, 348B, } \\
\text { 22C, 49C, 82C, 86C, 93C, 99C, 101C, 120C, 130C, 158C, 160C, Arg180C, 183C, 210C, 260C, 264C, 290C, } \\
\text { 294C, 301C, 326C, 335C, 348C, 352C, 356C, 369C } \\
\text { 20D, 21D, 22D, 52D, 82D, 101D, 120D, 127D, Leu160D, 183D, 213D, 216D, 239D, 250D, 260D, 264D, } \\
\text { 290D, 294D, 316D, 326D, 335D }\end{array}$ \\
\hline 2d & $\begin{array}{l}\text { 82, 93, Lys112, Glu158, Leu160, 180, 328, } 329 \\
\text { 82, Arg114, Leu160, 328, } \\
\text { Lys112, Arg114, Glu158, Leu160, 328, } \\
\text { Lys112, Arg114, 253, 287, 328, } \\
\text { Glu111, Arg114, 253, } \\
\text { 82, Glu111, Phe132 } \\
\text { 82, Lys112, Leu160, 253, 328, 335, } \\
\text { Glu111, Glu158, 252, 253, 287, 328, } 335\end{array}$ \\
\hline $2 e$ & $\begin{array}{l}\text { Lys120A, Ser226A, 329A } \\
\text { Lys112B, Ser226B } \\
\text { Glu111C, Lys112C, Ser226C } \\
\text { Arg114D, Ser226D, 253D } \\
\text { Phe132E, Ser226E, Arg180E } \\
\text { Glu111F,Ser226F } \\
\text { Ser226G, 253G, 335G } \\
\text { Lys112H, Lys120H, Ser226H }\end{array}$ \\
\hline
\end{tabular}

Tab. IV.4.d Auflistung der aufgrund nicht interpretierbarer Elektronendichte in den Strukturen 1a, 4d und 4e als Alanin verfeinerten Aminosäurenseitenketten. Für den Katalyse- oder Regulationsmechanismus entscheidende Aminosäuren wurden fett gedruckt. 


\section{Ergebnisse und Diskussion}

\section{V.1 Das aktive Zentrum}

Um den Katalysemechanismus der Deoxy-arabino-Heptulosonat-7-Phosphat-Synthese aus den Edukten Phosphoenolpyruvat und Erythrose-4-Phosphat durch die hier untersuchte tyrsensitive DAHP Synthase aus S. cerevisiae besser zu verstehen, wurden die Strukturen verschiedener Metallion-, Substrat-, und Analogon-Komplexe des Proteins untersucht. Da DAHP Synthasen selbst bei tiefen Temperaturen mit hohen Umsatzraten arbeiten, konnte keine Struktur des Enzyms im Komplex mit beiden Substraten gemeinsam untersucht werden. Stattdessen wurde versucht, Komplexe mit jeweils einem Substrat und einem Analogon des anderen Substrates (siehe $A b b$. VIa zu kristallisieren, um das Ablaufen der Reaktion zu verhindern.

\section{Substrate:}<smiles>O=C(O[Na])C(=O)O[Na]</smiles>

Analoga:
E4P<smiles></smiles>

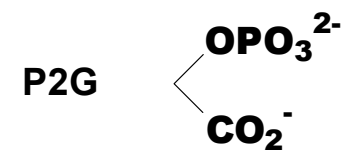

G3P<smiles>[R6]O[Po](=O)(O)C[C@@H](O)CO</smiles>

Abb. V1a

Lewis-Formeln der Substrate und ihrer Analoga. Dem PEP-Analogon 2Phosphoglycolat (P2G) fehlt die das E4P nucleophil angreifende Doppelbindung. Dem E4P-Analogon Glycerol3-Phosphat (G3P) fehlt die anzugreifende Carbonylgruppe des E4P.

Als Substratanalogon bietet sich für das Phosphoenolpyruvat (PEP) das 2-Phosphoglycolat (P2G) an, da dieser Verbindung die die Carbonylgruppe des E4Ps angreifende Doppelbindung fehlt. Als Analogon für das zweite Substrat Erythrose-4-Phosphat (E4P) scheint das Glycerol3-Phosphat (G3P) geeignet, da es außer der fehlenden, an der Reaktion beteiligten Carbonylgruppe mit dem zweiten Substrat identisch ist.

Die Bindungsstelle des ersten Substrates PEP war aus der Strukturbestimmung 1HFB [Hartmann 2002, eingereicht] bekannt (siehe $A b b$. V.1b). Im folgenden wird das aktive Zentrum mit Hilfe der im Rahmen dieser Arbeit bestimmten Komplex-Strukturen im Hinblick auf seine Bindungs- und Katalyseeigenschaften näher beschrieben. 

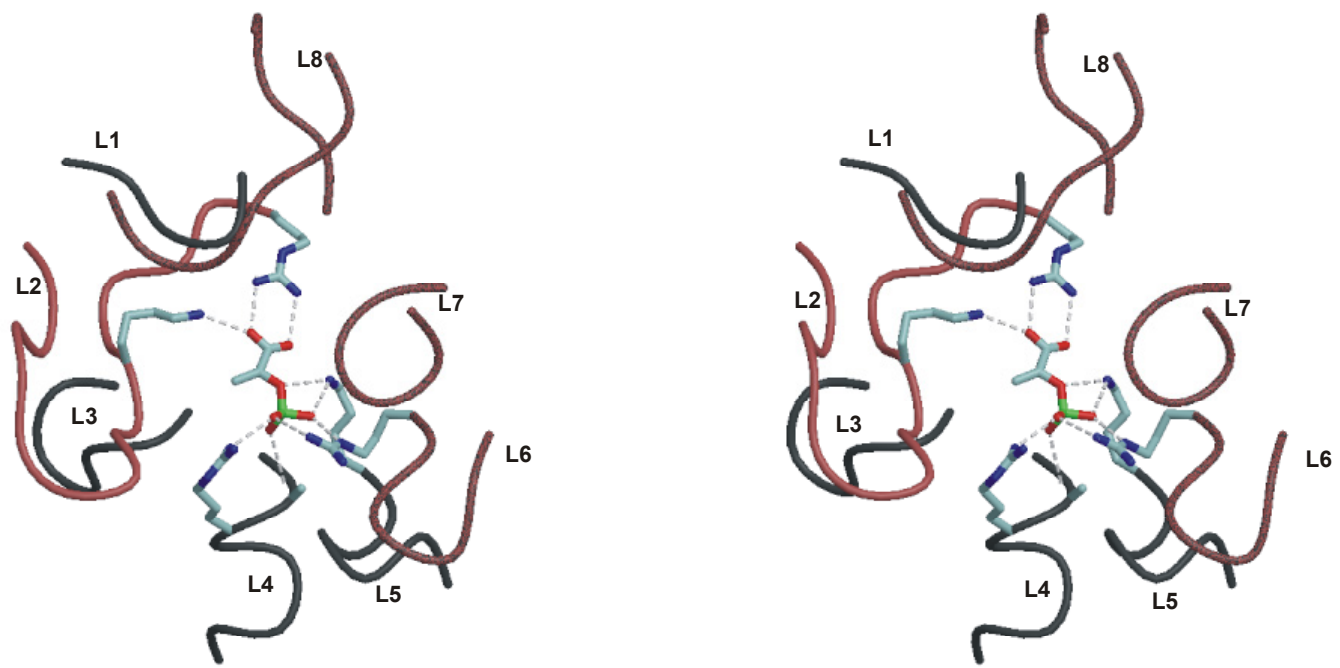

Abb. V1.b

Stereographische Darstellung des aktiven Zentrums der Struktur 1HFB. Alle loops der c-terminalen Seite des barrels sind dargestellt. Erweiterte loops sind rötlich hervorgehoben. Die das PEP im aktiven Zentrum fixierenden Wasserstoffbrücken sind als gestrichelte Linien eingezeichnet.

\section{V.1.1 Vergleich der Komplexstrukturen}

\section{V.1.1.1 DAHP Synthase komplexiert mit Mangan(II) (3a und 4a)}
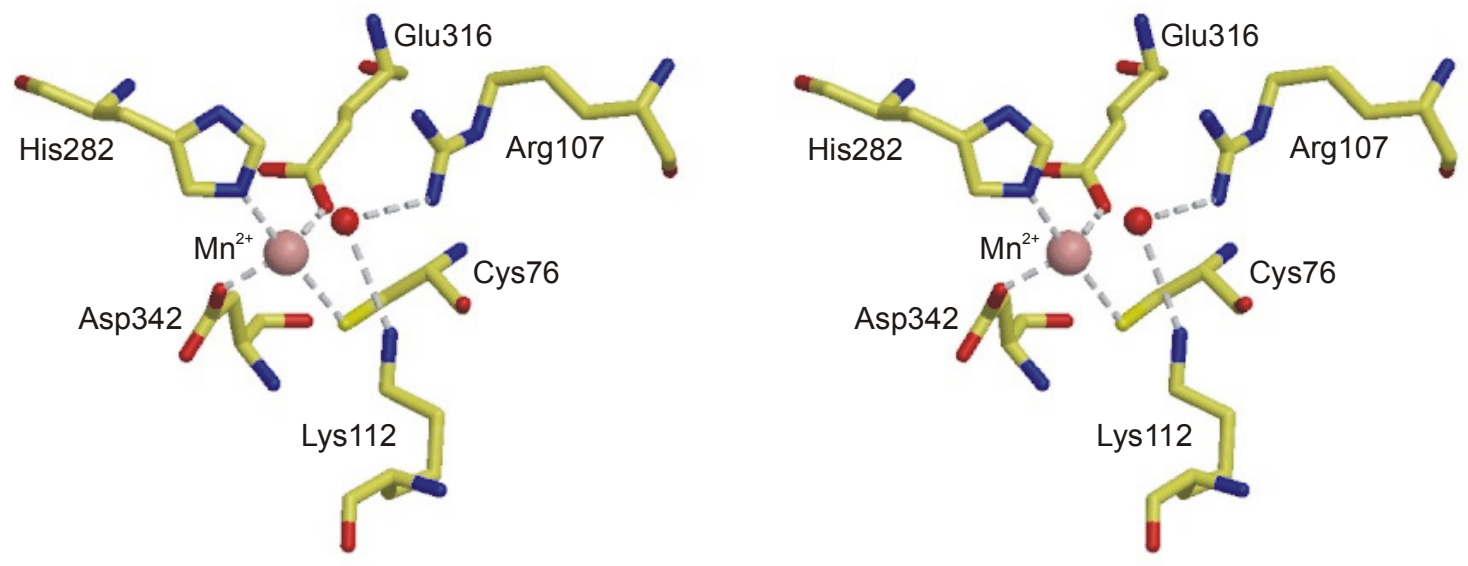

Abb. V.1.1.1a

Stereographische Darstellung der aktiven Tasche in der Struktur 4a. Die trigonal bipyramidale Koordination des $\mathrm{Mn}^{2+}$-Ions mit der freien, äquatorialen Koordinationsstelle sowie die Verbrückung der Aminosäuren Lys112 und Arg107 über ein Wassermolekül sind als gestrichelte Linien dargestellt.

Für die Metall(II)-Komplex-Struktur wurde zunächst aus den in Kap.IV.2 angesprochenen Gründen Mangan(II) als Cofaktor eingesetzt. Es wird im aktiven Zentrum von den Seitenketten der Aminosäuren Cys76, His282, Glu316 und Asp342 koordiniert. Diese Aminosäuren liegen ausschließlich in loops auf der c-terminalen Seite des barrels (Abb. Ib:A). Das Cys76 liegt im loop zwischen $\beta 1$ und $\alpha 1$ (L1), His282 im loop zwischen $\beta 7$ und $\alpha 7$ (L7) und die beiden sauren Aminosäuren Glu316 und Asp342 sind im loop zwischen 
$\beta 8$ und $\alpha 8$ lokalisiert (L8). Die Umgebung des Metallions entspricht einer trigonal bipyramidalen Anordnung, in der die Aminosäuren Cys76 und His282 die axialen Positionen einnehmen und die Aminosäuren Glu316 und Asp342 zwei der äquatorialen Lagen. Die dritte Koordinationsposition ist nicht besetzt. Die Bindungslängen sind in Tab. V.1.1a aufgelistet. Das Wassermolekül W718 liegt mit einem Abstand von $3.28 \AA$ zum Mangan(II) so weit entfernt, dass allenfalls von einer sehr schwachen Wechselwirkung gesprochen werden kann (eine Suche in der CSD [CSD 1998] ergab einen mittleren Wert aller in der Datenbank vorhandenen Abstände zwischen Mangan(II)ionen und metallionkoordinierenden Wassermolekülen von $2.17 \AA$ Å). Dieses Wassermolekül wird von den Aminosäuren Lys112 und Arg107 durch schwache Wasserstoffbrückenbindungen fixiert. Auf die Unterschiede in der Gesamtkonformation des Enzyms in den Strukturen 2a, 3a und 4a bedingt durch die unterschiedlichen Kristallisationbedingungen in den verschiedenen Raumgruppen, wird in Kap. V.1.2.1 eingegangen.

\section{V.1.1.2 DAHP Synthase komplexiert mit Metall(II) und PEP (2b, 4b und 4c)}
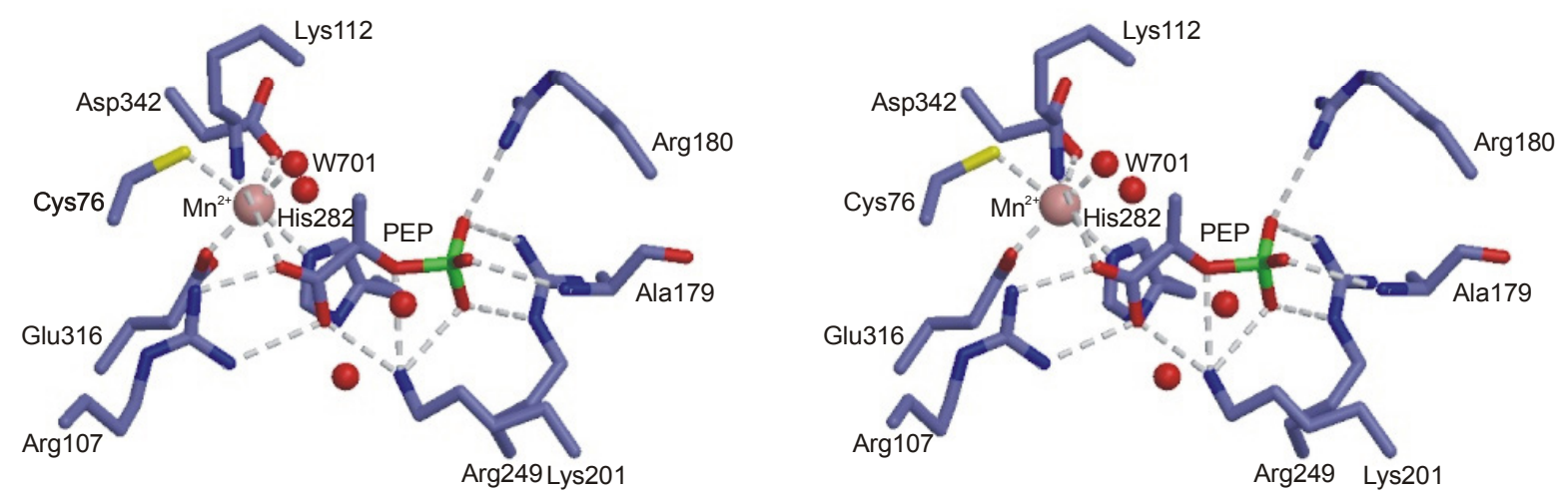

Abb. V.1.1.2a

Stereographische Darstellung der aktiven Tasche in der Struktur $\mathbf{4 b}$, die ein $\mathrm{Mn}^{2+}$-Ion und das Substrat PEP enthält. Die trigonal bipyramidale Koordinationssphäre des Metallions ist durch das Wassermolekül W701 vervollständigt. Zwischen dem Metallion und dem Substrat PEP bestehen keine direkten Wechselwirkungen. Auf der re-Seite des PEP befinden sich drei gut fixierte Wassermoleküle.

Dieser Enzymkomplex wurde sowohl mit Cobalt(II) als auch mit Mangan(II) als Metallion untersucht. Der Vergleich der beiden Strukturen wird in Kap. V.1.2.5 durchgeführt.

Die im vorherigen Abschnitt beschriebene trigonal bipyramidale Koordinationssphäre des Metallions wird in der mit PEP komplexierten Struktur durch das Wassermolekül W701 vervollständigt (siehe Abb.V.1.1.2a). Bindungslängen sind in Tab. V.1.1a aufgelistet. Das erste der beiden zu verknüpfenden Substrate, das Phosphoenolpyruvat, wird mit seiner Carboxylatgruppe über zwei starke Wasserstoffbrückenbindungen von der Guanidingruppe des Arg107 festgehalten. Zusätzlich bestehen Wechselwirkungen zwischen dem Sauerstoffatom PEP:O1 der Carboxylatgruppe und sowohl dem metallionkoordinierenden 
Wassermolekül (diese Bindung ist in $A b b . V .1 .1 .2 a$ nicht eingezeichnet) als auch weniger stark ausgeprägt mit der Amingruppe des Lys112. Das zweite Carboxylatsauerstoffatom (PEP:O2') wird zusätzlich durch das Lys201 koordiniert, das gleichzeitig mit dem verbrückenden Sauerstoffatom PEP:O2 und einem Sauerstoffatom der Phosphatgruppe wechselwirkt. Außerdem fixiert dieses Carboxylatsauerstoffatom im van-der-Waals-Abstand gemeinsam mit dem zweiten Phosphatsauerstoffatom ein Wassermolekül auf der re-Seite des Enolpyruvates. Die Phosphatgruppe wird in ihrer Bindungstasche durch starke Wechselwirkungen mit Arg180, Arg249, dem Amidstickstoffatom des Ala179 und gut koordinierten Wassermolekülen (in Abb. V.1.1.2a nicht dargestellt) festgehalten. Ebenso wie die Aminosäuren der Metallionbindungsstelle befinden sich die oben genannten PEPbindenden Aminosäuren auf der Carboxylatseite des barrels. Sie sind relativ gleichmäßig über die loops zwischen den $\beta$-Strängen und $\alpha$-Helices verteilt: Lys112 liegt im erweiterten loop L2, Ala179 und Arg180 liegen im loop L4 zwischen $\beta 4$ und $\alpha 4$, Lys201 befindet sich im loop L5 zwischen $\beta 5$ und $\alpha 5$ und Lys249 im loop zwischen $\beta 6$ und $\alpha 6$. Zum in der aktiven Tasche vorhandenen und für die Aktivität des Enzyms benötigten Metallion bildet das Substrat keine direkte Substrat-Metallion-Wechselwirkung aus. Der Abstand zwischen dem Sauerstoffatom $\mathrm{O} 1$ des PEP und dem Metallion ist mit $3.22 \AA \mathrm{zu}$ groß, als dass es sich um eine relevante Koordinationswechselwirkung handeln könnte. In der Struktur 4c konnte zusätzlich zum Metallion und zum PEP ein Glycerol in der aktiven Tasche verfeinert werden. Auf Lage und Bedeutung dieses Lösungsmittelmoleküls wird in Kap. V.1.2.8 eingegangen. Bindungslängen sind in Tab. V.1.1 $a$ aufgelistet.

\section{V.1.1.3 DAHP Synthase komplexiert mit PEP (1HFB)}
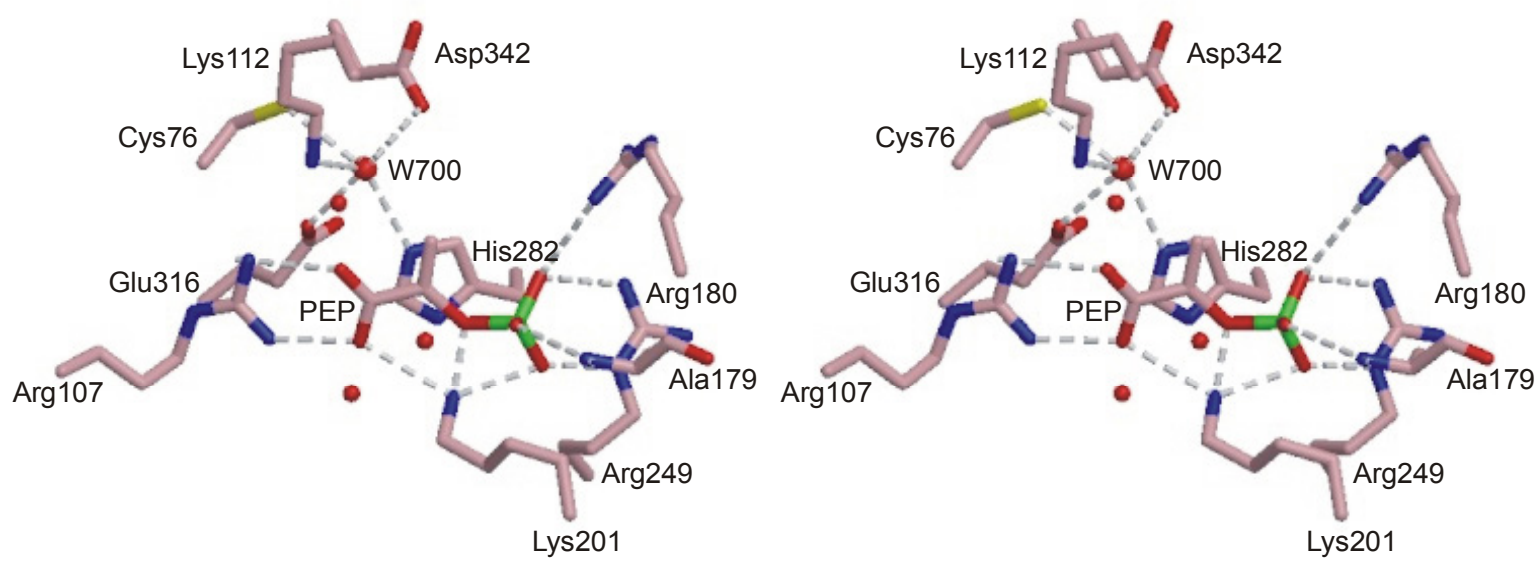

Abb. V.1.1.3a

Stereographische Darstellung der aktiven Tasche in der Struktur 1HFB. Die Metallion-Position aus den Strukturen 4a und 4b (siehe oben) ist durch das Wassermolekül W700 besetzt. Durch eine leichte Positionsänderung und zusätzliche Koordination durch Lys112 besitzt es eine verzerrt tetragonal pyramidale Umgebung. Die Bindungspartner des PEP bleiben im Vergleich zu 4b unverändert. 
Das Substrat in der nur mit PEP kristallisierten Struktur 1HFB [Hartmann 2002, eingereicht] ist über dieselben Wechselwirkungen in der aktiven Tasche fixiert wie in den mit Metallionen komplexierten Strukturen. Die Metallionposition ist unbesetzt, doch befindet sich ein Wassermolekül zwischen den Lagen des Metallionatoms und des an ihn koordinierten Wassermoleküls. Dieses, das Metallion ersetzende Wassermolekül, wird von den selben Aminosäureseitenketten koordiniert wie in den oben beschriebenen Strukturen das Metallion. Durch die leichte Änderung der Position wird jedoch die trigonal bipyramidale MetallionKoordinationssphäre aufgegeben und eine für Wassermoleküle typischere, stark verzerrte tetragonal pyramidale Umgebung erreicht. Hierzu wird die Koordination des Metallion ersetzenden Wassermoleküls zusätzlich zu den vier bekannten Aminosäuren in dieser metallionfreien Komplexstruktur durch das Lys112 ergänzt. Mit dem Substrat PEP geht dieses Wassermolekül keine Wechselwirkungen ein. Bindungslängen sind in Tab. V.1.1a aufgelistet.

\section{V.1.1.4 DAHP Synthase komplexiert mit Cobalt(II) und P2G (4d).}

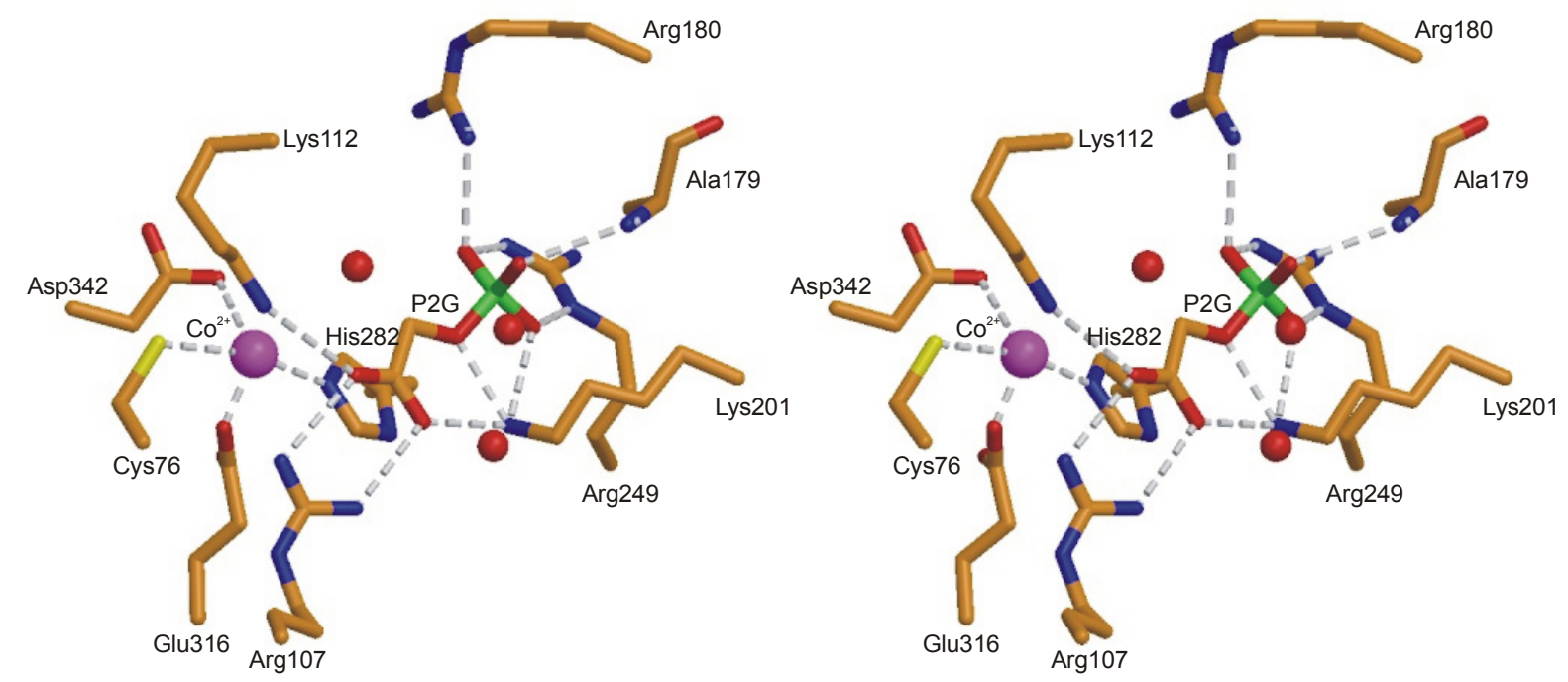

\footnotetext{
Abb. V.1.1.4a
}

Stereographische Darstellung der aktiven Tasche in der Struktur 4d. Die Koordinationssphäre des $\mathrm{Co}^{2+}$-Ions entspricht einer trigonal bipyramidale Geometrie mit einer freien, äquatorialen Koordinationsstelle. Die Bindungspartner des PEP-Analogons P2G sind mit denen des Substrates PEP identisch. Auch die drei gut fixierten Wassermoleküle auf der re-Seite des PEP-Analogons bleiben erhalten.

Das PEP-Analogon P2G wird (im Gegensatz zu den Beobachtungen von T. Wagner in der phe-sensitiven Struktur aus E. coli, siehe Kap. V.1.3.1.2 [Wagner 2000 J. Mol. Biol]) über dieselben Wasserstoffbrückenbindungen an das Enzym gebunden wie das Substrat PEP. Die Koordinationssphäre des Cobalt(II) entspricht der nur mit Metallion komplexierten Struktur (3a und 4a). Es handelt sich also um eine trigonal-bipyramidale Umgebung, in der die äquatoriale Position, die in den Strukturen (4b und 4c) mit einem Wassermolekül besetzt ist, frei bleibt. Bindungslängen sind in Tab. V.1.1a aufgelistet. 


\section{V.1.1.5 DAHP Synthase komplexiert mit Cobalt(II), PEP und G3P (4e)}
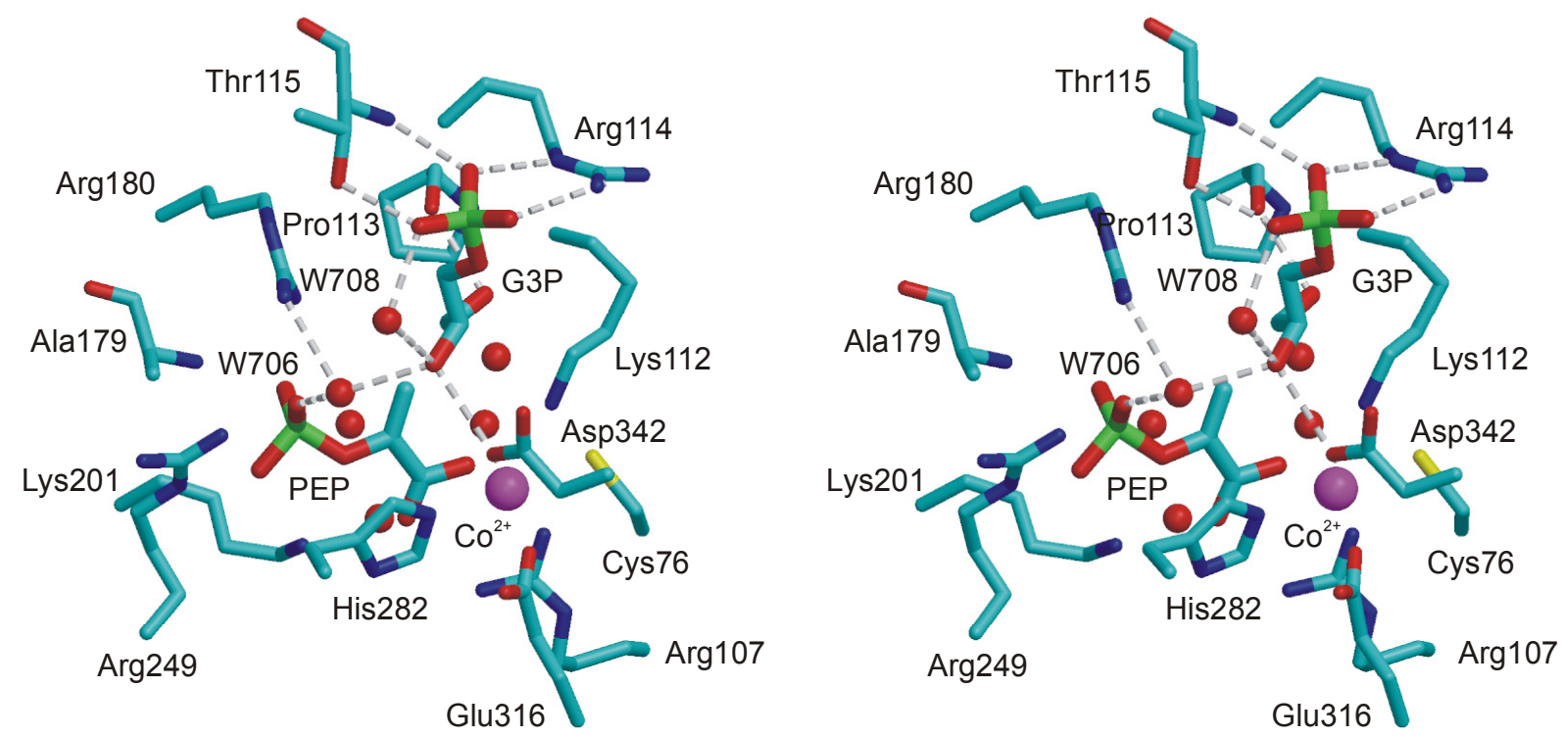

Abb. V.1.1.5a

Stereographische Darstellung der aktiven Tasche in der Struktur 4e. Im aktiven Zentrum sind ein $\mathrm{Co}^{2+}$-Ion, das Substrat PEP und das E4P-Analogon G3P enthalten. Das G3P wird sowohl über seine Phosphat- als auch seine Hydroxylgruppen durch Wasserstoffbrücken an den loop L2 und zusätzlich durch das das Metallion koordinierende Asp342 fixiert. Die Bindungspartner des PEP bleiben erhalten. Die Koordinationssphäre des Metallions wird durch das Wassermolekül W701 zu einer trigonal bipyramidalen Geometrie aufgefüllt. Aus Gründen der Übersichtlichkeit wurden nur die Wasserstoffbrückenbindungen zum G3P dargestellt.

Die Koordinationssphäre des Cobalt(II) und die Wasserstoffbrückenbindungen des ersten Substrates PEP in der Struktur 4e sind identisch mit denen der Struktur (4c). Das E4PAnalogon G3P bindet mit seiner Phosphatgruppe an den in allen Strukturen unterschiedlich flexiblen loop L2 (siehe Tab. VI.4c). Ein Phosphatsauerstoffatom wird über die Hydroxylgruppe des Thr115:OG1 an das Enzym gebunden, das zweite sowohl an das Stickstoffatom der Amidgruppe Thr115 als auch an das Stickstoffatom NE des Arg114. Das dritte freie Sauerstoffatom der Phosphatgruppe wird ebenfalls über ein Stickstoffatom, das NH2 der Guanidingruppe, des Arg114 gebunden. Zusätzlich wird die Phosphatgruppe durch gut koordinierte Wassermoleküle abgesättigt. Das Wassermolekül W708 verbrückt die Phosphatgruppe mit der Hydroxylgruppe G3P:OH2 und bestimmt so die Konformation des Substrat-Analogons mit. An das Enzym ist diese Hydroxylgruppe durch zwei Wasserstoffbrückenbindungen zum Asp342 gebunden. Die Hydroxylgruppe G3P:OH1 wird mit einer starken Wasserstoffbrücke an das Carbonylsauerstoffatom des Pro113 gebunden. Das Wassermolekül W706 verbrückt die Hydroxylgruppe G3P:OH2 des Substrat-Analogons mit der Phosphatgruppe des Substrates PEP und bildet eine schwache Wasserstoffbrückenbindung zum Arg180 aus (vgl. Abb. V.1.1.5a). Auch die Bindungsstellen für das E4P-Analogon G3P befinden sich ausschließlich auf der Carboxylatseite des barrels. Jedoch liegen sie mit Pro113 
und der Phosphatbindungsstellen Arg114 und Thr115 gehäuft im erweiterten loop L2. Das Asp342, das gleichzeitig in die Metallionkoordination miteingebunden ist, liegt, wie oben erwähnt, im loop zwischen $\beta 8$ und $\alpha 8$. Bindungslängen sind in Tab. V.1.1a aufgelistet.

\section{V.1.1.6 Unkomplexierte Struktur der DAHP Synthase (1a)}

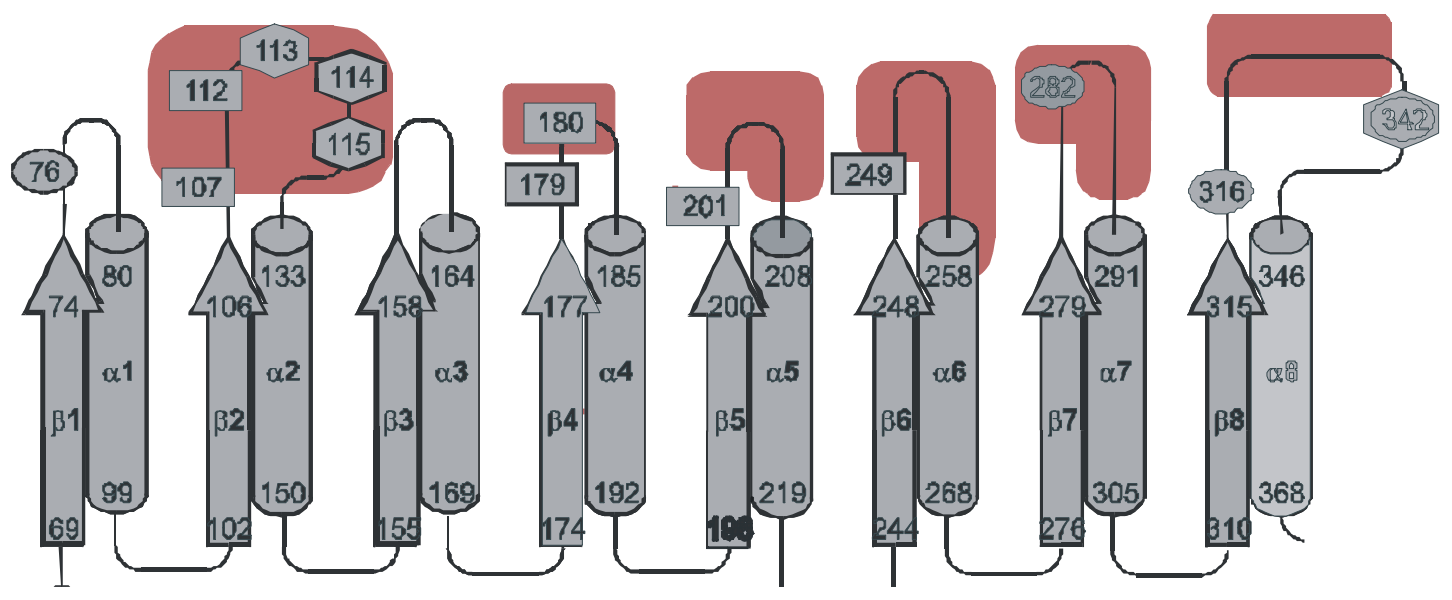

Abb. V.1.1.6a

TIM-Barrel-Ausschnitt des Topologiediagramms der Struktur 1a. Fehlgeordnete Bereiche der leeren Struktur sind rötlich unterlegt. Die auffällig hohe Anzahl fehlgeordneter Enzymbereiche liegt ausschließlich auf der c-terminalen, das aktive Zentrum bildenden Seite des barrels.

Die metallion- und substratfreie Struktur der DAHP Synthase zeichnet sich durch ungewöhnlich viele, nicht in der Elektronendichte sichtbare Bereiche aus (siehe Tab. IV.4c). Diese ungeordneten Regionen liegen ausschließlich in den loops auf der Carboxylatseite des barrels. Der fehlende Bereich zwischen AS111-120 schließt die Phosphatbindungsstelle des E4P-Analogons G3P mit ein. Die Seitenkette des in die PEP-Bindung involvierten Arg180 ist ebenfalls nicht in der Elektronendichte sichtbar (Tab. IV.4d). In dem in dieser Struktur fehlgeordneten loop L7 ist das in den komplexierten Strukturen an das Metallion koordinierende His282 involviert. Auch die Regionen AS250-256 (L5) und 323-335 (L8), die in dieser Struktur nicht modellierbar sind, wirken in den komplexierten Strukturen zwar nicht direkt an der Metallion- oder Substratbindung mit, sind für die aktive Tasche jedoch auf jeden Fall strukturgebend (siehe Abb. V.1.1.6a). 


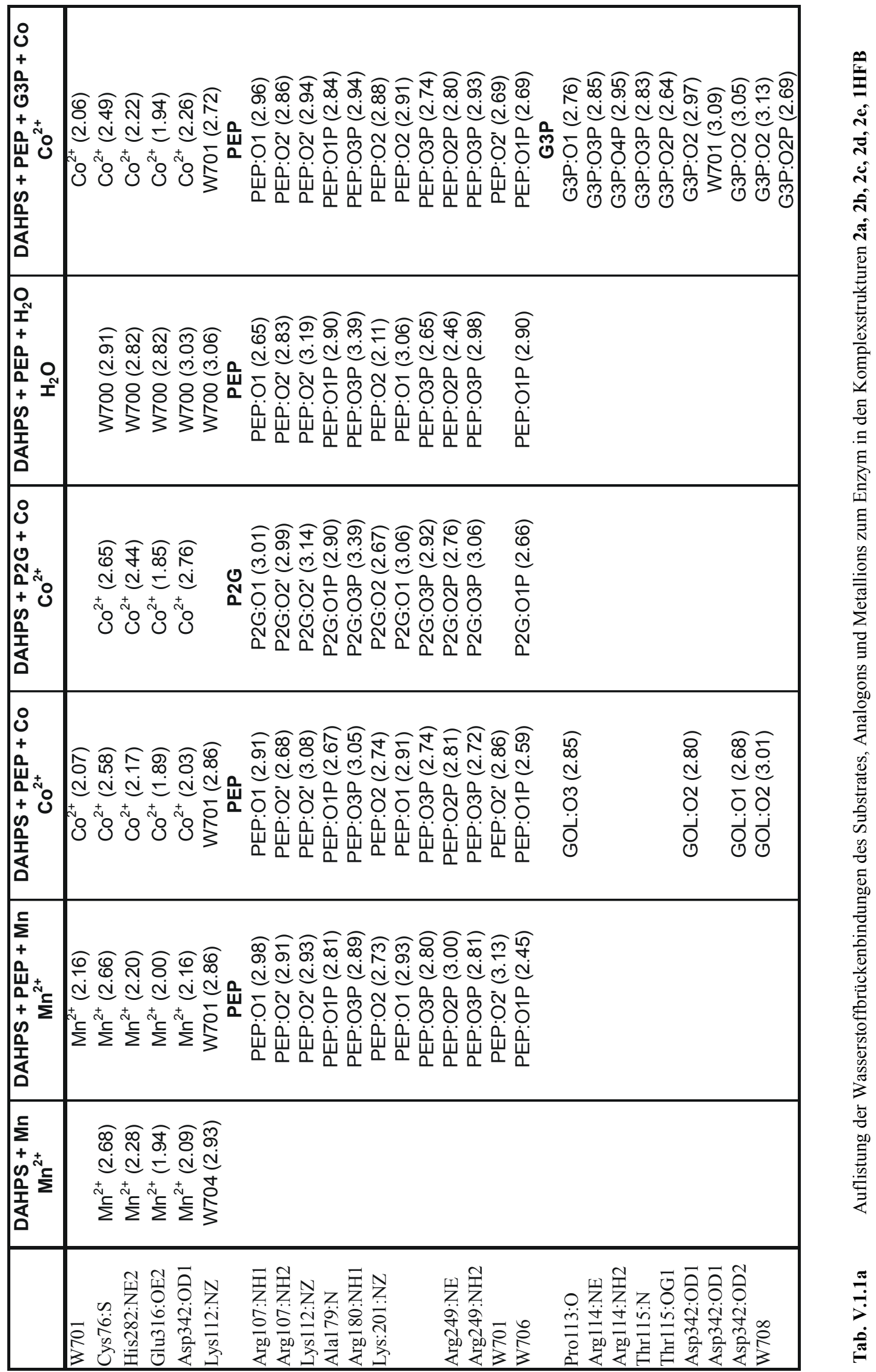




\section{V.1.2 Vergleiche innerhalb der Komplex-Strukturen}

Um die Strukturen und insbesondere die aktiven Zentren der verschiedenen Enzym-Komplexe zu vergleichen, wurde zunächst, da die asymmetrischen Einheiten der untersuchten Kristallformen jeweils mehrere Moleküle enthielten, ermittelt, inwieweit sich die Strukturen innerhalb einer Kristallstruktur unterscheiden. Hierzu wurden die kristallographisch unabhängigen Moleküle mit dem Programm ESCET [Schneider 2002] bei einem $\sigma$-Wert von 2.0 untersucht. In den Raumgruppen $\mathrm{P} 1_{\mathrm{gr}}$ und $\mathrm{P} 1_{\mathrm{kl}}$ sowie $\mathrm{C} 2$ konnten jeweils $98 \%$ der $\mathrm{C}_{\alpha}$-AtomPositionen als konformationell invariant identifiziert und als strukturell identisch angesehen werden [Schneider 2002]. Für die weiteren Vergleiche dieser Strukturen untereinander wurden jeweils die Moleküle mit der niedrigsten Standardabweichung gewählt (Molekül D aus 1a, Molekül Daus 2c, Molekül D aus 3a, Molekül A aus 4a, Molekül B aus 4b, Molekül B aus 4c, Molekül A aus 4d, Molekül A aus 4e).

\section{V.1.2.1 Vergleich innerhalb der Mangan(II)-Komplex-Strukturen (3a, 4a)}

Vergleicht man die vier kristallographisch unabhängigen Moleküle in der trigonalen Kristallform untereinander, so weisen sie in ihren Strukturen erhebliche Unterschiede auf. Anhand der bei $1.5 \sigma$ berechneten Distanzmatrizen erkennt man, dass jeweils Molekül A und Molekül C bzw. Molekül B und Molekül D strukturell ähnlich sind, während sich die beiden Monomere eines Dimers unterscheiden (siehe Abb.V.1.2.1a:A). Die konformationell verschiedenen Enzymbereiche sind in $A b b$. V.1.2.1a:B farbig hervorgehoben.

$\begin{array}{cllll} & \text { A } & \text { B } & \text { C } & \text { D } \\ \text { <esd> [A] } & 0.25 & 0.25 & 0.25 & 0.24 \\ \text { A } & & 88.9 * & 99.9 * & 88.1 \\ \text { B } & & & 89.2 * & 99.8 * \\ \text { C } & & & & 88.5 \\ \text { D } & & & & \end{array}$

\section{A}

Abb. V.1.2.1a kristallographisch unabhängigen Molekülen der Struktur 3a bei einem sigma-Level von 1.5 aus einer Berechnung ohne NCS-restraints. Molekül A und C sowie Molekül B und D können als konformationell nahezu identisch angesehen werden, während sich die Monomere innerhalb eines Dimers (A und B bzw. C und D) in ihrer Konformation signifikant unterscheiden; B: Die bei $1.5 \sigma$ konformationell unterschiedlichen Enzymbereich sind im Topologiediagramm rötlich unterlegt. Neben den loops des aktiven Zentrums ist das dem TIM-Barrel zugefügte $\beta$-Faltblatt $\beta 6 \mathrm{a} / \mathrm{b}$ in diese Konformationsänderungen involviert. 


$\begin{array}{cllll} & \text { 4e } & \text { 3a_A } & \text { 3a_B } & \text { 2c } \\ \text { <esd> [A] } & 0.05 & 0.24 & 0.26 & 0.16 \\ \text { 4e } & & 88.7 & 97.6 & 88.8 \\ \text { 3a_A } & & & 97.2 & 93.1 \\ \text { 3a_B } & & & & 97.9 \\ \text { 2c } & & & & \end{array}$

\begin{abstract}
Abb. V.1.2.1b Kreuztabelle aus der Distanzmatrizenberechnung zwischen den konformationell unterschiedlichen Molekülen A und B der Struktur 3a und der Struktur des Doppelkomplexes 4e sowie der inhibierten Struktur 2c bei einem sigma-Level von 2.5. Signifikante konformationelle Unterschiede sind zwischen allen vier Molekülen vorhanden. Übereinstimmungen mit der aktiven oder inhibierten Konformation in Teilbereichen der unterschiedlichen Monomere aus 3a sind anhand der Tabellenwerte zu erkennen.
\end{abstract}

Da diese Bereiche im Kristallgitter unterschiedliche Konformationen annehmen, kann davon ausgegangen werden, dass es sich um Regionen handelt, die in Lösung flexibel sind. Sie liegen auf der Carboxylat-Seite des barrels in den Loopregionen L2, L3, L4, L5, L6 und reichen über die Helix $\alpha 5$ in das zusätzliche Faltblatt $\beta 6$ hinein (AS112-119, AS159-162, AS177-189, AS199-237, AS251-254).

Wichtige Bindungsstellen der beiden Substrate sowie Regionen, die für die Inhibierungsübertragung von Bedeutung sind (siehe Kap. V.2), weisen in den unterschiedlichen Mangan(II)-Komplexen teilweise eine Konformation auf, die der aktiven, teilweise aber auch die der inhibierten Struktur ähnelt (z. B. Arg180, Leu160, Glu111, Lys120, Lys112).

Anhand dieser Kristallstrukturen kann also vermutet werden, dass das nur mit dem Metall(IIkation komplexierte Enzym konformationell vergleichsweise flexibel ist und erst durch die Einlagerung des ersten Substrates PEP bzw. des Effektors Tyrosin in einer der beiden energetisch günstigen Konformationen, der aktiven bzw. der inhibierten Form, festgehalten wird.

\title{
V.1.2.2 Vergleich zwischen der unkomplexierten Struktur (1a) und den Mangan(II)- Komplex-Strukturen (3a, 4a)
}

Der Vergleich der metallion- und substratfreien Struktur 1a mit der metall(II)komplexierenden Struktur in 3a und 4a verdeutlicht die strukturgebende Rolle des Metallions. Vier der in den Mangan(II)komplexen in unterschiedlichen Konformationen vorkommenden Enzymbereiche sind in der Elektronendichte der unkomplexierten Struktur 1a nicht zu erkennen und somit wahrscheinlich fehlgeordnet (vgl. Tab. IV.4c, Abb. V.1.1.6a und Abb. V.1.2.1a). Betrachtet man die Metallionenbindungsstelle, stimmt von den Positionen der Liganden in der unkomplexierten lediglich die Position des Cysteins mit seiner Lage im Metallionkomplex überein. Während der gesamte loop des His282 fehlgeordnet ist, ist vom 
Glu316 lediglich die Hauptkette modellierbar. Die Position des Asp342 bewegt sich mit seinem im Metallionkomplex an das Kation bindenden Sauerstoffatom um $1.6 \AA$ von der Metallionbindungsstelle weg. Neben den loops L6 und L8, die für das aktive Zentrum strukturgebend sind, in dieser leeren Struktur nicht modelliert werden konnten, sind viele Seitenketten innerhalb der Bindungstasche fehlgeordnet (z. B. Glu158, Arg180, Arg249). Anhand dieses Strukturvergleichs wird deutlich, dass das Metallkation durch die koordinierende Wirkung auf seine Liganden nicht nur diese, sondern auch die sie umgebenden Loopbereiche stabilisiert und somit der aktiven Tasche des Enzyms seine für die katalytische Reaktion essentielle Struktur gibt.

\section{V.1.2.3 Vergleich der Mangan(II)-Komplex-Struktur (4a) und der PEP- Mangan(II)-Komplex-Struktur (4b) im monoklinen Kristallsystem}

Der Vergleich der mangan(II)komplexierten Struktur 4a in der Raumgruppe C2 mit der sowohl mit Mangan(II) als auch mit PEP komplexierten Struktur in C2 ergibt keine großen strukturellen Unterschiede $\left(99.7 \%\right.$ der $\mathrm{C}_{\alpha}$-Atome sind konformationell invariant bei einem $\sigma$ Wert von 2). Die Bindungsstelle des PEP, die schon in Kap. V.1.1.2 näher beschrieben wurde, wird in der substratfreien Struktur durch zwei Wassermoleküle (W716 und W718) ersetzt, die schwache Wasserstoffbrückenbindungen $\mathrm{zu}$ den PEP-bindenden Aminosäuren Arg107, Lys201 und Arg24 ausbilden. Der bemerkenswerteste Unterschied ist das die bipyramidale Koordinationssphäre des Metallions vervollständigende Wassermolekül W701. Es befindet sich in einem Abstand von $2.16 \AA$ zum Metallion und im Wasserstoffbrückenbindungsabstand von $3.18 \AA$ zum Sauerstoffatom der Carboxylatgruppe des PEP. Die Abstände zu den die Doppelbindung ausbildenden Kohlenstoffatomen C3 und C2 betragen 2.86 und $3.40 \AA$ (siehe Abb. V.1.1.2a).

\section{V.1.2.4}

\section{Vergleich zwischen der Cobalt(II)-PEP-Komplex-Struktur (4c) und der PEP-Komplex-Struktur $1 \mathrm{HFB}$}

Die für die aktive Tasche strukturgebende Funktion des Metallions wurde schon durch den Vergleich der Struktur des leeren (1a) mit der des mangan(II)haltigen Enzyms (2a, 3a, 4a) gezeigt. Vergleicht man nun die Struktur des metallionfreien PEP-Komplexes 1HFB [Hartmann 2002 eingereicht] mit der mit Cobalt(II) und PEP komplexierten Struktur (4c), so zeigen sich weitere Aufgaben des Metallions. 

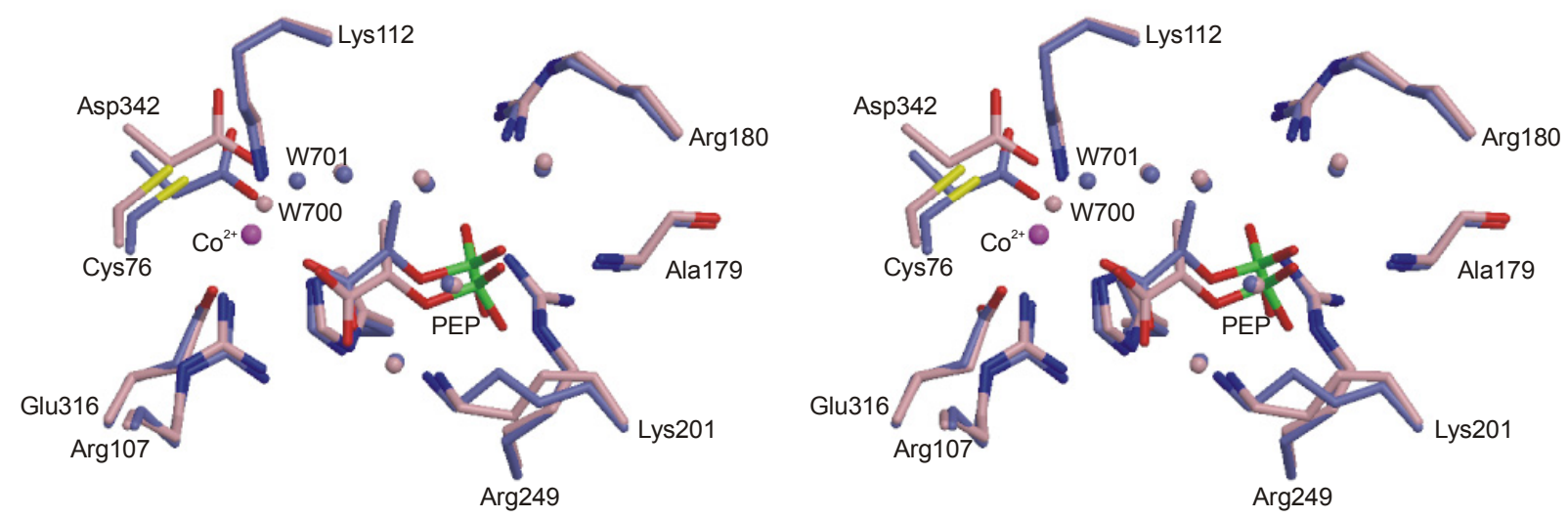

\begin{abstract}
Abb. V.1.2.4a
Stereographische Darstellung der superpositionierten aktiven Zentren der Strukturen 2b (lila) und 1HFB (rosa). Die Position des das Metallion ersetzenden Wassermoleküls W700 liegt zwischen der Position des Metallions und der des an ihn koordinierenden Wassermoleküls W701. Die trigonal bipyramidale Koordination des Metallions in 2b wird für das Wassermolekül in 1HFB nicht aufrecht erhalten, Asp342 zieht sich mit seinem gesamten loop aus der Bindungstasche zurück. Die Position des PEP schiebt sich um im Mittel $0.7 \AA$ aus der Bindungstasche heraus. Die auf der re-Seite des PEP fixierten Wassermoleküle (entsprechend der Strukturen gefärbt) behalten ihre Positionen bei.
\end{abstract}

Während es dem leeren Enzym an Stabilität der aktiven Tasche fehlt, ist in dem metallionfreien PEP-Komplex das Substrat die Komponente, die die Struktur des aktiven Zentrums aufrecht erhält. Fehlgeordnete Bereiche werden in der aktiven Tasche nicht beobachtet.Die verzerrt tetragonal bipyramidale Koordination des Wassermoleküls W700, das das Metallion in dieser Struktur ersetzt, wurde in Kap. V.1.1.3 beschrieben. Durch das Fehlen des Metallkations ist auch das koordinierende Wassermolekül W701 in der metallionfreien Struktur nicht vorhanden. Auffällig ist auch hier, dass sich durch das fehlende Metallion das Asp342 aus der Bindungstasche zurückzieht und mit ihm der gesamte loop L8. Dadurch, dass das Wassermolekül W700 im Vergleich zum Metallion aus der Bindungsstelle um $1.2 \AA$ herauswandert, braucht das das PEP koordinierende Lys112 seine Position nicht zu verändern, um eine Wasserstoffbrückenbindung zu diesem Wassermolekül aufzubauen. Vergleicht man nun die Lage des PEP zwischen metallionhaltiger und metallionfreier Struktur, so beobachtet man eine signifikante Substratverschiebung (Abb. V.1.2.4a). Das Substrat PEP wird in der metallionhaltigen im Vergleich zur metallionfreien Struktur um im Mittel $0.7 \AA$ in die Richtung der vermuteten E4P-Bindungsstelle verschoben. Das Metallion ist also nicht nur für die Strukturgebung der aktiven Tasche notwendig, sondern auch für die optimale Positionierung des ersten Substrates. Die das PEP komplexierenden Liganden ändern ihre Position nicht signifikant, so dass das Vorhandensein des Metallions sowohl zu Verlängerungen als auch zu Verkürzungen der Wasserstoffbrücken führt, die das Substrat binden. Da das Metallion jedoch nicht direkt mit dem PEP in Wechselwirkung tritt, müssen für die Positionsänderung indirekt auf das Metallion zurückzuführende Gründe vorliegen. Die 
einzige neben dem Metallion selbst vorhandene, signifikante Veränderung in den Strukturen ist das Wassermolekül W701, welches das Metallion koordiniert. Wie schon in Kap. V.1.1.2 beschrieben, bildet es nicht nur zu dem PEP koordinierenden Lys 112 eine Wasserstoffbrücke, sondern ebenfalls zur Carboxylatgruppe des PEP eine mit $2.8 \AA$ recht starke Bindung aus. Die Abstände von $3.4 \AA$ zu PEP:C2 und $2.9 \AA$ zu PEP:C3 weisen auf eine zusätzliche Wechselwirkung des Wassermoleküls mit dem $\pi$-System der Doppelbindung des PEP hin. Dieser Strukturvergleich zeigt, dass an der Positionierung des ersten Substrates nicht nur das Metallion selbst, sondern auch das daran koordinierende Wassermolekül mitwirkt.

\section{V.1.2.5 Vergleich zwischen den Metall(II)-PEP-Komplex-Strukturen (4b und 4c)}

Um den Einfluss der unterschiedlichen Metall(II)ionen auf die Aktivierung des durch EDTA aufgereinigten Enzyms zu untersuchen, wurde das Enzym zum einen mit Cobalt(II) (4c, 4d, 4e), das die Aktivität des Enzyms im Vergleich zum nativen Zustand um 167\% erhöht, und zum anderen mit Mangan(II) (1b, 2a, 2b, 2c, 2d, 3a, 4a, 4b) komplexiert, das die Aktivität des Enzyms nur zu etwa 20\% wiederherstellen kann [Schnappauf 1998]. Die Strukturen lassen sich mit einer mittleren rms-Differenz von $0.1 \AA$ übereinander legen, so dass sie als identisch angesehen werden können. Vergleicht man die Koordinationssphäre der Metallionen der Strukturen 4b und $\mathbf{4 c}(T a b . V .1 .1 a)$, so ist eine Tendenz zu minimal kürzeren Bindungslängen im Cobalt(II)komplex zu erkennen. Diese Tendenz ist auf den kleineren Ionenradius (0.72 $\AA$ für $\mathrm{Co}^{2+} \mathrm{im}$ Vergleich $\mathrm{zu} 0.80 \AA$ für $\mathrm{Mn}^{2+}$ [Hollemann 1985]) zurückzuführen. Doch lassen sich durch diese im Vergleich zu den Koordinatenfehlern wahrscheinlich nicht signifikanten Änderungen nicht die großen Aktivitätsunterschiede der unterschiedlichen Metallionenkomplexe erklären. Die Aktivitätsunterschiede sind demnach für die Metallionen der ersten Übergangsreihe weniger auf strukturelle Veränderungen im Enzym als auf die unterschiedlichen chemischen Eigenschaften der Metallionen zurückzuführen, wie z. B. unterschiedliche Koordinationseigenschaften und damit einhergehende Ligandenfeldstabilisierungen, unterschiedliche Bevorzugung von harten oder weichen Liganden sowie die Fähigkeit, Wassermoleküle oder Carbonylgruppen zu aktivieren, bzw. $\mathrm{pK}_{\mathrm{a}}$-Werte $\mathrm{zu}$ erniedrigen. Hingegen lassen sich strukturelle Unterschiede $\mathrm{zu}$ dem mit einem Blei(II)-Ion komplexierten Metallionzentrum in der Struktur der phe-sensitiven DAHP Synthase aus E. coli (1QR7) vermutlich auf die unterschiedliche Radiengröße und das äußere Elektronenpaar des Blei(II)-Ions zurückführen (siehe Kap. V.1.3.1.1). 
V.1.2.6

Vergleich zwischen der Cobalt(II)-PEP- und der Cobalt(II)-P2GKomplex-Struktur

Vergleicht man die Strukturen des mit Cobalt(II) und PEP komplexierten Enzyms (4c) mit der Struktur, die mit Cobalt(II) und dem PEP-Analogon P2G komplexiert wurde (4d), so lassen sich auch diese beiden Strukturen mit einer rms-Differenz von $0.1 \AA$ übereinander legen, so dass sie als identisch angesehen werden können. Betrachtet man die aktiven Zentren näher, die sich prinzipiell nur durch die Doppelbindung des Substrates unterscheiden, so erkennt man auch hier eine zwar mit im Mittel $0.4 \AA$ nicht so starke, aber doch signifikante Substratverschiebung. Die Position des Substratanalogons P2G ist im Vergleich zu Struktur 4c vom Metallion und der Bindungsstelle des zweiten Substrates weggerückt. Bemerkenswerterweise fehlt auch in diesem Fall (wie bei der nur mit einem Metallion komplexierten Struktur) das an das Metallion koordinierende Wassermolekül W701. Vergleicht man die B-Werte des metallionkoordinierenden Wassermoleküls mit den übrigen in der aktiven Tasche positionierten Wassermoleküle, so zeigt sich, dass die metallionkoordinierende Wassermolekülposition sehr flexibel zu sein scheint. Der über die Strukturen $\mathbf{4 b}, \mathbf{4 c}$ und $\mathbf{4 e}$ gemittelte B-Werte des metallionkoordinierenden Wassermoleküls W701 beträgt $26.9 \AA^{2}$, während der Mittelwert der restlichen Wassermoleküle in der aktiven Tasche W702-W709 bei $19.3 \AA^{2}$ liegt. Andererseits zeigt sich, dass die Existenz dieses Wassermoleküls Einfluss auf die Position des Substrates PEP innerhalb des Enzyms zu haben scheint (s. o.).

\section{V.1.2.7 Vergleich zwischen der Cobalt(II)-PEP- und der Cobalt(II)-PEP- G3P-Komplex-Struktur}

Ein Vergleich der Strukturen 4c und 4e in der Raumgruppe C2 zeigt trotz Einlagerung des E4P-Analogons G3P erstaunlicherweise keine signifikanten konformationellen Änderungen. Die Einlagerung des zuerst bindenden Substrates PEP scheint also die Konformation der aktiven Tasche für das Binden des zweiten Substrates vorzubereiten. Lediglich die leicht verringerten B-Werte des loops L2 in der Struktur 4e im Vergleich zur Struktur 4d weisen auf eine Stabilisierung dieses loops durch Anlagerung des Substrat-Analogons G3P hin, die nach Bindung des zweiten Substrates (4e) nicht mehr gegeben ist. 


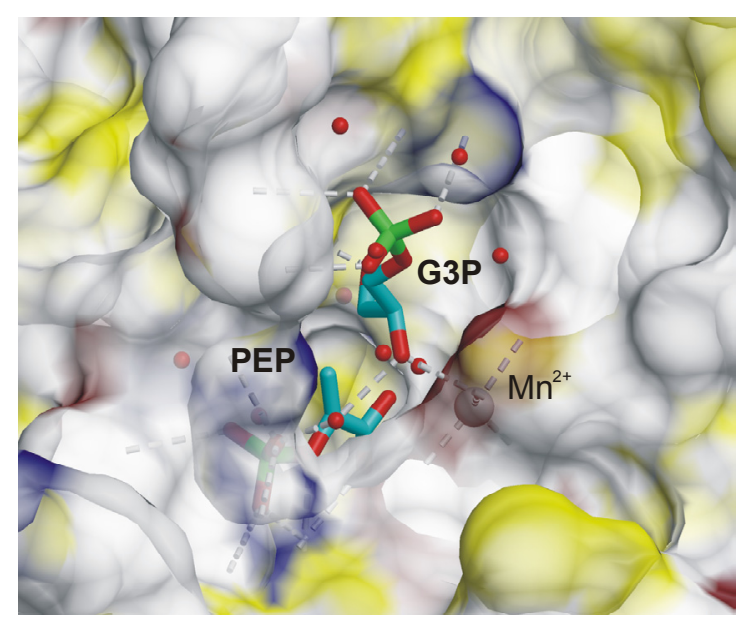

Abb. V.1.2.7a Transparente Oberflächendarstellung [DINO 2001, Sanner 1996] des aktiven Zentrums. Während das erste Substrat PEP im aktiven Zentrum gut von der Umgebung abgeschirmt ist, liegt das E4P-Analogon G3P frei zugänglich am Eingang der Bindungstasche.

Aus $A b b$. V.1.2.7a werden die unterschiedlichen $\mathrm{K}_{\mathrm{m}}$-Werte der beiden Substrate verständlich. Während PEP im aktiven Zentrum weitgehend von der Umgebung abgeschirmt ist, liegt das zweite Substrat (bzw. hier sein Analogon) relativ frei zugänglich am Einlass der Bindungstasche. Demzufolge besitzt PEP als zuerst bindendes Substrat einen mit $125 \mu \mathrm{M}$ wesentlich geringeren $\mathrm{K}_{\mathrm{m}}$-Wert als das der Umgebung ausgesetzte, zweite bindende Substrat E4P mit $500 \mu \mathrm{M}$ [Schnappauf 1998].

Lagert man nun alle unterschiedlichen Komplexvarianten übereinander, so fällt auf, dass die aktive Tasche durch die Einlagerung der Substrate innerhalb einer Kristallform keinen wesentlichen Konformationsänderungen unterliegt. Auffällig ist die unterschiedliche Lage des PEP. Vergleicht man die Wassermolekülpositionen der unterschiedlichen Komplexe in der aktiven Tasche, so scheinen sie mit Ausnahme des am Metall(II)ion koordinierten Wassermoleküls W701, weitgehend equivalent zu sein. Die im Komplex 4e mit G3P besetzten Hydroxylgruppen-Bindungsstellen sind in den Strukturen 4a-d systematisch mit Wassermolekülen besetzt. Ein in der Struktur 4c durch die Behandlung mit Cryoprotektand eindiffundiertes Glycerolmolekül besetzt mit seinen Hydroxylgruppen ebenfalls die Bindungsstellen der G3P-Hydroxylgruppen sowie die eines Wassermoleküls (siehe Abb. V.1.2.7b). Die Tatsache, dass die gesamte Bindungstasche, sofern das erste Substrat ersteinmal gebunden ist, sehr rigide zu sein scheint, wird durch die erstaunliche Invarianz der Hydroxyl- bzw. Wassermolekülbindungsstellen bestärkt. Dies lässt vermuten, dass auch während der Katalysereaktion weder die Substrate noch die aktive Tasche großen Konformationsänderungen unterworfen werden. 

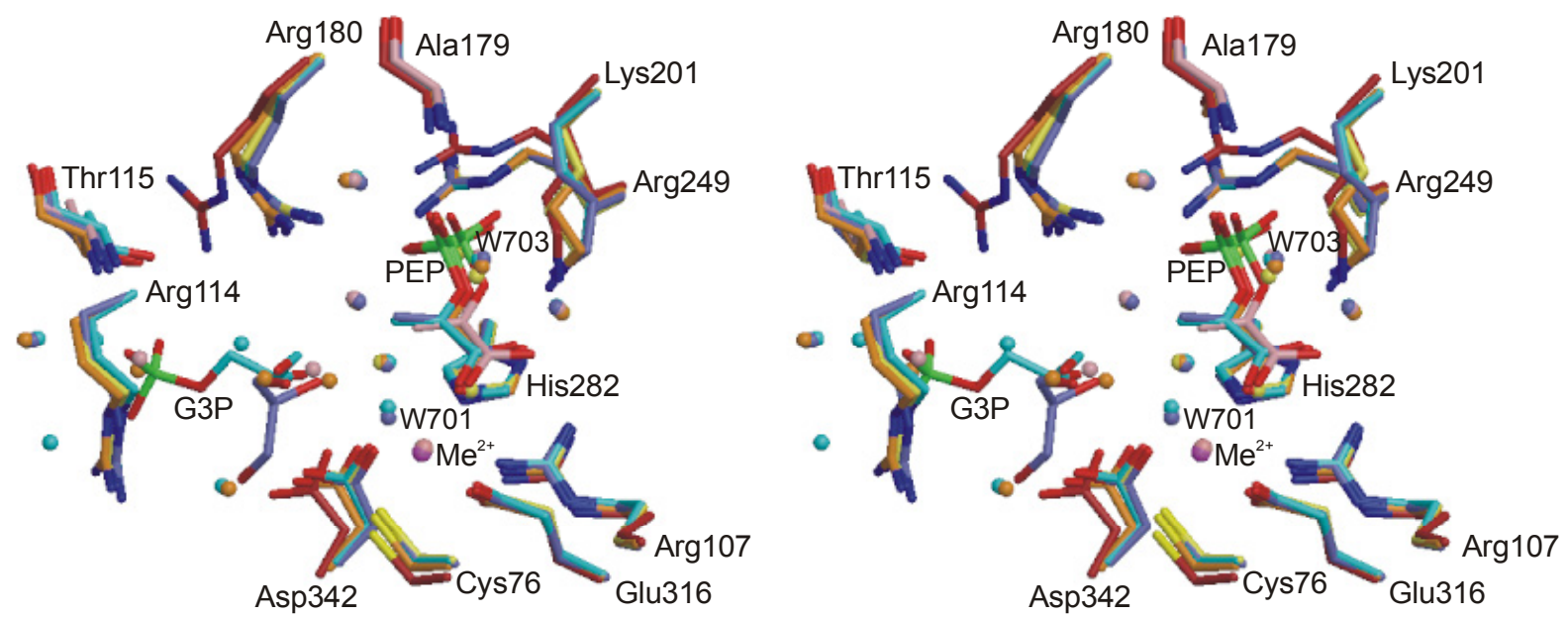

Abb. V.1.2.7b

Stereographische Darstellung der Superpositionierung der aktiven Zentren aus den Strukturen 1a (braun), 4a (gelb), 4c (blau), 4d (orange), 4e (türkis) und 1HFB (rosa). Die Wassermoleküle wurden den Strukturen entsprechend eingefärbt. Auffällig ist die hohe Rigidität der Bindungstasche nach Binden des Substrates PEP sowie die Konsistenz der Wassermolekülpositionen. Sauerstoffatompositionen der Substrate werden im nicht beladenen Zustand systematisch von Wassermolekülen oder einem Glycerolmolekül ersetzt. Lediglich die Position des an das Metallion koordinierenden Wassermoleküls W701 ist nur bei Vorhandensein des PEP besetzt.

\section{V.1.3 Literaturvergleich}

V.1.3.1 Strukturvergleiche mit Komplexen der phe-sensitiven DAHP Synthase aus E. coli

[Shumilin 1999; Wagner 2000]

Zur Zeit existieren aus der Vielzahl der DAHP Synthasen Kristallstrukturen zweier Isoenzyme, der hier näher untersuchten tyr-sensitiven DAHP Synthase aus $S$. cerevisiae und der phe-sensitiven DAHP Synthase aus E. coli [Shumilin 1999; Wagner 2000].

Mit einer Homologie von 54\% zwischen den Peptidsequenzen dieser zwei Isoenzyme [Altschul 1990], können $300 \mathrm{C}_{\alpha}$-Atomen (entsprechend 81\% der Hauptkette) [Holm 1993] mit einer mittleren rms-Differenz von lediglich $0.51 \AA$ superpositioniert werden [Kabsch 1976].

\section{V.1.3.1.1 Vergleich zwischen der Struktur der phe-sensitiven DAHP Synhase aus E. coli komplexiert mit Blei(II) und PEP (1QR7) und der Cobalt(II)-PEP- Komplex-Struktur $4 c$}

Ein Vergleich der Metallion- und PEP-Bindungsstelle, für den die Hauptkettenatome der metallionkoordinierenden Aminosäuren überlagert wurden (rms-Differenz $=0.20 \AA$ ), zeigt eine in diesem Bereich stark konservierte Bindungstasche. Entscheidende Unterschiede in der 
Metall(II)koordinationssphäre und der PEP-Lage innerhalb der Tasche sind auf die unterschiedlichen, komplexierten Metallionen zurückzuführen. Im Fall der phe-sensitiven Struktur aus E. coli befindet sich ein zur Strukturlösung eingeführtes Blei(II)-Ion an der Metall(II)bindungsstelle. Das so komplexierte Enzym besitzt keine nennenswerte Enzymaktivität [Shumilin 1999]. Vergleicht man die $\mathrm{Pb}(\mathrm{II})$-Koordination mit der des Co(II)-Ions im tyr-sensitiven Enzym aus S. cerevisia (4c), so werden Unterschiede deutlich, die in diesem Fall (im Gegensatz zum Vergleich zwischen der Mn(II)- und der Co(II)-Koordinationssphäre) zum einen tatsächlich auf den Radienunterschied der Kationen, zum anderen aber auch auf die spezielle Elektronenkonfiguration des $\mathrm{Pb}$ (II)-Ions zurückzuführen sind. Um die Radiengrösse (1.2 ^ [Hollemann, 1985]) des Pb(II)-Ions auszugleichen, werden im Vergleich zur Koordination in Struktur 4c sämtliche Seitenketten der Metallionkoordiantionssphäre aus ihrer ursprünglichen Position herausgedrängt. Die Koordinationsart des Asp302 (entspricht Asp342 in 4c) wechselt von mono- zu bident. Dies könnte ein entscheidender Grund für die Inaktivierung des Enzyms durch $\mathrm{Pb}$ (II)-Ionen sein, da die Struktur 4e eine wichtige Substratbindung des E4P-Analogons G3P über diese Aminosäure an das Enzym zeigt (siehe Abb. V.1.1.5a).
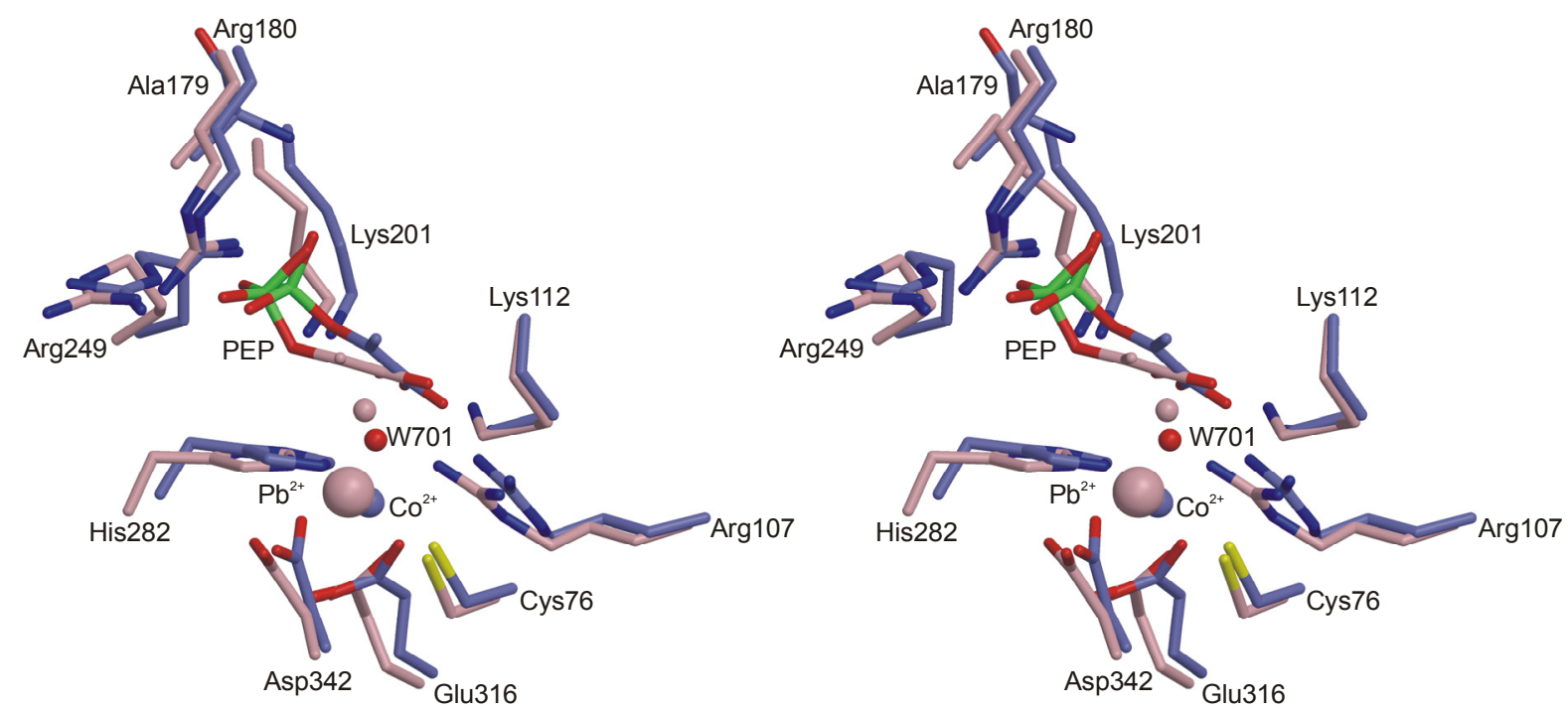

\begin{abstract}
Abb. V.1.3.1.1a
Stereographische Darstellung der superpositionierten aktiven Zentren der Strukturen 4c (tyr-sensitive DAHP Synthase aus S. cerevisiae, blau) und 1QR7 (phe-sensitive DAHP Synthase aus E. coli, altrosa). Die Beschriftung der Aminosäuren bezieht sich auf die Struktur 4c. Erkennbar ist die Aufweitung des aktiven Zentrums durch den im Vergleich zum $\mathrm{Co}^{2+}$-Ion größeren Ionen-Radius des $\mathrm{Pb}^{2+}$ in $\mathbf{1 Q R 7}$. Das in die Bindung des E4P involvierte Asp342 liegt hier als das Metallion bident koordinierendes Rotamer vor. Es besteht eine Wechselwirkung zwischen dem $\mathrm{Pb}$ (II)-Ion und PEP, das eine Konformationsänderung des Substrates hervorruft.
\end{abstract}

Das an das Metallion koordinierende Wassermolekül ist als solches nicht vorhanden, jedoch befindet sich $2.5 \AA$ versetzt ein schlecht lokalisiertes Wassermolekül (siehe Abb. V.1.3.11a). Das Pb(II)-Ion selbst ist im Vergleich zur Co(II)-Position um $0.7 \AA$ aus der Bindungstasche 
heraus verschoben. Die Salz- und Wassertoffbrückenbindungspartner des PEP sind in beiden Strukturen die gleichen. Es wird eine Konformationsänderung und Drehung des Substrates innerhalb der aktiven Taschen beobachtet. Während der Torsionswinkel C3-C2-O2-P des PEP im Fall des Co(II)-Komplexes $3^{\circ}$ beträgt und die Phosphatgruppe zur Doppelbindung eine energetisch günstige, gestaffelte anti-Konformation annimmt, liegt der Torsionswinkel C3C2-O2-P im Blei(II)-Komplex bei $68^{\circ}$. Das Pyruvat-Gerüst wird aufgrund der Wechselwirkungen zum Metallion gezogen und die Phosphatgruppe dreht sich relativ zu ihren vorgegebenen Bindungsstellen heraus (siehe $A b b$.V.1.3.1.1a). Diese Unterschiede sowohl in bezug auf die Orbitalwechselwirkungen als auch auf die stereochemischen Aspekte machen den Aktivitätsverlust des mit Blei(II) beladenen Enzyms im Gegensatz zum mit Cobalt(II) beladenen Enzym verständlich. Die Sulfatbindungsstelle in der phe-sensitiven Struktur, die als Phosphat-Bindungsstelle des E4P postuliert wurde, entspricht mit leichter Versetzung $(0.7 \AA)$ und Orientierung tatsächlich der Phosphatbindungsstelle des E4PAnalogons G3P. Das unterschiedliche Rotamer des das Sulfat- bzw. Phosphation bindenden Arg114 lässt sich eventuell auf die unterschiedliche Bindungsgeometrie zurückführen und weist auf die Flexibilität dieser Seitenkette hin.

\section{V.1.3.1.2 Strukturvergleich zwischen der phe-sensitiven DAHP Synhase aus E. coli komplexiert mit Mangan(II) und dem PEP-Analogon P2G (1GG1) und der Cobalt(II)-P2G-Komplex-Struktur 4d}
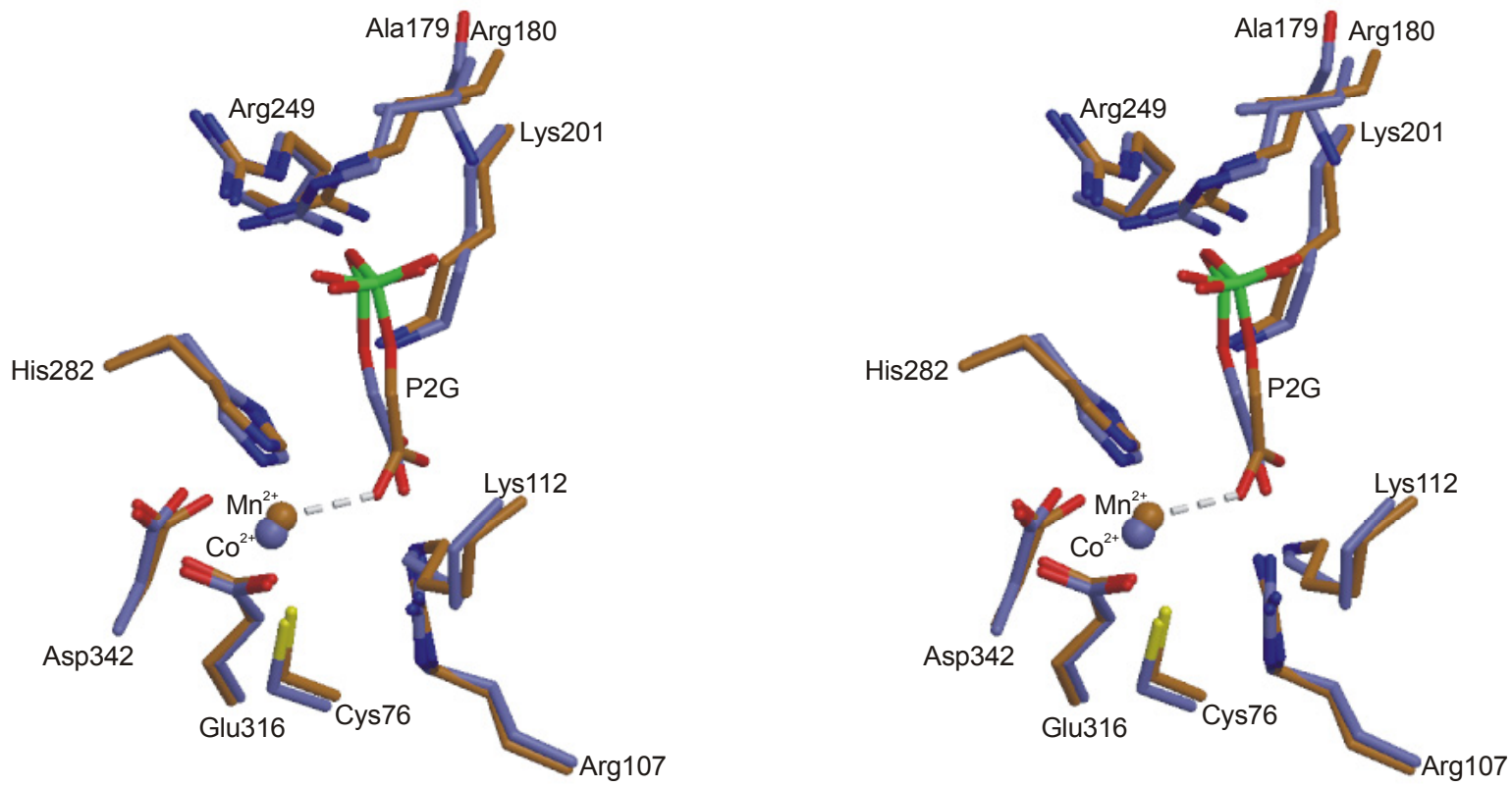

Abb. V.1.3.1.2a

Stereographische Darstellung der superpositionierten aktiven Zentren der Strukturen 4d (tyr-sensitive DAHP Synthase aus $S$. cerevisiae, blau) und 1GG1 (phe-sensitive DAHP Synthase aus E. coli, braun) jeweils komplexiert mit einem Metallion $\left(\mathrm{Mn}^{2+}\right.$ bzw. $\left.\mathrm{Co}^{2+}\right)$ und dem PEP-Analogon P2G. Erkennbar ist die unterschiedliche Koordination des Metallions. Während Das P2G in 4d keine direkte Wechselwirkung mit dem Metallion aufbaut, wird es in 1GG1 durch die Carboxylatgruppe des P2G koordiniert. 
Der zweite von der phe-sensitiven DAHP Synthase aus E. coli existierende Komplex enthält ein Mn(II)-Ion und das PEP-Analogon P2G [Wagner 2000] und sollte der Struktur 4d im Prinzip entsprechen. Lagert man jedoch wiederum die Hauptkettenatome der metallionkoordinierenden Aminosäuren übereinander (rms-Differenz $=0.27$ ), so beobachtet man entscheidende Unterschiede. Während sich das P2G in der Struktur 4d im Vergleich zum PEP in der Struktur 4c wie in Kap. V.1.2.5 beschrieben, leicht in seiner Position relativ zum Metallion verschiebt, ändert sich in den Strukturen der phe-sensitiven Enzyme aus E. coli (1GG1 bzw. 1QR7) die Lage des P2G zum Mn(II)-Ion im Vergleich zum PEP im mit Pb(II) komplexierten Enzym grundlegend. Dies hat wahrscheinlich zum einen die maßgebliche Ursache im Wechsel des Metallions und zum anderen im Austausch des Substrates durch sein Analogon, so dass aus diesen Unterschieden schlecht Rückschlüsse auf den Mechanismus gezogen werden können. Der Vergleich der beiden P2G-Komplex-Strukturen (4d und 1GG1) zeigt unerwarteterweise unterschiedliche Metallion-Koordinationen. Das Co(II)-Ion ist in der Struktur 4d, wie auch im substratfreien Komplex, trigonal bipyramidal von seinen Liganden umgeben, die dritte äquatoriale Position bleibt jedoch unbesetzt. In der Struktur des phesenitiven Enzyms dreht sich die Carboxylatgruppe des PEP-Analogons P2G so, dass sie in einem Molekül der asymmetrischen Einheit mit einem Sauerstoffatom die Metallionumgebung zu einer verzerrten trigonal bipyramidalen, in dem anderen Molekül der asymmetrischen Einheit mit einem zusätzlichen Wassermolekül zu einer verzerrt oktaedrischen Koordinationssphäre auffüllt. Diese Tatsache wurde in der Literatur [Wagner 2000] als Hinweis darauf gedeutet, dass das PEP im Fall eines Mn(II)-Ions anstatt des Pb(II)-Ions ebenfalls an das Metallion koordiniert. Dies kann jedoch anhand der Strukturen $\mathbf{4 b}$ und $\mathbf{4 c}$ für das tyr-sensitive Enzym aus S. cerevisiae ausgeschlossen werden, da das Substrat in beiden Fällen keine direkte Wechselwirkung mit dem Metallion ausbildet. Warum das Substrat-Analogon P2G allerdings im Mn(II)-Komplex 1QR7 einmal eine trigonal bipyramidale Koordinationssphäre und einmal eine oktaedrische Koordinationssphäre aufweist, im Fall des Co(II)-Komplexes 4d jedoch nicht mit dem Metallion in Wechselwirkung tritt, bleibt fraglich. Unwahrscheinlich ist, dass hier die Art des Metallions (Co(II) im Vergleich zu Mn(II)) eine Rolle spielt, da beide Ionen sowohl in oktaedrischer als auch in trigonal bipyramidaler Umgebung in der Natur vorzufinden sind [Holm 1996]. Realistischer ist die Annahme, dass sich das am C2Atom $\mathrm{sp}^{3}$-hybridisierte Substrat-Analogon, das damit dem Endprodukt gleicht, in unterschiedlichen, energetisch ähnlichen Positionen in die aktive Tasche einfügen kann. Dies würde den Prozess der Produktfreisetzung erleichtern. 


\section{V.1.3.2 Strukturvergleiche mit Komplexen der mechanistisch verwandten KDOP Synthasen}

[Radaev 1999; Duewel 2000, Asojo 2001, Wang 2001]

Vergleicht man die Familie der KDOP Synthasen mit der der DAHP Synthasen, deren gemeinsame evolutionäre Abstammung trotz geringer sequenzieller Homologie diskutiert wird [Radaev 1999; Wang 2001], so fällt zunächst die große Gemeinsamkeit in der zu katalysierenden Reaktion auf. Beide katalysieren eine einer Aldolkondensation ähnliche, stereoselektive Verknüpfung eines PEP-Moleküls mit einer Aldose. Im Fall der DAHP Synthasen handelt es sich um den C-4 Zucker Erythrose-4-Phosphat (E4P), im Fall der KDOP Synthasen um den C-5 Zucker Arabinose-5-Phosphat (A5P). In beiden Reaktionen findet die Phosphatbindungsspaltung zwischen dem Kohlenstoff- und dem Sauerstoffatom statt. Während es von den DAHP Synthasen verschiedene durch ihre Endprodukte negativ feedback-regulierte Isoenzyme gibt, besitzen die KDOP Synthasen keine Regulierung. Ihre Klasse lässt sich in zwei Gruppen einteilen, in die der Metalloenzyme und die Gruppe der metallionfrei arbeitenden Synthasen. Überlagert man Teile des aktiven Zentrums (PEP, Cys67, His282 und Asp342 mit einer rms-Differenz von $0.47 \AA$ ) der tyr-sensitiven DAHP Synthase im Doppelkomplex mit PEP und dem E4P-Analogon G3P mit den analogen Bereichen des Metalloproteins KDOP Synthase aus Aquifex aeolicus (1FWW) komplexiert mit PEP und A5P, so stellt man eine große Überseinstimmung im Bereich der Metallion- und PEP-Bindungsstelle fest. Während die Metallionbindungsstellen der aktiven Taschen vollständig erhalten sind, finden in den PEP-Bindungsstellen der beiden Enzyme einige Austausche statt, die die Lage des PEP jedoch nicht wesentlich beeinflussen (siehe $A b b$. V.1.3.2a). Statt des die Carboxylatgruppe fixierenden Arg107 bildet in der KDOP Synthase das Lys41 eine starke Wasserstoffbrückenbindung zum Sauerstoff O1 aus, während das Sauerstoffatom O2' von einem in der DAHP Synthase nicht vorhandenen Gln99 fixiert wird. Die Phosphatbindungsstelle ist in beiden Enzymen fast vollständig identisch. Einziger, für die negative Rückkopplung (siehe Kap.V.2) jedoch wichtiger Unterschied ist die in der DAHP Synthase zusätzliche Fixierung der Phosphatgruppe durch das Arg180. Auch die Bindungsstelle der zweiten Substrate (E4P bzw. A5P) stimmen in bezug auf ihre Lage in der aktiven Tasche in beiden Strukturen überein. Die Phosphatbindungsstellen der beiden Substrate PEP/E4P bzw. PEP/A5P liegen im Fall der KDOP Synthase $10.3 \AA$ voneinander entfernt, im Fall der DAHP Synthase $9.5 \AA$ auseinander. Mit $0.8 \AA$ ist dieser Unterschied zu gering, als dass er eine Einlagerung der zusätzlichen C-OH-Einheit der A5P erklären würde. Dies weist auf eine unterschiedliche Orientierung der beiden Substrate innerhalb der Bindungstasche hin, die durch Unterschiede in der aktiven Tasche im Bindungsbereich der 
Zuckerkette des zweiten Substrates erklärt werden kann. In beiden Fällen wird die Phosphatgruppe durch Wasserstoffbrückenbindungen im loop L2 über Arg114 und Thr115 (bzw. ihre Analoga) festgehalten, doch findet in der KDOP Synthase eine zusätzliche Fixierung durch das Arg106 des Partner-Monomers innerhalb eines Dimers und durch das Ser197, das sich im loop L7 befindet, statt. In diesem, sich bei der Einlagerung schließenden loop, befindet sich auch das Gln188, das eine zusätzliche Bindung zum Sauerstoffatom A5P:O2 aufbaut. Der gesamte loop L7, der die aktive Tasche in der KDOP Synthase nach der A5P-Einlagerung von der Umgebung abschirmt, ist in den DAHP Synthasen nicht vorhanden, so dass bei ihnen die aktive Tasche während der Katalyse frei zugänglich bleibt. Auch für das Asn48 in der KDOP Synthase, das durch zwei zusätzliche Wasserstoffbrückenbindungen das Substrat fixiert, gibt es in der DAHP Synthase kein Analogon. In beiden Strukturen einheitlich ist die Bindung des Sauerstoffs O2 (G3P) bzw. O4 (A5P) an das das Metallion koordinierende Asp342 (bzw. Asp233 in der KDOP Synthase).
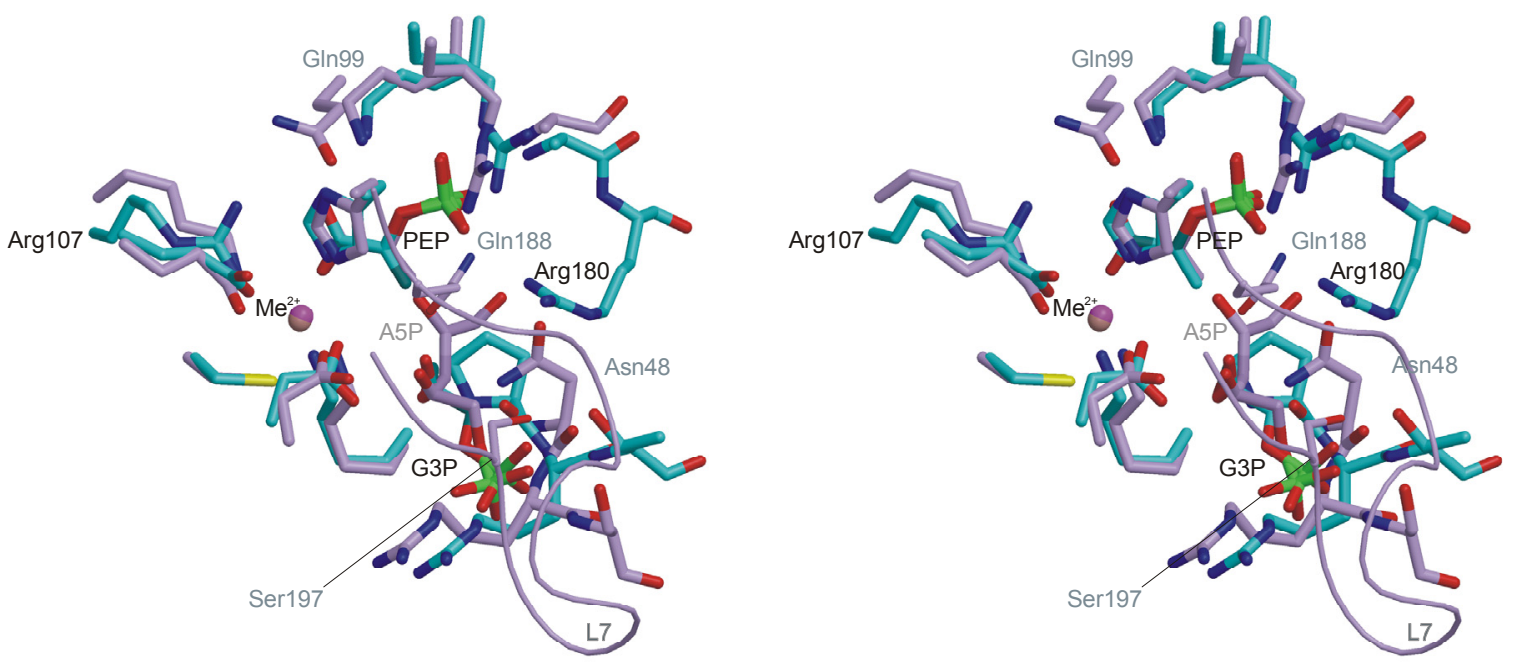

\begin{abstract}
Abb. V.1.3.2a Stereographische Darstellung der superpositionierten aktiven Zentren von 4e (tyrsensitive DAHP Synthase aus S. cerevisiae, türkis) und 1FWW (KDOP Synthase aus Aquifex aeolicus, lila). Die schwarze Beschriftung bezieht sich auf die Aminosäuren der DAHP Synthase, die graue auf in der KDOP Synthase zusätzliche Elemente. Die Lage und die Bindungspartner des Metallions und des PEP sind gut konserviert, während man in Lage und Bindungpartner der zweiten Substrate bzw. Analoga A5P und G3P Unterschiede erkennt. Der die aktive Tasche schließende loop L7 ist nur in der KDOP Synthase vorhanden.
\end{abstract}

Bemerkenswerterweise stimmen die Positionen des sich an die Phosphatgruppe anschließenden Zuckergerüstes trotz unterschiedlicher Bindungsstellen gut überein (siehe Abb. V.1.3.2a). Da die DAHP Synthase lediglich mit dem E4P-Analogon G3P komplexiert wurde, kann die Lage der während der Katalyse reagierenden Carbonylgruppe nur postuliert werden. Durch die Lage des in der KDOP Synthase nicht vorhandenen, für den Rückkopplungsmechanismus jedoch wichtigen Arg180, kann eine ähnliche Position der Carbonylgruppe wie die des A5P ausgeschlossen werden (siehe Abb. V.3.2a). Auch im Fall 
der KDOP Synthasen verläuft die Reaktion über einen Angriff eines Wassermoleküls auf das Substrat PEP. Vergleicht man die Positionen der für diesen Angriff in Frage kommenden Wassermoleküle (siehe Kap. V.1.4), so findet man auch hier eine bemerkenswerte Übereinstimmung (in der Abbildung nicht dargestellt). Durch die unterschiedliche Lage der anzugreifenden Carbonylgruppen muss der Reaktionsverlauf in den beiden Enzymen stereochemisch jedoch leicht unterschiedlich verlaufen.

Ein Gesamtvergleich der Aminosäuresequenzen der beiden Enzymfamilien zeigt mit 10\% identischen oder konservativ ausgetauschten Aminosäuren [Altschul 1990] zunächst keine offensichtlichen Homologien.
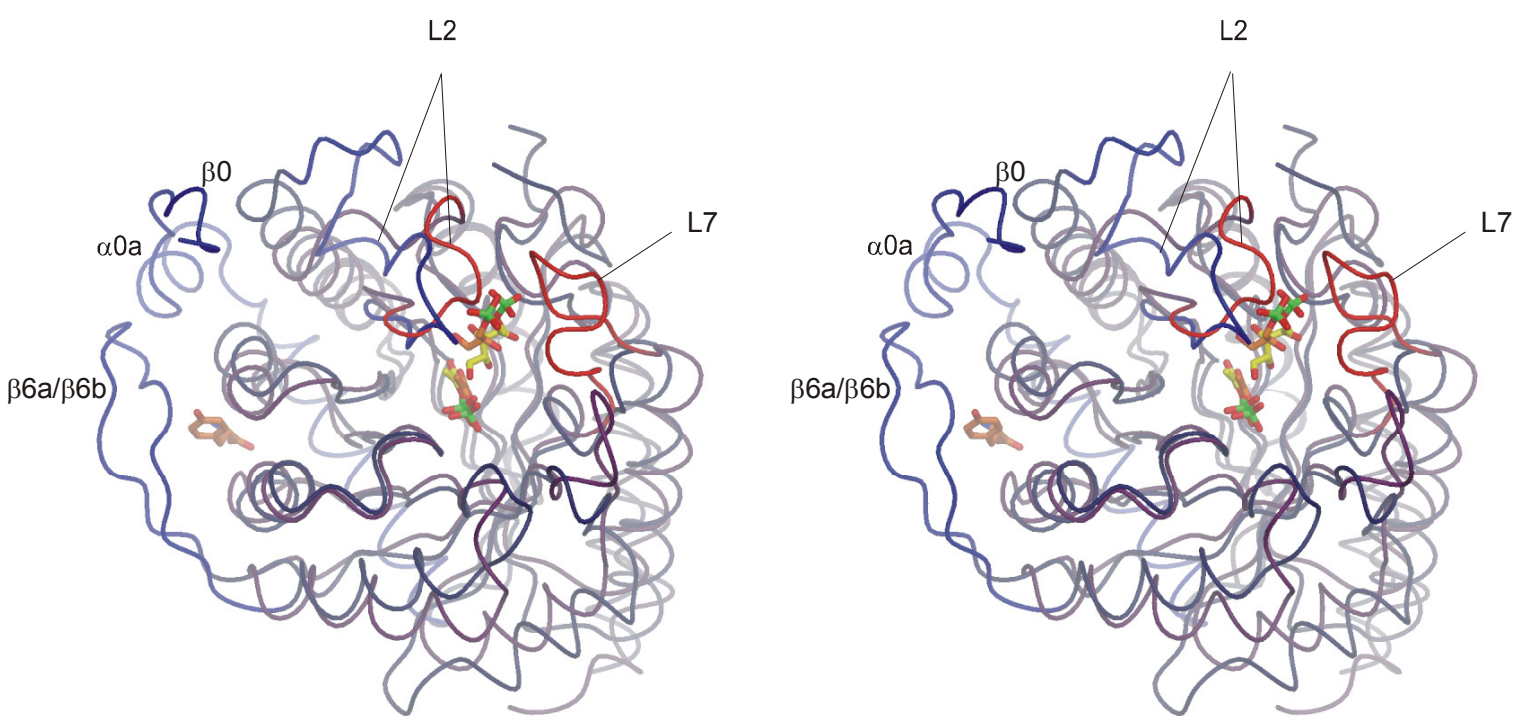

\begin{abstract}
Abb. V.1.3.2b
Stereographische Darstellung des Hauptkettenverlaufes von 4e (tyr-sensitive DAHP Synthase aus S. cerevisiae, graublau) und 1FWW (KDOP Synthase aus Aquifex aeolicus, graurot) mit eingefügten Substraten und dem DAHP Synthase-Effektor Tyrosin (siehe Kap. V.2). Die in der KDOP Synthase im Vergleich zur DAHP Synthase stark unterschiedlichen oder zusätzlichen Bereiche sind in rot, die analogen Bereiche der DAHP Synthase in blau dargestellt. Unterschiede im das zweite Substrat bindenden loop L2 sowie im in 1FWW die aktive Tasche schließenden loop L7 und die für die Effektorbindung in der DAHP Synthase zusätzlichen Elemente sind erkennbar.
\end{abstract}

Ein strukturbasierendes Alignment der tyr-sensitiven DAHP Synthase aus S. cerevisiae und der metallionabhängigen KDOP Synthase aus Aquifex aeolicus hingegen zeigt, dass sich 37\% der Enzyme in ihrer Struktur ähneln und sich mit einer rms-Differenz von $1.8 \AA$ superpositionieren lassen (siehe $A b b . V \cdot 1.3 .2 b$ ).

In $A b b$. V.1.3.2b sind die sich unterscheidenden Bereiche der beiden Strukturen farbig hervorgehoben. Deutlich sind die Unterschiede im Bereich der Bindungsstelle des zweiten Substrates zu erkennen (L2 und L7). In Kap. V.2 wird auf die Funktion der zusätzlichen Strukturelemente $\beta 0$ und $\beta 6 \mathrm{a} / \mathrm{b}$ innerhalb der negativen Rückkopplung durch das Endprodukt eingegangen. Diese in der DAHP Synthase zum TIM-Barrel zusätzlichen strukturellen Elemente sind in der nicht regulierbaren KDOP Synthase nicht wiederzufinden. 


\section{V.1.4 Katalysemechanismus}

In diesem Abschnitt werden aus dem Vergleich der Enzym-Komplexe Rückschlüsse auf den Katalysemechanismus gezogen.

\section{Lage der Carbonylgruppe des zweiten Substrates E4P}

Durch den mit PEP und dem E4P-Analogon besetzten Doppelkomplex (4e) konnte die Bindungsstelle des zweiten Substrates definiert werden. Dadurch, dass sich das gesamte aktive Zentrum nach Binden des ersten Substrates PEP als wenig flexibel erweist, kann angenommen werden, dass sowohl die Phosphatbindungsstelle, als auch die stark ausgebildeten Bindungen der Hydroxylgruppen des G3P mit den analogen des Substrates E4P übereinstimmen. Nimmt man aus den unter Kap. V.1.2.8 genannten Gründen für das E4P die gleiche Position wie für das G3P an, so muss als nächstes versucht werden, die Lage der im Substrat zusätzlich vorhandenen Carbonylgruppe vorherzusagen. Dadurch, dass die Chiralität am E4P:C2 des E4Ps, das dem achiralen G3P:C1 im G3P entspricht, bekannt ist, ist die Lage des Carbonylkohlenstoffatoms weitgehend vorgegeben. Die so festgelegte Position dieses Kohlenstoffatoms E4P:C1 scheint plausibel, da sie zu dem Kohlenstoffatom der PEPDoppelbindung PEP:C3, das es während des Katalysemechanismus nucleophil angreift, nur etwa $2.7 \AA$ entfernt liegt. Dies ist für einen Abstand zweier nicht kovalent gebundener Kohlenstoffatome sehr kurz, für eine spätere Bindungsknüpfung allerdings erwünscht. Es bleibt die Position des Sauerstoffatoms, das theoretisch frei um die C2-C1-Bindung drehbar ist, festzulegen. Geht man die verschiedenen möglichen Lagen des Carbonylsauerstoffatoms durch, so fällt auf, dass sich durch sterische Wechselwirkungen mit dem Kohlenstoffatom PEP:C3 oder der Phosphatgruppe des PEP, der Hydroxylgruppe O2 des eigenen Moleküls oder der Carboxylatgruppe des Asp342 ein großer Bereich für die Sauerstoffatomposition ausschließen lässt. Die einzige Lage, in der sich die Carbonylgruppe frei von sterisch ungünstigen Wechselwirkungen befinden kann, entspricht ungefähr der Lage des sehr flexiblen, an das Metallion koordinierenden Wassermoleküls. In dieser Position ist das Sauerstoffatom mit einem Abstand von etwa $2.4 \AA$ an das Metallion koordiniert. Dieses würde zu einer Aktivierung der Carbonylgruppe und so zu einem erleichterten nucleophilen Angriff durch die PEP-Doppelbindung führen. Dass das Metallion nicht nur eine strukturgebende, sondern auch eine katalytische Bedeutung hat, wurde schon in Punktmutations- und Spektroskopieversuchen gezeigt [Howe 2000]. Zusätzlich entstände eine Wasserstoffbrückenbindung zum Lys112, das das für die Entstehung des Produktes DAHP notwendige Proton auf das Carbonylsauerstoffatom übertragen könnte. Für diese Position 
spricht weiterhin die konformationell günstige Lage für einen re-Angriff der PEPDoppelbindung auf die Carbonylgruppe, der für die geforderte Stereochemie am neuaufzubauenden chiralen Zentrum DAHP:C4 essentiell ist. Auch der nucleophile Angriffswinkel der Doppelbindung wäre mit um die $95^{\circ}$ dem energetisch günstigen Bürgi-Dunitz-Winkel von $103^{\circ}$ sehr nahe [Brückner 1996]. Betrachtet man die katalysierte Reaktion als nucleophilen Angriff auf eine an ein stereogenes Zentrum benachbarte, prochirale Carbonylgruppe, so würde das Substrat nach dem Cram-Modell [Carey 1995; Cram 1952] wiederum in einer energetisch für den Angriff bevorzugten Konformation festgehalten werden. Der größte Rest des angrenzenden chiralen Kohlenstoffatoms, in diesem Fall die restliche Zuckerkette mit der Phosphatgruppe, stände mit um die $95^{\circ}$ beinahe senkrecht zur Carbonylgruppe. Dies würde der Theorie nach zu einer Stabilisierung des Carbonyl-LUMO durch das $\sigma$-Orbital des senkrecht stehenden Restes führen, was die Wechselwirkung mit dem angreifenden HOMO begünstigen würde [Carey 1995].

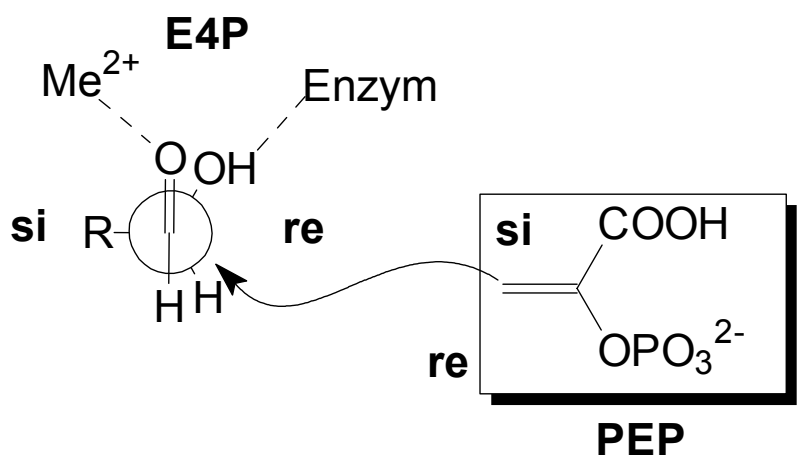

\begin{abstract}
Abb. V.1.4a: $\quad$ Schematische Darstellung der Stereochemie der katalysierten Reaktion. Zum Aufbau des chiralen Zentrums DAHP:C4 des Produktes greift die si-Seite des PEP die re-Seite der prochiralen Carbonylgruppe des E4P an. Nach der Theorie von Cram [Cram 1952] wird das benachbarte E4P:C2 durch die senkrechte Anordnung des Zuckerrestes zur Carbonylgruppe in einer für den nucleophilen Angriff günstigen Konformation festgehalten.
\end{abstract}

Der Angriff des Nucleophils würde dann antiperiplanar, in diesem Fall von der re-Seite der Carbonylgruppe, und aus sterischen Gründen aus der Richtung des kleinsten Substituenten, in diesem Fall aus der Richtung des Wasserstoffatoms des benachbarten Kohlenstoffatoms E4P:C2, erfolgen. Diese postulierte Lage der Carbonylgruppe wird auch durch die in der Literatur beschriebenen Abhängigkeit der Kinetik von der Metallionenart in bezug auf E4P bestärkt [Stephens 1991]. 

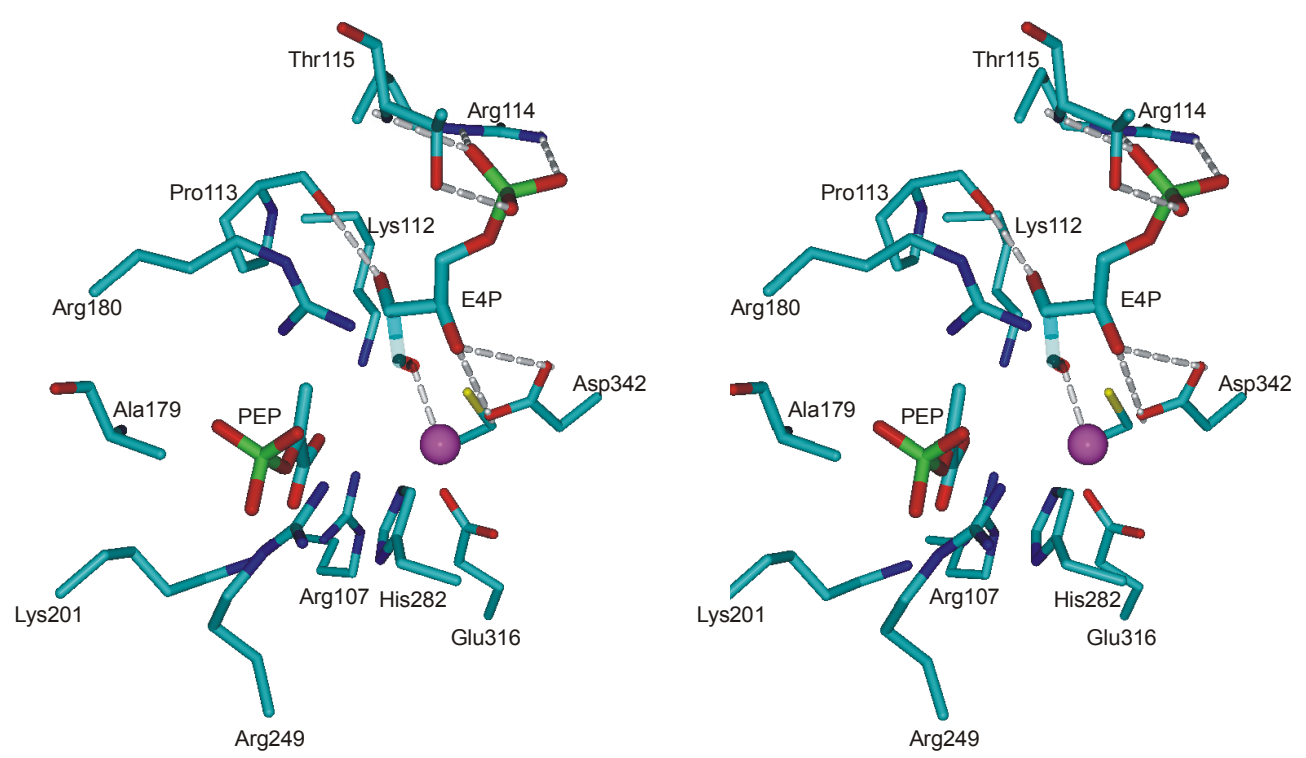

\begin{abstract}
Abb. V.1.4b
Stereographische Projektion des Aktiven Zentrums. Dargestellt sind die in der aktiven Tasche involvierten Aminosäureseitenketten sowie die Positionen des in der Struktur 4e verfeinerten $\mathrm{Co}^{2+}$-Ions, des PEP und des E4P-Analogons G3P. Die im E4P zusätzliche Carbonylgruppe wurde in die Struktur aus den im Text erläuterten Gründen als an das Metallion koordinierend modelliert und ist in der Abbildung transparent dargestellt.
\end{abstract}

Nimmt man diese sterischen, stereochemischen und orbitaltheoretischen Beobachtungen zusammen, so scheint die in $A b b$. V1.4.b dargestellte Lage des E4P, das mit seiner Carbonylgruppe an das Metallion bindet und mit dem Carbonylkohlenstoffatom einen sehr kurzen Abstand zur angreifenden Doppelbindung besitzt, für die Reaktion wahrscheinlich. Hierbei würde das metallionkoordinierende Wassermolekül durch das Sauerstoffatom der Carbonylgruppe ersetzt.

\title{
Varianten des Katalysemechanismus
}

Für den Reaktionsmechanismus werden in der Literatur [Wang 2001] zwei mögliche, in Abb. V.1.4c dargestellte Reaktionswege vorgeschlagen. Der erste Weg A beginnt mit dem nucleophilen Angriff der Doppelbindung und führt über einen Wassermolekülangriff auf das entstandene Oxocarbeniumion zum Endprodukt. Beim zweiten Mechanismus nach Weg B beginnt die Reaktion mit dem Angriff eines Wassermoleküls bzw. eines $\mathrm{OH}^{-}$-Ions auf die Doppelbindung, so dass das entstandene Carbanion nucleophil die Carboxylatgruppe des E4P angreift. In beiden Varianten ist aufgrund der Phosphatabspaltung durch einen Bruch der CO-Bindung ein Angriff eines Wassermoleküls auf das Kohlenstoffatom PEP:C2 nötig. Betrachtet man die Umgebung des PEP in seiner Bindungstasche, so kommen für diesen Angriff zwei Wassermoleküle in Frage. Zum einen handelt es sich um das Wassermolekül W703, das sich auf der re-Seite des PEP in einem van-derWaal-Abstand von $3.15 \AA$ zum PEP:C2 befindet. 


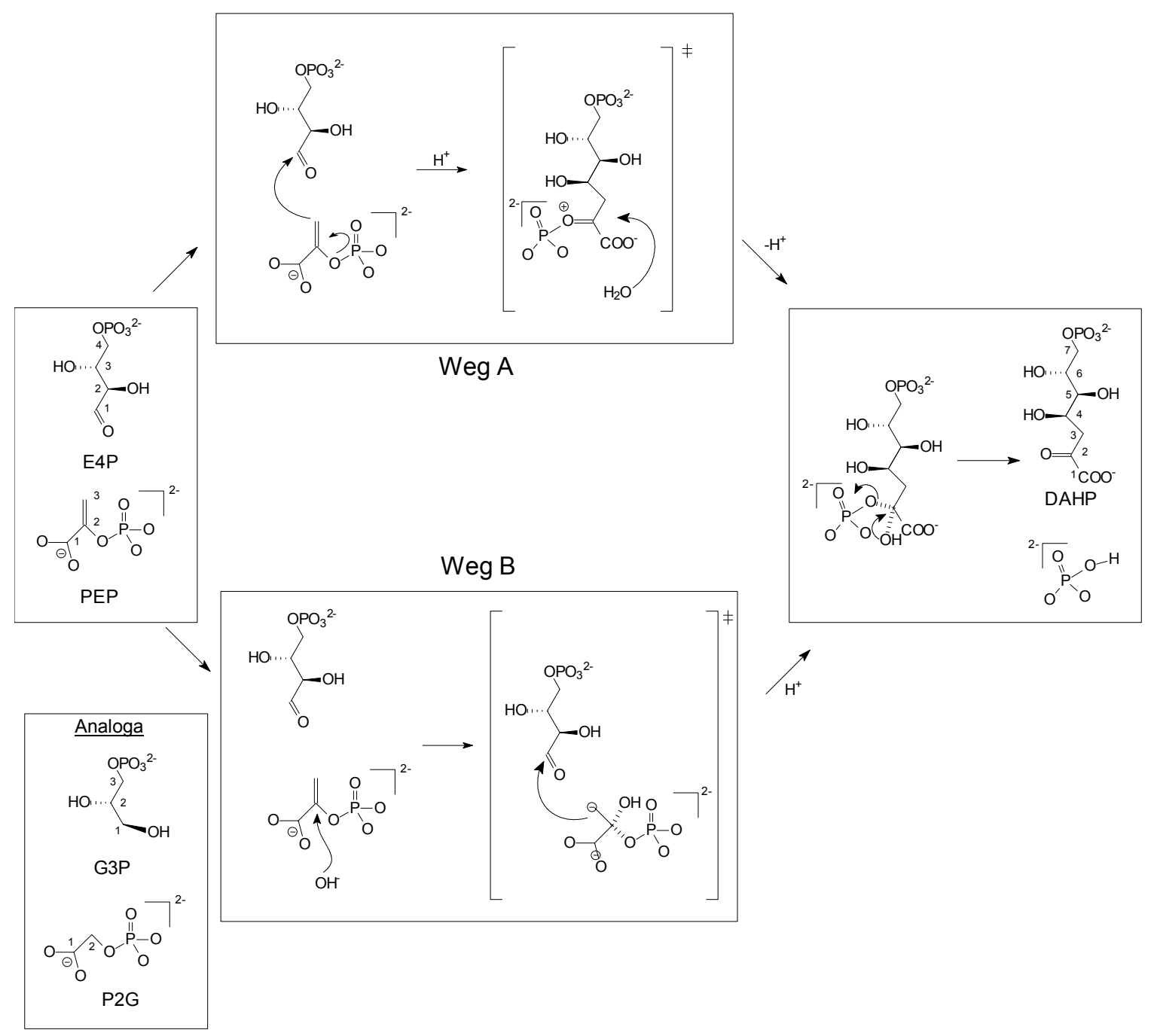

Abb. V.1.4c

Schematische Darstellung der zwei für die DAHP und KDOP Sythasen diskutierten Katalysemechanismen [Wang 2001]. Die Darstellung mesomerer Grenzformen und Partialladungen wurde aus Gründen der Übersichtlichkeit stark vereinfacht.

Es ist über starke Wasserstoffbrückenbindungen an das Glu158 (2.78 A) und ein gut lokalisiertes Wassermolekül W702 (2.74 Å) gebunden. Unabhängig von der Art des Komplexes wird es in der aktiven Tasche des Enzyms vorgefunden. Der Angriffswinkel des nucleophil angreifenden Wassermoleküls beträgt im bezug auf die Doppelbindung $102^{\circ}$.

Das zweite für die Reaktion in Frage kommende Wassermolekül W701 koordiniert an das Metallion. Es befindet sich auf der si-Seite des PEP-Moleküls in einem Abstand von $3.1 \AA$ zum PEP:C2 und einem Abstand von $2.74 \AA$ zum PEP:C3. Der Angriffwinkel auf PEP:C2 beträgt im bezug auf die Doppelbindung $62^{\circ}$. Aus den Komplexvergleichen in Kap. V.1.2 ging hervor, dass dieses Wassermolekül W701 trotz seiner vielfachen Bindungen sowohl an das Metallion (2.06 $\AA$ ) als auch an die Carboxylatgruppe des PEP (2.81 $\AA$ ) und das Lys112 $(2.72 \AA)$ sowie durch eine schwache Wechselwirkung mit der Doppelbindung des PEP nicht gut lokalisiert ist. 

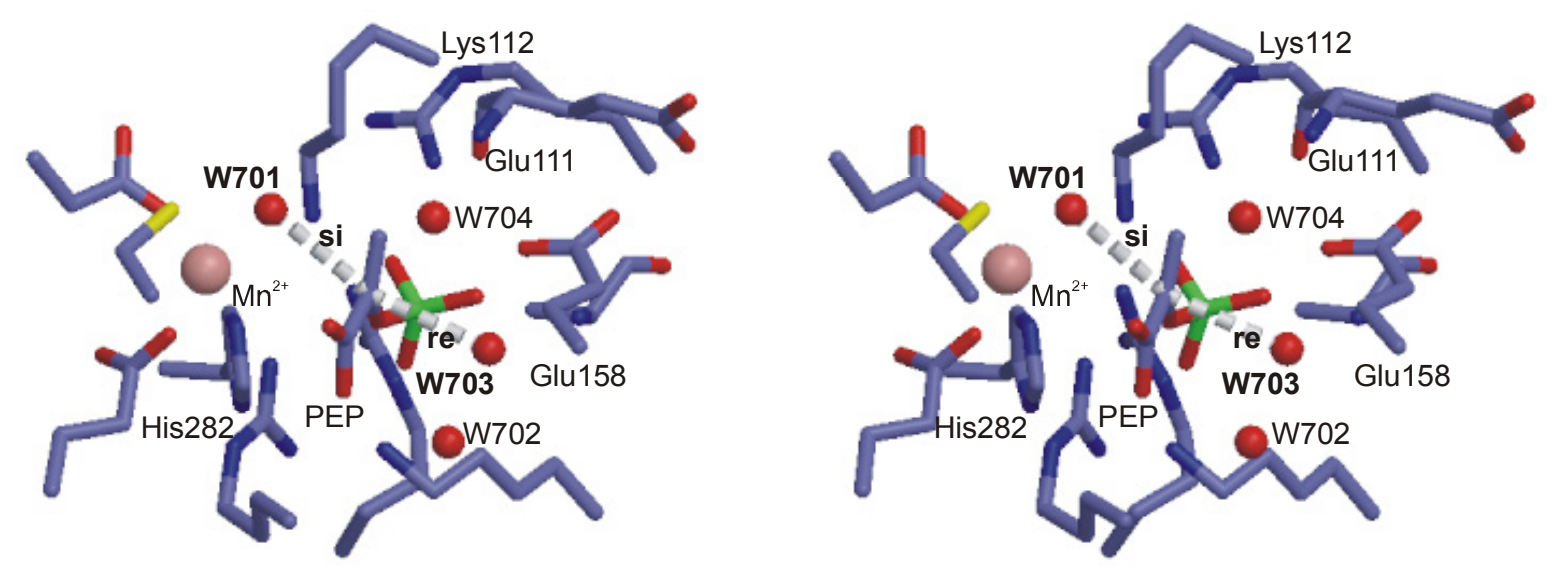

\begin{abstract}
Abb. V.1.4d
Stereographische Darstellung des aktiven Zentrums im Hinblick auf die Position der
\end{abstract} für den re-bzw. si-Seiten-Angriff des PEP diskutierten Wassermoleküle W701 und W703.

Im folgenden soll kurz das Für und Wider der beiden unterschiedlichen Wassermolekülangriffe betrachtet werden.

\title{
Weg A: Angriff des Wassermoleküls W703
}

Für einen re-Seiten-Angriff des Wassermolekül W703 spricht sowohl der van-der-WaalsAbstand von $3.1 \AA$ als auch der optimale Angriffswinkel von $102^{\circ}$. In diesem Fall würde der Mechanismus über den Weg A in $A b b . V .1 .4 c$ verlaufen. Das flexible Wassermolekül W701 würde der Carbonylgruppe des E4P Platz machen (Abb. V.1.4e: A), das durch das Metallion für den nucleophilen Angriff der PEP-Doppelbindung optimal positioniert und aktiviert wird (siehe Abb.V.1.4b ). Das Lys112 würde als Protonen-Donor für die aus der Carbonylgruppe neu entstehende Hydroxylgruppe an DAHP:C4 fungieren ( $A b b$. V.1.4e: B/C). Das entstehende Oxocarbeniumion ( $A b b$.V.1.4e: $\boldsymbol{C}$ ) würde den nucleophilen Angriff des Wassermoleküls W703 von der re-Seite des PEP bewirken, dessen Proton kurzfristig vom Glu158 aufgenommen und vermittelt über das in allen Strukturen vorhandene Wassermolekül W702 auf das Lys 112 übertragen würde ( $A b b$. V.1.4e: D). Diese erneute Protonierung des Lys112 würde die Freisetzung des Produktes erleichtern. Währenddessen könnte das Lys201 als Lewis-Säure/Base wirken, indem es das Proton der neugebildeten Carbonylgruppe aufnimmt und gleichzeitig ein Proton auf die sich abspaltende Phosphatgruppe übertrüge (Abb. V.1.4e: $\boldsymbol{D} / \boldsymbol{E})$. 

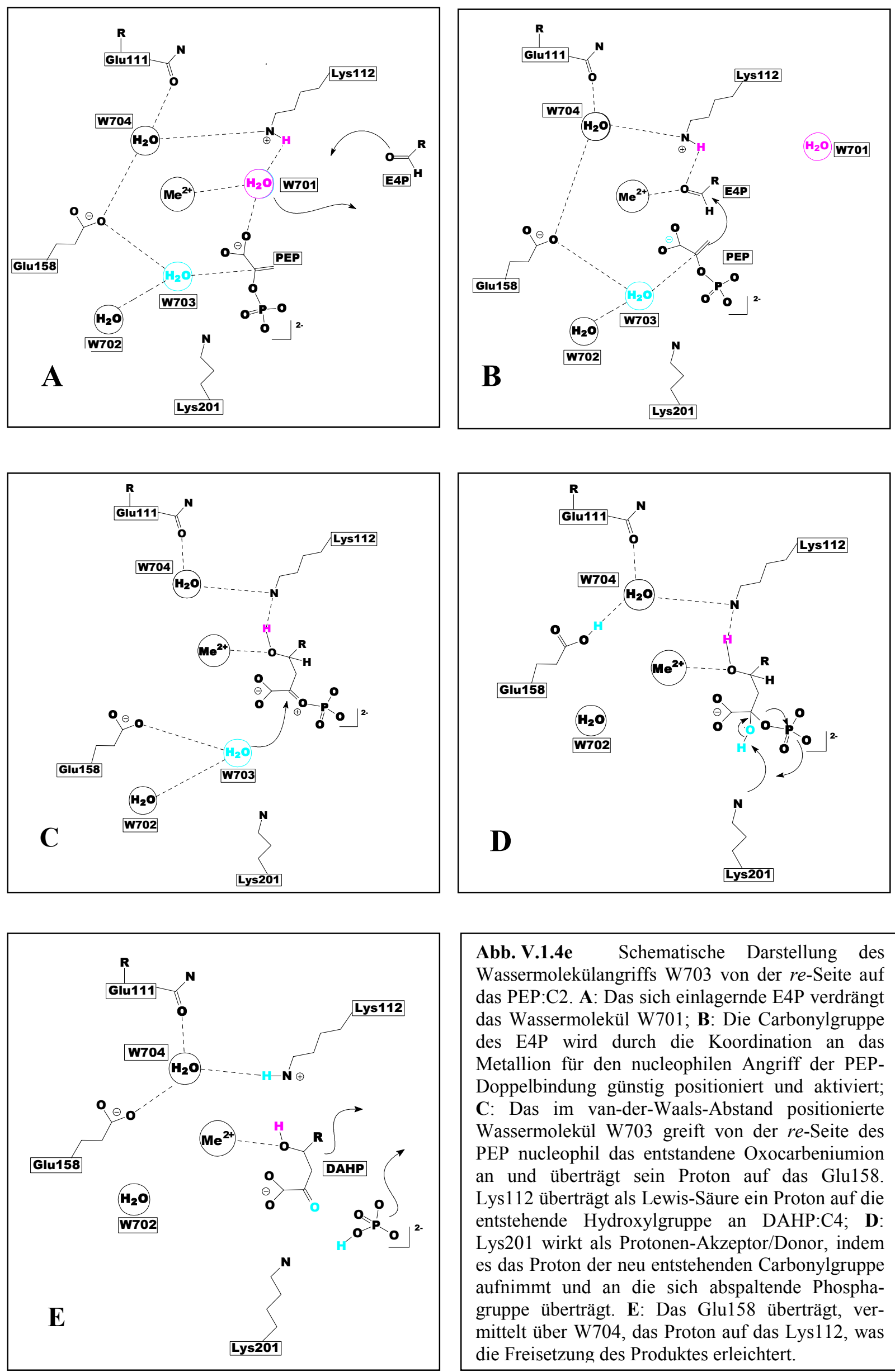

Abb. V.1.4e Schematische Darstellung des Wassermolekülangriffs W703 von der re-Seite auf das PEP:C2. A: Das sich einlagernde E4P verdrängt das Wassermolekül W701; B: Die Carbonylgruppe des E4P wird durch die Koordination an das Metallion für den nucleophilen Angriff der PEPDoppelbindung günstig positioniert und aktiviert; C: Das im van-der-Waals-Abstand positionierte Wassermolekül W703 greift von der re-Seite des PEP nucleophil das entstandene Oxocarbeniumion an und überträgt sein Proton auf das Glu158. Lys112 überträgt als Lewis-Säure ein Proton auf die entstehende Hydroxylgruppe an DAHP:C4; D: Lys201 wirkt als Protonen-Akzeptor/Donor, indem es das Proton der neu entstehenden Carbonylgruppe aufnimmt und an die sich abspaltende Phosphagruppe überträgt. E: Das Glu158 überträgt, vermittelt über W704, das Proton auf das Lys112, was die Freisetzung des Produktes erleichtert. 

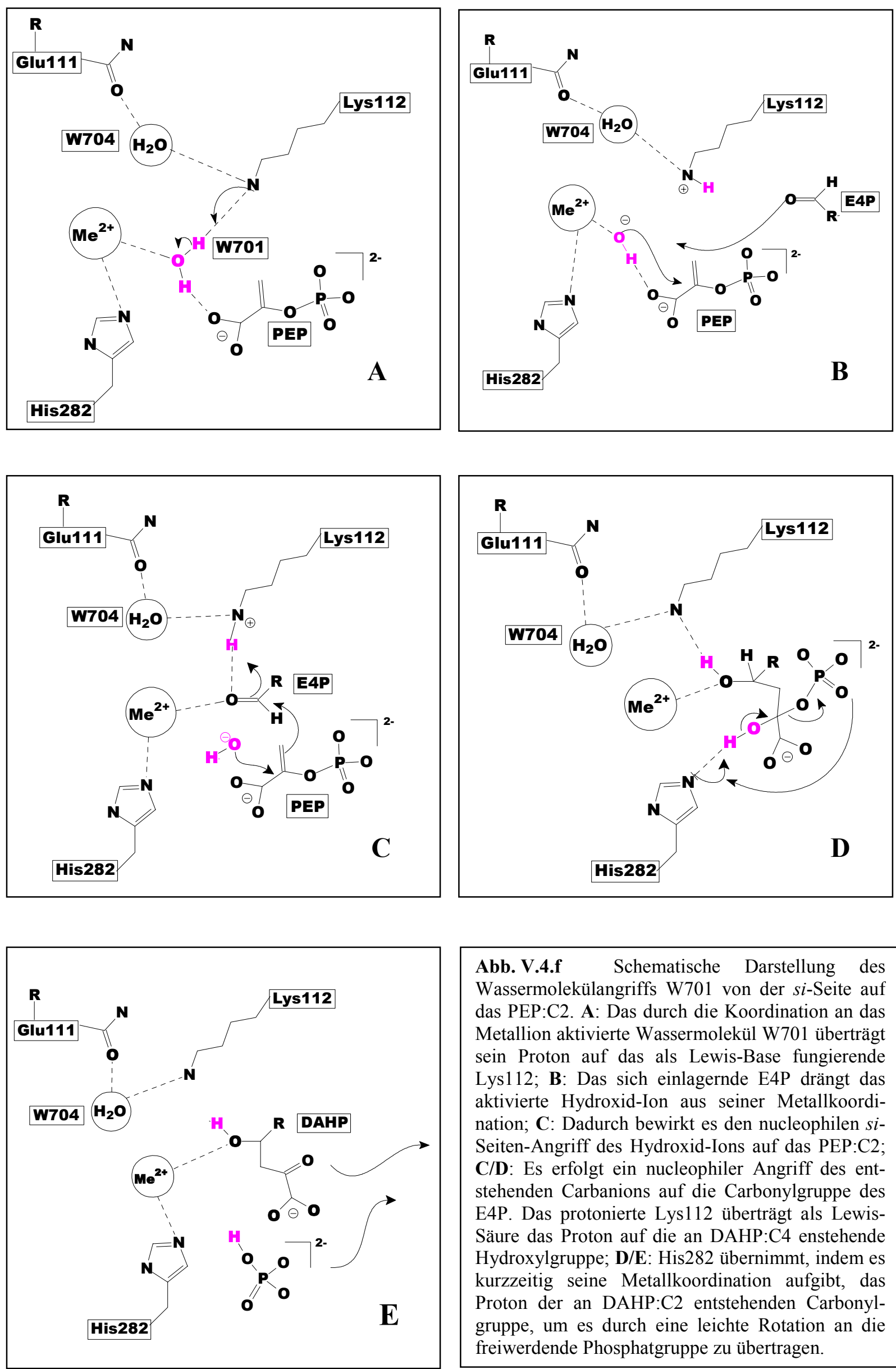

Abb. V.4.f Schematische Darstellung des Wassermolekülangriffs W701 von der si-Seite auf das PEP:C2. A: Das durch die Koordination an das Metallion aktivierte Wassermolekül W701 überträgt sein Proton auf das als Lewis-Base fungierende Lys112; B: Das sich einlagernde E4P drängt das aktivierte Hydroxid-Ion aus seiner Metallkoordination; C: Dadurch bewirkt es den nucleophilen siSeiten-Angriff des Hydroxid-Ions auf das PEP:C2; C/D: Es erfolgt ein nucleophiler Angriff des entstehenden Carbanions auf die Carbonylgruppe des E4P. Das protonierte Lys112 überträgt als LewisSäure das Proton auf die an DAHP:C4 enstehende Hydroxylgruppe; D/E: His282 übernimmt, indem es kurzzeitig seine Metallkoordination aufgibt, das Proton der an DAHP:C2 entstehenden Carbonylgruppe, um es durch eine leichte Rotation an die freiwerdende Phosphatgruppe zu übertragen. 


\section{Weg B: Angriff des Wassermoleküls W701}

Der über den Weg B verlaufende Mechanismus erfordert die Entstehung eines Hydroxid-Ions. Dieses könnte aus dem an das Metallion koordinierendes Wassermolekül W701 durch die Übertragung des Protons auf das als Lewis-Base fungierende Lys112 entstehen. Gegen diesen si-Seiten-Angriff des Wassermoleküls W701 sprechen zunächst der relativ kurze Abstand von 2.7 ̊̊ zu PEP:C3 gegenüber 3.1 $\AA$ zu PEP:C2 und auch der sehr spitze Angriffswinkel von $62^{\circ}$ in bezug auf die Doppelbindung, sowie die postulierte Wechselwirkung zwischen ihm und der Doppelbindung des PEP. Eindeutig für den Angriff dieses Wassermoleküls spricht jedoch die in der Literatur oft beschriebene [z. B. Liao 2002] Aktivierung eines metallionkoordinierten Wassermoleküls, dessen $\mathrm{pK}_{\mathrm{a}}$-Wert sich aufgrund der Stabilisierung der negativen Ladung durch das Metallion um mehrere Potenzen erniedrigen kann [Lippard 1995]. In diesem Fall kann das sich im Wasserstoffbrückenbindungsabstand befindliche Lysin1 12 das Proton aufnehmen und so die Bildung eines aktivierten Hydroxid-Ions fördern (Abb. V.1.4f: A/B). Das sich für die Reaktion in die aktive Tasche einlagernde E4P könnte das Hydroxid-Ion aus seiner metallion- und doppelbindungskoordinierenden Position herausdrängen, so dass es nucleophil das PEP:C2 angreifen könnte (Abb. V.1.4f: B/C). Das protonierte Lys112 würde nun als Lewis-Säure eines seiner Protonen auf das an das Metallion koordinierte Sauerstoffatom der nucleophil angegriffenen Carbonylgruppe übertragen (Abb. V.1.4f: C/D). Die Abstraktion des Protons von der neu entstehenden Carbonylgruppe müsste in diesem Fall, da der Angriff von der si-Seite des PEP erfolgt, über das das Metallion komplexierende His282 verlaufen, so dass dieses kurzfristig seine Metallionkoordination aufgeben müsste. Die Abgabe des Protons könnte durch leichte Drehung entweder auf die Carboxylatgruppe des Produktes oder auf die sich abspaltende Phosphatgruppe übertragen werden, was zu einer Aufhebung der negativen Ladung, und damit der Bindungsstärke der Produkte in ihrer Bindungstasche führen würde ( $A b b$. V.1.4f: E). Diese Reaktionsvariante wird in der Literatur für die KDOP Synthasen [Duewel 2000; Wang 2001] favorisiert, scheint jedoch für die hier untersuchte DAHP Synthase aufgrund der unterschiedlichen Lage der Carbonylgruppe im Vergleich zu KDOP Synthasen und der notwendigen Bewegung des das Metallion koordinierenden His282 weniger geeignet als der Angriff des Wassermoleküls W703 von der re-Seite des PEP.

Anhand der hier vorliegenden Kristallstrukturen ist jedoch keine eindeutige Aussage über die Art des Wassermolekülangriffs zu treffen. Um einen der beiden möglichen, hier sehr theoretisch beschriebenen Mechanismen zu verifizieren, detaillieren oder zu widerlegen, müssten weiterführende Experimente durchgeführt werden. Punktmutationen könnten zur 
Klärung des Mechanismus beitragen. Hierbei muss jedoch beachtet werden, dass kleinste Änderungen im aktiven Zentrum vielfältige Wirkungen auf das Zusammenspiel des Katalysemechanismus haben können. Eine Lys112Ala-Mutante würde z. B. nicht nur die Lewis-Säure-Base-Funktion des Lysins aufheben sondern ebenfalls einen Beitrag zur PEPBindung. Dieser kann jedoch als gering angesehen werden, da die Carboxylatgruppe durch wesentlich stärkere Bindungen vom Arg107 festgehalten wird. Einen Hinweis auf die Wichtigkeit dieser Aminosäure für den Mechanismus gibt der Sequenzvergleich $(A b b . I d)$, der die Konservierung dieser Seitenkette in allen DAHP Synthasen und KPOP Synthasen zeigt. Wäre die Katalysewirkung des Enzyms durch diese Punktmutation stark herab- bzw. außer Kraft gesetzt, würde das auf eine in beiden Varianten postulierte, entscheidende Funktion dieser Lewis-Säure/Base hinweisen. Um die Gültigkeit des ersten Mechanismus zu bestätigen, wäre eine Glu158Ala-Mutante denkbar. Diese würde in der ersten Version zum einen die Position des angreifenden Wassermoleküls durch Wegnahme der einzigen, an das Enzym bindenden Wasserstoffbrücke schwächen und zum anderen die Protonenübertragung vom das PEP angreifenden Wassermolekül W703 verhindern. Auf die zweite Variante sollte diese Mutation keine oder nur geringfügige Auswirkungen haben. Das für die erste Variante ebenfalls als Lewis-Säure/Base wichtige Lys201 ist für eine Punktmutation nicht geeignet, da sie mit drei Wasserstoffbrückenbindungsmöglichkeiten zum Substrat PEP eine zu große strukturgebende Bedeutung hat. Das gleiche Problem ergibt sich für die Überprüfung des zweiten möglichen Mechanismusweges. Auch hier hat das eventuell als Lewis-Säure/Base fungierende His282 durch seine Metallionkoordination eine zu hohe strukturelle Bedeutung, als dass aus einer auf eine Punktmutation an dieser Stelle zurückzuführende Aktivitätsänderung eindeutig auf den Wegfall der Lewis-Säure/Base-Funktion geschlossen werden könnte. 


\section{V.2 Mechanismus der allosterischen Regulierung}

\section{V.2.1 Die Struktur des DAHP Synthase-Tyrosin-Mangan(II)-Komplex}

Das mit Tyrosin inhibierte und mit Mangan(II) versetzte Enzym kristallisiert wie auch das mit PEP komplexierte Enzym als loses Oktamer in der Raumgruppe $\mathrm{P} 1_{\text {gr }}$ mit acht unabhängigen Molekülen in der asymmetrischen Einheit. Im Gegensatz zu der mit PEP komplexierten Struktur ist das loop L2 nicht eindeutig in der Elektronendichte erkennbar. Auffällig ist, dass in allen acht unabhängigen Molekülen der N-Terminus bis AS18 (im Gegensatz zu allen bisher besprochenen Strukturen, in denen er nur bis AS23 sichtbar ist) geordnet in der Elektronendichte zu erkennen ist.

Die durch nichtkristallographische Symmetrie verwandten unabhängigen Moleküle unterscheiden sich z. T. in ihrer Elektronendichte-Qualität, so dass sich die folgende Strukturbeschreibung auf das aus den Monomeren C und D bestehende Dimer bezieht, die nach Qualitätsuntersuchung mit ESCET [Schneider 2000] mit $0.16 \AA$ den kleinsten esd-Wert aufwiesen.

\section{V.2.1.1 Die Tyrosin-Bindungsstelle}
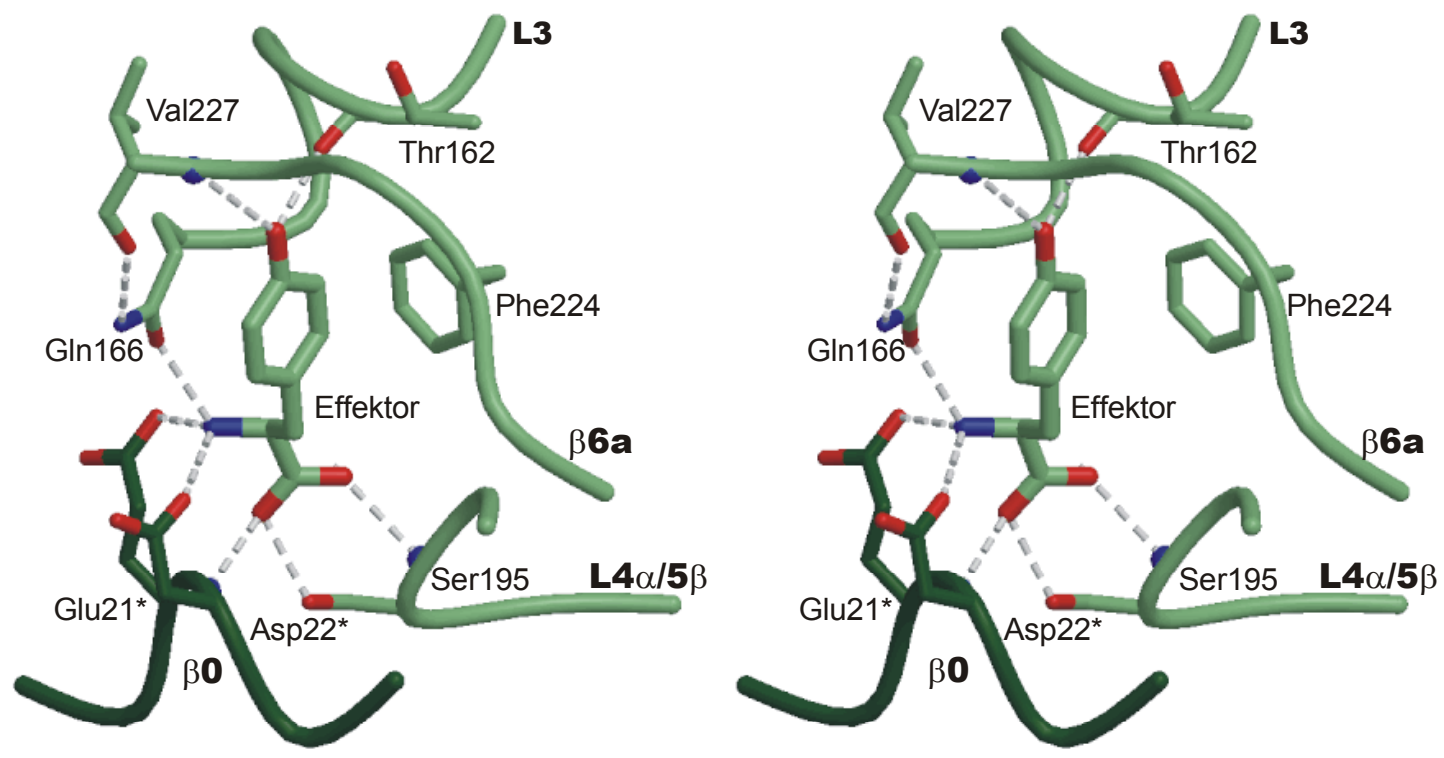

Abb V. 2.1.1a

Stereographische Darstellung des Effektors Tyrosin in seiner Bindungstasche. Diese wird gebildet durch Wechselwirkungen mit den loops L3 und L4 $\alpha / 5 \beta$, sowie dem $\beta 6$ a-Strang des dem TIMbarrel hinzugefügten $\beta 6 \mathrm{a} / \mathrm{b}$-Faltblattes (grün). Geschlossen wird die Bindungstasche durch den N-Terminus des Nachbarmonomers (dunkelgrün). 
Die Bindungsstelle des Tyrosins befindet sich in einer hydrophoben Tasche, die durch die Hauptkettenbereiche L3, L $4 \alpha / 5 \beta$ und $\beta 6$ a gebildet und durch Interaktion mit dem $\beta$-Strang $\beta 0$ des Partner-Monomers geschlossen wird (Abb. V.2.1.1a).

In der Kristallstruktur sind innerhalb eines Dimers beide Bindungsstellen mit Tyrosin besetzt. Diese Bindungstaschen des Effektors liegen von den aktiven Zentren des jeweils selben Monomers ca. $22 \AA$ entfernt, während die beiden Tyrosin-Bindungstaschen innerhalb des Dimers nur ca. $13 \AA$ voneinander entfernt sind.
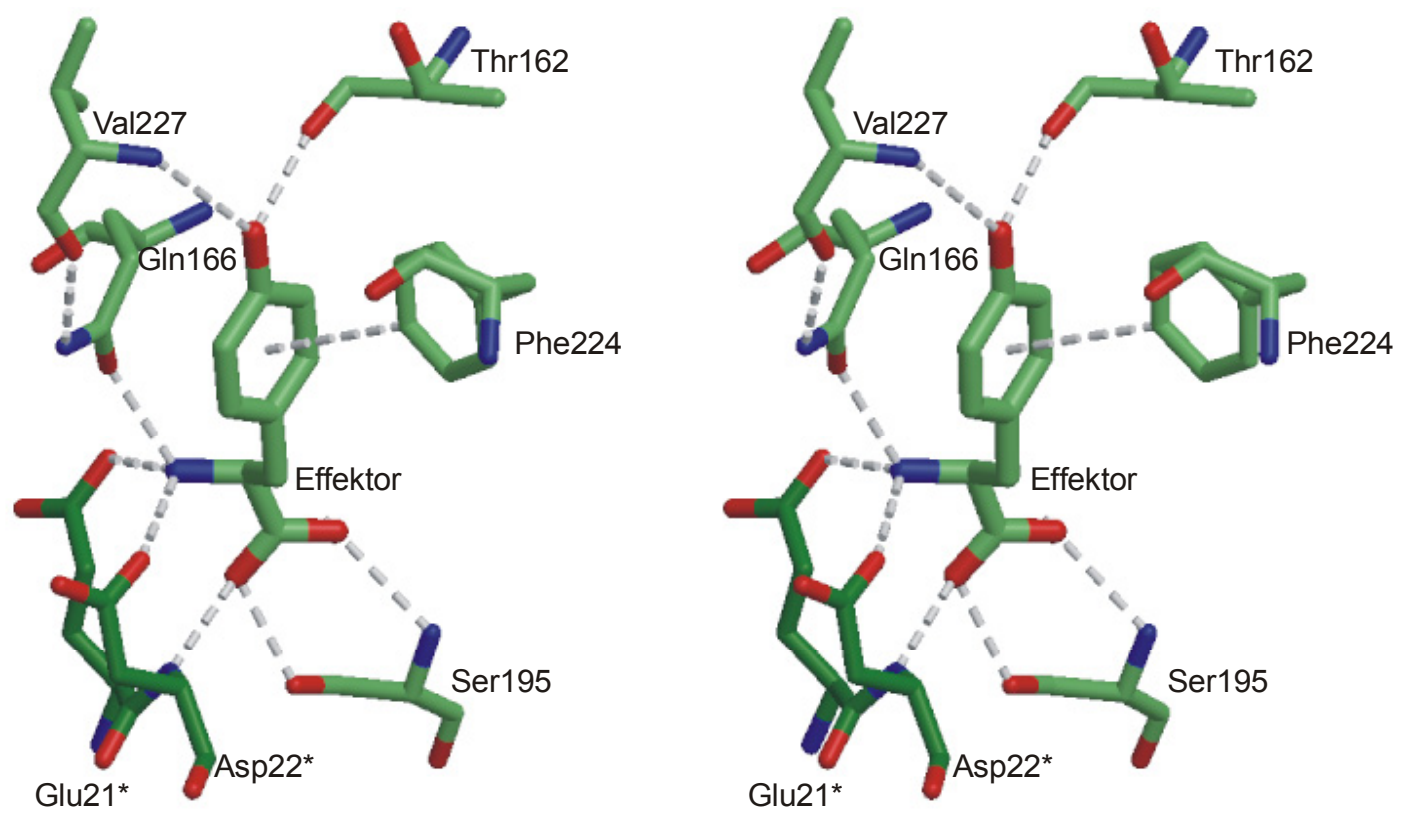

\begin{abstract}
Abb. V. 2.1.1b
Stereographische Darstellung des Effektors Tyrosin mit den ihn in der Bindungstasche fixierenden Wasserstoffbrückenbindungen, bzw. der Aromat-Aromat-Wechselwirkung [Burley 1985] zwischen Phe224 und dem aromatischen System des Effektors.
\end{abstract}

Das Tyrosin wird in seiner Bindungstasche von starken Wasserstoffbrückenbindungen sowie von Aromat-Aromat-Wechselwirkungen festgehalten (Abb. V.2.1.1b).

Die Carboxylatgruppe des Effektors bindet über zwei starke Wasserstoffbrückenbindungen sowohl an das Amidstickstoffatom (2.8 $\AA$ ) als auch an die Hydroxylgruppe $(2.7 \AA)$ des Ser195. Dieses Ser195 liegt an einer exponierten Stelle im loop zwischen $\alpha 4$ und $\beta 5$ und teilt somit das gesamte TIM-Barrel in zwei Hälften (siehe Abb. VIb). Dass diese Aminosäure wichtig für den negativen Rückkopplungsmechanismus ist, wurde schon aus Punktmutationsexperimenten an DAHP Synthasen aus verschiedenen Organismen [Ger 1994; Liao 2000] vermutet. In struktureller Hinsicht kommt dem Bereich zwischen den beiden TIM-BarrelHälften häufig funktionelle Bedeutung zu [Lang 2000; Nozomi 2002].

Die Amingruppe des Tyrosins wird durch eine starke Wasserstoffbrückenbindung (2.8 $\mathrm{A}) \mathrm{zu}$ Gln166 fixiert. Auffällig ist, dass sowohl Ser195 als auch Gln166 in allen Isoenzymen (trp-, tyr-, phe-sensitiv) sowohl aus E. coli als auch aus $S$. cerevisiae konserviert sind, dass also die 
Amin- und die Carboxylatgruppen, die den drei Effektoren gemein sind (siehe $A b b$. Id), wahrscheinlich in allen DAHP Synthasen über diese beiden Aminosäuren an das Enzym gebunden werden. Einen Hinweis darauf geben auch die im Rahmen dieser Arbeit durchgeführten Kristallisationsversuche der tyr-sensitiven DAHP Synthase mit den Aminosäuren Alanin und Phenylalanin (siehe Kap. IV.2). Die für den Effektor Tyrosin charakteristische Hydroxylgruppe ist zum einen über eine schwache (3.1 $\AA$ ) Wasserstoffbrückenbindung an das Stickstoffatom der Amidgruppe des Val227 gebunden und zum anderen mit einer starken Wasserstoffbrückenbindung $(2.5 \AA)$ an das Carbonylsauerstoffatom des Thr162. Eine starke Aromat-Aromat-Wechselwirkung geht das Phe224 mit dem Effektor ein. Sein aromatischer Ring steht so senkrecht auf dem aromatischen Ring des Tyrosins, dass das paraWasserstoffatom mit dem $\pi$-System des Inhibitors in Wechselwirkung treten kann [Desiraju 2001, Burley 1985]. Auch diese Aminosäure ist in allen drei Isoenzymen aus den verschiedenen Organismen konserviert, so dass angenommen werden kann, dass die aromatischen Ringe aller drei Inhibitoren (Tyrosin, Phenylalanin, Tryptophan) durch die Aminosäure Phe224 (bzw. ihrer entsprechenden Analoga) in der Bindungstasche festgehalten werden.

Dass das in allen DAHP Synthasen dem "konventionellen" TIM-Barrel zugefügte $\beta$-Faltblatt$\beta 6 \mathrm{a} / \mathrm{b}$ am negativen Rückkopplungsmechanismus beteiligt sein muss, wurde schon aufgrund von Zufalls- und Punktmutationsexperimenten vermutet [Hartmann 2001]. Besondere Bedeutung kommt dabei den Punktmutationen Gly226Ser und Gly226Thr zu. Durch sie lässt sich die Regulation von tyr- auf phe-sensitive umstellen, während die Mutation Gly226Ala nur die Aktivität herabsetzt, die feedback-Regulation des Tyrosins jedoch beibehalten wird. Zumindest die Änderung in der Regulation durch Tyrosin ist nun erklärbar: die vergleichsweise geringe Platzeinnahme der zusätzlichen Methylgruppe bei der Gly226Ala Mutante hat nur einen geringen Einfluss auf den Regulierungsmechanismus. Währenddessen machen die größeren Seitenketten von Serin und Threonin wahrscheinlich die Einlagerung des Effektors Tyrosin unmöglich, da es in diesem Bereich der Tasche die im Vergleich zum Phenylalanin zusätzliche Hydroxylgruppe trägt. Auf die Regulationsumkehr der tyr-sensitiven DAHP Synthasen aus $S$. cerevisiae von tyr- auf phe-sensitiv wird in Kap. 2.3 eingegangen.

Auch die Beteiligung des Bereiches zwischen den Aminosäuren Glu158 und Gln166 wurde schon anhand von Mutationsexperimenten an verschiedenen Isoenzymen der DAHP Synthase vermutet [Ray 1988; Kikuchi 1996].

Zusätzlich zu diesen Bindungen innerhalb der Bindungstasche bildet das Tyrosin starke Wasserstoffbrückenbindungen zum N-Terminus des Partner-Monomers innerhalb seines Dimers aus. Die im Vergleich zu der mit PEP komplexierten Struktur nun zusätzlich in der 
Elektronendichte sichtbaren Aminosäuren AS18-23 bilden sowohl zum in der Tasche gebundenen Effektor Tyrosin als auch zum Partner-Monomer neue Wasserstoffbrückenbindungen aus und ergeben so im Kristall eine ,geordnete“ Struktur (siehe Tab. IV.4c). Das Amidstickstoffatom des Asp22* bindet mit einer starken Wasserstoffbrückenbindung (2.7 $\AA$ ) an das Carboxylatsauerstoffatom $\mathrm{O}$ des $\mathrm{Tyr}_{\text {eff }}$ und das Glu21:OE1* bindet $(2.9 \AA)$ an die Amingruppe des $\mathrm{Tyr}_{\mathrm{eff}}$. Durch diese zusätzliche Bindung des N-Terminus des PartnerMonomers $\left(^{*}\right)$ an den gebundenen Effektor $\left(\mathrm{Tyr}_{\mathrm{eff}}\right)$ und $\mathrm{im}$ folgenden der weiteren Aminosäuren AS20*-AS18* an das Enzym selbst wird die bis dahin offene Bindungstasche geschlossen (Abb. V.2.1.1c: $A$ und $B)$. .
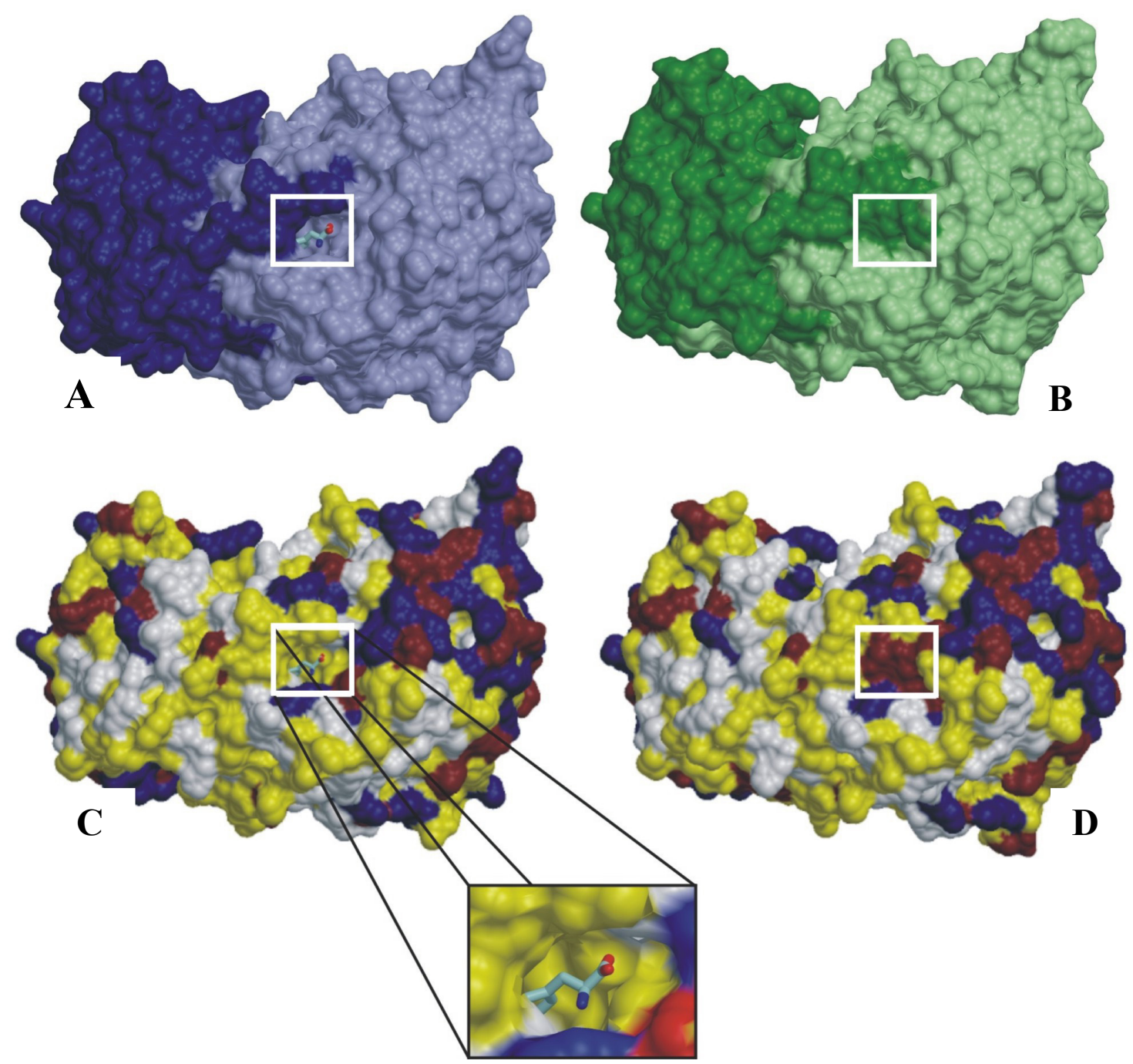

\begin{abstract}
Abb. 2.1.1c
A: Darstellung der Enzymoberfläche des Dimers (blau/hellblau) der Struktur 4b mit einmodelliertem Effektor Tyrosin in die aus der Struktur 2c bekannte Bindungsstelle. Das Tyrosin läge frei zugänglich in der offenen Bindungstasche. B: Darstellung der Enzymoberfläche des Dimers (grün/hellgrün) der Struktur 2c mit dem bindenden Effektor Tyrosin. Die Bindungstasche wird durch den N-Terminus des Partnermonomers geschlossen, so dass der Effektor von der Umgebung abgeschlossen ist. C: Darstellung der Enzymoberfläche der Struktur 4b mit einmodelliertem Effektor Tyrosin in die aus der Struktur 2c bekannte Bindungsstelle. Die Aminosäuren wurden entsprechend ihrer Ladungen eingefärbt (blau: positive Partialladung, rot: negative Partialladung, gelb: hydrophobe Aminosäuren). Das Tyrosin ist in seiner hydrophoben Bindungstasche frei zugänglich. D: Darstellung der Enzymoberfläche der Struktur 2c mit dem bindenden Effektor Tyrosin. Der Hydrophile N-Terminus schließt die hydrophobe Effektor-Bindungstasche und schirmt sie so von der hydrophilen Umgebung ab.
\end{abstract}


Dadurch wird die hydrophile Bindungstasche (gebildet aus u. a. Ile25, Pro34, Pro165, Ala169, Leu194, Leu194, Phe224) des aromatischen Effektors mit einem nach außen hydrophilen "Deckel" (die hydrophilen Seitenketten von Asp20*/22* befinden sich auf der Außenseite des „Deckels“) von der hydrophilen Umgebung abgetrennt (Abb. V.2.1.1c: C und D). Der Inhibitor wird dadurch zusätzlich festgehalten und am Herausdiffundieren gehindert $(A b b$. V.2.1.1c: $A$ und B). Dass dieser über das Dimer arbeitende Mechanismus auch bei den tyrund phe-sensitiven DAHP Synthasen aus E. coli und A. nidulans abläuft, ist zu vermuten und wird durch die Tatsache bestärkt, dass das zum Inhibitor Wasserstoffbrückenbindungen ausbildende Glu22 in diesen DAHP Synthasen konserviert ist. Ein Hinweis darauf, dass die Schließung der Bindungstasche durch den N-Terminus des Partner-Monomers für den negativen Rückkopplungs-Mechanismus von Bedeutung ist, gibt auch die Mutante 4p1.20Del.Mut [Hartmann 2001], die wenig aktiv und sogar tyr-aktivierend und nicht inhibierend ist.

\section{V.2.1.2 Vergleich des Tyrosin-Mangan(II)-Komplex (2c) mit dem PEP-Mangan(II)- (4b) bzw. mit dem PEP-Cobalt(II)-G3P-Komplex (4e)}

Um die mit Metallion, PEP und G3P komplexierte Struktur 4e der tyr-sensitiven DAHP Synthase mit ihrer mit Tyrosin inhibierten Struktur 2c vergleichen zu können, wurden zunächst mittels Distanzmatrizen-Berechnung [Schneider 2000] die Enzym-Bereiche ermittelt, die sich nach der Einlagerung des Effektors (2c) im Vergleich zu der Struktur des aktiven Enzyms (4c) nicht stärker als $1 \sigma$ bewegt haben. Diese Bereiche wurden mit Hilfe des Programms LSQKAB [Kabsch 1976] superpositioniert. Zur Analyse der sich durch Einlagerung des Effektors konformationell ändernden Regionen wurde der $\sigma$-Wert auf 4 erhöht, um nur die für die Einlagerung charakteristischen Konformationsänderungen zu erhalten. Aus dieser Analyse ergaben sich folgende Bereiche, die sich aufgrund der TyrosinEinlagerung bewegt haben (siehe Abb. V.2.1.2a): AS18-22 ( $\beta 0)$, AS109-133 (L2), AS157-165 (L3) und AS222-237 ( $\beta 6 \mathrm{a} / \mathrm{b})$. Auffällig ist hierbei, dass es sich bei drei der vier Bereiche um Strukturelemente handelt, die das TIM-Barrel erweitern: der N-Terminus, der um 30 Aminosäuren erweiterte loop L2 und das zusätzliche $\beta$-Faltblatt $\beta 6 \mathrm{a} / \mathrm{b}$. Der vierte Bereich befindet sich in der Loopregion zwischen $\beta 3$ und $\alpha 3$ auf der c-terminalen Seite des barrels in dem einzigen c-terminalen loop, der nicht in die Substratbindung in der aktiven Tasche involviert ist. 

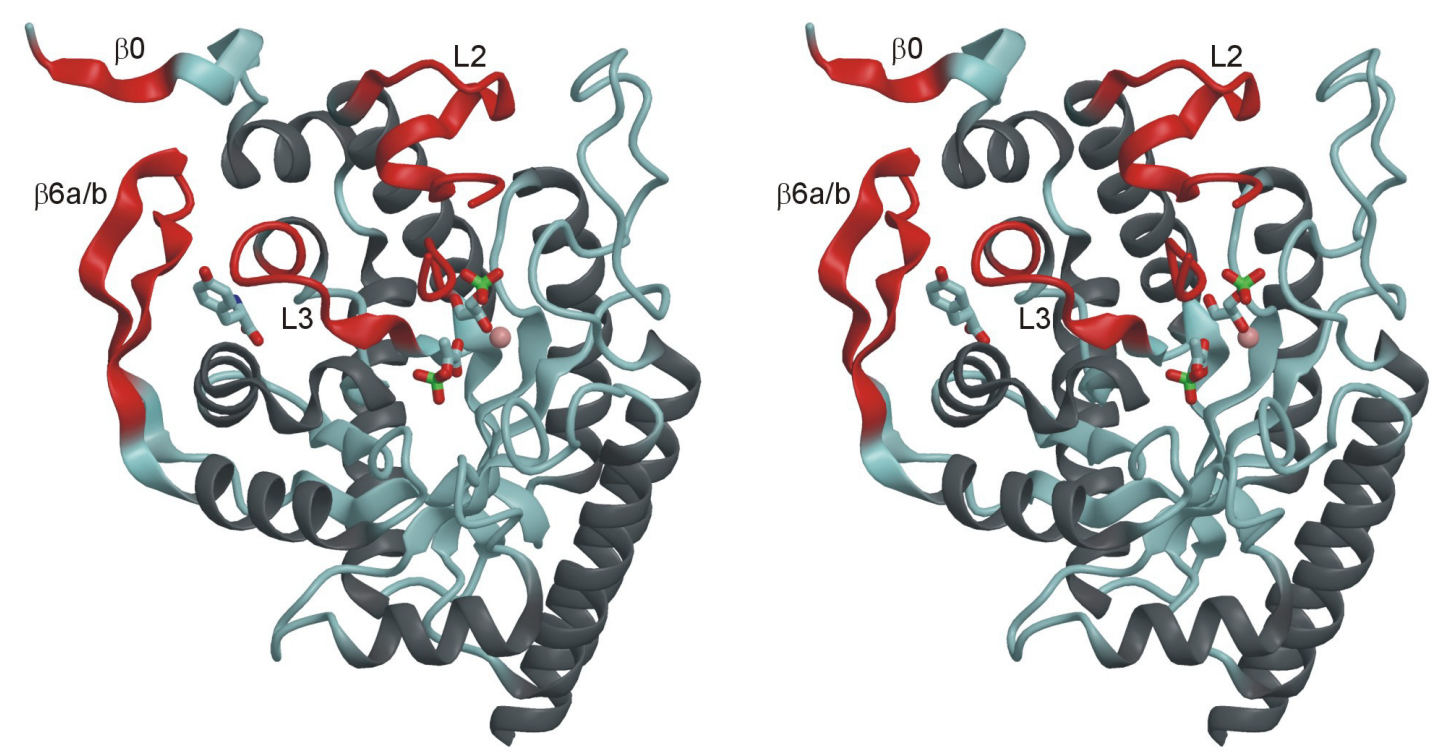

Abb. V.2.1.2a

Stereographische Darstellung der Tertiärstruktur von $2 \mathbf{c}$ mit dem Metallion $\mathrm{Mn}^{2+}$ und dem Effektor Tyrosin sowie die an den Positionen der Substrate in der Struktur 4e entsprechenden Lagen einmodellierten Substrate bzw. Analoga PEP und G3P. $\beta$-Stränge sind in hellgrau, $\alpha$-Helices in dunkelgrau dargestellt. Rot markiert sind Bereiche, die sich nach Distanzmatrizenberechnungen [Schneider 2000] im Vergleich der Strukturen $\mathbf{2} \mathbf{c}$ und $4 \mathbf{e}$ bei $4 \sigma$ signifikant bewegt haben.

\section{V.2.1.2.1}

Änderungen im aktiven Zentrum

Wie in Kap. V.1.2.1. gezeigt, scheint die Struktur des aktiven Zentrums im nur mit Metallion komplexierten Fall (2a, 3a, 4a) recht flexibel. In der Struktur 3a liegt das Enzym in zwei Konformationen vor, von denen die eine der mit PEP komplexierten und die andere der mit Tyrosin inhibierten ähnelt. Das konformationell flexible, unbeladene Enzym scheint also durch das erste Substrat PEP oder durch den Effektor Tyrosin in der aktiven oder inhibierten Konformation festgehalten zu werden.
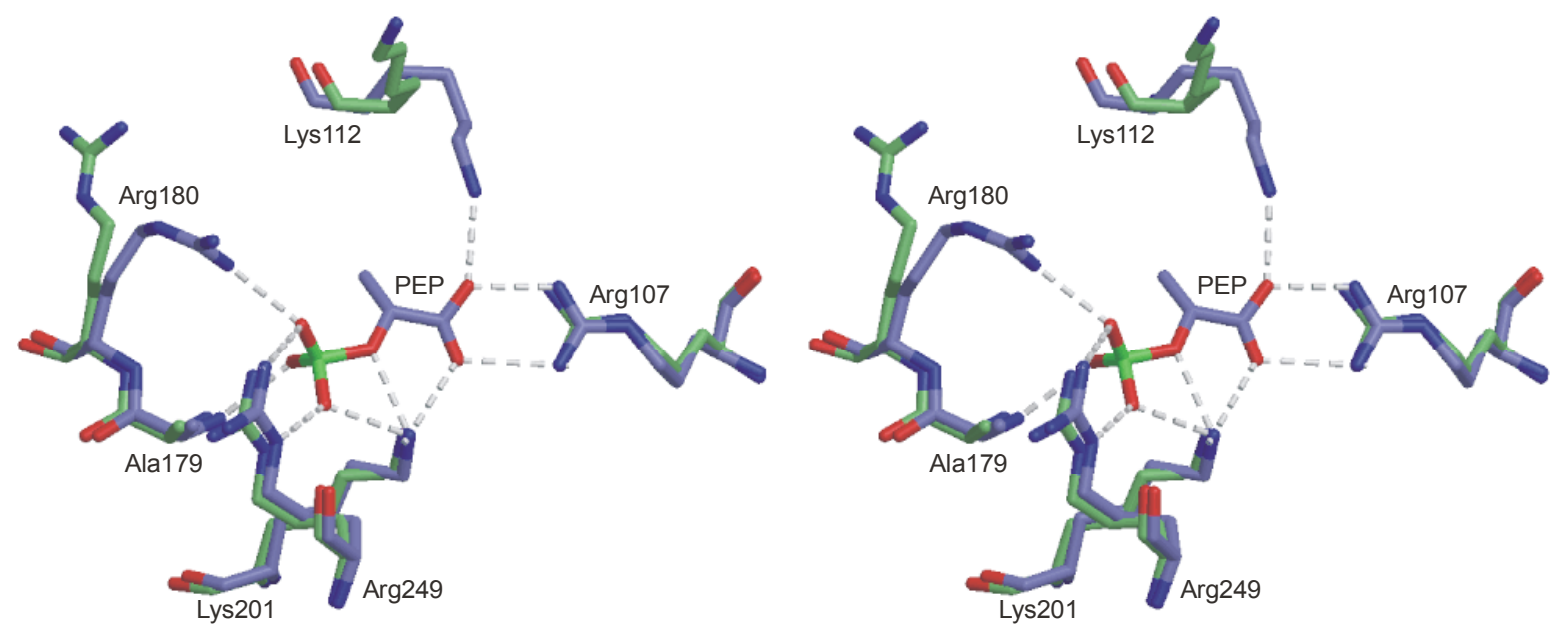

Abb. V. 2.1.2.1a Stereographische Darstellung der superpositionierten PEP-Bindungsstellen der Strukturen 4b (blau) und 2c (grün). In der tyr-inhibierten Struktur werden durch Rotameränderungen zwei für die PEP-Fixierung in der aktiven Tasche wichtige Wasserstoffbrückenbindungen (Arg180, Lys112) aufgegeben. 
Vergleicht man die Positionen der an der Substratbindung beteiligten Seitenketten in der aktiven Struktur 4b mit der inhibierten Struktur 2c, so erkennt man, dass in letzterer Struktur zwei der Substrat-bindenden Wasserstoffbrückenbindungen aufgebrochen sind. Das Arg180, welches in der aktiven Form eine Wasserstoffbrückenbindung zur Phosphatgruppe des PEP ausbildet, liegt in der inhibierten Form als ein Seitenketten-Rotamer der $\mathrm{C}_{\beta}$ - $\mathrm{C}_{\gamma}$-Bindung vor. Dieses weist vom aktiven Zentrum weg (siehe $A b b$. V.2.1.2.1a). Das Lys112, das nicht nur als Bindungspartner für PEP sondern auch als Lewis-Säure/Base diskutiert wurde, hat in der Struktur 2c seine Wasserstoffbrückenbindung zur Carboxylatgruppe des PEP wegen starker Hauptkettenbewegung aufgegeben. Alle übrigen Aminosäuren im aktiven Zentrum behalten die Position ihrer Seitenketten bei (siehe Abb. V.2.1.2.1a).

Ein Vergleich der inhibierten Struktur 2c mit dem Doppelkomplex 4e zeigt, dass die Loopbewegung im Bereich AS109-133 (L2), in der die Phosphat- und eine der Hydroxylbindungsstellen des zweiten Substrates E4P liegt, zu einer Verformung der aktiven Tasche führt. Dieser loop scheint im inhibierten Zustand sehr flexibel zu sein, da er nur in einem Monomeren der asymmetrischen Einheit vollständig, jedoch mit erhöhten B-Werten zu definieren ist. In den übrigen 7 Monomeren sind nur Fragmente in der Elektronendichte erkennbar. Die maximale Positionsänderung des loops L2 liegt in der Hauptkette bei $2.5 \AA$ (Pro115), im Bereich der Seitenketten sogar bei $6 \AA$ (Lys120). Der loop L2 wird so in die aktive Tasche hineingeschoben, dass eine Bindung des E4P unmöglich erscheint ( $A b b$. V.2.1.2.1b).
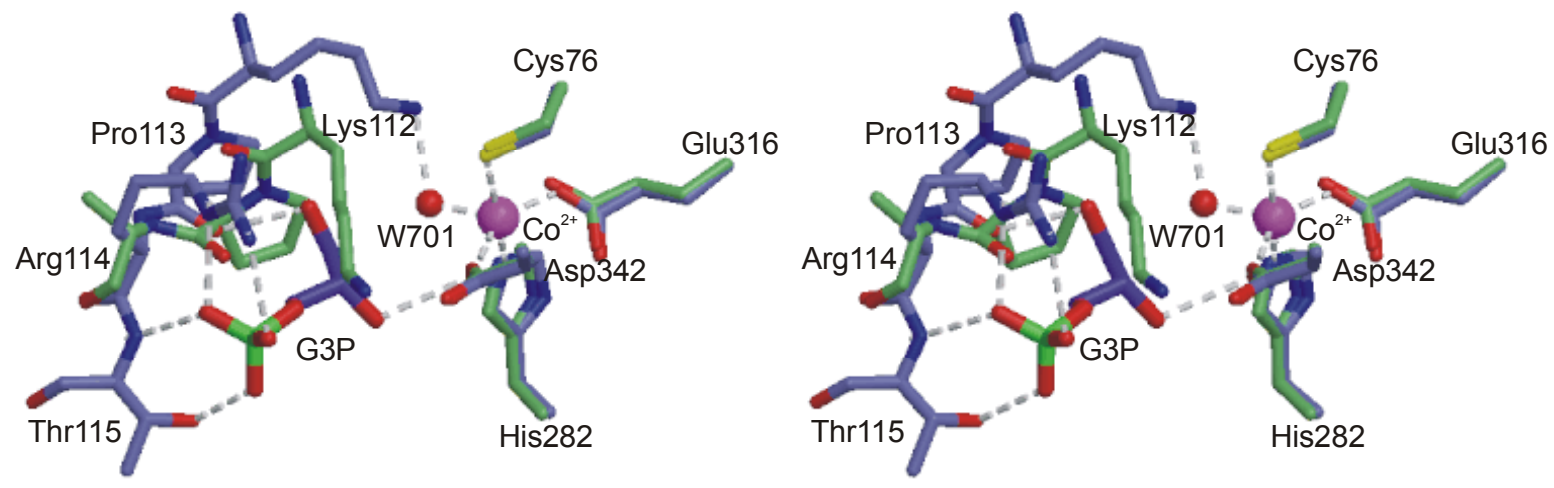

\footnotetext{
Abb. V.2.1.2.1b Stereographische Darstellung der E4P-Bindungsstellen nach Superposition der strukturell invarianten Bereiche der Strukturen 4e (blau) und 2c (grün). Aufgrund der durch die Effektoreinlagerung hervorgerufenen Verschieben des loops L2 in das aktive Zentrum verformt sich die Bindungsstelle des E4P-Analogons G3P, so dass eine Einlagerung des Substrates E4P unmöglich erscheint.
} 


\section{V.2.1.2.2 Änderungen in der Effektor-Bindungstasche}
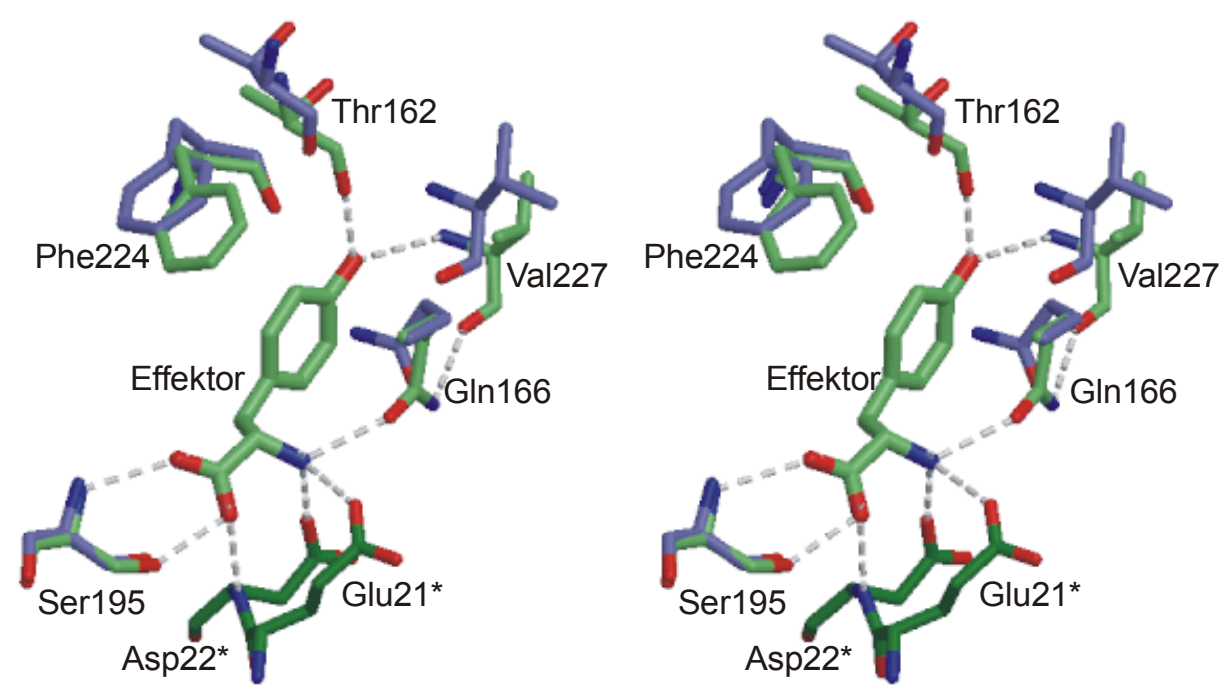

Abb. V.2.1.2.2a Stereographische Darstellung der Effektor-Bindungsstellen nach Superposition der strukturell invarianten Bereiche der Strukturen 4b (blau/dunkelblau) und 2c (grün/dunkelgrün). Während die Position des Ser195 erhalten bleibt, werden die Aminosäuren des loops L3 (Thr162 und Gln166) und des $\beta$ Stranges $\beta 6 \mathrm{a}$ (Phe224 und Val227) durch den Effektor mit ihren Hauptketten in die Bindungstasche gezogen. In dieser inhibierten Konformation stabilisieren sie sich gegenseitig über die Wasserstoffbrückenbindungen zwischen dem zum Tyrosin parallel angeordneten Asn166 und dem Val227 sowie über die Tyrosin-verbrückte Wasserstoffbrückenbindung zwischen Thr162 und Val227.

Vergleicht man die Struktur der Inhibitor-Bindungstasche des aktiven $\mathbf{4 b}$ mit der Struktur der Bindungstasche des inhibierten Enzyms 2c, so fällt auf, dass die Einlagerung des Inhibitors bei einigen Aminosäuren der Bindungstasche erhebliche Konformationsänderungen verursacht, während sie auf andere Aminosäuren, die ebenfalls Wasserstoffbrückenbindungen zum Effektor aufbauen, keinen Einfluss zu haben scheint. Das Ser195, das die Carboxylatgruppe des Tyrosins über zwei Wasserstoffbrückenbindungen bindet, wird nur wenig $\left(0.41 \AA, C_{\alpha}\right)$ in Richtung des Effektors gezogen. Auch die im Vergleich zur Struktur der aktiven Form des Enzyms zusätzlich in der Elektronendichte sichtbaren Aminosäuren Glu21* und Asp22* des Partner-Monomers sowie die an das inhibierte Monomer bindenden Aminosäuren AS18*-20* bewirken durch ihre Wasserstoffbrückenbindungen am Enzym selbst keine signifikanten Konformationsänderungen.

Die größten Konformationsänderungen und damit die inhibierende Wirkung scheint vom aromatischen System und der Hydroxylgruppe des Tyrosins auszugehen. Am auffälligsten ist die Aromat-Aromat-Wechselwirkung zwischen dem aromatischen Ring des Effektors Tyrosin und des Phe224. Diese stehen im inhibierten Zustand des Enzyms im rechten Winkel zueinander (Abb. V.2.1.1b), so dass das para-Wasserstoffatom des Phe224 mit dem delokalisierten $\pi$-System des Inhibitors in Wechselwirkung treten kann [Burley 1985]. Dadurch wird die gesamte Aminosäure Phe224 bis zu $1.7 \AA$ in das Innere der Bindungstasche 
gezogen. Auch Val227 wird durch die Wasserstoffbrückenbindung zur Hydroxylgruppe des Inhibitors in die Bindungstasche hineingezogen (1.03 $\left.\AA, \mathrm{C}_{\alpha}\right)$. Durch diese beiden EnzymInhibitor-Wechselwirkungen wird der gesamte $\beta$-Strang $\beta 6$ a bewegt. Dieser zieht das über Wasserstoffbrückenbindungen mit ihm in Kontakt stehende $\beta 6 \mathrm{~b}$ geringfügig mit. Die zweite, durch die Inhibierung hervorgerufene Hauptketten-Bewegung resultiert aus den Wasserstoffbrückenbindungen zwischen der Tyrosin-Hydroxylgruppe und Thr162 sowie der TyrosinAmingruppe und Gln166, die beide in die Bindungstasche hineingezogen werden und dadurch eine Hauptkettenbewegung des gesamten loops L3 (AS156-166) hervorrufen.

Gln166 ordnet sich durch diese Bewegung mit seiner Seitenkettengruppe energetisch günstig parallel zum aromatischen System des Tyrosins an und bildet so nicht nur die Wasserstoffbrückenbindung zum Tyrosin, sondern auch mit seiner Amingruppe eine Wasserstoffbrückenbindung zur Carbonylgruppe von Val227 aus. Durch diese Wasserstoffbrückenbindung stabilisieren sich das loop L3 und das $\beta$-Faltblatt $\beta 6 \mathrm{a} / \mathrm{b}$ (AS156-166 und AS222230) gegenseitig in der inhibierten Konformation (siehe Abb.V.2.1.1a). Dass diese Wasserstoffbrückenbindung zwischen Gln166 und Val227 für den Rückkopplungsmechanismus von Bedeutung sein muss, bestätigt die wenig aktive und nicht tyr-sensitive Mutante Gln166Glu [Hartmann 2001]. In dieser Mutante ist die Ausbildung der Wasserstoffbrücke, die die beiden loops stabilisiert wegen des Tausches der Amid- mit einer Carboxylatgruppe nicht mehr möglich.

Durch die Einlagerung des Inhibitors werden also unmittelbar in der Effektorbindungsregion der loop L3 (AS156-166) und der $\beta$-Strang $\beta 6$ a bewegt. Dies geschieht, indem zwei Aminosäuren, die vier bzw. fünf Aminosäuren voneinander entfernt liegen (Thr162 und Gln166 bzw. Phe224 und Val227), mit dem Inhibitor wechselwirken und somit die gesamte Hauptkette in ihrem Bereich mit sich ziehen. Durch die neuaufgebaute Wasserstoffbrückenbindung zwischen Val227 und Gln166 und indirekt über die Verbrückung von Thr162 und Val227 durch die Hydroxylgruppe des Effektors Tyrosins stabilisieren sich diese beiden bewegten Enzymregionen gegenseitig.

\section{V.2.1.3 Der negative Rückkopplungsmechanismus}

Es kann nun vermutet werden, auf welche Weise die Information, dass ausreichend Tyrosin in der Umgebung vorhanden und demnach kurzfristig keine weitere Produktion von DAHP für das Überleben des Organismus notwendig ist, von der Inhibitor-Bindungstasche zum ca. $22 \AA$ entfernten aktiven Zentrum übertragen wird. 

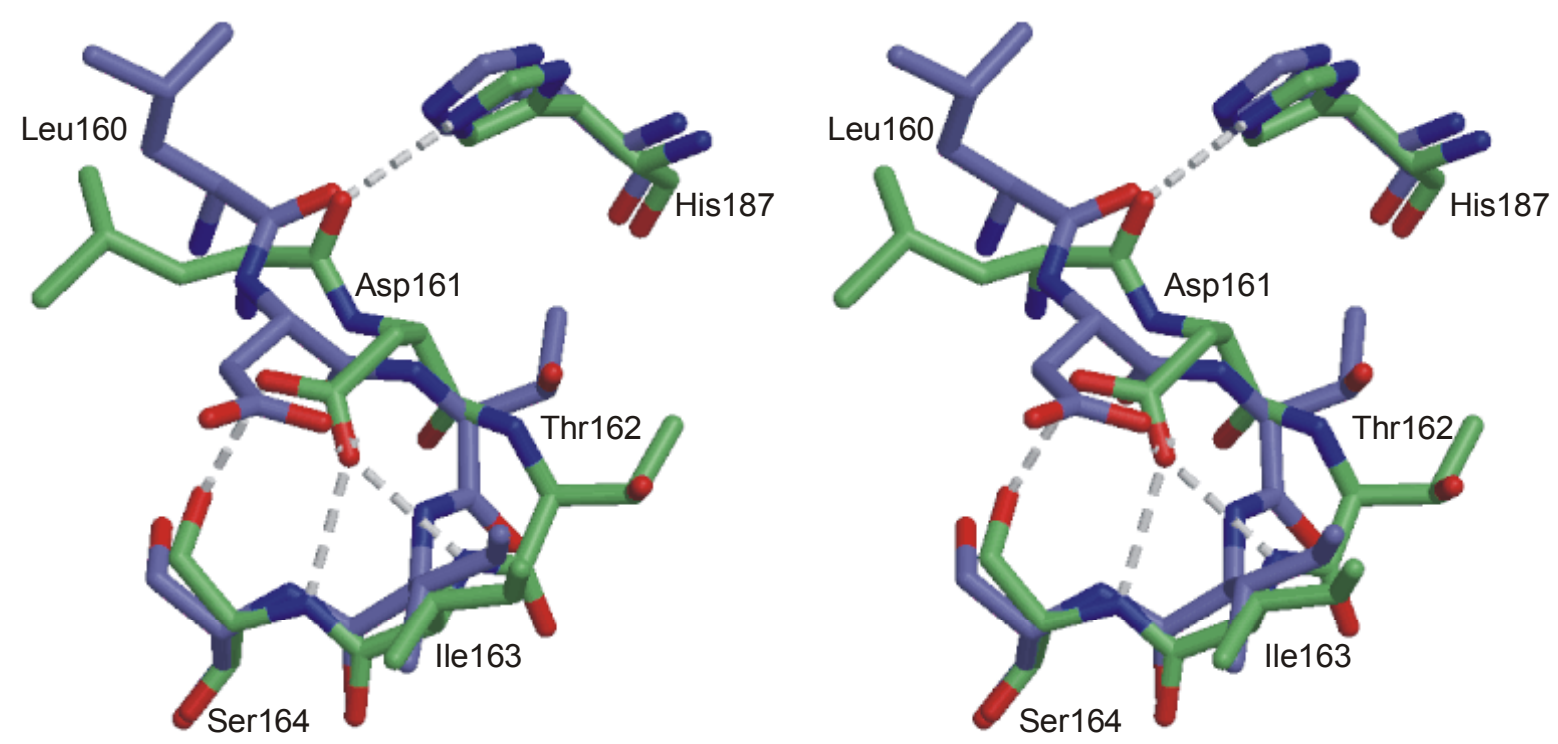

\begin{abstract}
Abb. V.2.1.3a Stereographische Darstellung des sich durch die Einlagerung des Effektors konformationell stark ändernden loops L3 nach Superposition der strukturell invarianten Bereiche der Strukturen 4b (blau) und 2c (grün). Durch die Fixierung der Position des Leu160:O durch eine starke Wassertstoffbrückenbindung zum His 187 wird dem Leu160 eine Seitenkettendrehung von ca. $60^{\circ}$ aus seiner ursprünglichen Position aufgezwungen.
\end{abstract}

Betrachtet man zunächst die Auswirkungen der Loopbewegung von L3 (AS156-166) (siehe Abb. V.2.1.3a), so ist folgender Mechanismus nachvollziehbar:

Durch die Wechselwirkung der Hydroxylgruppe des Tyrosins mit der Carbonylgruppe des Thr162 wird die Hauptkette signifikant (1.9 $\left.\AA, C_{\alpha}\right)$ zum Inhibitor gezogen (siehe Abb. V.2.1.2.2a). Durch eine Wasserstoffbrückenbindung (3.0 ̊) zwischen dem Amidstickstoffatom von Ile163 und dem Carboxylatsauerstoffatom des Asp161 wird die Hauptkette in dieser Richtung ebenfalls herangezogen (siehe $A b b$. V.2.1.3a). Dadurch, dass jedoch die Carbonylgruppe von Leu160 durch eine starke Wasserstoffbrückenbindung (2.8 ̊) vom His 187 in seiner Position festgehalten wird (siehe $A b b$. V.2.1.3a), weicht die Hauptkette samt Seitenkette von Glu158-Leu160 dieser aufgebauten Spannung aus, indem sie sich von der Inhibitor-Bindungstasche wegdreht (siehe $A b b . V \cdot 2 \cdot 1.3 a$ ). Dies bewirkt, dass sich die Seitenkette von Leu160 um einen Winkel von ca. $60^{\circ}$ aus ihrer ursprünglichen Position bewegt (siehe Abb. V.2.1.3a und Abb. V.2.1.3b). Dass die Wasserstoffbrückenbindung zwischen der Carbonylgruppe von Leu160 und dem Imidazol-Stickstoffatom von His 187 für den Wirkungsmechanismus des Enzyms von Bedeutung ist, erkennt man zum einen daran, dass dieses Histidin in allen Isoenzymen in den unterschiedlichen Organismen konserviert ist, aber auch an durchgeführten Punktmutationen [Hartmann 2001]. Tauscht man das Histidin gegen ein Phenylalanin, so erhöht sich die Aktivität um fast das dreifache seiner ursprünglichen Aktivität, tauscht man es gegen ein Leucin, so ist die Mutante nicht lebensfähig. Die durch die Tyrosin-Einlagerung verursachte $60^{\circ}$-Drehung der Leu160- 
Seitenkette ist wohl die entscheidende Bewegung, die die Information zunächst auf den räumlich benachbarten loop L2 (AS109-132) überträgt (siehe Abb. V.2.1.b). Die Position des Leu160 in der inhibierten Struktur liegt quasi auf der gleichen Position wie die Seitenketten des Glu111 der aktiven Struktur. Dieses Glu111 ist in der aktiven Struktur mit seiner Carboxylatseitenkette über sehr starke Wasserstoffbrückenbindungen zu Ser164:OG (2.58 $\AA$ ) und zu Asp161:N (2.91 $\AA$ ) mit dem loop L3 AS156-166 verknüpft (Tab. V.2.1.3a). Durch die Drehung des Leu160 wird nun die Seitenkette des Glu111 und mit ihr der gesamte, auch in der aktiven Struktur schon recht labile loop L2 AS109-132 bewegt (siehe Abb. V.2.1.3a), da die stabilisierende Wechselwirkung durch das Glu111 mit dem loop L3 (AS156-166) wegfällt. Die direkte Nachbarschaft vom am aktiven Zentrum beteiligten Lys112 zum bewegten Glu111 bewirkt auch hier eine vollständige Konformationsänderung der Haupt- und Seitenkette. In seiner neuen Position ist es dem Lys112 unmöglich, eine Wasserstoffbrückenbindung zum Substrat PEP einzugehen (siehe $A b b$. V.2.1.3a). Somit ist nicht nur eine wichtige Substrat-Enzym-Wechselwirkung aufgehoben, sondern auch eine für den Katalysemechanismus notwendige Lewis-Säure/Base-Funktion.
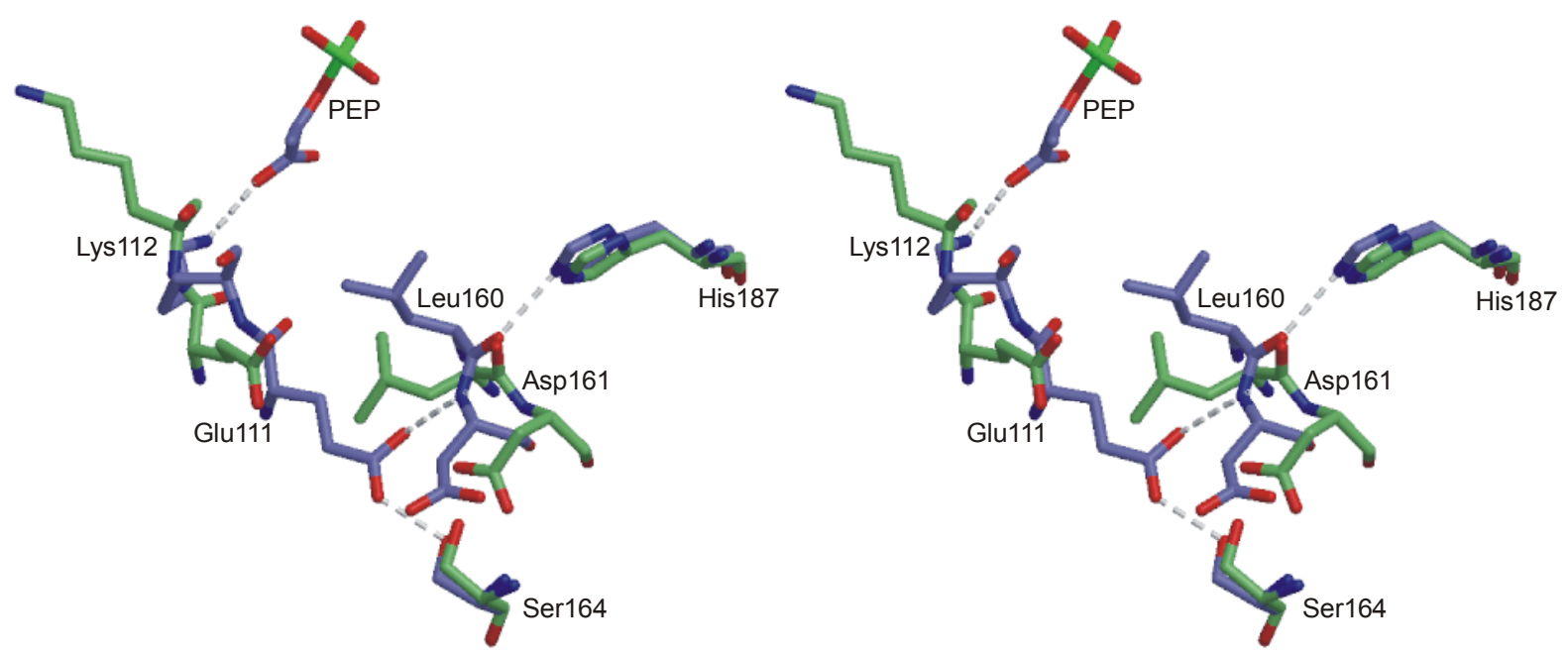

\begin{abstract}
Abb. V.2.1.3b Stereographische Darstellung der Kontakte zwischen loop L2 und loop L3 nach Superposition der strukturell invarianten Bereiche der Strukturen 4b (blau) und 2c (grün). Aufgrund der Drehung des Leu160 in der inhibierten Struktur brechen die starken Wasserstoffbrückenbindungen zwischen Glu111 und dem loop L3 auf, über die das loop L2 in seiner aktiven Form stabilisiert wurde. Die Seitenkette des Leu160 nimmt in der inhibierten Konformation die Position der Seitenkette des Glu111 der aktiven Konformation ein. Im inhibierten Zustand wird der gesamte loop L2 um mehrere $\AA$ bewegt, so dass unter anderem die Bindung des PEP durch Lys112 aufgegeben werden muss.
\end{abstract}

Wodurch die Aufgabe der Arg180-PEP-Wechselwirkung erzwungen wird, ist nicht so eindeutig nachzuvollziehen. Wahrscheinlich spielen hierbei viele kleine Faktoren eine Rolle. Das Arg180 wird sicherlich u. a. durch die Umlagerung des loops L2 AS109-132 dazu bewegt, seine in der aktiven Struktur besetzte Position aufzugeben. Während es in der aktiven Struktur nur durch die Bindung zum Substrat PEP stabilisiert wird, geht es in der Position der 
inhibierten Struktur Wasserstoffbrückenbindungen ein, die diese Position gegenüber der mit PEP komplexierten bevorzugt (Abb. V.2.1.3c). Die eine Amingruppe des Guanidinrestes bildet eine Wasserstoffbrückenbindung zur Carbonylgruppe des verschobenen (da in L2 gelegenen) Arg114 aus, dessen Seitenkette in sechs der acht Monomeren fehlgeordnet ist. Durch dieselbe Positonsänderung wird die den loop L2 in seiner aktiven Konformation stabilisierende Wasserstoffbrückenbindung zwischen dem Amid-Stickstoff des Arg114 und der Seitenkette von Gln185* des Partner-Monomers aufgebrochen, so dass die Seitenkette von $\mathrm{Gln} 185^{*}$ um seine $\mathrm{C}_{\beta}-\mathrm{C} \gamma$-Bindung rotiert $(A b b$. V.2.1.3c). In dieser Position kann es nun eine starke Wasserstoffbrückenbindung zur zweiten Amingruppe des Arg180 ausbilden. Die dritte stabilisierende Wasserstoffbrückenbindung bildet sich ebenfalls zwischen den beiden Monomeren aus, und zwar zwischen der Carbonylgruppe des Glu183* und dem NE des zu stabilisierenden Arg180. Auffallend ist, dass sich die Stabilisierung des Arg180 in der inhibierten Struktur über zwei Wechselwirkungen zwischen den beiden zum Dimer vereinigten Monomeren ausbildet.
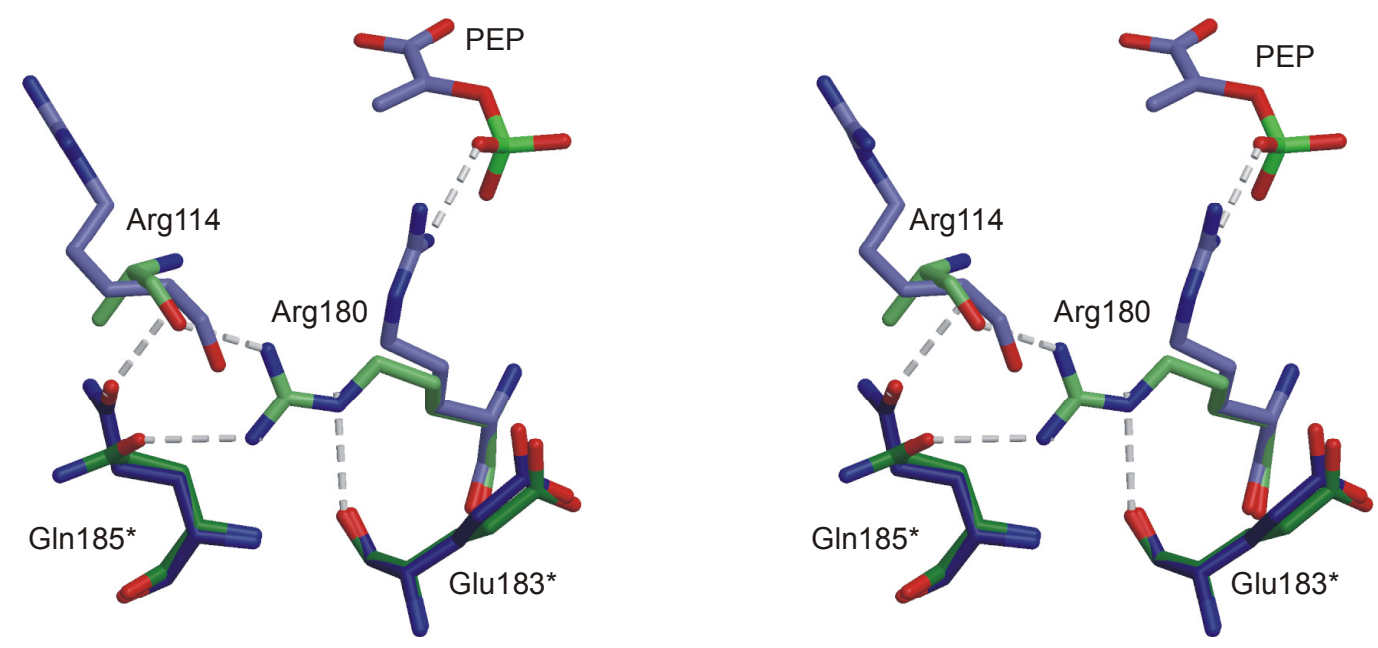

\begin{abstract}
Abb. V.2.1.3c
Stereographische Darstellung der Rotamerfixierung des Arg180 nach Superposition der strukturell invarianten Bereiche der Strukturen 4b (blau/dunkelblau) und 2c (grün/dunkelgrün). In der aktiven Konformation bindet das Arg180 das in der aktiven Tasche eingelagerte PEP. Im inhibierten Zustand wird es als $\mathrm{C}_{\beta}-\mathrm{C}_{\gamma}$-Rotamer über mehrere Wechselwirkung auch zwischen den beiden Monomeren eines Dimers fixiert.
\end{abstract}

Eine weitere erwähnenswerte Wechselwirkung zwischen den beiden Monomeren ist die $\pi-\pi-$ Wechselwirkung der Seitenketten von His223 und Phe132*. Dadurch, dass His223 durch die Aromat-Aromat-Wechselwirkung von Phe224 mit dem Effektor Tyrosin in die Richtung der Bindungstasche gezogen wird, zieht es den mit ihm wechselwirkenden Phenylring des Phe132* und mit ihm auch die Hauptkette in diesem Bereich mit sich. Dies 
führt wahrscheinlich ebenfalls zu einer Stabilisierung des loops L2 in der inhibierten Form des Enzyms.

Um die hier postulierte Informationsübertragung zu verifizieren, wären kinetisch Untersuchungen an Punktmutationen sinnvoll, die den Effektor-Mechanismus nach oben beschriebener Theorie ausschalten müssten. In erster Linie interessant wäre die Doppelmutante Leu160Ala/Glu111Ala. In dieser Mutante sollte der Übertragungsweg über die beiden loops L3 auf L2 unterbrochen sein. Weiterhin von Interesse wäre die Punktmutante Arg180Ala. Durch sie könnten Rückschlüsse auf den Einfluss dieses Arginins auf die PEP-Bindung und auf die Konsequenz der Bindungsaufgabe gezogen werden. Auch die schon in Kap. V.1.4 im Zusammenhang mit dem Katalysemechanismus vorgeschlagene Lys112Ala-Mutante wäre hier von Bedeutung. Um die Bedeutung der Aromat-Aromat-Wechselwirkung zwischen Effektor und Phe224 besser einordnen zu können, wäre neben der schon existierenden Phe224Tyr-Mutante die Phe224Ala-Mutante wahrscheinlich aussagekräftiger.

\begin{tabular}{|c|c|c|c|c|c|}
\hline \multicolumn{5}{|c|}{ unterschiedliche, intramolekulare Wasserstoffbrückenbindungen zwischen $2 \mathrm{c}$ und $4 \mathrm{e}$} & \multirow{3}{*}{$\begin{array}{l}\text { [̊̊] } \\
3.31\end{array}$} \\
\hline \multicolumn{2}{|c|}{ Tyr-Mn ${ }^{2+}-K o m p l e x ~(2 c)$} & \multirow{2}{*}{$\frac{[\AA ̊]}{2.91}$} & \multicolumn{2}{|c|}{ PEP-G3P-Mn ${ }^{2+}-$ Komplex (4e) } & \\
\hline Tyr28:OH & Asp22:OD2 & & Leu110:N & Ser157:OG & \\
\hline Asn124:ND2 & Lys120:O & 2.97 & Lys112:N & Lys120:O & 2.78 \\
\hline Asn133:N & Asn124:O & 2.94 & Arg114:NH2 & Trp119:O & 2.87 \\
\hline Thr162:OG1 & Met225:O & 3.24 & Phe132:N & Asp125:OD1 & 3.02 \\
\hline Arg180:NE1 & $\operatorname{Arg} 114: 0$ & 3.08 & Ile134:N & Phe132:O & 2.90 \\
\hline \multirow[t]{3}{*}{ Gln185:NE2 } & Glu189:OE2 & 3.05 & Leu160:N & Glu111:OE1 & 3.17 \\
\hline & & & Asp161:N & Glu111:OE1 & 2.95 \\
\hline & & & Ser164:OG & Glu111:OE2 & 2.68 \\
\hline \multicolumn{6}{|c|}{ unterschiedliche, intermolekulare Wasserstoffbrückenbindungen zwischen $2 \mathrm{c}$ und $4 \mathrm{e}$} \\
\hline \multicolumn{2}{|c|}{ Tyr-Mn ${ }^{2+}-$ Komplex (2c) } & {$[\AA ̊ 丿]$} & \multicolumn{2}{|c|}{ PEP-G3P-Mn ${ }^{2+}-$ Komplex (4e) } & [̊̊] \\
\hline Asp22:N & Ser195:OG* & 3.11 & Arg114:N & Gln185:OE1* & 2.91 \\
\hline Gln38:NE2 & Glu21:OE2* & 2.88 & Lys120:NZ & Glu189:OE2* & 2.71 \\
\hline Lys52:NZ & Gly18:O* & 2.76 & Lys120:NZ & His222:ND1* & 2.81 \\
\hline Arg55:NH1 & Glu20:O* & 2.79 & Asn124:ND2 & His 223:O* & 2.74 \\
\hline Arg55:NH1 & Glu20:OE1* & 2.90 & Gln185:NH2 & Lys112:O* & 2.99 \\
\hline Arg180:NE & Glu183:O* & 2.98 & Gln185:NH2 & Lys112:O* & 2.99 \\
\hline $\operatorname{Arg} 180: \mathrm{NH} 2$ & Glu183:O* & 3.00 & Arg188:NH1 & Thr115:O* & 2.81 \\
\hline Arg180:NH2 & $\mathrm{G} \ln 185: \mathrm{OE} 1 *$ & 3.09 & & & \\
\hline Lys229:NZ & Glu21:OE1* & 2.79 & & & \\
\hline Lys229:NZ & Glu21:OE2* & 2.88 & & & \\
\hline
\end{tabular}

Tab.V.2.1.3a Auflistung der Wasserstoffbrückenbindungen, die im Vergleich zwischen der Struktur des aktiven Enzyms (4e) und der Struktur des inhibierten Enzyms (2c) zusätzlich aufgebaut wurden. Mit * gekennzeichnete Aminosäuren gehören zum Partner-Monomer innerhalb des Dimers. 
Aus kinetischen Untersuchungen [Hartmann 1996] ist bekannt, dass die tyr-sensitive DAHP Synthase aus S. cerevisiae nicht nur durch Tyrosin sondern auch durch Phenylalanin inhibierbar ist. Mit einem $\mathrm{K}_{\mathrm{i}}$ von $270 \mu \mathrm{M}$ sind jedoch 100mal höhere Aminosäurekonzentrationen notwendig als für die Inhibierung mit dem Effektor Tyrosin $\left(K_{i}=0.9 \mu \mathrm{M}\right)$. Schon aus den Kristallisationsversuchen (siehe Kap. IV.1.2) wurde ersichtlich, dass die Komplexbildungskonstante des Enzyms mit Phenylalanin (bzw. Alanin) deutlich geringer als die des tatsächlichen Effektors zu sein scheint. Betrachtet man nun die Effektorbindungstasche der DAHP Synthase im Komplex mit Phenylalanin, so fällt auf, dass das Enzym zwar in der gleichen Raumgruppe kristallisiert $\left(\mathrm{P} 1_{\mathrm{gr}}\right.$ im Gegensatz zur nur mit Metallion komplexierten trigonalen Kristallform), dass jedoch nicht jede der acht kristallographisch unabhängigen Bindungstaschen vollständig mit Phenylalanin besetzt ist. Nur in den Monomeren $\mathrm{C}$ und D bzw. G und H konnte die Elektronendichte als Phenylalanin verfeinert werden.
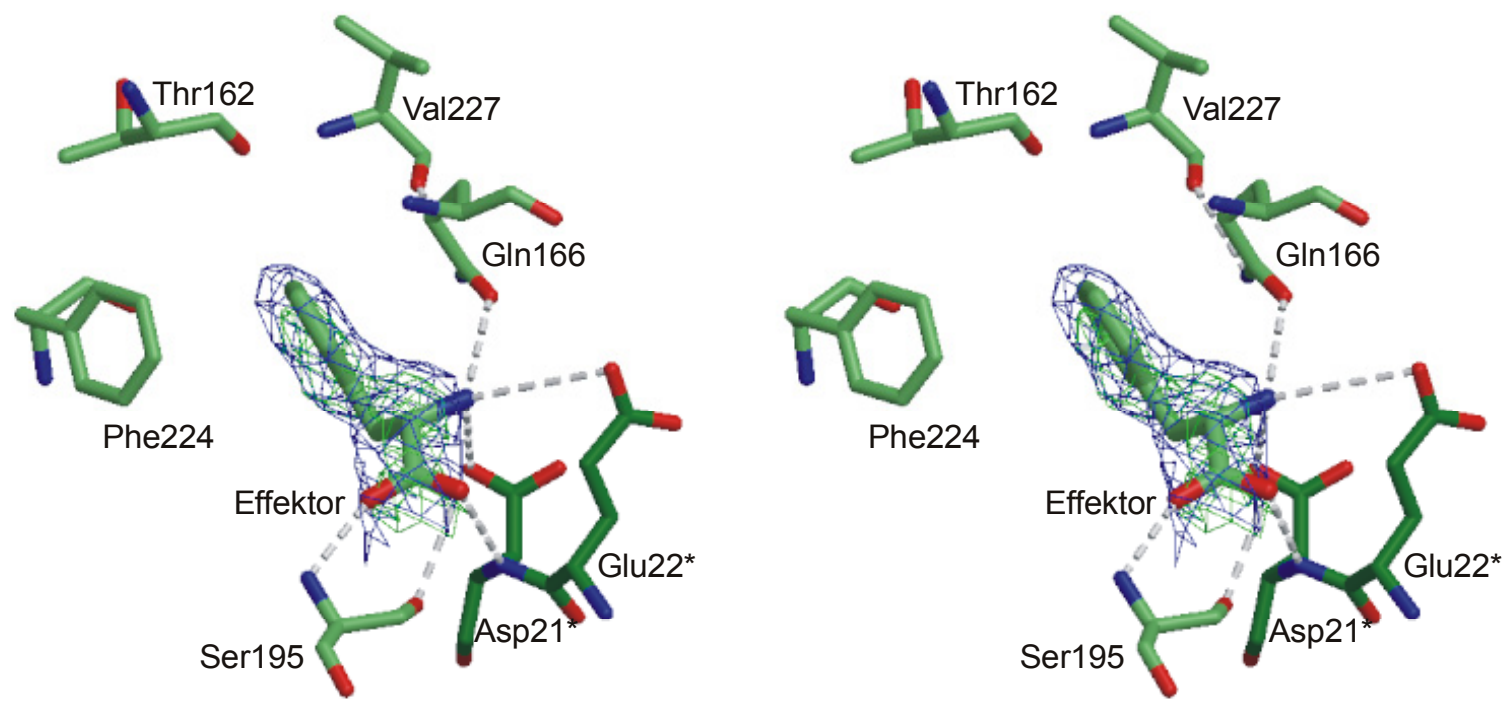

\begin{abstract}
Abb. V.2.2a Stereographische Darstellung der Effektorbindungstasche mit dem für die tyr-sensitive DAHP Synthase nicht spezifischen Effektor Phenylalanin. blau: sigmaA gewichtete 2mfo-Dfc-omit-map konturiert bei $1 \sigma$, grün: fo-fc-omit-map konturiert bei $3 \sigma$. Während die Bindungsstellen der Carboxylatgruppe und der Amingruppe erhalten bleiben, können die durch die Hydroxylgruppe des Tyrosins ausgebildeten Wasserstoffbrücken zu Thr162 und Val227 nicht geformt werden.
\end{abstract}

Bemerkenswert ist, dass die Bindung eines Effektors die Bindung eines zweiten Effektors im Partner-Monomer zu fördern scheint. Über die Kooperativität in bezug auf den Effektor werden in der Literatur für die unterschiedlichen Isoenzyme in verschiedenen Organismen unterschiedliche Angaben gemacht [Stephens 1991; Akowski, 1997, u. a.]. Sie ist möglicherweise auf die bei Effektoreinlagerung beobachtete Monomerkontaktänderungen innerhalb des Dimers zurückzuführen (Tab. V.2.1.3a). Diese Teilbesetzung der Effektorbindungstasche ist 
ein weiterer Hinweis auf die schwache Bindung des Phenylalanins an die Bindungstasche des für dieses Isoenzym spezifischen Effektors Tyrosin. Vergleicht man nun die Bindungsverhältnisse des Tyrosins mit denen des Phenylalanins, so wird der Unterschied in der Komplexbindungsstärke verständlich. Zunächst ist die Bindungstasche des Phenylalanins mit der des Effektors Tyrosin identisch. Wie vermutet wird die aromatische Aminosäure über die in allen DAHP Synthasen konservierten Bindungsstellen (Glu21, Asp22, Ser195, Asn166 und Phe224) festgehalten. Das Asn166 ordnet sich auch hier energetisch günstig parallel zum Aromaten des Effektors an und bildet Wasserstoffbrückenbindungen sowohl zur Amingruppe des Effektors als auch zum Carbonylsauerstoffatom des Val227 aus. Auch das Phe224 wird durch den aromatischen Ring des Effektors in die Bindungstasche hineingezogen, allerdings ist diese Bewegung mit $1.2 \AA$ nicht so stark ausgeprägt wie bei der Inhibierung mit Tyrosin ( siehe $A b b$. V.2.2.b).
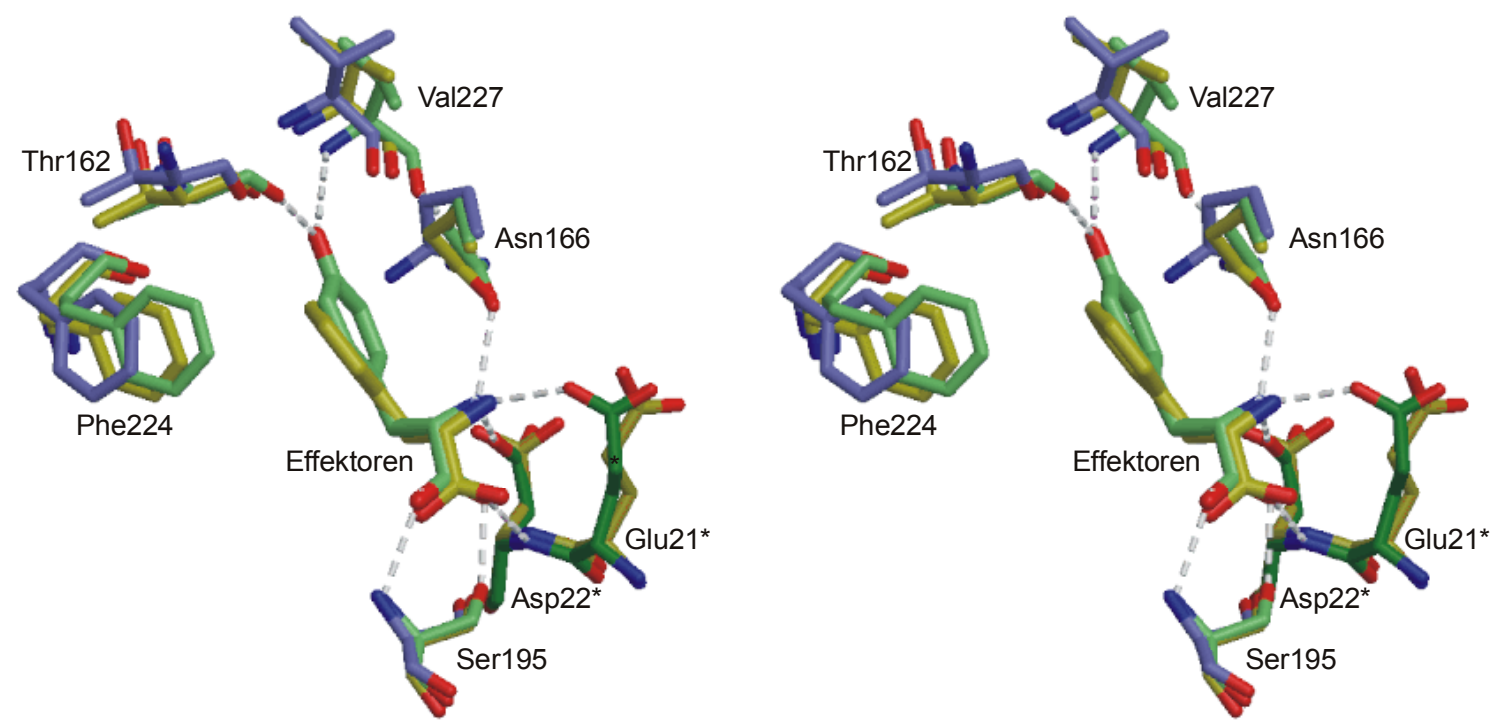

Abb. V.2.2b

Stereographische Darstellung der Effektorbindungstaschen aus den Strukturen 2c (grün), 2d (gelbgrün) und 4e (blau) nach Superpositionierung der konformationell invarianten Enzymbereiche. Aufgrund der fehlenden Wasserstoffbrückenbindungen des Phenylalanins zu Thr162 und Val227, die in der Struktur 2c die Konformationsänderungen des loops L2 und des $\beta$-Strangs $\beta 6$ a stabilisieren, ist die Lage des aromatischen Rings zu der des Tyrosins leicht verschieden. Daraus resultiert eine weniger stark ausgeprägte Aromat-Aromat-Wechselwirkung des Phe226 mit dem aromatischen System des Effektors.

Im Fall des Phenylalanins als Effektor fehlen die für das Tyrosin charakteristischen Wasserstoffbrückenbindungen der Hydroxylgruppe zu Thr162:OG und Val227:N. Dies führt zum einen zu einer sehr viel geringeren Bindungsstärke des Phenylalanins an das Enzym im Vergleich zum Tyrosin, zum anderen fehlt für den Inhibierungsmechanismus eine wichtige Wechselwirkung zwischen dem loop L160-166 und dem $\beta$-Strang $\beta$ a (AS224-227), die im Fall des Tyrosins über seine Hydroxylgruppe stattfindet und zur Stabilisierung der inhibierten Struktur beiträgt. Die Elektronendichte der Struktur 2d weist im Bereich der Informationsübertragung (Leu160 (L3) und Glu111 (L2) ) schlechte Qualität auf, so dass die Lagen der 
Seitenketten nicht eindeutig zu bestimmen sind. Die Lage der Seitenkette des Arg180 liegt jedoch in sieben der acht Fällen in der inhibierten Konformation vor. Die schlecht definierte Elektronendichte der für den Inhibierungsmechanismus wichtigen loops kann unterschiedliche Ursachen haben. Ein Grund liegt wahrscheinlich in der mäßigen Qualität des Datensatzes mit einer Auflösung von $2.7 \AA$, die jedoch auch durch die Flexibilität einiger Enzymbereiche bedingt sein könnte. Ursache für diese Flexibilität könnte sein, dass die verfeinerten Lagen der Phenylalanine aufgrund fehlender, wichtiger Wasserstoffbrückenwechselwirkungen wahrscheinlich nicht zu 100\% besetzt sind. Dieses Problem könnte eventuell durch Kristallisation mit einem höheren Überschuss an Phenylalanin aufgehoben werden. Doch auch im komplexierten Zustand scheint die inhibierte Konformation nicht so stabilisiert zu werden, wie dies im mit Tyrosin komplexierten Enzym der Fall ist. Dadurch dass die Brückenfunktion der Tyrosin-Hydroxylgruppe zwischen dem loop L2 und dem $\beta$-Strang $\beta$ a (Thr162 und Val227 über Tyrosin) nicht vorhanden und auch die Aromat-AromatWechselwirkung zwischen Phe224 und dem Effektor nicht so stark ausgeprägt ist (siehe Abb. V.2.2b), kann die Stabilisierung der komplexierten Enzymkonformation im Fall des Phenylalanins als Effektor nur über die Wechselwirkung des Asn166 sowohl mit dem Aromaten des Effektors, als auch mit Val227 stattfinden.

\section{V.2.3 Strukturbeschreibung der Punktmutante Gly226Ser (2e)}

Für die unterschiedliche Sensibilität (phe-, tyr- und trp-sensitiv) und Kinetik (kompetitiv bzw. nicht-kompetitiv bezüglich der Substrate) der negativen Rückkopplungsmechanismen der drei Isoenzyme sind wahrscheinlich Unterschiede in der Sequenz und daraus folgend im strukturellen Aufbau der Isoenzyme verantwortlich.

Vergleicht man die Aminosäuresequenz der informationsübertragenden Bereiche $\beta 6 \mathrm{a}$ (224227) und L3 (160-166) in den Isoenzymen der verschiedenen Organismen, so fällt eine große Übereinstimmung auf (siehe $A b b . I d$ ). Im loop L3 sind wie schon in Kap. V.2.1.1 beschrieben die in den Effektormechanismus involvierten Aminosäuren Leu160 und Asn166 in allen Isoenzymen konserviert, ebenso das Asp161. Pro165 ist mit Ausnahme der trp-sensitiven DAHP Synthase in allen Isoenzymen enthalten. Dies lässt darauf schließen, dass die Bindungstasche der trp-sensitive DAHP Synthase in diesem Bereich statt der Aminosäure Prolin ein Glycin als „Scharnierfunktion“ der Loopregion benutzt, um Platz für den im Tryptophan zusätzlich vorhandenen Pyrrolring zu schaffen. Die Aminosäuren Thr162, Ile163 und Ser164 sind in den übrigen Isoenzymen zum Teil konservativ durch Methionin, Valin und 
Threonin ausgetauscht. Auch im Bereich des $\beta$-Stranges $\beta 6 \mathrm{a}$ sind die hydrophoben Seitenketten zum Teil konserviert (Phe224) oder konservativ ausgetauscht (Met225 gegen Leu oder Val und Val227 gegen Ile oder Phe). Auffällig ist der Wechsel der Aminosäuren auf der Position AS226. Während sich in den tyr-sensitiven DAHP Synthasen sowohl aus E. coli als auch aus $S$. cerevisiae an dieser Position ein Glycin befindet, wird dieses systematisch in den phe- und trp-sensitiven Isoenzymen durch ein Serin ersetzt $(A b b . I d)$. Kinetische Untersuchungen [Hartmann 2001] an den Punktmutanten Gly226Ser und Gly226Thr der tyrsensitiven DAHP Synthase aus $S$. cerevisiae ergaben tatsächlich eine Umkehr der Sensibilität (Tab. Ia). Um zu verstehen, wieso ein selektiver Austausch einer Aminosäure die Sensibilität der DAHP Synthase von tyr- auf phe-sensitiv umstellt, wurde die Kristallstruktur der Punktmutanten Gly226Ser mit Phenylalanin komplexiert. Alle acht Effektorbindungstaschen der asymmetrischen Einheit sind mit Phenylalanin besetzt. Die Lage des Phenylalanins entspricht in etwa der Lage des Phenylalanins in Kap. V.2.2 ( siehe Abb. V.2.2b) und ist in allen acht Monomeren eindeutig in der Elektronendichte zu bestimmen. Auch die Position des Ser226: $C_{\beta}$ der Punktmutation ist eindeutig definiert, wohingegen auch nach mitteln über die acht unabhängigen Moleküle aufgrund der Elektronendichte nicht eindeutig auf die Lage der Hydroxylgruppe Ser226:OH geschlossen werden kann (siehe Abb. V.2.3a). Dieses Phänomen ist zum einen auf die schlechte Qualität des Datensatzes bei $2.7 \AA$ zurückzuführen, zum anderen wären Fehlordnungen der Hydroxylgruppe möglich. Lässt man die Hydroxylgruppe des Ser226 um die $\mathrm{C}_{\alpha}-\mathrm{C}_{\beta}$-Bindung rotieren, so ergeben sich drei mögliche Positionen, in denen sie sinnvolle Wasserstoffbrückenbindungen ausbilden kann (Abb. V.2.3b).
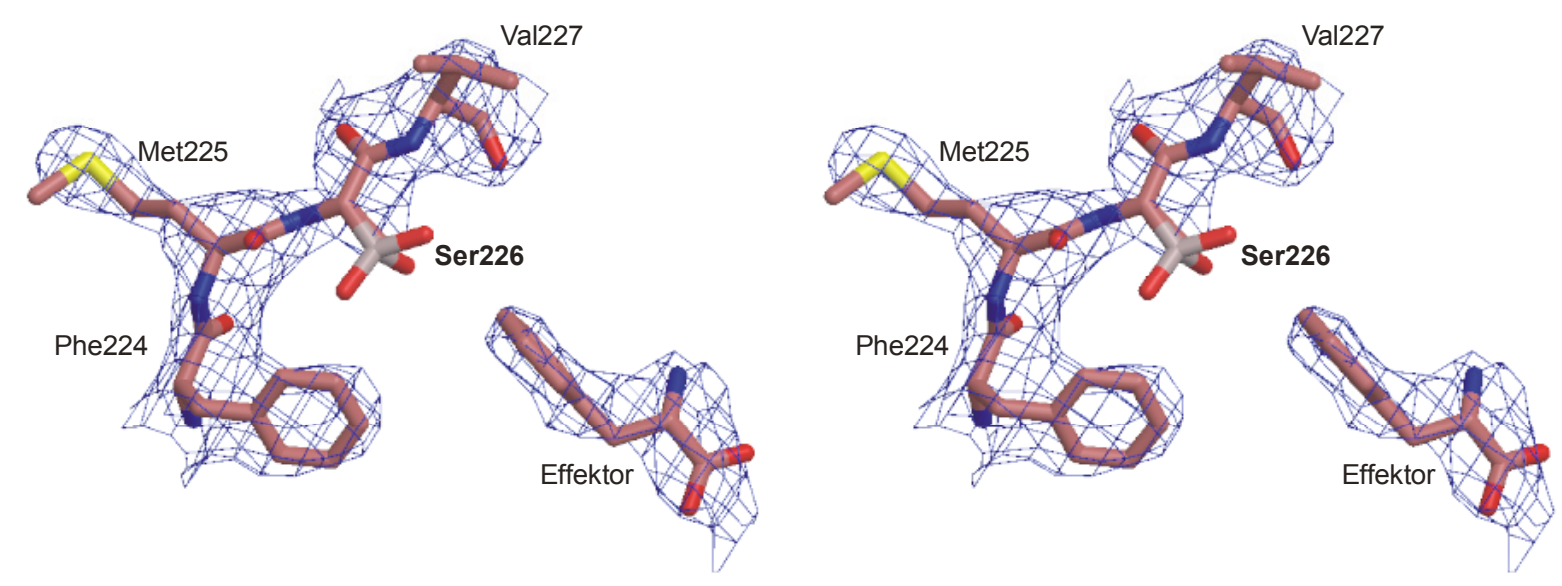

\footnotetext{
Abb. V.2.3a Stereographische Darstellung des $\beta$-Stranges mit der Punktmutanten Gly226Ser und des Effektors Phenylalanin. Die dargestellte Elektronendichtekarte entspricht einer bei $1 \sigma$ konturierten $2 \mathrm{mfo}-$ Dfc-omit-map im Bereich des Phenylalanins und der gesamten Aminosäure Ser226. Die Lage des Effektors und des Ser226:CB ist eindeutig in der Elektronendichte zu erkennen, während für die Hydroxylgruppe Ser226:OG drei mögliche, in bezug auf Wasserstoffbrückenausbildung günstige Rotamere dargestellt sind (hellrosa).
} 

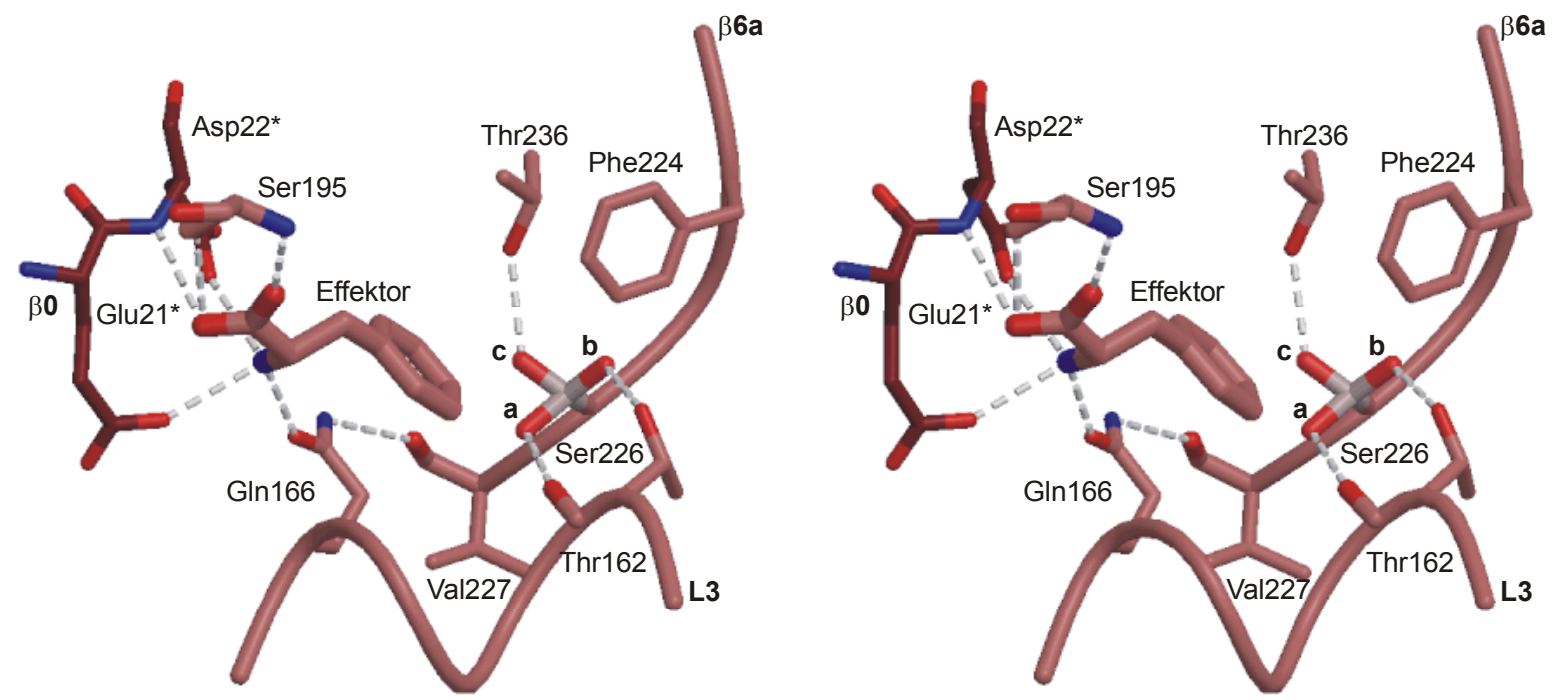

Abb. V.2.3b

Stereographische Darstellung der Effektorbindungstasche der Punktmutanten Gly226Ser. Zwei der möglichen, dargestellten Wasserstoffbrückenbindungen des Ser226 würden zu einer gegenseitigen Stabilisierung von L3 und $\beta 6$ a im durch Phenylalanin inhibierten Zustand führen (a und $\mathbf{b}$ )

Eine Möglichkeit, die sich in Molekül B, C und $\mathrm{H}$ als Position andeutet, wäre eine Wasserstoffbrückenbindung zum Carbonylsauerstoffatom des Thr162 (Abb. V.2.3b: a), eine weitere sinnvolle Wasserstoffbrücke könnte zur Hydroxylgruppe des Thr162 ausgebildet werden ( $A b b$. V.2.3b: b) und eine dritte mögliche Wasserstoffbrücke würde sich durch das Rotamer c (Abb. V.2.b3: c) zu Thr236 ergeben.

Während das dritte Rotamer nicht zu einer Stabilisierung der inhibierten Struktur beitragen würde, hätten die beiden ersten, möglichen Rotamere entscheidenden Einfluss auf die Stabilität der inhibierten Struktur. Sie würden zur beim Tyrosin von der Hydroxylgruppe übernommenen Aufgabe der Stabilisierung der beiden bewegten Bereichen L3 und $\beta 6 \mathrm{a}$ beitragen ( $A b b$. V.2.3b). Durch eine direkte Wasserstoffbrückenbindung zwischen den beiden loops (Ser226:OG mit Thr162:O) würden sie die über das Tyrosin verbrückte (Val227:N über Tyr $_{\text {eff: }} \mathrm{OH}$ zu Thr162:O) Bindung ersetzten. Diese im Vergleich zum unkomplexierten Enzym neu ausgebildete, stabilisierende Wasserstoffbrückenbindung kann sich erst dadurch ausbilden, dass sich die beiden loops durch Wechselwirkungen (z. B. Phe224, Glu166) mit dem eingelagerten Effektor Phenylalanin näherkommen.

Die Möglichkeit der Wasserstoffbrückenbindung c zwischen der Punktmutation Ser226 (bzw. Ser219 in der phe-sensitiven aus E. coli) und Thr236 (bzw. Val229 in der phe-sensitiven aus E. coli) ist in der phe-sensitiven DAHP Synthase aus E. coli nicht gegeben, da die analoge Aminosäure Valin keine Wasserstoffbrückenbildung ermöglicht. Eine Doppelmutante Gly226Ser/Thr236Val sollte demnach, falls tatsächlich eine Wasserstoffbrücke zwischen Ser226 und Thr236 ausgebildet werden kann, die Inhibierungseffektivität der Mutanten zusätzlich erhöhen. 

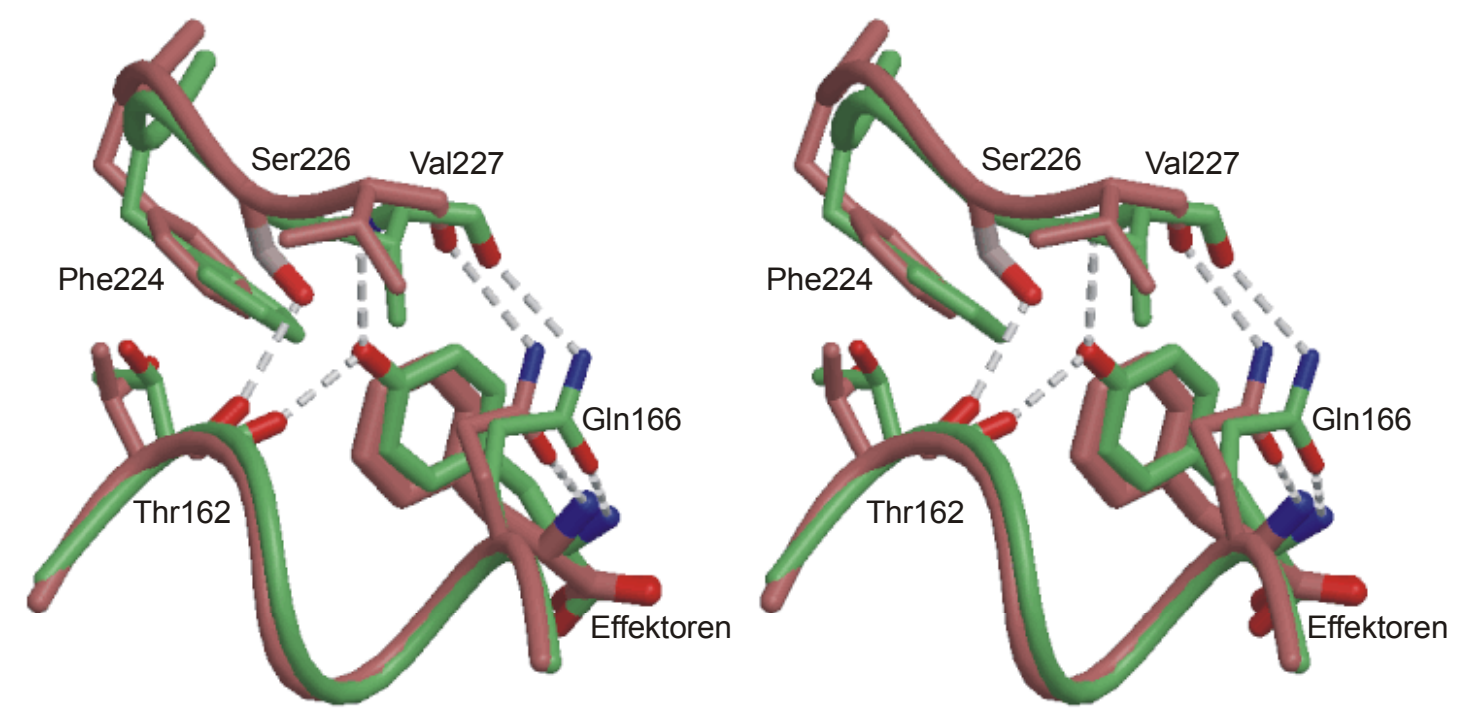

Abb. V.2.3c

Stereographische Darstellung der superpositionierten Effektorbindungstaschen der Strukturen 2c (grün) und 2e (altrosa). In beiden Fällen werden L3 und $\beta 6$ a im inhibierten Zustand durch Wasserstoffbrückenbindungen zwischen beiden Enzymbereichen stabilisiert. In Struktur 2c verläuft diese Stabilisierung über die Hydroxylgruppe des Effektors Tyrosin, in der phe-sensitiven Punktmutante Gly226Ser (2e) über eine direkte Verknüpfung der Bereiche durch die Hydroxylgruppe des Ser226.

Auch die Wasserstoffbrückenbindung b zur Hydroxylgruppe des Thr162 kann in der phesensitiven DAHP Synthase aus E. coli nicht ausgebildet werden, da die analoge Aminosäure hier ein Methionin ist. Auch hier sollte eine doppelte (Gly226Ser/Thr162Met) bzw. eine dreifache (Gly226Ser/Thr162Met/Thr236Val) Punktmutante die Effektivität der Phenylalanin-Sensibilität erhöhen.Der negative Rückkopplungsmechanismus in dieser Punktmutante wird trotz Austausch der Effektoren quasi durch das Übertragen der Hydroxylgruppe vom Tyrosin (das zum Phenylalanin wird) auf das Gly226 (das zum Ser226 wird) und so durch Aufbau eines ähnlichen Wasserstoffbrückenbindungsnetzes aufrechterhalten. Es kann also vermutet werden, dass in den phe-sensitiven DAHP Synthasen die Stabilisierung der bewegten Enzymbereiche L3 und $\beta 6$ a im inhibierten Zustand über die oben diskutierte Wasserstoffbrückenbindung des Serins erfolgt.

In diesem Fall würde auch im phe-sensitiven Enzym die Information von loop L3 auf den die Bindungsstellen der Substrate beinhaltenden loop L2 übertragen werden. Nicht geklärt wären damit die Unterschiede in der Kinetik, denn falls beide Enzyme über den in Kap. 2.1.3 postulierten Rückkopplungsmechanismus funktionieren würden, müssten sie beide kompetitiv in bezug auf PEP und nicht-kompetitiv in bezug auf E4P arbeiten. Dies wird jedoch nicht beobachtet [Paravicini 1989]. Wahrscheinlich existieren also zwischen beiden Isoenzymen noch weitere strukturelle und damit mechanistische Unterschiede, die nicht durch die Mutation Gly226Ser simuliert werden können. 


\section{V.2.4 Literaturvergleich}

In einem kürzlich vom Arbeitskreis Kretsinger veröffentlichten Artikel [Shumilin 2002] über die Struktur der phe-sensitiven DAHP Synthase aus E. coli im Komplex mit Mn(II), Phenylalanin und PEP wird im wesentlichen der hier postulierte Inhibierungsmechanismus bestätigt. Wie vermutet (siehe Kap. V.2.1.3), befindet sich die Phe-Bindungsstelle in der relativ hydrophoben Bindungstasche analog $\mathrm{zu}$ der hier besprochenen tyr-sensitiven DAHP Synthase. Der Effektor Phenylalanin wird erwartungsgemäß über die in allen DAHP Synthasen konservierten Aminosäuren Ser180 (bzw. Ser195 in der tyr-sensitiven DAHP Synthase aus S. cerevisiae), Gln151 (bzw. Gln166) in der Bindungstasche gebunden, die durch die Aminosäuren Asp06 und Asp07 (bzw. Glu21 und Asp22) aus dem N-Terminus des Partnermonomers geschlossen wird (siehe Kap. V.2.1.1). Auch die im Rahmen dieser Arbeit postulierte Loop-Stabilisierung durch eine die Wasserstoffbrückenbindungen zur Hydroxylgruppe des Effektors Tyrosin ersetzende Wasserstoffbrückenbindung des Ser211:OH (bzw. Ser226) zum Met147:O (bzw. Thr162) (siehe Kap. V.2.3) scheint ausschlaggebend für die Stabilisierung der effektorinduzierten Konformationsänderung zu sein. Die Loop-Bewegungen und damit die Informationsübertragung von der Effektorbindungsstelle zum aktiven Zentrum findet ebenfalls in beiden Enzymen über die gleichen Enzymbereiche, den loop L3, das zusätzliche $\beta$-Faltblatt $\beta 6 \mathrm{a} / \mathrm{b}$ und den erweiterten, in die Bindungstasche involvierten loop L2 statt. Unterschiedlich scheint die Informationsübertragung vom loop L3 auf den loop L2 zu sein. Zwar brechen auch in der phe-sensitiven DAHP Synthase aus E. coli die Wasserstoffbrückenbindungen des Glu96 (analog Glu111 in der tyr-sensitiven DAHP Synthase aus $S$. cerevisiae) zum loop L3 auf, jedoch scheint dies erstaunlicherweise nicht durch eine Drehung des dem Leu160 analogen Leu145 hervorgerufen zu sein. Die Änderungen im aktiven Zentrum sind, wie aufgrund der Sequenzhomologie erwartet (siehe Kap. V.2.1.1), geprägt durch die zur aktiven Struktur verschiedenen Rotamere der das PEP bindenden Aminosäuren Lys97 (bzw. Lys112) und Arg164 (bzw. Arg180). Aufgrund der gleichen Beobachtungen wurde in Kap. V.2.1.3 angenommen, dass das Substrat PEP wegen des Verlustes wichtiger Wasserstoffbrückenbindungen nicht in seiner Bindungstasche verbleibt. Dies würde mit den kinetischen Ergebnissen der kompetitiven Hemmung in bezug auf das erste Substrat PEP in Einklang stehen. Erstaunlich erscheint die Beobachtung der Autoren, dass sich in der ähnlich veränderten Bindungstasche der phesensitiven DAHP Synthase aus E. coli das Substrat PEP um $180^{\circ}$ rotiert mit der Phosphatgruppe an der Carboxylatbindugsstelle und mit der Carboxylatgruppe an der 
Phosphatbindungsstelle einlagert. Diese Beobachtung sollte im Fall der tyr-sensitiven DAHP Synthase durch einen Kristallisationsansatz sowohl mit dem Effektor Tyrosin als auch mit dem Substrat PEP überprüft werden.

Insgesamt kann von einer weitgehenden Übereinstimmung der Mechanismen der beiden Isoenzyme aus den unterschiedlichen Organismen gesprochen werden, deren Sensibilität sich wechselseitig durch den Austausch einer einzigen Aminosäure vertauschen lässt [Hartmann 2001]. Ungeklärt verbleiben bei dieser vermeintlichen Übereinstimmung des Regulierungsmechanismus die in der Literatur beschriebenen [Schnappauf 1998; Stevens 1991; Shumilin 2002] Unterschiede in der Kinetik der Inhibition. Zur Erklärung dieser widersprüchlich erscheinenden Beobachtungen wären detailliertere Strukturuntersuchungen sowohl an möglichst hochaufgelösten Datensätzen der inhibierten Wildtypen als auch an ausgewählten Punktmutanten sowie kinetische Untersuchungen $\mathrm{zu}$ ihren unterschiedlichen Inhibierungsarten in bezug auf die Substrate von Nutzen.

\section{V.3 Raumgruppen, Kristallpackungen und Oligomerisierung}

Im Rahmen dieser Arbeit wurde die tyr-sensitive DAHP Synthase aus S. cerevisiae und Komplexe dieses Enzyms in vier unterschiedlichen Kristallformen untersucht. Nur minimale Unterschiede in den Kristallisationsbedingungen, wie z. B. PEG-Konzentration, Art und Weise der Substrat- und Effektorzugabe, Temperatur und pH-Wert sowie Dauer des Soakens in der Cryoprotektandenlösung (siehe Kap.IV.2) führten zu diesem Wechsel des Kristallaufbaus. Im folgenden sollen unterschiedliche Aspekte der Kristallpackungen untersucht werden.

\section{Betrachtung in der Asymmetrischen Einheit}

Im Fall der großen P1-Zelle, in der sämtliche Effektor-Komplexe (2c, 2d, und 2e) kristallisieren, die aber auch mit dem einfachen Metall(II)-Enzym-Komplex (2a) oder Metall(II)-PEP-Enzym-Komplex (2b) existiert, befinden sich acht Moleküle in der asymmetrischen Einheit und somit in der Zelle. Die Moleküle bilden ein loses Oktamer aus zwei Tetrameren, die sich aus zwei Dimeren zusammensetzen (Abb. V.3a: A). Anhand der Selbstrotationsfunktion der Daten ( $A b b$. V.3b:A) lässt sich eine nichtkristallographische 222Symmetrie erkennen, die jeweils die Monomere bzw. die Dimere innerhalb eines Tetramers ineinander überführt. Die beiden Tetramere einer asymmetrischen Einheit sind durch eine Translation nahezu exakt ineinander überführbar. Der scheinbare Translationsvektor beträgt in etwa (0.5 0.5 0), was auch in der Patterson-Dichtekarte an einem Maximum in der Ebene $\mathrm{Z}=0 \mathrm{zu}$ erkennen ist $(A b b . V .3 a: B)$. 

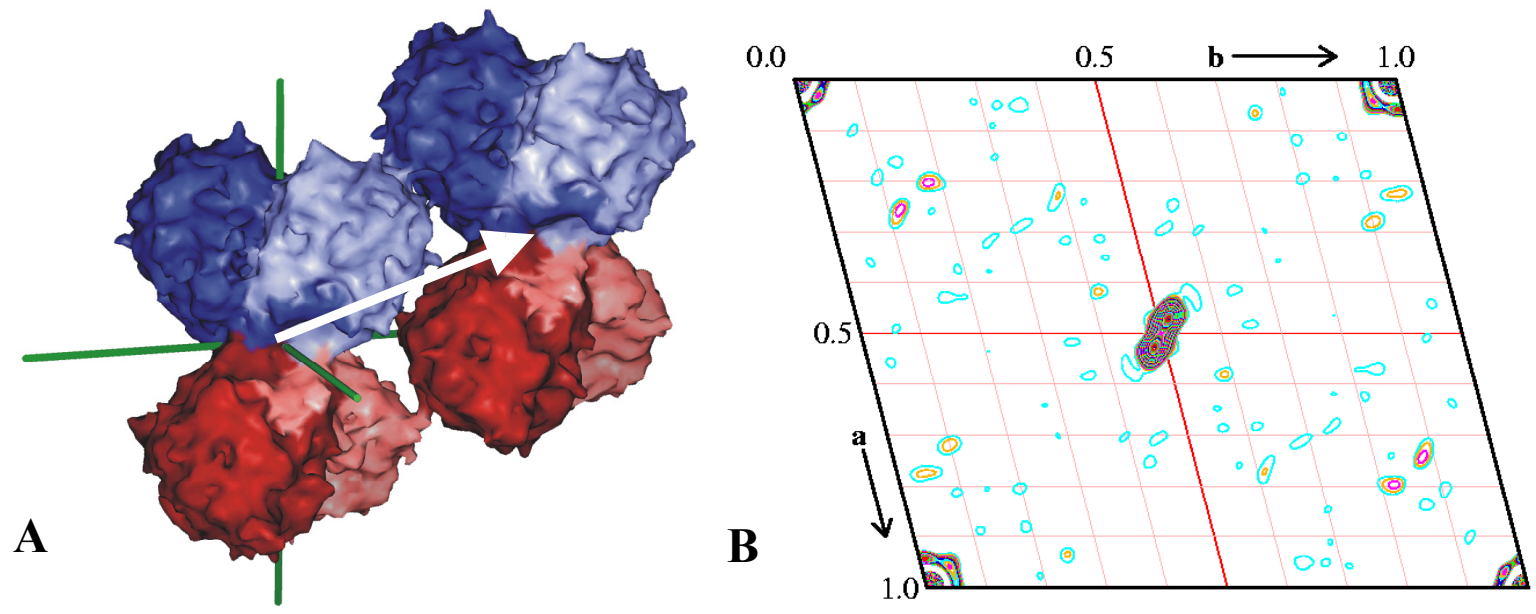

Abb. V.3a A: Kristallpackung des Oktamers in der großen P1-Zelle mit eingezeichneten nichtkristallographischen 2-zähligen Achsen der 222 Symmetrie und dem Translationsvektor entlang $(0.5,0.5,0)$ B: Pattersondichtekarte der großen P1-Zelle in der Höhe $Z=0$ bei einem Konturintervall von $1 \sigma$ mit dem Translationsmaximum mit einer Höhe von $37.1 \sigma$ auf $(0.527,0.482,0)$.
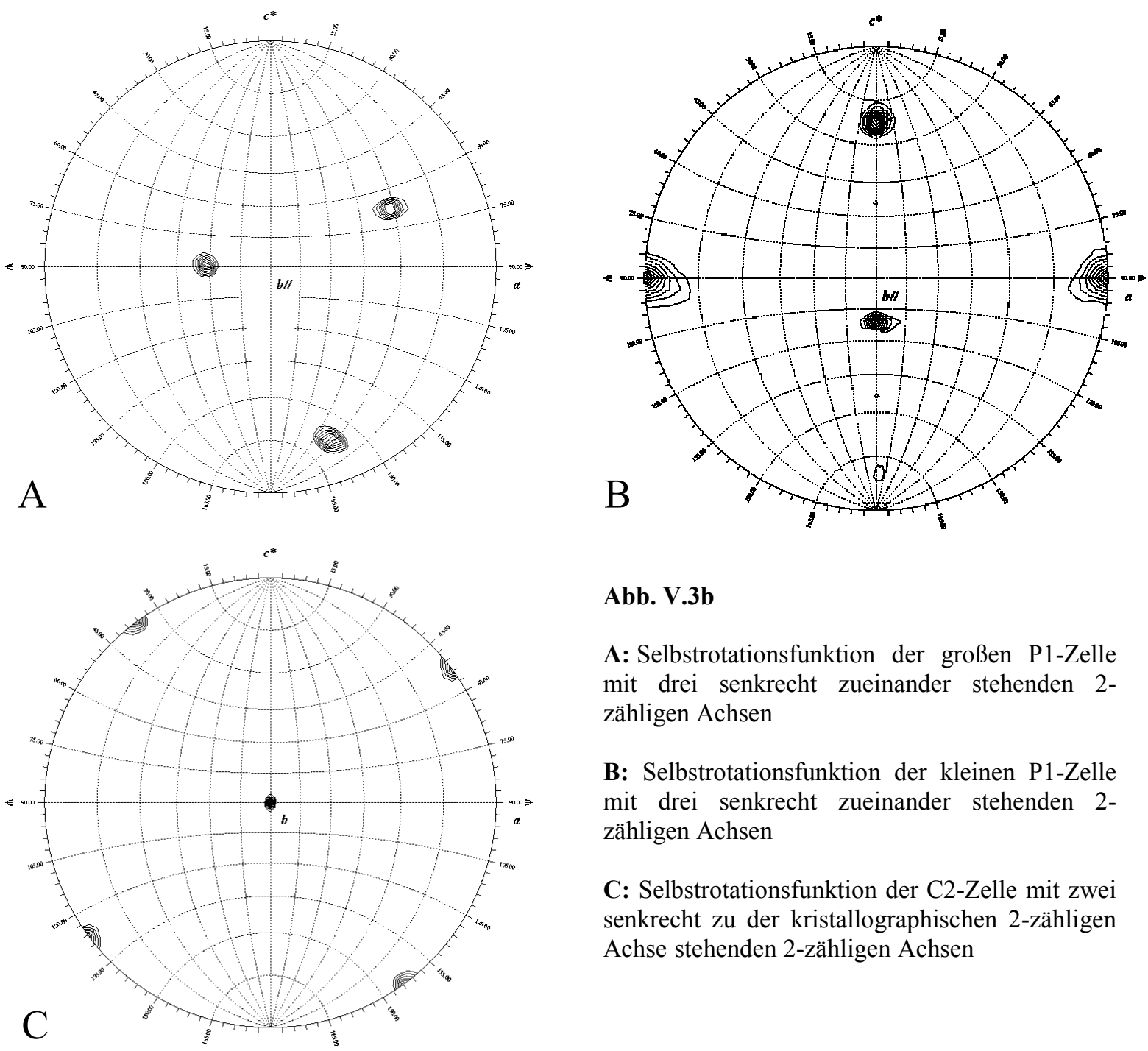

Abb. V.3b

A: Selbstrotationsfunktion der großen P1-Zelle mit drei senkrecht zueinander stehenden 2zähligen Achsen

B: Selbstrotationsfunktion der kleinen P1-Zelle mit drei senkrecht zueinander stehenden 2zähligen Achsen

C: Selbstrotationsfunktion der C2-Zelle mit zwei senkrecht zu der kristallographischen 2-zähligen Achse stehenden 2-zähligen Achsen 
Dies entspricht einer scheinbaren „C-Zentrierung“ der P1-Zelle. Würde es sich tatsächlich um eine reine Translation in Richtung der halben Diagonalen der C-Fläche handeln, so wäre die Zelle eine um diesen Vektor verkleinerte P1-Zelle mit nur einem Tetramer in der asymmetrischen Einheit. In der kleinen P1-Zelle, in der sowohl das unkomplexierte Enzym (1a), als auch der erste Kristall der mit Phenylalanin komplexierten Gly226Ser Mutante (1b) gemessen wurde, befindet sich tatsächlich nur ein Tetramer in der asymmetrischen Einheit. Innerhalb dieses Tetramers lassen sich die Monomere bzw. Dimere wiederum über eine nichtkristallographische 222 Symmetrie ineinander überführen ( $A b b$. V.3b:B). Aus der Selbstrotationsfunktion wird deutlich, dass sich eine der nichtkristallographischen zweizähligen Achsen parallel zur a-Achse der Zelle befindet. In der C2-Zelle, die in ihrer asymmetrischen Einheit nur ein Dimer enthält, wird das Tetramer durch die kristallographische zweizählige Achse generiert. Durch zwei senkrecht zu ihr stehende nichtkristallographische zweizählige Achsen wird auch hier eine 222-Symmetrie des Tetrameres erzeugt (siehe $A b b . V .3 b: C$ ).

\section{Vergleich der Zellen}

Beim näheren Untersuchen der Zellen fällt auf, dass sich die Packung der Kristallformen 1, 2 und 4 stark ähneln.

\section{$\mathrm{C} 2-\mathrm{P} 1_{\mathrm{kl}}$}

Die Zelle der Kristalle in C2 lässt sich durch die Transformation $\left(\begin{array}{lllllllll}0 & 1 & 0 & 0 & 0 & 1 & 1 / 2 & 1 / 2 & 0\end{array}\right)$ beinahe in die kleine P1-Zelle überführen. In $A b b . V .3 c$ ist die Zellverzerrung zu sehen, die die Aufhebung der Symmetrie und somit die Änderung des Kristallsystems verursacht.
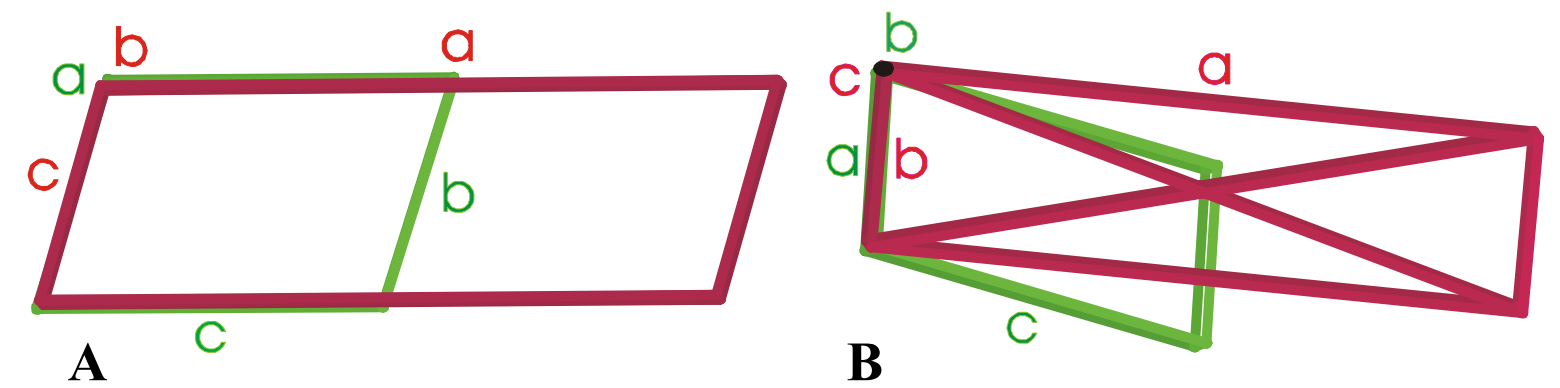

Abb. V.3c A: Überlagerung der Zellen 1 (grün) und 4 (rot). In B wird die leichte Verschiebung der Zellkanten sichtbar, die den Raumgruppenwechsel verursacht. 


\section{P1kl-P1gr}

Auch die Zellen der beiden triklinen Kristallsysteme sind miteinander verwandt. Zeichnet man in die große P1-Zelle die möglichen Translationsvektoren $\left(\begin{array}{lll}1 / 2 & 1 / 2 & 0\end{array}\right)$ bzw. $\left(\begin{array}{lll}-1 / 2 & 1 / 2 & 0\end{array}\right)$ der Packung ein, so erkennt man, dass diese ungefähr den Zellkanten a und b der kleinen P1-Zelle entsprechen, während die Zellkante c in etwa gleich bleibt. Abb. V.3d zeigt, dass die kleinere Zelle jedoch in c-Richtung im Vergleich zur großen P1 Zelle verzerrt ist, wodurch die unterschiedlichen Winkel hervorgerufen werden.
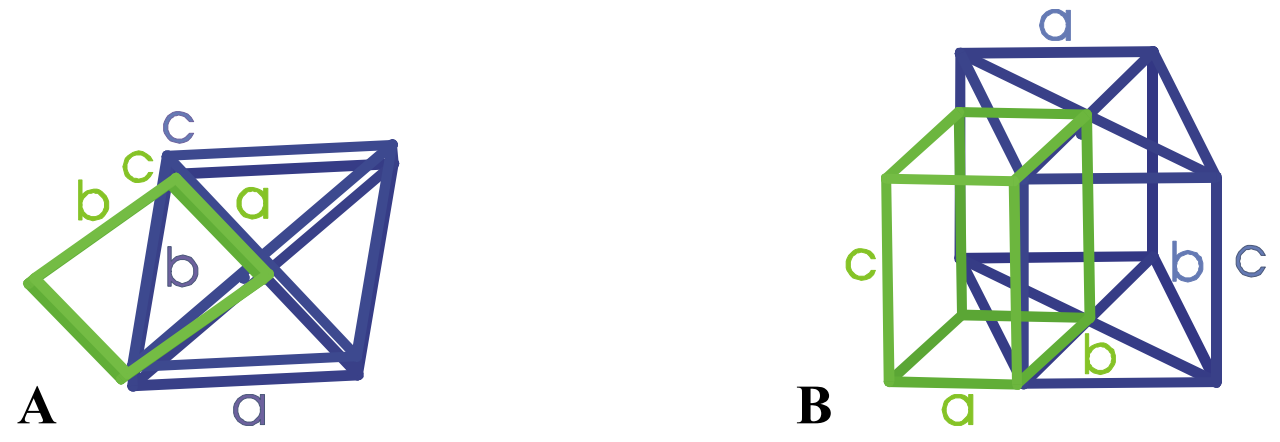
Abb. V.3d Überlagerung der großen P1-Zelle 2 (blau) und der kleinen P1-Zelle 1. Die NCS-Translation
wurde aus Gründen der Übersichtlichkeit als „C-Zentrierung“ in die große P1-Zelle eingezeichnet.

\section{Oligomerisierungsstatus}

Oft ist es schwierig, anhand von Kristallstrukturen Aussagen über den Oligomerisierungszustand oder über flexible Bereiche eines Enzyms in Lösung zu treffen, da das Enzym im Kristallgitter Packungszwängen ausgesetzt ist, die in Lösung wegfallen. Kristallisiert jedoch das selbe Enzym in unterschiedlichen Gittern, werden präzisere Aussagen möglich.

Dass die DAHP Synthase in jedem Fall wenigstens als Dimer in Lösung vorliegt, haben Gelfiltrationsuntersuchungen ergeben [Pfeil 2002]. Aufgrund der vielfältigen und unterschiedlichen Wechselwirkungen in der aktiven im Vergleich zur inhibierten Enzymkonformation scheint die Existenz des Dimers sowohl für den Katalysemechanismus, als auch für den Regulationsmechanimus essentiell notwendig zu sein. Die Unterschiede in den Dimerisierungskontakten im aktiven und im inhibierten Enzym sind in Tab.V.2.1.3a aufgelistet. Sie bestärken die These, dass die Kommunikation zwischen den beiden Monomeren eines Dimers notwendig für die Regulierbarkeit des Enzyms ist, und somit die Annahme, dass es sich bei der aktiven Form des Enzyms mindestens um ein Dimer handelt. Auf die konkreten Auswirkungen dieser Änderungen in der Dimerisierung wurde in Kap. V.2.1 eingegangen. 


\title{
Tetramerisierung
}

Über die höhere Oligomerisierung des Enzyms herrscht noch Unklarheit [Pfeil 2002]. Betrachtet man die Dimerkontaktstellen, durch die eine Tetramerisierung in allen Kristallformen hervorgerufen wird, so fällt auf, dass als Wechselwirkungen keine starken Wasserstoff- oder Salzbrückenbindungen vorliegen. Vielmehr handelt es sich hierbei hauptsächlich um hydrophobe van-der-Waals-Wechselwirkungen zwischen den Aminosäureseitenketten aller vier Monomere (siehe Abb. V.3g).
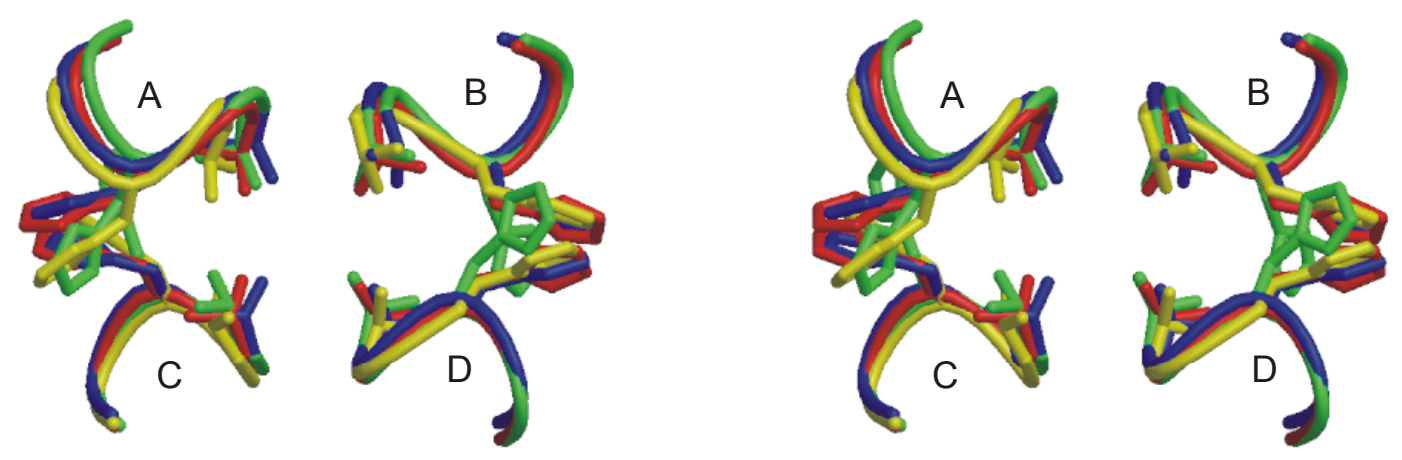

\begin{abstract}
Abb. V.3e Stereographische Darstellung der hydrophoben Wechselwirkungen der Aminosäuren His230 und Val232 zwischen allen vier Monomeren an der Tetramerbindungsstelle
\end{abstract}

Sie liegen jeweils im Bereich des loops zwischen den Strängen des zusätzlichen $\beta$-Faltblattes $\beta 6 \mathrm{a} / \mathrm{b}$ (His230, Val232) und in der zusätzlichen Helix $\alpha 0$ (Pro30, Ala32, Ala35, Leu36) sowie in den entsprechenden Bereichen der nicht kristallographisch 222-symmetrieverwandten Monomere. Auffällig ist die Lage des His230 an der Tetramerkontaktstelle. Es bildet in keiner der Raumgruppen und Komplexe Wasserstoffbrückenbindungen aus. Vergleicht man nun diese Tetramerbindungsstellen nicht nur in den unterschiedlichen Kristallformen, sondern auch in der gleichen Kristallform aber in unterschiedlichen Komplexen miteinander, so fällt die flexible Position der Histidine His230 auf (Abb. V.3e).

Durch diese Konformationsunterschiede an der Dimer-Kontaktstelle ist eine geringfügig unterschiedliche Anordnung der Dimere innerhalb eines Tetramers möglich. Dies wird deutlich, wenn man aus allen Kristallformen Monomer A eines jeden Tetramers übereinanderlagert $(A b b$. V.3f) Die mittlere Abweichung der superpositionierten Moleküle beträgt nur $0.2 \AA$, während die größten Abweichungen in Monomer D bei $5.5 \AA$ liegen. 


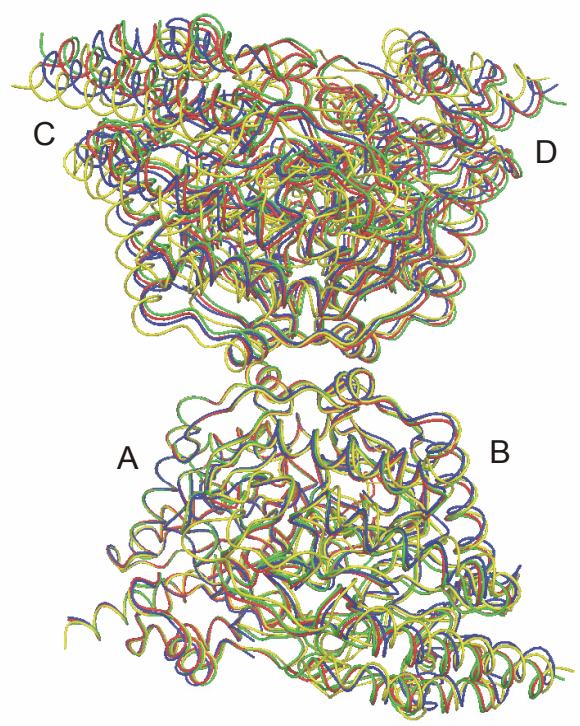

\begin{abstract}
Abb. V.3f Die Monomere A aus den Tetrameren der Strukturen 1a (blau), 2c (grün), 3c (gelb), 4b (rot) wurden superpositioniert. Durch Änderungen in der Dimerkontaktstelle resultieren Abweichungen von bis zu $5.5 \AA$ in den Monomeren $\mathrm{C}$ und $\mathrm{D}$.
\end{abstract}

Der Winkel zwischen den beiden das Tetramer ausbildenden Dimeren entspricht in der Struktur 1a in etwa $72^{\circ}$ (errechnet zwischen den Geraden durch die Massenschwerpunkte der Monomere A und B bzw. C und D). Dieser Winkel wird in den anderen Komplexstrukturen nur um wenige Grad verändert ( $A b b$. V.3f), so dass er als charakteristisch für dieses Enzym angesehen werden kann.
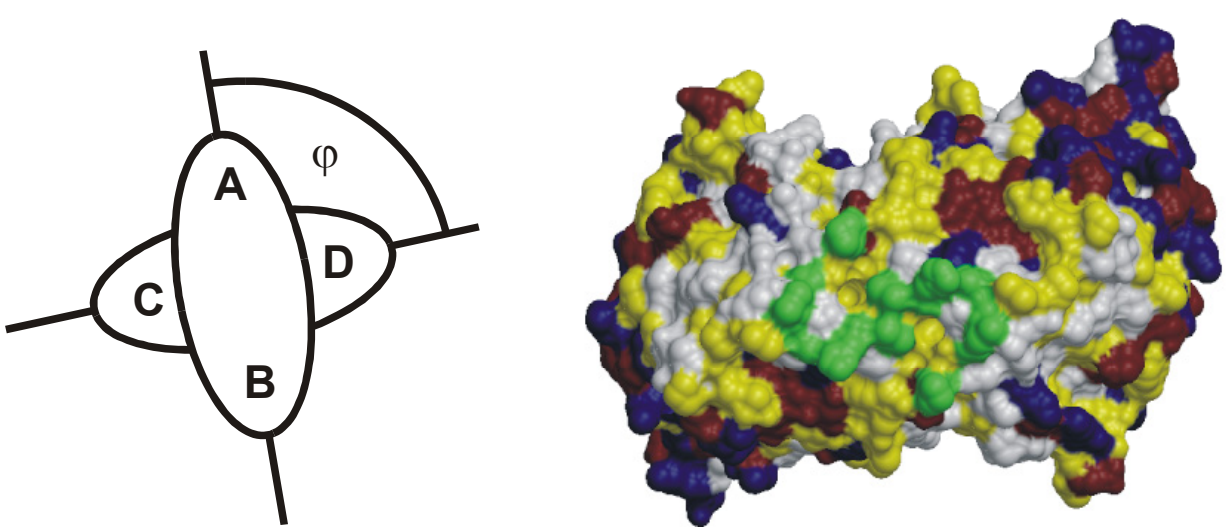

\begin{abstract}
Abb. V.3g A: schematische Darstellung des Tetramers mit Winkel $\varphi$ zwischen den Dimeren. B: Dimeroberfläche, deren Aminosäureseitenketten entsprechend ihrer Partialladung eingefärbt sind (blau: positive Partialladung, rot: negative Partialladung, gelb: hydrophobe Aminosäuren). Die hydrophoben Dimerkontaktstellen tragen eine grüne Einfärbung.
\end{abstract}

\title{
Oktamerisierung
}

Auch die Okta- bzw. Oligomerisierung aus den Tetrameren erfolgt in den zwei triklinen und der monoklinen Zelle ähnlich, während man in der trigonalen Zelle nicht von einer Oktamerisierung sprechen kann, da die Tetramere trotz großer Wasserkanalbereiche unterschiedlich starke Wechselwirkungen mit mehr als einem Symmetrieäquivalent eingehen. Im Fall der kleinen P1-Zelle handelt es sich um eine Oligomerisierung, da sich die Tetramerkontakte 
translatorisch durch das Gitter fortsetzen. Starke Wasserstoffbrücken bilden sich zwischen Ser273:O_A des einen Tetramers und Gly272:N_B des nächsten translationsäquivalenten Tetramers, bzw. Gly272:N_A des einen und Ser273:O_B des nächsten translationsäquivalenten Tetramers aus. Entsprechendes gilt für die Monomere C und D. Diese Bahnen von oligomerisierten Tetrameren sind durch Wasserkanäle voneinander getrennt. Der Wassergehalt der Zelle entspricht 53\%.

Im Fall der großen P1-Zelle sind die Wechselwirkungen zwischen den Tetrameren innerhalb der asymmetrischen Einheit wesentlich schwächer ausgeprägt. Hier bestehen schwache Wasserstoffbrückenbindungen zwischen Thr349:OG1_B und Glu082_OE1_F, Lys294:NZ_B und Glu086_OE2_F sowie zwischen ALA332:O_D und Arg290:NH2_H. Die Wechselwirkung zum nächsten Translationsäquivalent entspricht allerdings wieder der schon oben beschriebenen Wasserstoffbrückenbindungen zwischen wechselseitig dem Ser273 und dem Gly272 der entsprechenden Tetramere. Die in der kleinen P1-Zelle beobachteten Wasserbereiche zwischen den Tetramerschichten sind hier weniger stark ausgeprägt, so dass der Wassergehalt auf 39\% sinkt.

In der C2-Zelle sind wiederum die Wasserstoffbrücken zwischen Ser273 und Gly272 wechselseitig erhalten. Hinzu kommen Wasserstoffbrückenbindungen, die die oligomerisierten Tetramerbahnen untereinander verknüpfen. Es bilden sich zusätzlich Wasserstoffbrückenbindungen zwischen A_Lys260:NZ und \#B_Ser261:OG bzw. \#B_Thr255:OG und A_264OE3 und \#B_260 NZ und umgekehrt zwischen B_Lys260:NZ und \#A_Glu264:OE2 und B_Thr255:OH und B_Ser261:OH zu \#A_Lys260:NZ aus. Dies führt im Vergleich zur kleinen P1-Zelle ebenfalls zu eine Verringerung des Wassergehaltes auf 40\%.

Aussagen über den Oligomerisierungszustand des aktiven Enzyms in Lösung sind demnach auch anhand der hier erfolgten Untersuchung nicht eindeutig aufzustellen. Jedoch kann eine Oktamerisierung aufgrund der schwachen und in den einzelnen Raumgruppen unterschiedlichen Wechselwirkungen als kristallimmanent angesehen und für das Verhalten in Lösung ausgeschlossen werden. Die Dimere fügen sich in allen Komplexen über die gleichen hydrophoben Kontaktstellen zu einem Tetramer zusammen, jedoch scheint dieser Bereich durch das His232 recht flexibel zu sein, so dass leichte Änderungen im Winkel zwischen den Dimeren möglich sind. Aufgrund der Tatsache, dass es sich ausschließlich um hydrophobe Wechselwirkungen handelt, ist anzunehmen, dass sich die Dimere auch in Lösung als Tetramere zusammenfinden, um ihren Anteil an hydrophober Oberfläche zu minimieren. $\mathrm{Ob}$ über diese Kontaktstelle ebenfalls, wie zwischen den Dimeren, ein Informationsaustausch bzw. eine Konformationsstabilisierung stattfindet, bleibt fraglich. 
Zusammenfassung und Ausblick

\begin{tabular}{|c|c|c|c|c|c|c|}
\hline Kristallform & Zelle: & $\begin{array}{l}\mathbf{a} \quad \mathbf{b} \\
\alpha \beta\end{array}$ & & & Komplexe & Nr. \\
\hline $\mathbf{P} \mathbf{1}_{\mathrm{kl}}$ & $\begin{array}{r}51.6 \\
106.4\end{array}$ & $\begin{array}{r}69.0 \\
101.5\end{array}$ & $\begin{array}{c}102.5 \\
94.8\end{array}$ & & $\begin{array}{l}\text { DAHPS } \\
\text { DAHPS }+\mathrm{Mn}^{2+}+\text { Phe }\end{array}$ & $\begin{array}{l}1 \mathrm{a} \\
1 \mathrm{~b}\end{array}$ \\
\hline $\mathbf{P} 1_{\mathrm{gr}}$ & $\begin{array}{l}82.3 \\
65.1\end{array}$ & $\begin{array}{l}94.0 \\
85.7\end{array}$ & $\begin{array}{l}105.1 \\
75.7\end{array}$ & & $\begin{array}{l}\text { DAHPS }+\mathrm{Mn}^{2+} \\
\text { DAHPS }+\mathrm{Mn}^{2+}+\text { PEP } \\
\text { DAHPS }+\mathrm{Mn}^{2+}+\text { Tyr } \\
\text { DAHPS }+\mathrm{Mn}^{2+}+\text { Phe } \\
\text { Gly226Ser }+\mathrm{Mn}^{2+}+\text { Phe }\end{array}$ & $\begin{array}{l}2 \mathrm{a} \\
2 \mathrm{~b} \\
2 \mathrm{c} \\
2 \mathrm{~d} \\
2 \mathrm{e}\end{array}$ \\
\hline $\mathrm{C} 2$ & $\begin{array}{c}196.6 \\
90\end{array}$ & $\begin{array}{c}50.5 \\
106.4\end{array}$ & $\begin{array}{c}64.9 \\
90\end{array}$ & 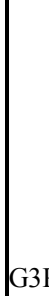 & $\begin{array}{l}\text { DAHPS }+\mathrm{Mn}^{2+} \\
\text { DAHPS }+\mathrm{Mn}^{2+}+\text { PEP } \\
\text { DAHPS }+\mathrm{Co}^{2+}+\text { PEP } \\
\text { DAHPS }+\mathrm{Co}^{2+}+\mathrm{P} 2 \mathrm{G} \\
\text { DAHPS }+\mathrm{Co}^{2+}+\mathrm{PEP}+\end{array}$ & $\begin{array}{l}4 a \\
4 b \\
4 c \\
4 d \\
4 e\end{array}$ \\
\hline P3(1)21 & $\begin{array}{c}105.7 \\
90\end{array}$ & $\begin{array}{c}105.7 \\
90\end{array}$ & $\begin{array}{c}268.8 \\
120\end{array}$ & & DAHPS $+\mathrm{Mn}^{2+}$ & $3 a$ \\
\hline
\end{tabular}

Abb. VIa Zusammenfassung der im Rahmen dieser Arbeit verfeinerten Komplex-Strukturen der tyrsensitiven DAHP Synthase aus S. cerevisiae in den verschiedenen Raumgruppen.

Im Rahmen dieser Arbeit wurde der Katalyse- und Rückkopplungsmechanismus der DAHP Synthasen anhand von Kristallstrukturen unterschiedlicher Komplexe der tyr-sensitiven DAHP Synthase aus Saccharomyces cerevisiae auf molekularer Ebene untersucht.

\section{Enzym-Komplexe in ihren Kristallpackungen}

Die verschiedenen Komplexe des Enzyms wurden in vier unterschiedlichen Kristallformen betrachtet. Drei dieser Kristallformen $\left(\mathrm{P} 1_{\mathrm{kl}}, \mathrm{P} 1_{\mathrm{gr}}\right.$ und $\left.\mathrm{C} 2\right)$ sind durch minimale Veränderungen in der Kristallpackung ineinander überführbar (siehe Kap.V.3). Die trigonale Kristallform zeichnet sich durch unterschiedliche Konformationen der beiden Monomere eines Dimers aus. Das unbeladene, auch ohne Metallion komplexierte Enzym (1a) zeigt eine große Flexibilität besonders im Bereich der aktiven Tasche. Dies lässt auf eine u. a. strukturgebende Rolle des Metallions schließen.

\section{Das aktive Zentrum}

Durch Strukturuntersuchungen an unterschiedlichen Metallionen-, Substrat- bzw. AnalogaEnzym-Komplexen konnte die aktive Tasche der Enzymfamilie charakterisiert werden. Bemerkenswert ist die in allen Komplexen beobachtete hohe Rigidität der Bindungstasche, die hergestellt wird, sobald das erste Substrat oder sein Analogon bindet. Dies lässt vermuten, 
dass erst durch die Bindung des ersten Substrates die Bindungstasche in ihrer aktiven Form festgehalten und für die Einlagerung des zweiten Substrates und somit für die Katalyse vorbereitet wird. Ein solcher sequentieller Mechanismus wurde sowohl für die DAHP Synthasen als auch für die verwandte Familie der KDOP Synthasen in der Literatur diskutiert [Schnappauf 1998; Kohen 1993]. Der strukturgebende Einfluss des Metallions auf die Positionierung des PEP konnte anhand des Vergleiches der Strukturen $\mathbf{2 b}$, 4b und 4c mit den metallionfreien Struktur 1HFB und 1a erschlossen werden (Kap. V.1.2).
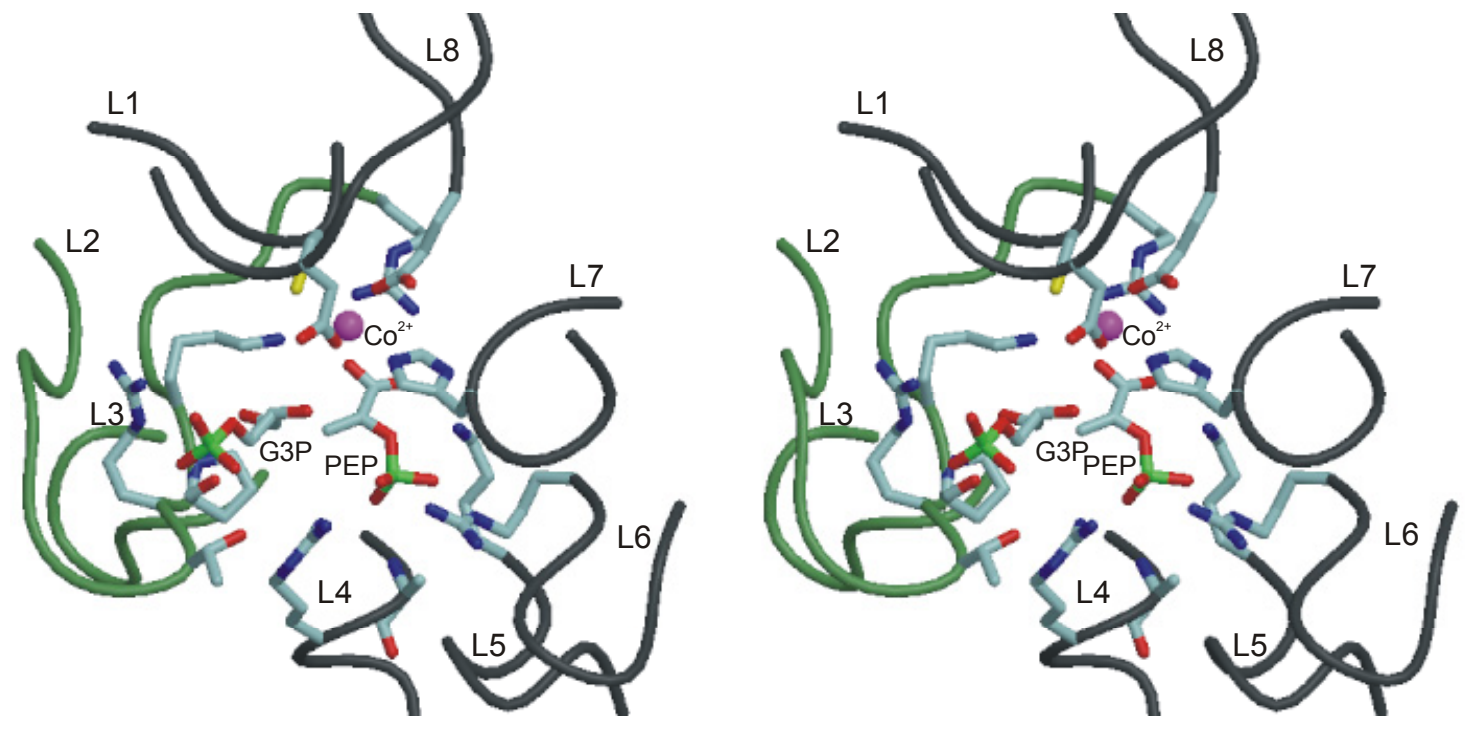

Abb. VIa Stereographische Darstellung des aktiven Zentrums der tyr-sensitiven DAHP Synthase im Komplex mit Cobalt(II), PEP und dem E4P-Analogon G3P. Die in Bindungen involvierten Aminosäureseitenketten sind als Kugelstabmodell eingezeichnet. Die loops L2 und L3, die durch die Effektoreinlagerung bewegt werden, sind grün hervorgehoben.

Anhand des Doppelkomplexes 4e wurde die Sulfatbindungsstelle in der Struktur 1QR7 [Shumilin 1999] als Bindungsstelle für das E4P-Analogon G3P verifiziert. Die Phosphatbindungsstelle dieses zweiten Substrates liegt mit den Aminosäuren Arg114 und Thr115 im erweiterten loop L2 am Eingang der Bindungstasche, die sich - wie bei TIM-Barrel-Enzymen weit verbreitet - auf der c-terminalen Seite des barrels befindet. Die Zuckerkette des E4Ps (bzw. seines Analogons G3P) ragt in die Bindungstasche hinein und wird mit ihren Hydroxylgruppen über die Aminosäuren Pro113 (L2) und das Asp342 (L8) fixiert, das zusätzlich das Metallion koordiniert. Die in der Bindung des E4P-Analogons involvierten Aminosäuren sind in allen Isoenzymen konserviert. Aufgrund der beschriebenen Rigidität der Bindungstasche nach Einlagerung des ersten Moleküls PEP und aufgrund der Beobachtung, dass die Lagen der Hydroxylsauerstoffatome des G3P in den Komplexen 4a, 4b und 4c systematisch mit Wassermolekülen oder einem Glycerol besetzt sind (Kap. V.1.2.8), kann angenommen werden, dass das Substrat E4P über die gleichen Wasserstoffbrücken an das Enzym gebunden 
wird. Aufgrund sterischer, stereochemischer und orbitaltheoretischer Überlegungen konnte das Rotamer der in dem Katalysemechanismus reagierenden Carbonylgruppe des E4P als an das Metallion koordinierend postuliert werden (Kap.V.1.4).

\section{Katalysemechanismus}

Die zwei in der Literatur vorgeschlagenen Mechanismen der Katalyse wurden in bezug auf den re-bzw. si-Seiten-Angriff der beiden, für diese Reaktion günstig positionierten Wassermoleküle W701 und W703 diskutiert (Kap.V.1). In beiden Fällen würde die Koordination der Carbonylgruppe zu einer Aktivierung des nucleophilen Angriffs durch die Doppelbindung des PEP führen. Im nach Mechanismus A (Kap.V.1) ablaufenden re-Seiten-Angriff des Wassermoleküls W703 übernähmen Lys112, Lys201 und Glu158 die Aufgaben der Proton-vermittelnden Lewis-Säuren/Basen. Dieser Reaktionsweg könnte eventuell durch die Mutanten Glu158Ala oder weniger radikal durch die Mutante Glu158Gln verifiziert werden. Der nach Mechanismus B (Kap.V.1) ablaufende, theoretisch mögliche si-Seiten-Angriff des Wassermoleküls W701, bzw. des entstandenen Hydroxid-Ions, erscheint aufgrund postulierter Seitenkettenbewegungen des als Lewis-Säure/Base agierenden, in die Metallionkoordination involvierten His282 weniger wahrscheinlich als der Angriff des Wassermoleküls W703 von der re-Seite des PEP. Anhand der vorliegenden Kristallstrukturen ist jedoch noch keine endgültige Aussage über den Angriffsmechanismus zu treffen.

\section{Effektorbindungstasche}

Schon durch Zufalls- und Punktmutationen in verschiedenen Isoenzymen unterschiedlicher Organismen [Ya-Ming Ger 1994; Kikuchi 1997; Liao 2000; Hartmann 2001] wurden Hinweise auf die Lage der Effektorbindungstasche erhalten. Die Struktur 2c zeigt, dass die relativ hydrophobe Effektor-Bindungstasche durch die in allen Isoenzymen weitgehend konservierten Enzymbereiche $\beta 0^{*}, \mathrm{~L} 3, \mathrm{~L} \alpha 4 / \beta 5$ und $\beta 6$ a gebildet wird. Bemerkenswert ist die hohe Konservierung der in die Effektorbindung involvierten Aminosäuren in allen Isoenzymen (Glu21*, Asp22*, Gln166, Ser195, Phe224, Va1226). Auffällig ist die aus Phe224 und seinen Analoga aufgebaute Aromat-Aromat-Wechselwirkung, die durch die Stabilisierung des paraWasserstoffatoms des Phe224 mit dem aromatischen $\pi$-System des Effektors entsteht.

\section{Negativer Rückkopplungsmechanismus}

Während sich die Position des die Carboxylatgruppe fixierenden Ser195 im Vergleich zur aktiven Form in der inhibierten Struktur nicht verändert, findet sowohl im Bereich des $\beta 6 \mathrm{a}-$ Stranges als auch in der Region des loops L3, verursacht durch die Einlagerung des Effektors, eine Bewegung um bis zu $1.7 \AA$ statt. 

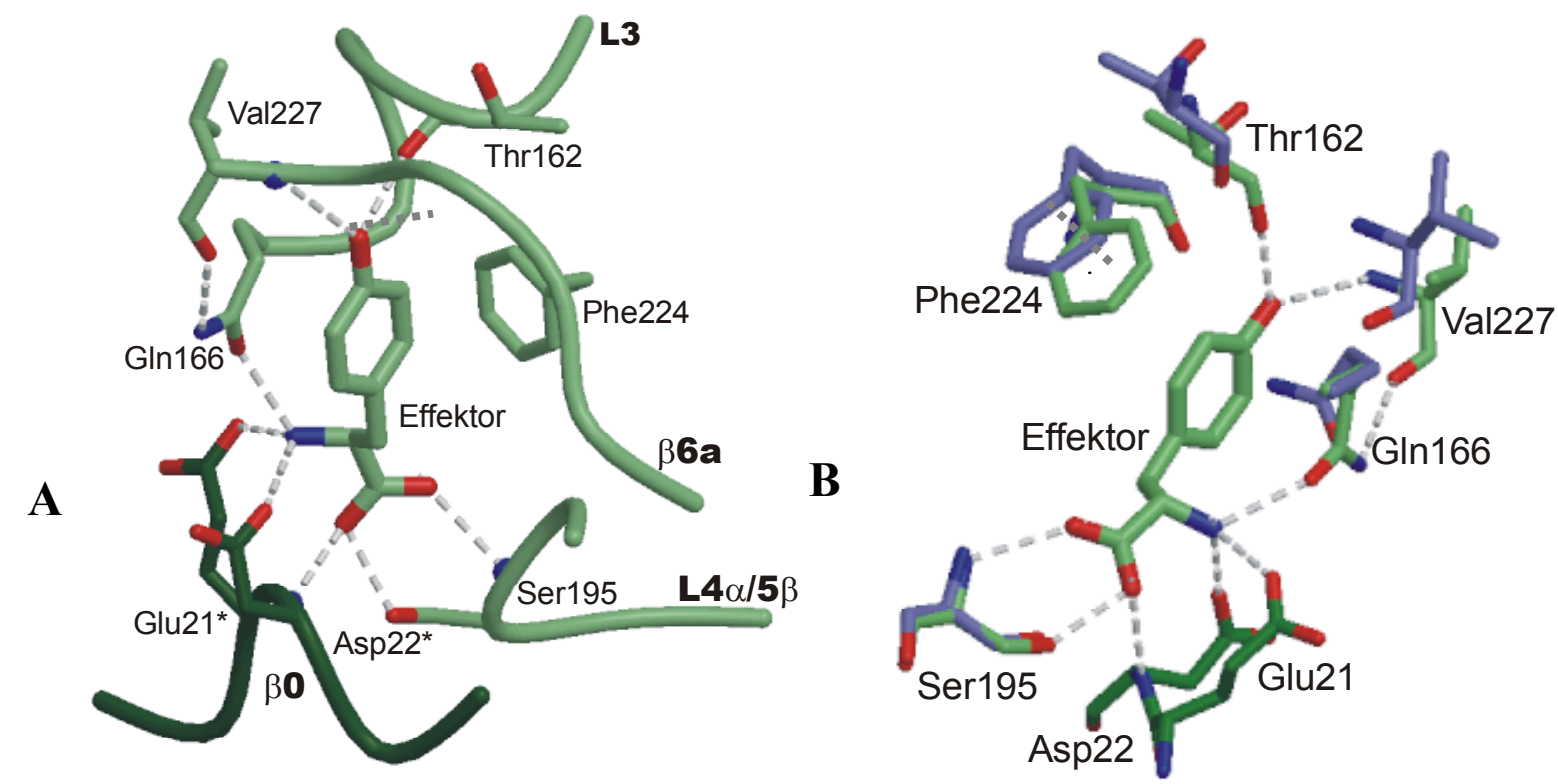

\begin{abstract}
Abb. VIa A: Darstellung des Effektors Tyrosin in seiner Bindungstasche, die vom N-Terminus des Partner-Monomers geschlossen wird (dunkelgrün). B: Superpositionierung der Strukturen des aktiven (blau) und des inhibierten Komplexes (grün) mit eingezeichneten, die loops in der inhibierten Konformation stabilisierenden Wasserstoffbrückenbindungen.
\end{abstract}

Beide veränderten Konformationen stabilisieren sich sowohl durch die in allen Isoenzymen mögliche Wasserstoffbrücke des Gln166 zum Val227, als auch durch die Tyrosin-spezifische Verbrückung von Thr162 und Val226 über $\mathrm{Tyr}_{\text {eff: }} \mathrm{OH}$ gegenseitig.

Die Informationsübertragung von der Effektor-Bindungstasche zur aktiven Tasche scheint durch einen sterischen Konflikt zwischen dem, sich aufgrund der Effektoreinlagerung (Kap. IV.2.1.3) um $60^{\circ}$ drehenden Leu160 und dem im loop L2 gelegenen, im aktiven Zustand über drei Wasserstoffbrücken an den loop L3 fixierten, Glu111 zu verlaufen. Um diese Annahme zu verifizieren, wäre eine Doppelmutante Glu111Ala/Leu160Ala hilfreich, deren negativer Rückkopplungsmechanismus außer Kraft gesetzt sein sollte. Durch die Verschiebung des Glu111 durch den loop L3 wird der gesamte in die Bindung der beiden Substrate involvierte, erweiterte loop L2 konformationell so verändert, dass die Einlagerung des E4P unmöglich erscheint. Die Bindungstasche des PEP wird durch die Aufgabe zweier Wasserstoffbrückenbindungen (Arg180, Lys112) geschwächt. Bemerkenswert ist die Involvierung des Rotamers Arg180 im inhibierten Zustand in Dimer-Dimer-Wechselwirkungen (siehe Tab. V. 2.1.3a). Ob diese zwei fehlenden Wechselwirkungen tatsächlich, wie im Rahmen dieser Arbeit postuliert, zur Bindungsunfähigkeit des PEP durch das Enzym führt, könnte anhand der Punktmutationen Lys112Ala und Arg180Ala ermittelt werden. 


\section{Kristallstruktur des Phe-Komplex (2d)}

Anhand der mit Mangan(II) und Phenylalanin komplexierten Struktur der tyr-sensitiven DAHP Synthase aus S. cerevisiae (2d) konnte aufgrund der nur teilbesetzten Effektorbindungstaschen gezeigt werden, dass dieser Effektor prinzipiell auf die gleiche Weise an das Enzym bindet wie Tyrosin. Durch die zwei fehlenden, den loop L3 und den $\beta 6$-Strang in ihrer inhibierten Konformation stabilisierenden Wasserstoffbrückenbindungen der Tyr-OHGruppe ist die Effektor-Bindung zum einen weniger fest als im Fall des Tyrosins. Zum anderen wird die inhibierte Form des Enzyms nicht so effektiv stabilisiert wie im Komplex mit Tyrosin. Dies konnte auch aus der nicht so ausgeprägten Aromat-Aromat-Wechselwirkung zwischen Phe224 mit dem Effektor sowie der schlecht definierten Elektronendichte im Bereich der Informationsübertragung (Leu160, Glu111) geschlossen werden.

\section{Kristallstruktur der Gly226Ser-Mutante (2e)}

Anhand der Strukturbestimmung der Punktmutanten Gly226Ser konnte der an ihr beobachtete Austausch von tyr-sensitiv auf phe-sensitiv trotz schlecht definierter Eletronendichte der Hydroxylgruppe Ser226:OH erklärt werden. Die Hydroxlgruppe des Serins übernimmt die das loop L3 und den $\beta$-Strang $\beta 6$ a im inhibierten Zustand stabilisierende Rolle der Hydroxylgruppe des Effektors Tyrosin, die im Fall des Phenylalanins als Effektor nicht vorhanden ist. Diese Vermutung wurde durch die kürzlich veröffentlichte Struktur der phesensitiven DAHP Synthase aus E. coli unterstützt [Shumilin 2002].

\section{Oligomerisierung}

Aufgrund der vielfältigen und unterschiedlichen Wechselwirkungen in der aktiven im Vergleich zur inhibierten Enzymkonformation scheint die Existenz des Dimers sowohl für den Katalyse- als auch für den Regulationsmechanimus essentiell zu sein. Die Dimerwechselwirkungen innerhalb eines Tetramers beruhen ausschließlich auf hydrophoben Wechselwirkungen (siehe Kap. V.3), so dass zwecks Verkleinerung hydrophober Enzymoberflächen eine Tetramer-Bildung des Enzyms in Lösung günstig erscheint. Eine Notwendigkeit dieser Tetramerisierung für den Katalyse- oder Rückopplungsmechanismus ist nicht ersichtlich. Eine Oktamerisierung kann aufgrund von in den verschiedenen Kristallpackungen sich ändernden Wechselwirkungen ausgeschlossen werden. 

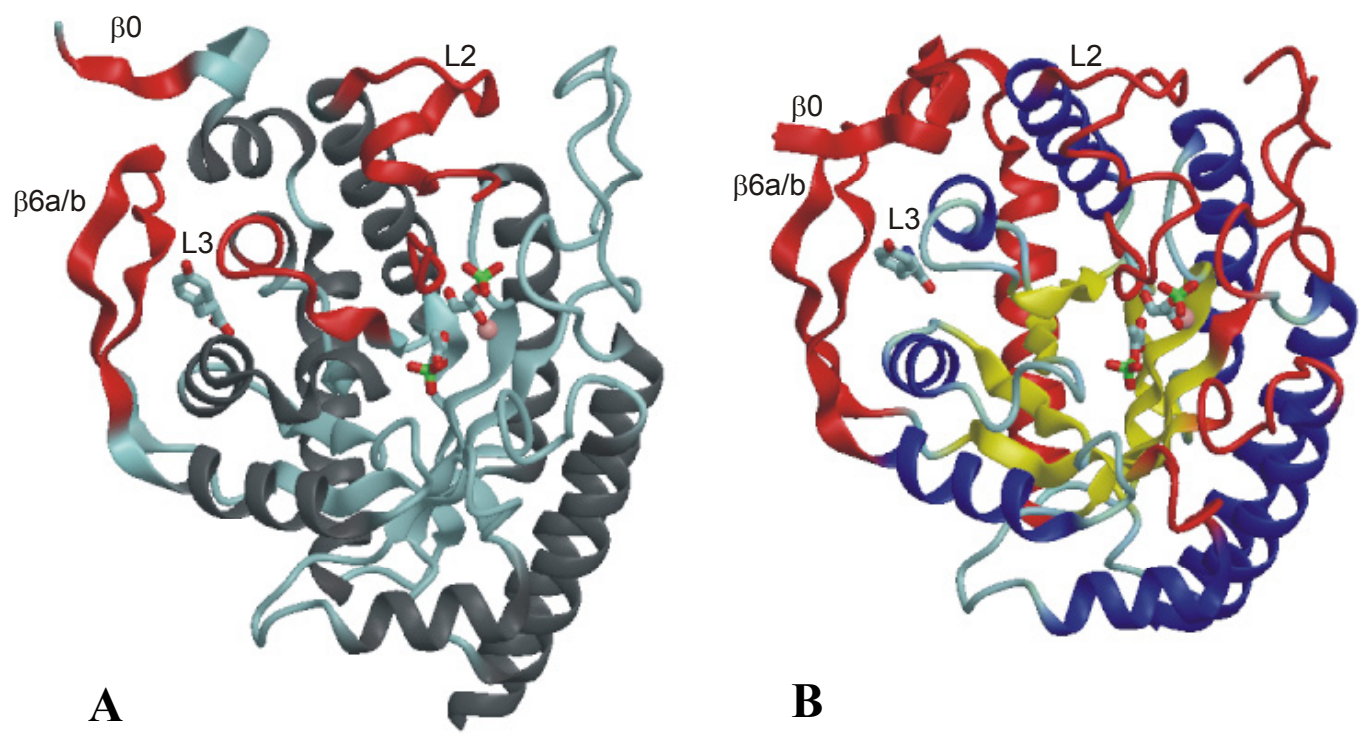

B

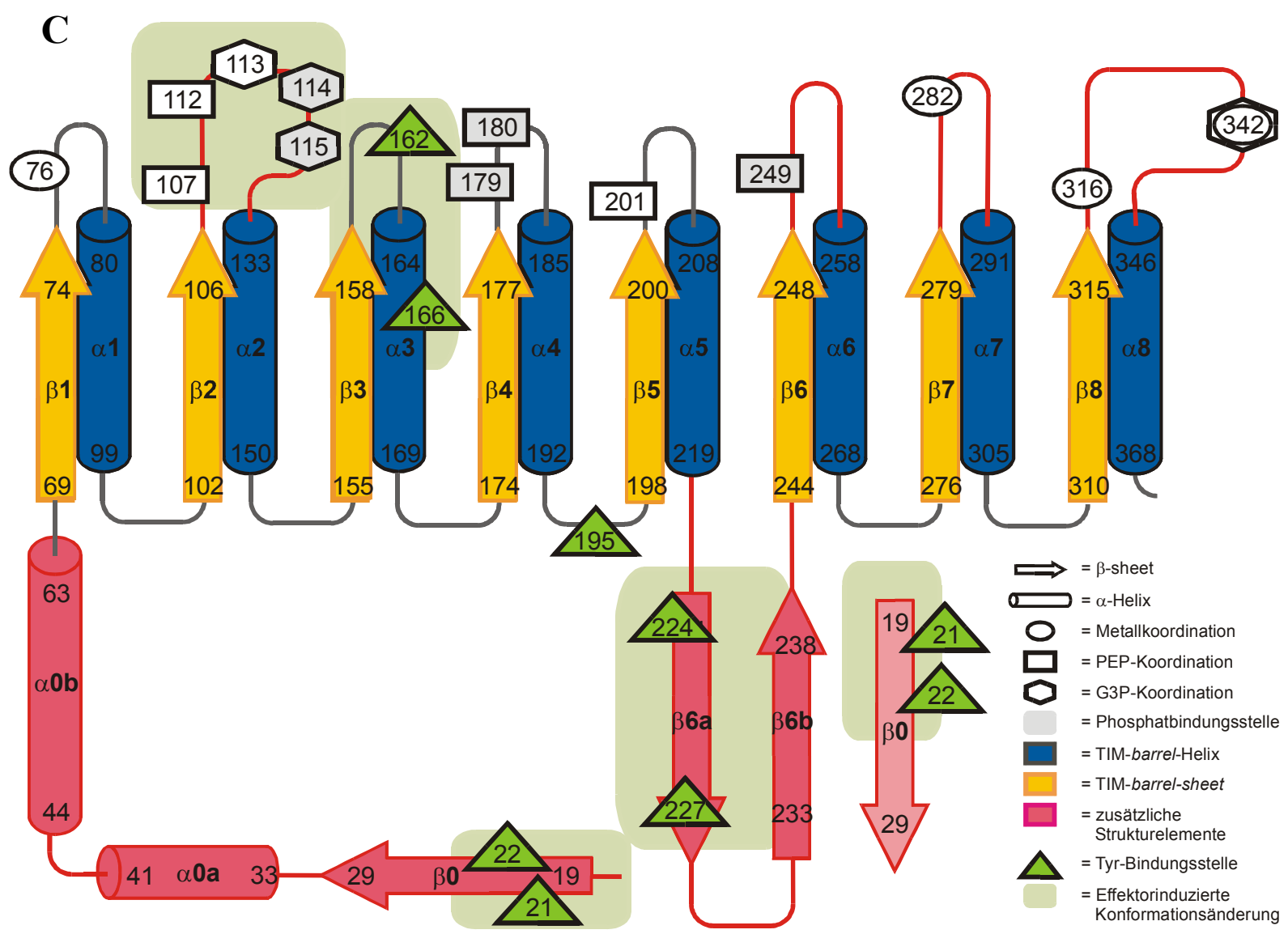

Abb. VIb A: Monomer der tyr-sensitiven DAHP Synthase aus S. cerevisiae. Die Bereiche, die sich konformationell durch die Einlagerung des Effektors ändern, sind rot eingefärbt. B: Monomer der tyr-sensitiven DAHP Synthase aus $S$. cerevisiae entsprechend C eingefärbt. Ein Vergleich zwischen A und B zeigt, dass die in den Rückkopplungsmechanismus involvierten Enzymbereiche hauptsächlich in den dem TIM-Barrel-Gerüst zugefügten Bereichen liegen. C: Schematische Darstellung der Sekundärstruktur der tyr-sensitiven DAHP Synthase aus S. cerevisiae mit eingezeichneter Metallion-, PEP-, E4P-Analogon und Effektor-Bindungsstelle, sowie Einfärbung der durch die Einlagerung des Effektors sich bewegenden Bereiche. Farbgebung siehe Legende. 


\section{TIM-Barrel Betrachtung}

Betrachtet man die hier untersuchte DAHP Synthase im Hinblick auf ihre TIM-BarrelStruktur, so fällt zunächst die für Enzyme dieser Faltung typische Lage der aktiven Tasche auf der c-terminalen Seite des barrels auf. Strukturelle Elemente der für die Enzymklasse der DAHP Synthasen spezifischen negativen Rückkopplung liegen ausschließlich in speziellen Enzymbereichen. Das Ser195 befindet sich im das barrel halbierenden loop L $\alpha 4 / \beta 5$, die Aminosäuren Phe224 und Val227 im dem TIM-Barrel hinzugefügten $\beta$-Strang $\beta 6 \mathrm{a}$ des $\beta$ Faltblattes $\beta 6 \mathrm{a} / 6 \mathrm{~b}$ und die Aminosäuren Thr162 und Gln166 im loop L3, der als einziger cterminaler loop nicht in die Bildung der aktiven Tasche eingebunden ist ( $A b b$. VIb:C).

Auch der die hydrophobe Bindungstasche schließende N-Terminus des Partner-Monomers innerhalb eines Dimers ist ein dem TIM-Barrel hinzugefügter $\beta$-Strang, der sich durch die Bindung der Aminosäuren Glu21 und Asp22 an den Effektor strukturell ordnet und mit den $\beta$ Strängen $\beta 6 \mathrm{a}$ und $\beta 6 \mathrm{~b}$ ein kurzes dreisträngiges Faltblatt bildet. Ein Vergleich mit Enzymstrukturen aus der Familie der KDOP Synthasen (Kap. V.1.3.2) zeigt sowohl Unterschiede in der Bindungstasche des zweiten Substrates als auch das Fehlen der für die Regulation nötigen Strukturelemente.

Die Klasse der DAHP Synthasen ist demnach ein Beispiel für das evolutionäre Entstehen von Enzymen mit spezifischen Funktionen durch Einführen zusätzlicher Strukturelemente (NTerminus, erweiterter loop L2, $\beta 6 \mathrm{a} / \mathrm{b}$-Faltblatt) zu einem bewährten Strukturgerüst (TIMBarrel). Die Struktur 2e der durch gezielten Austausch einer Aminosäure in ihrer Regulationsspezifität vertauschten Punktmutante Gly226Ser [Hartmann 2000] im Vergleich mit den Strukturen 2c und 1HFB zeigt auf struktureller Ebene die beeindruckend feinen Abstimmungsmöglichkeiten zwischen der Struktur und Funktion von Enzymen. 


\section{Literaturverzeichnis}

Ahmad, S., Johnson, J.L., Jensen, R.A. (1997) The recent evolutionary origin of the phenylalanine-sensitive isozyme of 3-deoxy-D-arabino-heptulosonate 7-phosphate synthase in the enteric lineage of bacteria. J. Mol. Evol., 25(2), 159-167.

Ahmad, S., Rightmire, B., Jensen, R.A. (1996) Evolution of the regulatory isozymes of 3deoxy-D-arabino-heptulosonate 7-phosphate synthase present in the Escherichia coli genealogy. J. Bacteriol, 165(1),146-154.

Akowski, J.P., Bauerle, R. (1997) Steady-state kinetics and inhibitor binding of 3-deoxy-Darabino-heptulosonate-7-phosphate synthase (tryptophan sensitive) from Escherichia coli. Biochemistry, 36(50), 15817-1522.

Altschul, S.F., Gish, W., Miller, W., Myers, E.W., Lipman, D.J. (1990) Basic local alignment search tool. J. Mol. Biol. 215, 403-410.

Altschul, S.F., Madden, T.L., Schaffer, A.A., Zhang, J., Zhang, Z., Miller, W., Lipman, D.J. (1997) Gapped BLAST and PSI-BLAST: a new generation of protein database search programs. Nucleic Acids Res., 25, 3389-3402.

Arndt, U.W. (1984) Optimum X-ray wavelength for protein crystallography, J. Appl. Cryst., 17, 118-119.

Baasov, T., Knowles, J.R. (1989) Is the first Enzyme of the Shikimate Pathway, DAHPS (tyrosine sensitive) a copper Metalloezyme? J. Bacteriol., 171, 6155-6160.

Berman, H.M., Battistuz, T., Bhat, T.N., Bluhm, W.F., Bourne, P.E., Burkhardt, K., Feng, Z., Gilliland, G.L., Iype, L., Jain, S., Fagan, P., Marvin, J., Padilla, D., Ravichandran, V., Schneider, B., Thanki, N., Weissig, H., Westbrook, J.D. and Zardecki, C. (2002) The Protein Data Bank, Acta Cryst., D58, 899-907.

Böhm, H.-J., Klebe, G., Kubinyi, H. (1996) Wirkstoffdesign, Spektrum Akademischer Verlag GmbH, Heidelberg, Berlin, Oxford.

Braus, G.H. (1991) Aromatic amino acid biosynthesis in the yeast Saccharomyces cerevisiae: a model system for the regulation of a eukaryotic biosynthetic pathway, Microbiol Rev., 55:3, 349-70.

Branden, C., Tooze, J. (1991) Introduction to Protein Structure, Garland Publishing, Inc., New York, London.

Birck, M.R., Woodard, R.W. (2001) Aquifix aeolicus KDO8P Synthase: A new Class of KDO8P Synthase?, J. Mol Evol., 52:2, 205-214.

Brückner, R. (1996) Reaktionsmechanismen, Organische Reaktionen, Stereochemie, moderne Synthesemethoden, Spektrum Akademischer Verlag GmbH, Heidelberg, Berlin, Oxford. 
Brünger, A.T. (1992) The Free R Value: A Novel Statistical Quantity for Assessing the Accuracy of Crystal Structures, Nature, 355, 472-474.

Brünger, A.T., Adams, P.D., Clore, G.M., DeLano, W.L., Gros, P., Grosse-Kunstleve, R.W., Jiang, J.-S., Kuszewski, J., Nilges, M., Pannu, N.S., Read, R.J., Rice, L.M., Simonson, T., Warren, G.L. (1998) Crystallography \& NMR System: A New Software Suite for Macromolecular Structure Determination, Acta Cryst., D54, 905-921.

Brünger, T.A., Adams, P.D., Rice, L.M. (1997) New Applications of simulated annealing in $\mathrm{X}$-ray crystallography and solution NMR.

Burley, S.K., Petsko, G.A. (1985) Aromatic-aromatic interaction: a mechanism of protein structure stabilization. Science, 229(4708), 23-8.

Burmeister, W.P. (2000) Structural changes in a cryo-cooled protein crystal owing to radiation damage. Acta Cryst., D56, 328-41.

Carey, F., Sundberg, R. J. (1995) Organische Chemie, VCH, Weinheim.

Collaborative Computational Project, Number 4 (1994) The CCP4 Suite: Programs for Protein Crystallography. Acta Cryst., D50, 760-763.

Cosier, J., Glazer, A.M. (1986) A Nitrogen-Gas-Stream Cryostat for General X-ray Diffraction Studies, J. Appl. Cryst., 19, 105-107.

Cram, D. J., Elhafez, F.A. (1952) J. Am. Society, 74, 5828.

Crowther, R.A., Blow, D.M. (1967) A method of positioning a known molecule in an unkown crystal structure. Acta Cryst., 23, 544-548.

Crowther, R.A., (1972) The Fast Rotation Function. 173-178 in: Rossmann, M.G. (ed), The Molecular Replacement Method. Int. Sci. Rev. Ser., 13. New York: Gordon and Breach.

CSD, Cambridge Structural Database (1998) (c) Cambridge Crystallographic Centre.

Dauter, Z. (1999) Data-collection strategies. Acta Cryst. D55 ( Pt 10): 1703-17.

Dauter, Z., Lamzin, V.S., Wilson, K.S. (1995) Proteins at atomic resolution, Curr. Op. Struct. Biology., 5, 784-790.

Dauter, Z., Wilson, K.S. (1994) Imaging plates in synchroton and conventional X-ray crystallographic data collection, Acta Physica Polonica., A86, 477-486.

DeLeo, A.B., Dayan, J., Sprinson, D.B. (1973) Purification and kinetics of tyrosine-sensitive 3-deoxy-D-arabino-heptulosonic acid 7-phosphate synthetase from Salmonella. J. Biol. Chem. 248(7), 2344-2353.

Desiraju, G. R., Steiner, T. (2001) The Weak Hydrogen Bond, In Structural Chemistry and Biology, Oxford University Press, Oxford, New York.

DINO, Visualizing Structural Biology (2001) http://www.dino3d.org. 
Doong, R.L., Ahmad, S., Jensen, R.A. (1991) Higher plants express 3-Deoxy-D-mannooctulosonate 8-phosphate synthase. Plant Cell Envior. 14, 113-120.

Drenth, J. (1994) Principles of Protein X-Ray Crystallography, Springer-Verlag.

Ducruix, A., Giegé, R. (1992) Crystallization of Nucleic Acids and Proteins: a practical approach, Oxford University Press, Oxford New York.

Duewel, H.S., Woodard, R.W. (2000) A Metal Bridge between two Enzyme Families, The $J$. Biol. Chem., 275, 22824-22831.

Engh, R.A., Huber,R. (1991) Accurate Bond and Angle Parameters for X-ray Protein Structure Refinement, Acta Cryst., A47, 392-400.

Floss, H.G., Onderka, D.K, Carroll, M. (1972) Stereochemistry of the 3-deoxy-D-arabinoheptulosonate 7-phosphate synthetase reaction and the chorismate synthetase reaction. J. Biol. Chem., 247(3), 736-744.

Garman, E.F., Schneider, T.R. (1997) Macromolecular Cryocrystallography, J. Appl. Cryst.. 30, 211-237.

Ger, Y.-M., Chen, S.-L., Chiang, H.-J., Shiuan, D. (1994) A single Ser-180 Mutation desensitizes feedback inhibition of the Phenylalanine-sensitive DAHP Synthase in E. coli, $J$. Biochem., 116, 986-990.

Giacovazzo, C. (1992) Fundamentals of Crystallography, Oxford University Press, Oxford, New York, 83-87.

Gruner, S.M., Ealick, S.E. (1995) Charge coupled device X-ray detectors for macromolecular crystallography, Structure. 3, 13-15.

Harris, E.L.V., Angal, S. (1990) Protein purification methods: a practical approach, Oxford University Press, Oxford, New York.

Hartmann, M. (2001) Fungal DAHP Synthase - Evolution and Structure of different regulated enzymes. Dissertation, Göttingen.

Hartmann, M. (1996) Charakterisierung der Tyrosin-inhibierbaren DAHP Synthase aus Bäckerhefe S. cerevisiae. Diplomarbeit, Erlangen.

Hartmann, M., Heinrich, G., Braus, G.H. (2001) Regulative fine-tuning of the two novel DAHP isoenzyms of aroFp and aroGp of the filamentous fungus Aspergillus nidulans, Arch. Microbiol., 175, 112-121.

Helliwell, J.R. (1992) Macromolecular Crystallography with Synchrotron Radiation, Cambridge University Press, Cambridge.

Hendrickson, W.A., editor Wyckoff, H.W., Hirs, C.H.W., Timasheff, S.N. (1985) Methods in Enzymology, Stereochemically Restrained Refinement of Macromolecular Structures, Academic Press Inc., Orlando, Florida. 115B, 252-270. 
Hollemann, A.F., Wiberg, E., Wiberg, N. (1995) Lehrbuch der Anorganischen Chemie, 91.100. verbesserte und stark erweiterte Aufl., Walter de Gruyter, Berlin, New York.

Holm, L., Sander, C. (1993) Protein Structure Comparison by Alignment of Distance Matrices, J. Mol. Biol. 233: 123-138.

Holm, R. H., Kennepohl, P., Solomon, E. I. (1996) Structural and Functional Aspects of Metalsights in Biology, Chem. Rev., 96, 2239-2314.

Howe, D.L., Duewel, H.S., Woodard, R.W. (2000) Histidine 268 in DAHP Sythase plays the same role as Histidine 202 in KDO8P, The Journal of Biological Chemistry, 275, 4025840265 .

Jones, T.A., Zou, J.Y., Cowan, S.W., Kjeldgaard, M. (1991) Improved methods for building protein models in electron density maps and the location of errors in these models, Acta Cryst., A47, 110-119.

Jordan, P.A., Bohle, D.S., Ramilo, C.A., Evans, J.N. (2001) New insights into the metal center of 3-deoxy-D-arabino-heptulosonate 7-phosphate synthase, Biochemistry. 40(28), 8387-8396.

Kabsch, W. (1976) A solution for the best rotation to relate two sers of vectors. Acta Cryst., A32, 922-923.

Kaim, W., Schwederski, B. (1991) Bioanorganische Chemie, B. G. Teubner, Stuttgart.

Keeling, P.J., Palmer, J.D., Donald, R.G., Roos, D.S., Waller, R.F., McFadden, G.I. (1999) Shikimate pathway in apicomplexan parasites. Nature, 397(6716), 219-220.

Kikuchi, Y., Tsujimoto, K., Karahashi O. (1997) Mutational Analysis o the feedback Site of Phenylalanine-Sensitive DAHPS of E.Coli, Appl. Environm. Microbiol., 63, 761-762.

Kissinger, C.R., Gehlhaar, D.K. \& Fogel, D.B. (1999) Rapid automated molecular replacement by evolutionary search. Acta Cryst., D55, 484-491.

Kohen, A., Jakob, A., Baasov, T. (1992) Mechanistic studies of 3-deoxy-D-manno-2octulosonate-8-phosphate synthase from Escherichia coli. Eur. J. Biochem. 208(2), 443-449.

Kottke, T., Stalke, D. (1993) Crystal Handling at Low Temperatures, J. Appl. Cryst., 26, 615.

Kraulis, P. (1991) MOLSCRIPT: A program to produce both detailed and schematic plots of protein structures). J. Appl. Cryst., 24, 946-950.

Kuenzler M., Paravincini, G., Egli, C.M., Irniger S., Braus, G.H. (1992) Cloning, primary structure and regulation of the Aro4 gene, encoding the tyrosine-inhibited DAHPS from Saccharmoyces cerevisiae. GENE, 113, 67-74.

Lamzin, V.S., Wilson, K.S. (1993) Automated Refinement of Protein Models, Acta Cryst., D49, 129-147. 
Lang, D., Thoma, R., Henn-Sax, M., Sterner, R., Wilmanns, M. (2000) Structural evidence for evolution of the beta/alpha barrel scaffold by gene duplication and fusion. Science, 289(5484), 1546-50.

Laskowski, R.A., MacArthur, M.W., Moss, D.S. \& Thornton, J.M. (1993) PROCHECK: a program to check the stereochemical quality of protein structures. J. Appl. Cryst., 26, 283291.

Liao, D.-I., Zheng Y.J., Viitanen, P.V., Jordan, D.B. (2002) Structural definition of the active site and catalytic mechanism of 3,4-dihydroxy-2-butanone-4-phosphate synthase. Biochemistry, 41, 795-806.

Liao, H.-F., Lin, L.-L., Chien, H.-R., Hsu, W.-H. (2000) Serine 187 is a crucial residue for allosteric regulation of Cornebacterium glutamicum DAHP Synthase, FEMS Microbiology Letter. 194, 59-64.

Lippard, S.J., Berg, J.M. (1995) Bioanorganische Chemie, Spektrum Akademischer Verlag GmbH, Heidelberg, Berlin, Oxford.

Lottspeich, F., Zorbas, H. (1998) Bioanalytik, Spektrum Akademischer Verlag GmbH, Heidelberg, Berlin.

McCandliss, R.J., Poling, M.D., Herrmann, K.M. (1978) DAHPS, Purification and molecular characterization of phenylalanine-sensitive isoensyme from E.coli, The Journal of Biologoical Chemistry, 253, 4259-4265.

McPherson, A. (1999) Crystallization of Biological Macromolecules, CSHL Press, New York.

McPherson, A. (1985) Methods Enzymol., 114, 13.

McRee, D.E. (1992) A visual protein crystallographic software system for X11/Xview, J. Molecular Graphics. 10, 44-46.

McRee, D.E. (1993) Practical Protein Crystallography, Academic Press, San Diego, CA.

McRee, D.E. (1999) XtalView/Xfit - A Versatile Program for Manipulating Atomic Coordinates and Electron Density, J. Struct. Biol., 125, 156-165.

Muday, G.K., Herrmann, K.M. (1990) Regulation of the Salmonella typhimurium aroF gene in Escherichia coli. J. Bacteriol., 172(5), 2259-2266.

Murshudov, G.N., Vagin, A.A., Dodson, E.J. (1997) Refinement of Macromolecular Structures by the Maximum-Likelihood Method. Acta Cryst., D53, 240-255.

Nagano, N., Orengo, C., Thornton, J. (2002) One Fold with Many Functions: The Evolutionary Relationships between TIM Barrel Families Based on their Sequences, Structures and Functions. J. Mol. Biol., 321(5), 741-765.

Navazza, J. (1994) AMoRe: An Automated Package for Molecular Replacement, Acta Cryst., D50, 157-163. 
Nimmo, G.A., Coggins, J.R. (1981) Some kinetic properties of the tryptophan-sensitive DAHPS from Neurospora crassa, Biochem. Journal. 199, 657-665.

Otwinowski, Z (1993) DENZO: An Oscillation data processing program for macromolecular crystallography, Yale University, NewHaven.

Otwinowski, Z. (1993) SCALEPACK: Software for the scaling together of integrated intensities measured on a number of separate diffraction images, Yale University, NewHaven.

Otwinowski, Z., Minor, W. (1997) Processing of X-ray Diffraction Data Collected in Oscillation Mode, Methods in Enzymology, Volume 276: Macromolecular Crystallography, part A, p. 307-326, 1997, C.W. Carter, Jr. and R.M. Sweet, Eds., Academic Press, New York.

Paravicini P., Schmidheini, T., Braus, G. (1989) Purification and Properties of DAHPS (phenyilalanine-inhibitable) of Saccharomyces Cerevisiae, European Journal of Biochemistry. 186, 361-366.

Park, O.K., Bauerle, R. (1999) Metal-catalysed Oxidation of phenyalanine-sensitive DAHPS from E.Coli: Inactivation and destabilization by oxidation of active-Site Cysteines, $J$. Bacteriol., 181, 1636-1642.

Parker, E.J., Bulloch, E.M.M., Jameson, G.B., Abell, C. (2001) Substrate Deactivation of Phenylalanine-sensitive DAHP Synthase by E4P, Biochemistry. 40, 14821-14828.

Pfeil, A. (2002) Persönliche Mitteilung.

Radaev S., Dastidar, P., Patel, M., Woodard, R. W. (2000) Structure and Mechanism of KDO8PS, The Journal of Biological Chemistry. 275, 9476-9484.

Ramachandran, G.N., Sassiekharan, V . (1968) Conformation of polypeptides and proteins., Adv. Prot. Chem., 28, 283-437.

Ray, J.M., Bauerle R. (1991) Purification and Properties of Tryptophan-sensitive DAHPS from E. coli. J. Bacteriol., 173, 1894-1901.

Ray, J.M., Yanofsky, C., Bauerle, R. (1988) Mutational analysis of the catalytic and feedback sites of the tryptophan-sensitive 3-deoxy-D-arabino-heptulosonate-7-phosphate synthase of Escherichia coli. J. Bacteriol., 170:12 5500-6.

Roberts, F., Roberts, C.W., Johnson, J.J., Kyle, D.E., Krell, T., Coggins, J.R.,Coombs, G.H., Milhous, W.K., Tzipor,i S., Ferguson, D.J., Chakrabarti, D., McLeod, R. (1998) Evidence for the shikimate pathway in apicomplexan parasites. Nature, 393(6687), 801-805.

Rodriguez, R., Chinea, G., Lopez, N., Pons, T. \& Vriend, G. (1998) Homology modeling, model and software evaluation : three related resources. CABIOS, 14, 523-528.

Rossmann, M. G., Arnold, E. (2001) International Tables For Crystallography, Volume F, Crystallography Of Biological Macromolecules, Kluwer Academic Publishers, Dordrecht, Boston London.

Rossmann, M.G., Blow, D.M. (1962) The detection of sub-units within the crystallographic asymmetric unit, Acta Cryst., 15, 24-31. 
Sanner, M.F., Spehner, J.-C. \& Olson, A.J. (1996) Reduced Surface: an Efficient Way to Compute Molecular Surfaces. Biopolymers, 38, 305-320.

Schnappauf, G., Hartmann, M., Kuenzler, M., Braus, G.H. (1998) The two DAHP Synthase isoenzymes from Saccharomyces cerevisiae show different kinetic modes of inhibition, Arch. Microbiol., 169, 517-524.

Schneider, T.R. (2000) Objective comparison of protein structures: Error-scaled difference distance matices, Acta Cryst., D56, 714-721.

Schneider, T.R. (2002) A genetic algorithm for the identification of conformationally invariant regions in protein molecules. Acta Cryst., D58, 195-208.

Schneider, T.R., Hartmann, M., Braus, G.H. (1999) Crystallization and preliminary X-ray analysis of DAHPS (tyrosine inhibitable) from Saccharomyces cerevisiae, Acta Cryst., D55, $1586-1588$.

Schomaker, V., Trueblood, K.N. (1968) On the rigid-body motion of molecules in crystals, Acta Cryst., B24, 63-76.

Schoner, R., Herrmann, M. (1976) DAHPS: purification, properties and kinetics of the tyrosine-sensitive isoenzyme from E. Coli, The Journal of Biochemical Chemistry. 251, 54405447.

Sheflyan, G.Y., Howe, D.L.,Wilson, T.L. and Woodard, R.W. (1998) Enzymatic Synthesis of KDO8P, 3-Deoxy-altro-octulosonate (-Phosphate, 3,5-Dideoxy-D-gluco(manno)octulosonate 8-Phosphate by DAHP Synthase, J. Am. Chem. Soc., 120, 11027-11032.

Sheldrick, G.M. (1997) XPREP: Programm zur Bearbeitung von Beugungsdaten und Untersuchung reziproker Gitter V5.15 (c) Bruker AXS.

Shumilin, I.A., Kretsinger, R.H., Bauerle R. (1996) Purification, Crystallization and preliminary Crystallographic Analysis of DAHPS from E. coli, PROTEIN: Structure, Function and Genetics. 24, 404-406.

Shumilin, I.A., Kretsinger, R.H., Bauerle, R. H., (1999) Crystal Structure of Phenylalanineregulated DAHP Synthase from E. coli, Stucture. 7, 865-875.

Shumilin, I.A., Zhao, C., Bauerle, R., Kretsinger, R.H. (2002) Allosteric Inhibition of 3Deoxy-D-arabino-heptulosonate-7-phosphate Synthase alters the Coordination of Both Substrates, J. Mol. Biol., 320, 1147-1156.

Stephens, C.M., Bauerle B. (1992) Essential Cysteines in DAHPS from E.Coli, The Journal of Biologoical Chemistry. 267, 5762-5767.

Stephens, C.M., Bauerle R. (1991), Analysis of the metal requirement of DAHP Synthase from E. coli, The Journal of Biological Chemistry, 266, 20810-20817.

Stryer, L. (1994) Biochemie, 2. korr. Nachdruck1994 der völlig neubearb. Aufl. 1990, Heidelberg; Berlin; Oxford: Spektrum Akad. Verlag. 
Stura, E.A., Nemerow, G.R., Wilson, I.A. (1992) Strategies in the crytsallization of glycoprotein and protein complexes. Journal of Crystal Growth, 112, 273-285.

Subramaniam, P.S., Xie, G., Xia, T., Jensen, R.A. (1998) Substrate Ambiguity of KDO8P Synthase from N. g. in the Context of its membership in a protein family containing a subset of DAHP Synthases, J. Bacteriol., 180:1, 119-127.

Tong, L., Rossmann, M.G. (1997) Rotation function calculations with GLRF program. Methods Enzymol., 276, 594-611.

Vagin, A. \& Teplyakov, A. (1997) MOLREP: An automated program for molecular replacement. J. Appl. Cryst., 30, 1022-1025.

Vagin, A., Teplyakov, A. (2000) Approach to multi-copy search in molecular replacement. Acta Cryst., D56, 1622-1624.

Voet, D., Voet, J.G. (1995) Biochemestry, second edition, John Wiley \& Sons Inc., New York, Chichester, Brisbane, Toronto, Singapore.

Wagner, T., Shumilin, I.A., Bauerle, R. (2000) Structure of DAHP Synthase from E. coli: Comparison of the $\mathrm{Mn} 2+2$-Phosphoglycolate and the $\mathrm{Pb} 2+$ Phosphoenolpyruvate Complexes and Implications of Catalysis, J. Mol. Biol., 301, 389-399.

Wang, J., Duewel, H.S., Woodard, R.W., Gatti, D.L. (2001) Structures of Aquifex aeolicus KDO8P Synthase in Complex with R5P and PEP and with a Bisubstrate Inhibitor: Role of Active Site Water in Catalysis, Biochemistry, 40, 15676-15683.

Watenpaugh, K.D. (1991) Macromolecular Crystallography at cryogenic temperatures, Curr. Op. Struct. Biol., 1, 1012-1015.

Weiss, M.S., Hilgenfeld, R. (1999) Dehydration leads to a phase transition in monoclinic factor XIII crystals, Acta Cryst., D55:11, 1858-62.

Winn, M., Isupov, M., Murshudov, G.N. (2000) Use of Winn parameters to model anisotropic displacements in macromolecular refinement, Acta Cryst., D57, 122-133. 



\section{Danksagung}

Mein besonderer Dank gilt Herrn Prof. G. M. Sheldrick für die ausgezeichneten Möglichkeiten, in seiner Arbeitsgruppe Einblicke in das Gebiet der Proteinkristallographie zu bekommen.

Herrn Dr. Thomas R. Schneider danke ich für das große Interesse an meiner Arbeit und die ständige Diskussions- und geduldige Hilfsbereitschaft bei allen auftretenden Fragen und Problemen.

Herrn Prof. Dr. Braus gilt mein Dank für die Übernahme des Korreferates.

Außerdem möchte ich für die Möglichkeit danken, in seinem Arbeitskreis das Aufreinigen von Proteinen zu erlernen.

Mein ausführlichster Dank gilt Thomas Pape.

Andrea sei für ihre routinierte Unterstützung beim Aufreinigen der DAHP Synthase und für stets zuverlässige Proteinnachlieferung gedankt sowie für die vielen inspirierenden Arbeitskaffees.

Für das motivierende Korrekturlesen dieser Arbeit danke ich ganz herzlich Andrea, Angela, Annette, Eftichia, Fabio, Jörn, Manuel und Thomas.

Allen Mitarbeitern danke ich für das gute Arbeitsklima in der Abteilung.

Ganz besonders danke ich meinen Eltern, Großeltern, Geschwistern und P. A. für ihre Unterstützung. 


\section{LEBENSLAUF}

\section{Persönliche Daten}

$\begin{array}{ll}\text { Name } & \text { Verena König } \\ \text { Geburtsdatum } & \text { 3. Januar 1975 } \\ \text { Geburtsort } & \text { Münster } \\ \text { Familienstand } & \text { ledig } \\ \text { Staatsangehörigkeit } & \text { deutsch }\end{array}$

\section{Schulbildung}

08 / 81 - 07 / $85 \quad$ Kath. Grundschule Innenstadt Oldenburg

$08 / 85$ - $07 / 87 \quad$ Paulusschule Oldenburg

08 / 87 - 05 / $94 \quad$ Liebfrauenschule Oldenburg

\section{Hochschulstudium}

$10 / 94$

Diplomstudiengang Chemie in Göttingen

$10 / 96$

Vordiplom Chemie

WS 97

ERASMUS-Austausch am UC Dublin

$10 / 99$

Diplomprüfung Chemie

Titel der Diplomarbeit: „Röntgenstrukturuntersuchungen an Estronund Ascorbinsäurederivaten sowie dem $\alpha$-Amylase-Inhibitor Tendamistat"

$10 / 02$

Promotionsprüfung in den Fächern: Anorganische Chemie

Mineralogie / Kristallographie

Pharmakologie

Titel der Doktorarbeit: „Kristallstrukturuntersuchungen zum Katalyseund Regulationsmechanismus der Tyrosin-regulierten 3-Deoxy-Darabino-Heptulosonat-7-Phosphat-Synthase aus Saccharomyces cerevisiae 
